UNIVERSIDADE DE SÃO PAULO

INSTITUTO DE QUÍMICA

Programa de Pós-Graduação em Química

SABRINA KELLY REIS DE MORAIS

\title{
Constituintes químicos de algumas espécies de Myristicaceae
}




\section{SABRINA KELLY REIS DE MORAIS}

Constituintes químicos de algumas espécies de Myristicaceae

Tese apresentada ao Instituto de Química da Universidade de São Paulo para a obtenção do título de Doutor em Química (Química Orgânica).

Orientador: Prof. Dr. Massayoshi Yoshida 
Sabrina Kelly Reis de Morais

Constituintes químicos de algumas espécies de Myristicaceae

Dissertação apresentada ao Instituto de Química da Universidade de São Paulo para obtenção do Título de Doutor em Química.

Aprovado em:

\section{Banca Examinadora}

Prof. Dr. Massayoshi Yoshida

Instituição: Instituto de Química - USP

Assinatura:

Prof. Dr.

Instituição:

Assinatura:

Prof. Dr.

Instituição:

Assinatura:

Prof. Dr.

Instituição:

Assinatura:

Prof. Dr.

Instituição:

Assinatura: 
À minha família: mãe, irmã e padrasto. Pelo apoio incondicional e por acreditarem em mim mais do que eu mesma.

Ao Akira.

Por toda consideração e pela presença constante. 


\section{Agradecimentos}

Ao professor Dr. Massayoshi Yoshida, por ter me dado a oportunidade de realizar este trabalho sob a sua orientação. Obrigada pela confiança e pelos ensinamentos.

À Ingrit Diaz, pelas inúmeras ajudas.

Às amigas Ana Frazão e Elba Mustafa, pelo incentivo constante.

Ao professor Dr. Paulo Moreno, pela acolhida em seu laboratório, pelas diversas ajudas, dúvidas sanadas e pela correção do abstract.

Aos Drs. Adrian Pohlit e Sergio Nunomura, do Instituto Nacional de Pesquisas da Amazônia, por cederem espaço no laboratório e material para a extração dos óleos voláteis.

Ao grupo do Dr. Pedro Paulo R. Vieira, da Fundação de Medicina Tropical do Amazonas, pela realização do ensaio antimalárico.

Ao grupo do Dr. Ângelo Lindoso, do Instituto de Medicina Tropical de São Paulo, especialmente à Edite H. Y. Kanashiro pela realização do ensaio leishmanicida e pela paciência.

Ao Marcos Lima, pela realização do ensaio antimicrobiano dos óleos essenciais.

Aos funcionários da Central Analítica do IQ/USP, em especial ao Márcio Nardelli, pela enorme paciência e boa vontade.

Aos professores Josef Wilhelm Baader e Omar El Seoud, por toda atenção e ajuda nas atividades de monitoria.

Aos colegas Sérgio Galdino, Elvis, Adjaci, Tati, Valéria, Adelcimara, Ana Flávia, Rosilene, Danilo, Clécio, Adalberto, Juliana, Marcos Okida e Guilherme, pela convivência agradável e por sempre estarem dispostos a ajudar.

Ao Derisvaldo, pela ajuda na utilização do polarímetro.

A Dra. Patrícia Macari, por todo apoio inicial.

À amiga Luciana Reis, pela constante torcida a distância.

Aos meus tios Francisco e Sandra Gomes, pela ajuda financeira inicial.

A Capes, pela bolsa concedida. 


\section{RESUMO}

Morais, S.K.R. Constituintes químicos de algumas espécies de Myristicaceae. 2008. 174p. Tese - Programa de Pós-Graduação em Química. Instituto de Química, Universidade de São Paulo, São Paulo.

O presente trabalho descreve $\mathrm{o}$ isolamento e a caracterização estrutural dos constituintes químicos majoritários presentes nos frutos maduros das espécies Virola pavonis (A. CD.) A. C. Sm., Iryanthera juruensis Warburg e Osteophloeum platyspermum (Spruce ex A. DC.) Warburg. Foram isoladas vinte e oito substâncias, sendo catorze lignóides, dois tocotrienóis, dois sesquiterpenos, quatro diterpenos, um derivado do ácido cinâmico e cinco flavonóides.

Avaliou-se ainda a composição química e o teor do óleo volátil extraído das folhas e dos pericarpos das espécies supracitadas, o que revelou a predominância de hidrocarbonetos monoterpênicos e monoterpenos oxigenados nas folhas e nos pericarpos, respectivamente, de O. platyspermum, bem como de hidrocarbonetos sesquiterpênicos em ambos os órgãos vegetais de $I$. juruensis e de sesquiterpenos oxigenados nas folhas de $V$. pavonis. Como esperado, o óleo essencial dos pericarpos de O. platyspermum apresentou significativa atividade contra Escherichia coli e Candida albicans devido à alta concentração de monoterpenos oxigenados.

As substâncias di-hidrocarinatina e di-hidrocarinatidina, ambas isoladas do pericarpo de $V$. pavonis, inibiram o crescimento in vitro da cepa multiresistente $\mathrm{K} 1$ de Plasmodium falciparum (acima de $50 \%$ a 2,5 $\mu \mathrm{g} / \mathrm{mL}$ ). Enquanto que os lignóides verrucosina e guaiacina, ambos obtidos do arilo de I. juruensis, mostraram boa ação leishmanicida contra as formas promastigotas de Leishmania amazonensis $\left(\mathrm{IC}_{50}=27\right.$ e $45 \mu \mathrm{g} / \mathrm{mL}$, respectivamente).

Palavras-chave: miristicáceas, lignóides, óleos essenciais, malária, leishmania. 


\begin{abstract}
Morais, S.K.R. Chemical constituents of some Myristicaceae species. 2008. 174p. PhD Thesis - Graduate Program in Chemistry. Instituto de Química, Universidade de São Paulo, São Paulo.
\end{abstract}

This work describes the isolation and structural characterization of the major chemical constituents from ripe fruits of Virola pavonis (A. CD.) A. C. Sm., Iryanthera juruensis Warburg and Osteophloeum platyspermum (Spruce ex A. DC.) Warburg. Twenty-eight substances have been isolated and classified as fourteen lignoids, two tocotrienols, two sesquiterpenes, four diterpenes, one cinnamic acid derivative and five flavonoids.

Additionally, it was also analyzed the yields and chemical composition of the volatile oils from leaves and pericarps of all target species. This analysis indicated the predominance of oxygenated monoterpenes and monoterpene hydrocarbons respectively in leaves and pericarps of $O$. platyspermum, sesquiterpene hydrocarbons in both $I$. juruensis plant tissues and oxygenated sesquiterpenes in $V$. pavonis leaves. As one might expect, the oil from $O$. platyspermum pericarps presented significant activity against Escherichia coli and Candida albicans due to the high concentration of oxygenated monoterpene.

Dihydrocarinatin and dihydrocarinatidin, both isolated from $V$. pavonis pericarps, were able to inhibit the growth of the multi-drug resistant $\mathrm{K} 1$ strain of Plasmodium falciparum (up $50 \%$ at $2,5 \mu \mathrm{g} / \mathrm{mL}$ ). While the lignoids verrucosin and guaiacin, both obtained from $I$. juruensis arils, presented good antileishmanial activity against the promastigotes forms of Leishmania amazonensis $\left(\mathrm{IC}_{50}=27\right.$ and $45 \mu \mathrm{g} / \mathrm{mL}$, respectively).

Keywords: myristicaceous, lignoids, essential oils, malaria, leishmania. 
LISTA DE ABREVIATURAS E SIGLAS

\begin{tabular}{|c|c|}
\hline AcOEt & acetato de etila \\
\hline CC & Cromatografia em Coluna \\
\hline CCDC & Cromatografia em Camada Delgada Comparativa \\
\hline CCDP & Cromatografia em Camada Delgada Preparativa \\
\hline$\delta$ & deslocamento químico \\
\hline$d$ & dubleto \\
\hline$d d$ & duplo dubleto \\
\hline$d t$ & duplo tripleto \\
\hline$J$ & constante de acoplamento \\
\hline DCM & diclorometano \\
\hline DMSO- $d_{6}$ & dimetilsulfóxido hexadeuterado \\
\hline ELISA & Enzyme-Linked ImmunoSorbent Assay \\
\hline EM & Espectrometria de Massas \\
\hline EtOH & etanol \\
\hline HETERO-COSY & HETEROnuclear COrrelation SepctroscopY \\
\hline LTA & Leishmaniose Tegumentar Americana \\
\hline$m$ & multipleto \\
\hline$[\mathrm{M}]^{+}$ & pico do íon molecular \\
\hline $\mathrm{MeO}$ & metoxila \\
\hline $\mathrm{MeOH}$ & metanol \\
\hline$m / z$ & relação massa carga \\
\hline $\mathrm{BuOH}$ & álcool butílico \\
\hline OMS & Organização Mundial da Saúde \\
\hline RMN de ${ }^{13} \mathrm{C}$ & Ressonância Magnética Nuclear de Carbono Treze \\
\hline RMN de ${ }^{1} \mathbf{H}$ & Ressonância Magnética Nuclear de Hidrogênio \\
\hline $\mathbf{R P}$ & fase reversa \\
\hline $\boldsymbol{s}$ & singleto \\
\hline $\sin$. & sinônimo \\
\hline sl & singleto largo \\
\hline$t$ & tripleto \\
\hline UFC & Unidade Formadora de Colônia \\
\hline UV & ultravioleta \\
\hline
\end{tabular}




\section{LISTA DE FIGURAS}

Figura 1. (A) Cascas de I. juruensis (Fonte: VICENTINI e RODRIGUES, 1999); (B) 21 Ramo com folhas e frutos de O. platyspermum; (C) Frutos maduros de $V$. pavonis.

Figura 2. Estruturas moleculares de lignóides ativos isolados de miristicáceas 25 amazônicas.

Figura 3. Estruturas moleculares de flavonóides ativos isolados de miristicáceas 26 amazônicas.

Figura 4. Esqueleto básico de lignóides comumente encontrados em miristicáceas 54 neotropicais.

Figura 5. Estrutura molecular das neolignanas carinatina (1) e carinatidina (2). 55

Figura 6. Estruturas moleculares da di-hidrocarinatina (3) e da di-hidrocarinatidina (4). 57

Figura 7. Estrutura molecular do desidro-dieugenol.

Figura 8. Estereoquímica relativa das lignanas tetra-hidrofurânicas isoladas. 60

Figura 9. Estruturas moleculares das neolignanas tetra-hidrofurânicas isoladas. $\quad 61$

Figura 10. Padrão de fragmentação das lignanas tetra-hidrofurânicas de acordo com 63 Hattori et al. (1987).

Figura 11. Estrutura molecular das formas diastereoisoméricas da oxineolignana 64 isolada.

Figura 12. Conformações possíveis para as formas diastereoisoméricas de 8,4'- 64 oxineolignanas.

Figura 13. Proposta de fragmentação das oxineolignanas 11 e 12.

$\begin{array}{ll}\text { Figura 14. Estrutura molecular da carinatona. } & 67\end{array}$

Figura 15. Estrutura molecular da guaiacina. $\quad 68$

Figura 16. Proposta de fragmentação da neolignana guaiacina de acordo com Lopes 70 (1997).

Figura 17. Estrutura molecular do sargaol (15) e do sargacromenol (16). 72

Figura 18. Proposta de fragmentação para os tocotrienóides 15 e 16.

Figura 19. Estrutura molecular do espatulenol. $\quad 75$

Figura 20. Estrutura molecular do ent-4(15)-eudesmeno-1 $\beta, 6 \alpha$-diol. $\quad 77$

Figura 21. Estruturas moleculares dos ácidos ent-caur-16-en-19-óico (80) e 17-hidroxi- 78 16 $\alpha$-ent-cauran-19-óico (81).

Figura 22. Estrutura molecular das substâncias 82 e 83.

Figura 23. Estrutura molecular do ácido cis-cafêico.

Figura 24. Estrutura molecular da isoliquiritigenina. $\quad 84$

Figura 25. Estruturas moleculares das substâncias 19 e 20.

Figura 26. Estrutura molecular da 3',4',7-tri-hidroxi-flavona. $\quad 87$

Figura 27. Estrutura molecular da astilbina. 88

Figura 28. Estruturas moleculares da calopeptina e da machilina G. 91 


\section{LISTA DE ESQUEMAS}

Esquema 1. Obtenção dos extratos hexânicos e etanólicos.

Esquema 2. Partição dos extratos hexânicos.

Esquema 3. Partição dos extratos etanólicos das espécies estudadas. 44

Esquema 4. Isolamento das substâncias 1, 2, 3, 4, 5, 6, 7, 9, 10, 11 e 12.

Esquema 5. Isolamento das substâncias 8 e 13.

Esquema 6. Isolamento da substância 22.

Esquema 7. Isolamento das substâncias 10, 14, 15 e 16.

Esquema 8. Isolamento das substâncias 64, 79, 80, 81, 82 e 83.

Esquema 9. Isolamento das substâncias 17, 18, 19, 20 e 21. 


\section{LISTA DE TABELAS}

Tabela 1 - Constituintes químicos previamente isolados de Virola pavonis. 30

Tabela 2 - Constituintes químicos previamente isolados de Iryanthera juruensis. 34

Tabela 3 - Constituintes químicos previamente isolados de Osteophloeum 37 platyspermum.

Tabela 4 - Quantidade do material vegetal de partida e massas dos extratos 42 hexânicos e etanólicos obtidos dos frutos estudados.

Tabela 5 - Massas dos resíduos provenientes da partição dos extratos hexânicos das espécies estudadas.

Tabela 6 - Massas dos resíduos provenientes da partição dos extratos etanólicos das espécies em estudo.

Tabela 7 - Dados de RMN de ${ }^{1} \mathrm{H}$ e ${ }^{13} \mathrm{C}$ de 1 e $2\left(\mathrm{CDCl}_{3}, 4,7 \mathrm{~T}\right)$ e dados de $\mathrm{RMN}$ de ${ }^{13} \mathrm{C}$ da carinatina.

Tabela 8 - Dados de RMN de ${ }^{1} \mathrm{H}$ e ${ }^{13} \mathrm{C}$ de 2 e $4\left(\mathrm{CDCl}_{3}, 4,7 \mathrm{~T}\right)$ e dados de $\mathrm{RMN}$ de ${ }^{13} \mathrm{C}$ da di-hidrocarinatina e da di-hidrocarinatidina.

Tabela 9 - Dados de RMN de ${ }^{1} \mathrm{H}$ e ${ }^{13} \mathrm{C}$ da substância $5\left(\mathrm{CDCl}_{3}, 4,7 \mathrm{~T}\right)$ e dados de RMN de ${ }^{13} \mathrm{C}$ do desidro-dieugenol.

Tabela 10 - Dados de RMN de ${ }^{1} \mathrm{H}$ das substâncias 6, 7, 8, 9 e $10\left(\mathrm{CDCl}_{3}, 4,7 \mathrm{~T}\right)$.

43

44

56

58

59

Tabela 11 - Dados de RMN de ${ }^{13} \mathrm{C}$ das substâncias 6, 7, 8, 9 e 10 e das neolignanas galgravina, galbelgina, nectandrina $A$, nectandrina $B$ e verrucosina $\left(\mathrm{CDCl}_{3}, 4,7 \mathrm{~T}\right)$.

Tabela 12 - Fragmentos de massa das lignanas tetra-hidrofurânicas isoladas.

63

Tabela 13 - Dados de RMN de ${ }^{1} \mathrm{H}$ e ${ }^{13} \mathrm{C}\left(\mathrm{CDCl}_{3}, 4,7 \mathrm{~T}\right)$ de 11 e 12 e $\mathrm{RMN}$ de ${ }^{13} \mathrm{C}$ das formas eritro e treo (BRAGA et al., 1984).

Tabela 14 - Dados de $\mathrm{RMN}$ de ${ }^{1} \mathrm{H}$ de 13 e da carinatona $\left(\mathrm{CDCl}_{3}, 4,7 \mathrm{~T}\right)$.

67

Tabela 15 - Dados de RMN de ${ }^{1} \mathrm{H}$ e ${ }^{13} \mathrm{C}$ de 14 e da guaiacina $\left(\mathrm{CDCl}_{3}, 4,7 \mathrm{~T}\right)$. 69

Tabela 16 - Dados de RMN de ${ }^{1} \mathrm{H}$ e ${ }^{13} \mathrm{C}$ das substâncias 15 e $16\left(\mathrm{CDCl}_{3}, 4,7 \mathrm{~T}\right)$ e 73 dados de RMN de ${ }^{13} \mathrm{C}$ do sargaol e do sargacromenol.

Tabela 17 - Dados de RMN de ${ }^{1} \mathrm{H}$ e ${ }^{13} \mathrm{C}$ de $64\left(\mathrm{CDCl}_{3}, 4,7 \mathrm{~T}\right)$ e dados de $\mathrm{RMN}$ de ${ }^{13} \mathrm{C} \quad 76$ do espatulenol.

Tabela 18 - Dados de RMN de ${ }^{1} \mathrm{H}$ e ${ }^{13} \mathrm{C}$ de $79\left(\mathrm{CDCl}_{3}, 4,7 \mathrm{~T}\right)$ e RMN de ${ }^{13} \mathrm{C}$ do ent4(15)-eudesmeno-1 $\beta, 6 \alpha$-diol.

Tabela 19 - Dados de RMN de ${ }^{1} \mathrm{H}$ das substâncias 80 e $81\left(\mathrm{CDCl}_{3}, 4,7 \mathrm{~T}\right)$.

Tabela 20 - Dados de RMN de ${ }^{13} \mathrm{C}$ de 80 e $81\left(\mathrm{CDCl}_{3}, 4,7 \mathrm{~T}\right)$ e dos ácidos entcaurenóico e 17-hidroxi-16 $\alpha$-ent-cauran-19-óico.

Tabela 21 - Dados de RMN de ${ }^{1} \mathrm{H}$ das substâncias 82 e $83\left(\mathrm{CDCl}_{3}, 4,7 \mathrm{~T}\right)$.

Tabela 22 - Dados de $\mathrm{RMN}$ de ${ }^{13} \mathrm{C}$ do $\left(\mathrm{CDCl}_{3}, 4,7 \mathrm{~T}\right)$ de 82, 83, ent-8(17),13Elabdadieno-3 $\alpha, 15$-diol e do ácido $3 \alpha$-hidroxi-ent-8(17),13E-labdadieno-15óico.

Tabela 23 - Dados de RMN de ${ }^{1} \mathrm{H}$ e ${ }^{13} \mathrm{C}\left(\mathrm{DMSO}_{-} \mathrm{d}_{6}, 4,7 \mathrm{~T}\right)$ da substância 17. 
Tabela 24 - Dados de RMN de ${ }^{1} \mathrm{H}\left(\mathrm{CD}_{3} \mathrm{OD}, 4,7 \mathrm{~T}\right)$ e ${ }^{13} \mathrm{C}\left(\mathrm{CD}_{3} \mathrm{OD}, 7,05 \mathrm{~T}\right)$ da 84 substância 18 e RMN de ${ }^{13} \mathrm{C}$ da isoliquiritigenina.

Tabela 25 - Dados de RMN de ${ }^{1} \mathrm{H}$ das substâncias 19 e $20\left(\mathrm{CD}_{3} \mathrm{OD}, 4,7 \mathrm{~T}\right)$.

Tabela 26 - Dados de RMN de ${ }^{13} \mathrm{C}\left(\mathrm{CD}_{3} \mathrm{OD}, 4,7 \mathrm{~T}\right)$ das substâncias 19 e 20 e das 86 flavanonas liquiritigenina e butina.

Tabela 27 - Dados de RMN de ${ }^{1} \mathrm{H}$ e ${ }^{13} \mathrm{C}$ (DMSO- $\left.d_{6}, 4,7 \mathrm{~T}\right)$ da substância 21 e da 3',4',7-tri-hidroxi-flavona.

Tabela 28 - Dados de RMN de ${ }^{1} \mathrm{H}$ e ${ }^{13} \mathrm{C}$ (DMSO- $\left.d_{6}, 4,7 \mathrm{~T}\right)$ da substância 22 e da astilbina.

Tabela 29 - Porcentagem de inibição do crescimento in vitro da cepa K1 de $P . \quad 90$ falciparum frente às amostras testadas.

Tabela 30 - Atividade leishmanicida in vitro dos lignóides isolados frente às formas promastigotas de Leishmania amazonensis, L. braziliensis e L. chagasi.

Tabela 31 - Rendimento dos óleos essenciais das espécies em estudo.

Tabela 32 - Composição química dos óleos voláteis das espécies em estudo.

Tabela 33 - Atividade antimicrobiana dos óleos testados. 


\section{LISTA DE ESPECTROS}

Espectro 1. RMN de ${ }^{1} \mathrm{H}$ da substância $1\left(\mathrm{CDCl}_{3}, 4,7 \mathrm{~T}\right)$.

Espectro 2. RMN de ${ }^{1} \mathrm{H}$ da substância $2\left(\mathrm{CDCl}_{3}, 4,7 \mathrm{~T}\right)$. 109

Espectro 3. RMN de ${ }^{13} \mathrm{C}$ da substância $1\left(\mathrm{CDCl}_{3}, 4,7 \mathrm{~T}\right)$. 110

Espectro 4. RMN de ${ }^{13} \mathrm{C}$ da substância $2\left(\mathrm{CDCl}_{3}, 4,7 \mathrm{~T}\right)$. 111

Espectro 5. HETERO-COSY da substância $2\left(\mathrm{CDCl}_{3}, 4,7 \mathrm{~T}\right)$. 112

Espectro 6. (A) EM da substância 1 e (B) EM da substância 2 (IE, 70 ev). 113

Espectro 7. RMN de ${ }^{1} \mathrm{H}$ da substância $3\left(\mathrm{CDCl}_{3}, 4,7 \mathrm{~T}\right)$. 114

Espectro 8. RMN de ${ }^{1} \mathrm{H}$ da substância $4\left(\mathrm{CDCl}_{3}, 4,7 \mathrm{~T}\right)$. 115

Espectro 9. RMN de ${ }^{13} \mathrm{C}$ da substância $3\left(\mathrm{CDCl}_{3}, 4,7 \mathrm{~T}\right)$. 116

Espectro 10. RMN de ${ }^{13} \mathrm{C}$ da substância $4\left(\mathrm{CDCl}_{3}, 4,7 \mathrm{~T}\right)$. 117

Espectro 11. (A) EM da substância 3 e (B) EM da substância 4 (IE, 70 eV). 118

Espectro 12. RMN de ${ }^{1} \mathrm{H}$ da substância $5\left(\mathrm{CDCl}_{3}, 4,7 \mathrm{~T}\right)$. 119

Espectro 13. RMN de ${ }^{13} \mathrm{C}$ da substância $5\left(\mathrm{CDCl}_{3}, 4,7 \mathrm{~T}\right)$. 120

Espectro 14. EM da substância 5 (IE, 70 eV). 121

Espectro 15. RMN de ${ }^{1} \mathrm{H}$ da substância $6\left(\mathrm{CDCl}_{3}, 4,7 \mathrm{~T}\right)$. 122

Espectro 16. RMN de ${ }^{1} \mathrm{H}$ da substância $7\left(\mathrm{CDCl}_{3}, 4,7 \mathrm{~T}\right)$. 123

Espectro 17. RMN de ${ }^{1} \mathrm{H}$ da substância $8\left(\mathrm{CDCl}_{3}, 4,7 \mathrm{~T}\right)$. 124

Espectro 18. RMN de ${ }^{1} \mathrm{H}$ da substância $9\left(\mathrm{CDCl}_{3}, 4,7 \mathrm{~T}\right)$. 125

Espectro 19. RMN de ${ }^{1} \mathrm{H}$ da substância $10\left(\mathrm{CDCl}_{3}, 4,7 \mathrm{~T}\right)$. 126

Espectro 20. RMN de ${ }^{13} \mathrm{C}$ da substância $6\left(\mathrm{CDCl}_{3}, 4,7 \mathrm{~T}\right)$. 127

Espectro 21. RMN de ${ }^{13} \mathrm{C}$ da substância $7\left(\mathrm{CDCl}_{3}, 4,7 \mathrm{~T}\right)$. 128

Espectro 22. RMN de ${ }^{13} \mathrm{C}$ da substância $8\left(\mathrm{CDCl}_{3}, 4,7 \mathrm{~T}\right)$. 129

Espectro 23. RMN de ${ }^{13} \mathrm{C}$ da substância $9\left(\mathrm{CDCl}_{3}, 4,7 \mathrm{~T}\right)$. 130

Espectro 24. RMN de ${ }^{13} \mathrm{C}$ da substância $10\left(\mathrm{CDCl}_{3}, 4,7 \mathrm{~T}\right)$. 131

Espectro 25. (A) EM da substância 6, (B) EM da substância 7, (C) EM da substância 132 8, (D) EM da substância 9 e (E) EM da substância 10 (IE, 70 eV).

Espectro 26. RMN de ${ }^{1} \mathrm{H}$ da sustância $11\left(\mathrm{CDCl}_{3}, 4,7 \mathrm{~T}\right)$. 133

Espectro 27. RMN de ${ }^{1} \mathrm{H}$ da substância $12\left(\mathrm{CDCl}_{3}, 4,7 \mathrm{~T}\right)$. 134

Espectro 28. RMN de ${ }^{13} \mathrm{C}$ da substância $11\left(\mathrm{CDCl}_{3}, 4,7 \mathrm{~T}\right)$. 135

Espectro 29. RMN de ${ }^{13} \mathrm{C}$ da substância $12\left(\mathrm{CDCl}_{3}, 4,7 \mathrm{~T}\right)$. 136

Espectro 30. HETERO-COSY da substância $12\left(\mathrm{CDCl}_{3}, 4,7 \mathrm{~T}\right)$. 137

Espectro 31. (A) EM da substância 11 e (B) EM da substância 12 (IE, 70 eV). 138

Espectro 32. RMN de ${ }^{1} \mathrm{H}$ da substância $13\left(\mathrm{CDCl}_{3}, 7,05 \mathrm{~T}\right)$. 139 
Espectro 33. RMN de ${ }^{1} \mathrm{H}$ da substância $14\left(\mathrm{CDCl}_{3}, 4,7 \mathrm{~T}\right)$. 140

Espectro 34. RMN de ${ }^{13} \mathrm{C}$ da substância $14\left(\mathrm{CDCl}_{3}, 4,7 \mathrm{~T}\right)$. 141

Espectro 35. HETERO-COSY da substância $14\left(\mathrm{CDCl}_{3}, 4,7 \mathrm{~T}\right)$. 142

Espectro 36. EM da substância 14 (IE, $70 \mathrm{eV})$. 143

Espectro 37. RMN de ${ }^{1} \mathrm{H}$ da substância $15\left(\mathrm{CDCl}_{3}, 4,7 \mathrm{~T}\right)$. 144

Espectro 38. RMN de ${ }^{1} \mathrm{H}$ da substância $16\left(\mathrm{CDCl}_{3}, 4,7 \mathrm{~T}\right)$. 145

Espectro 39. RMN de ${ }^{13} \mathrm{C}$ da substância $15\left(\mathrm{CDCl}_{3}, 4,7 \mathrm{~T}\right)$. 146

Espectro 40. RMN de ${ }^{13} \mathrm{C}$ da substância $16\left(\mathrm{CDCl}_{3}, 4,7 \mathrm{~T}\right)$. 147

Espectro 41. (A) EM da substância 15 e (B) EM da substância 16 (IE, 70 eV). 148

Espectro 42. RMN de ${ }^{1} \mathrm{H}$ da substância $64\left(\mathrm{CDCl}_{3}, 4,7 \mathrm{~T}\right)$. 149

Espectro 43. RMN de ${ }^{13} \mathrm{C}$ da substância $64\left(\mathrm{CDCl}_{3}, 4,7 \mathrm{~T}\right)$. 150

Espectro 44. RMN de ${ }^{1} \mathrm{H}$ da substância $79\left(\mathrm{CDCl}_{3}, 4,7 \mathrm{~T}\right)$. 151

Espectro 45. RMN de ${ }^{13} \mathrm{C}$ da substância $79\left(\mathrm{CDCl}_{3}, 4,7 \mathrm{~T}\right)$. 152

Espectro 46. RMN de ${ }^{1} \mathrm{H}$ da substância $80\left(\mathrm{CDCl}_{3}, 4,7 \mathrm{~T}\right)$. 153

Espectro 47. RMN de ${ }^{1} \mathrm{H}$ da substância $81\left(\mathrm{CDCl}_{3}, 4,7 \mathrm{~T}\right)$. 154

Espectro 48. RMN de ${ }^{13} \mathrm{C}$ da substância $80\left(\mathrm{CDCl}_{3}, 4,7 \mathrm{~T}\right)$. 155

Espectro 49. RMN de ${ }^{13} \mathrm{C}$ da substância $81\left(\mathrm{CDCl}_{3}, 4,7 \mathrm{~T}\right)$. 156

Espectro 50. RMN de ${ }^{1} \mathrm{H}$ da substância $82\left(\mathrm{CDCl}_{3}, 4,7 \mathrm{~T}\right)$. 157

Espectro 51. RMN de ${ }^{1} \mathrm{H}$ da substância $83\left(\mathrm{CDCl}_{3}, 4,7 \mathrm{~T}\right)$. 158

Espectro 52. RMN de ${ }^{13} \mathrm{C}$ da substância $82\left(\mathrm{CDCl}_{3}, 4,7 \mathrm{~T}\right)$. 159

Espectro 53. RMN de ${ }^{13} \mathrm{C}$ da substância $83\left(\mathrm{CDCl}_{3}, 7,05 \mathrm{~T}\right)$. 160

Espectro 54. RMN de ${ }^{1} \mathrm{H}$ da substância 17 (DMSO- $d_{6}, 4,7 \mathrm{~T}$ ). 161

Espectro 55. RMN de ${ }^{13} \mathrm{C}$ da substância 17 (DMSO- $\left.d_{6}, 4,7 \mathrm{~T}\right)$. 162

Espectro 56. RMN de ${ }^{1} \mathrm{H}$ da substância $18\left(\mathrm{CD}_{3} \mathrm{OD}, 4,7 \mathrm{~T}\right)$. 163

Espectro 57. RMN de ${ }^{13} \mathrm{C}$ da substância $18\left(\mathrm{CD}_{3} \mathrm{OD}, 7,05 \mathrm{~T}\right)$. 164

Espectro 58. RMN de ${ }^{1} \mathrm{H}$ da substância $19\left(\mathrm{CD}_{3} \mathrm{OD}, 4,7 \mathrm{~T}\right)$. 165

Espectro 59. RMN de ${ }^{1} \mathrm{H}$ da substância $20\left(\mathrm{CD}_{3} \mathrm{OD}, 4,7 \mathrm{~T}\right)$. 166

Espectro 60. RMN de ${ }^{13} \mathrm{C}$ da substância $19\left(\mathrm{CD}_{3} \mathrm{OD}, 4,7 \mathrm{~T}\right)$. 167

Espectro 61. RMN de ${ }^{13} \mathrm{C}$ da substância $20\left(\mathrm{CD}_{3} \mathrm{OD}, 4,7 \mathrm{~T}\right)$. 168

Espectro 62. (A) ESI/EM da substância 19 e (B) ESI/EM da substância 20 (iozinação 169 positiva: $\mathrm{MeOH}+$ ácido fórmico 0,2\%).

Espectro 63. RMN de ${ }^{1} \mathrm{H}$ da substância 21 (DMSO- $\left.d_{6}, 4,7 \mathrm{~T}\right)$. 170

Espectro 64. RMN de ${ }^{13} \mathrm{C}$ da substância 21 (DMSO- $\left.d_{6}, 4,7 \mathrm{~T}\right)$. 171

Espectro 65. RMN de ${ }^{1} \mathrm{H}$ da substância 22 (DMSO-d 6 , 4,7 T). 172 
Espectro 66. RMN de ${ }^{13} \mathrm{C}$ da substância 22 (DMSO- $\left.d_{6}, 4,7 \mathrm{~T}\right)$.

Espectro 67. ESI/EM da substância 22 (iozinação positiva: $\mathrm{MeOH}$ + ácido fórmico 174 $0,2 \%$ ). 


\section{SUMÁRIO}

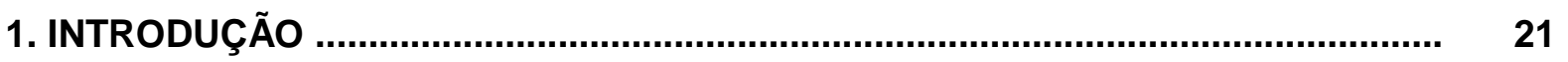

1.1 Considerações gerais sobre a família Myristicaceae ..................................... 21

1.2 Atividade biológica de miristicáceas neotropicais ...................................... 24

1.3 Óleos essenciais na família Myristicaceae .................................................... 26

1.4 Revisão bibliográfica das espécies estudadas .......................................... 27

1.4.1 Virola pavonis (A. DC.) A. C. Sm. ...................................................... 28

1.4.2 Iryanthera juruensis Warburg ............................................................... 33

1.4.3 Osteophloeum platyspermum (Spruce ex A. DC.) Warburg ........................ 36

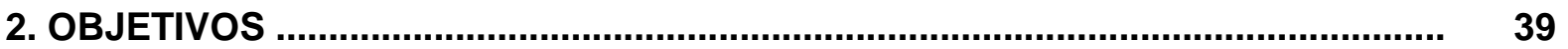

3. PROCEDIMENTO EXPERIMENTAL ............................................................ 40

3.1 Especificação de materiais e métodos ...................................................... 40

3.2 Procedimento fitoquímico ….............................................................................. 41

3.2.1 Coleta e identificação do material vegetal .................................................. 41

3.2.2 Obtenção dos extratos ................................................................... 41

3.2.3 Partição dos extratos ......................................................................... 42

3.2.4 Fracionamento dos resíduos e isolamento de substâncias ........................... 44

3.2.5 Fracionamento do resíduo clorofórmico do arilo de $V$. pavonis ...................... 45

3.2.6 Fracionamento do resíduo clorofórmico do pericarpo de $V$. pavonis .............. 46

3.2.7 Fracionamento do resíduo de acetato de etila do arilo de $V$. pavonis ............ 46

3.2.8 Fracionamento do resíduo clorofórmico do arilo de I. juruensis ..................... 47

3.2.9 Fracionamento do resíduo clorofórmico do pericarpo de O. platyspermum ... $\quad 47$

3.2.10 Fracionamento do resíduo acetato do tegumento de O. platyspermum ....... 48

3.3 Extração do óleo essencial ........................................................................ 48

3.4 Avaliação da atividade antimicrobiana ........................................................ 49

3.5 Avaliação da atividade antimalárica ........................................................... 50

3.5.1 Cultivo in vitro de Plasmodium falciparum ............................................... 50

3.5.2 Teste in vitro para avaliação da inibição do crescimento do $P$. falciparum ..... 51

3.6 Avaliação da atividade leishmanicida ......................................................... 52

4. RESULTADOS E DISCUSSÃO ..................................................................... 53

4.1 Caracterização estrutural das substâncias isoladas .................................... 53

4.1.1 Lignanas e neolignanas ................................................................... 53

4.1.1.1 Substâncias 1 e 2 ...................................................................... 54

4.1.1.2 Substâncias 3 e 4 ......................................................................... 56

4.1.1.3 Substância 5 ............................................................................ 58

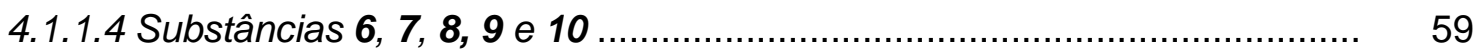


4.1.1.4 Substâncias 11 e 12 ........................................................................ 63

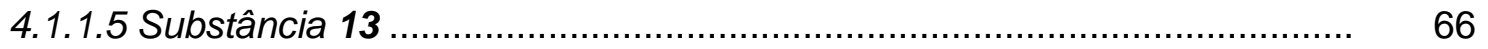

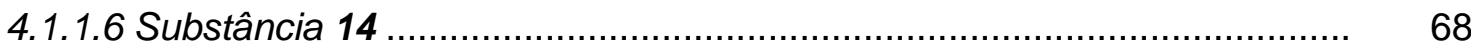

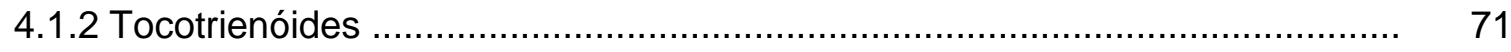

4.1.2.1 Substâncias 15 e 16 ......................................................................... 71

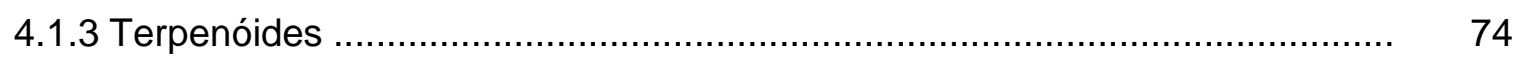

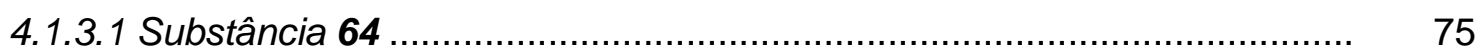

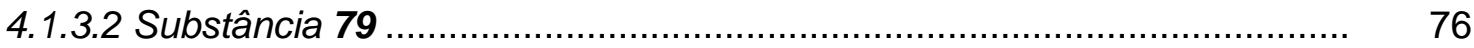

4.1.3.3 Substâncias 80 e 81 ......................................................................... 77

4.1.3.4 Substâncias 82 e 83 .................................................................... 80

4.1.4 Derivados do ácido cinâmico ...................................................................... 82

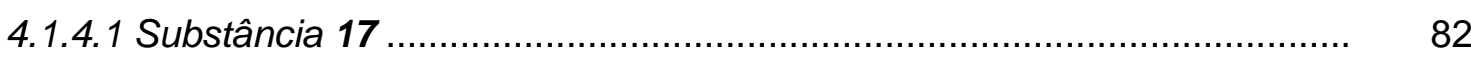

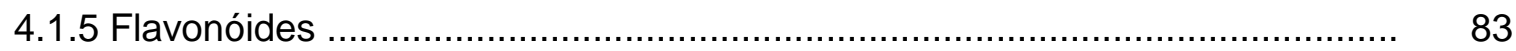

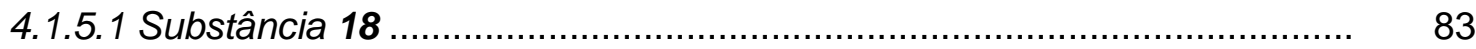

4.1.5.2 Substâncias 19 e 20 ....................................................................... 84

4.1.5.3 Substância 21 ............................................................................ 86

4.1.5.4 Substância 22 .............................................................................. 87

4.2 Atividade antimalárica dos lignóides ...................................................... 89

4.3 Atividade leishmanicida dos lignóides ...................................................... 91

4.4 Óleos voláteis .............................................................................................. 93

4.5 Atividade antimicrobiana dos óleos voláteis .............................................. 96

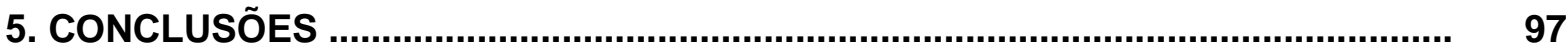

6. REFERÊNCIAS BIBLIOGRÁFICAS ............................................................. 99

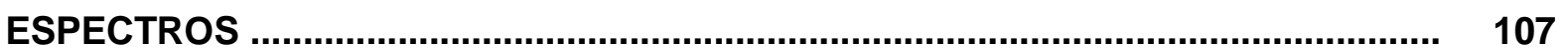




\section{SUBSTÂNCIAS IDENTIFICADAS}

\section{- Lignóides}<smiles>[R]c1ccc(-c2oc3c(OC)cc(CC=C)cc3c2C)cc1OC</smiles>

$$
\begin{gathered}
\mathrm{R}=\mathrm{OMe}(\mathbf{1}) \\
\mathrm{R}=\mathrm{OH}(\mathbf{2})
\end{gathered}
$$<smiles>[R]c1ccc([C@@H]2O[C@@H](c3ccc([R])c(OC)c3)[C@H](C)[C@H]2C)cc1OC</smiles>

$\mathrm{R}=\mathrm{MeO}, \mathrm{R}^{\prime}=\mathrm{MeO}(\mathbf{6})$

$\mathrm{R}=\mathrm{MeO}, \mathrm{R}^{\prime}=\mathrm{OH}(\mathbf{7})$

$\mathrm{R}=\mathrm{OH}, \mathrm{R}^{\prime}=\mathrm{OH}(8)$<smiles>[R]c1ccc([C@@H]2Oc3c(OC)cc(CC=C)cc3[C@@H]2C)cc1OC</smiles>

$$
\mathrm{R}=\mathrm{OMe}(\mathbf{3})
$$$$
\mathrm{R}=\mathrm{OH}(4)
$$<smiles>COc1ccc([C@H]2O[C@@H](c3ccc(OC)c(OC)c3)[C@H](C)[C@@H]2C)cc1OC</smiles>

9<smiles>C=CCc1cc(OC)c(O)c(C(C)C(=O)c2ccc(OC)c(OC)c2)c1</smiles>

13<smiles>C=CCc1cc(OC)c(O)c(-c2cc(CC=C)cc(OC)c2O)c1</smiles>

5<smiles>COc1cc([C@H]2O[C@@H](c3ccc(O)c(OC)c3)[C@H](C)[C@@H]2C)ccc1O</smiles><smiles>COc1cc([C@@H]2c3cc(O)c(OC)cc3C[C@@H](C)[C@H]2C)ccc1O</smiles>

14

- Tocotrienóides

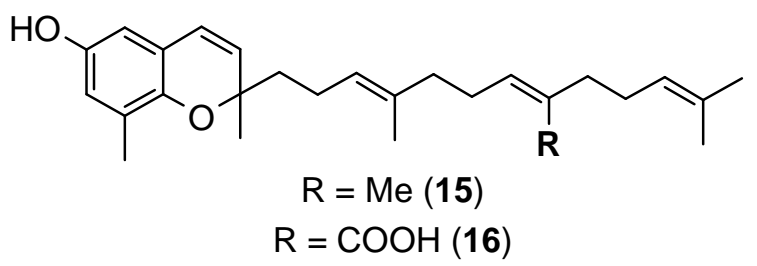

- Derivado do ácido cinâmico<smiles>O=C(O)/C=C\c1ccc(O)c(O)c1</smiles> 


\section{- Flavonóides}<smiles>O=C(/C=C/c1ccc(O)cc1)c1ccc(O)cc1O</smiles>

18<smiles>[R]c1ccc(C2CC(=O)c3ccc(O)cc3O2)cc1[R]</smiles>

$\mathrm{R}=\mathrm{H}, \mathrm{R}^{\prime}=\mathrm{OH}$ (19)

$\mathrm{R}=\mathrm{R}^{\prime}=\mathrm{OH}(20)$

$\mathrm{R}=\mathrm{R}^{\prime}=\mathrm{OH}, \Delta^{2,3}(\mathbf{2 1})$

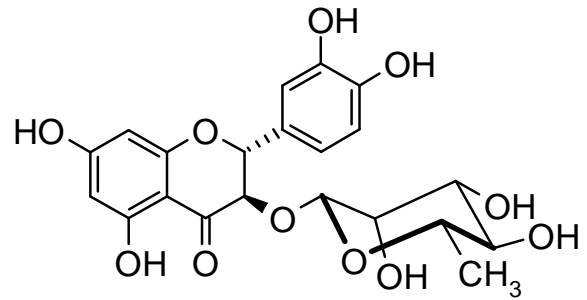

22

\section{- Terpenóides}

$\underbrace{}_{23}$<smiles>C=CC(=C)CCC=C(C)C</smiles><smiles>CC1=CCC(C(C)C)C=C1</smiles><smiles>CC1=CCC2C(C1)C2(C)C</smiles><smiles>CC1=CC=C(C(C)C)CC1</smiles><smiles>Cc1ccc(C(C)C)cc1</smiles><smiles>C=C(C)C1CC=C(C)CC1</smiles>

26

27

28

29

30

31

4<smiles>C=C/C(C)=C/CC=C(C)C</smiles><smiles>CC1=CCC(C(C)C)=CC1</smiles><smiles>CC1=CCC(=C(C)C)CC1</smiles><smiles>C=CC(C)(O)CCC=C(C)C</smiles>

33

34

35

36<smiles>CC1(C)[C@H]2C[C@@](C)(C2)[C@H]1O</smiles>

37

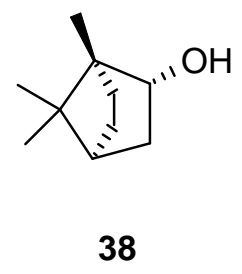<smiles>CC1=CCC(O)(C(C)C)CC1</smiles>

39<smiles>CC1=CCC(C(C)(C)O)CC1</smiles>

40<smiles>CC(C)=CCC/C(C)=C\CO</smiles>

41<smiles>C=C[C@]1(C)CCC(C(C)C)=C[C@H]1C(=C)C</smiles>

42<smiles>CC1=CC[C@]23C(C)CC[C@@H](C(C)C)[C@H]2[C@H]13</smiles>

43<smiles></smiles>

44<smiles>C=C1CC[C@]23C(C)CC[C@@H](C(C)C)C2[C@H]13</smiles>

45<smiles>C=C[C@]1(C)CC[C@@H](C(=C)C)C[C@H]1C(=C)C</smiles>

46

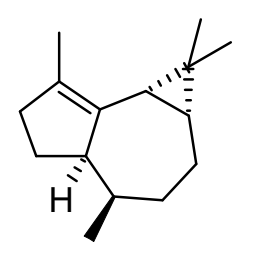

47

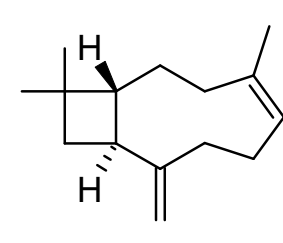

48

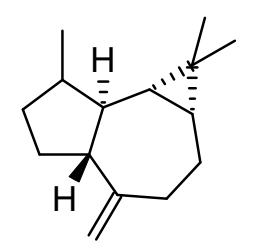

49

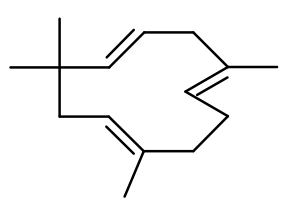

50 
<smiles>CC1=CC2=C(CC1)[C@@H](C)CC[C@@H]2C(C)C</smiles>

51<smiles>CC(C)=CCCC(C)C1=CC=C(C)CC1</smiles>

52<smiles>CC1=C[C@H]2C(C)=CC[C@H](C(C)C)[C@H]2CC1</smiles>

53<smiles>C=C1/C=C/[C@H](C(C)C)CC/C(C)=C/CC1</smiles>

54<smiles>C=C1CCC[C@]2(C)CC[C@@H](C(=C)C)C[C@H]12</smiles>

55<smiles>C/C1=C/C2C(C/C=C(\C)CCC1)C2(C)C</smiles>

56

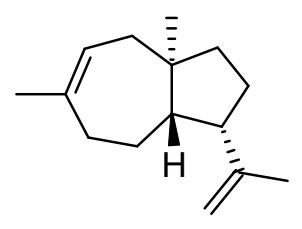

57<smiles>C=C(CCC=C(C)C)C1CC=C(C)CC1</smiles>

58<smiles>CC(C)=CCCC(C)C1=CCC(C)=CC1</smiles>

59<smiles>CC1=C[C@H]2C(=C(C)CC[C@@H]2C(C)C)CC1</smiles>

60<smiles>CC1=CC2=C(C(C)C)CC[C@H](C)[C@H]2CC1</smiles>

61<smiles>C=CC(C)(O)CCC=C(C)CCC=C(C)C</smiles>

62

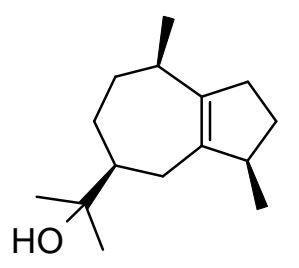

67<smiles>CC1=C[C@H]2[C@@H](C(C)C)CC[C@@H](C)[C@]2(O)CC1</smiles>

68

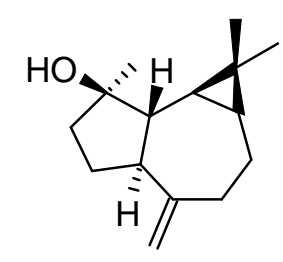

64

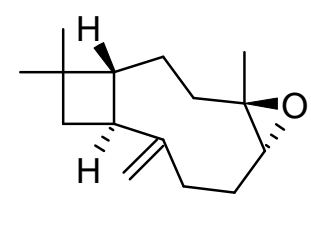

65

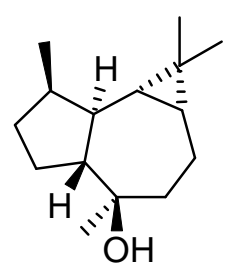

66

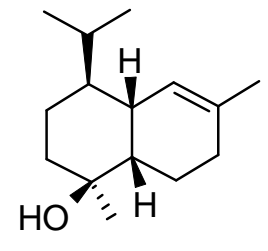

72<smiles>CC1=CCC[C@]2(C)CC[C@@H](C(C)(C)O)C[C@@H]12</smiles>

73<smiles>CC1=C2C[C@H](C(C)(C)O)CC[C@]2(C)CCC1</smiles>

69<smiles>CC1=C[C@H]2[C@@H](C(C)C)CC[C@@H](C)[C@H]2CC1</smiles>

70<smiles>CC1=C[C@H]2[C@@H](C(C)C)CC[C@@H](C)[C@H]2CC1</smiles>

71<smiles>CC(C)=CCC/C(C)=C\CC/C(C)=C\O</smiles>

77

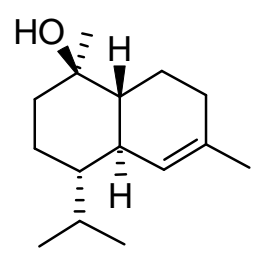

74<smiles>CC(C)=CCC[C@](C)(O)[C@H]1CC=C(C)CC1</smiles>

75<smiles>CC(C)=CCC[C@](C)(O)[C@H]1CC=C(C)CC1</smiles>

76<smiles>CCCCCC(C)(C)C</smiles>
78<smiles>C=C1CC[C@@H](O)[C@]2(C)CC[C@H](C(C)C)[C@H](O)[C@H]12</smiles>

79 


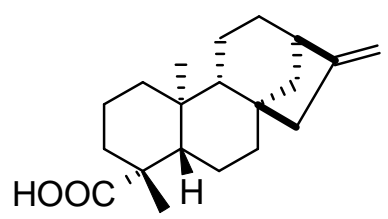

80

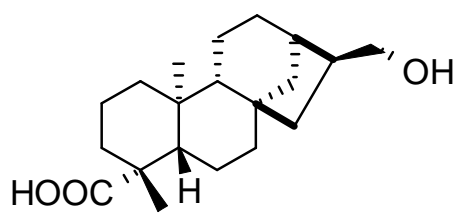

81

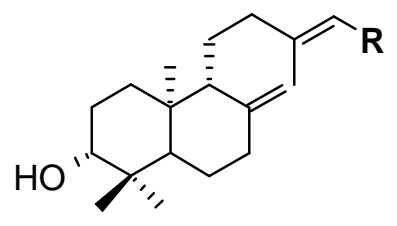

$\mathrm{R}=\mathrm{CH}_{2} \mathrm{OH}$ (82)

$\mathrm{R}=\mathrm{COOH}$ (83) 


\section{INTRODUÇÃO}

\subsection{Considerações gerais sobre a família Myristicaceae}

Myristicaceae é uma família com distribuição pantropical constituída por 18 gêneros e cerca de 500 espécies arbóreas ou raramente arbustivas, especialmente encontradas em florestas úmidas de planície. No Brasil esta família é representada pelos gêneros Compsoneura, Iryanthera, Osteophloeum, Otoba (sin. Dialyanthera) e Virola, os quais estão concentrados na Região Amazônica, onde as miristicáceas são genericamente conhecidas como ucuúbas (SOUZA e LORENZI, 2005; MOBOT, 2008).

Esta família é considerada uma das mais primitivas das angiospermas e suas espécies se caracterizam por apresentar látex avermelhado, folhas alternas, geralmente dísticas, simples, sem estípulas, inteiras e freqüentemente aromáticas. Inflorescência cimosa, racemosa ou paniculada, com flores pouco vistosas e unissexuadas. Seus frutos ocorrem em cápsulas, sendo constituídos por um pericarpo lenhoso, geralmente deiscente ao longo de duas suturas ventrais e dorsais. Suas sementes são oleaginosas, envolvidas por arilo comumente vermelho, carnoso e vistoso (Figura 1) (VAN ROOSMALEN et al., 1996; SOUZA e LORENZI, 2005).
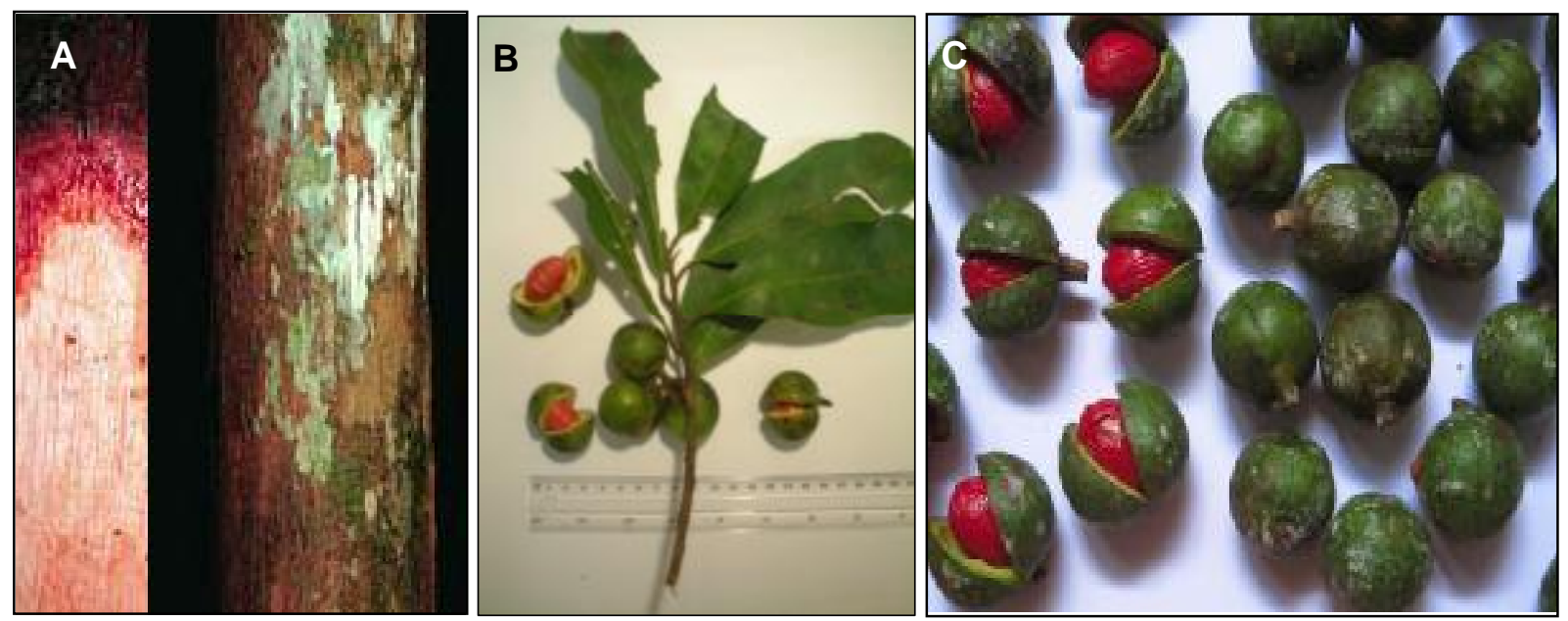

Figura 1. (A) Cascas de I. juruensis (Fonte: VICENTINI e RODRIGUES, 1999); (B) Ramo com folhas e frutos de O. platyspermum; (C) Frutos maduros de V. pavonis. 
Dentre os cinco gêneros endêmicos no Brasil, os que possuem o maior número de espécies incluem o Virola (60 spp.) e o Iryanthera (23 spp.), sendo o gênero Virola o mais amplamente disperso e o único com ocorrência na região extra-amazônica, destacando-se a espécie $V$. sebifera, relativamente comum no cerrado, bem como as espécies $V$. oleifera e V. bicuhyba, comumente encontradas na Mata Atlântica (VICENTINI e RODRIGUES, 1999; SOUZA e LORENZI, 2005; MOBOT, 2008).

Algumas miristicáceas possuem reconhecido valor econômico. A noz-moscada e o macis são especiarias apreciadas na culinária de todo o mundo e consistem nas amêndoas e no arilo, respectivamente, da espécie de origem asiática Myristica fragrans. Dentre as miristicáceas amazônicas, a espécie V. surinamensis (Rol.) Warb. apresenta importante valor comercial madeireiro, sendo bastante empregada na produção de compensados, laminados e na fabricação de caixas, palitos de fósforos, cabos de vassoura, celulose e papel (RODRIGUES, 1980).

As sementes das miristicáceas apresentam elevado teor de triglicerídeos e ácidos graxos, especialmente ácido mirístico $\left(\mathrm{C}_{14}\right)$, daí a denominação popular de ucuúba, que significa árvore produtora de gordura. Dessas sementes é extraída e comercializada a "manteiga de ucuúba", usada como matéria-prima na fabricação de velas e cosméticos em geral (RODRIGUES, 1980).

As miristicáceas neotropicais passaram a ser alvo de intensos estudos em meados dos anos cinqüenta, quando Schultes divulgou que certas tribos indígenas da Amazônia usavam as cascas e a resina de algumas espécies de Virola no preparo de rapés alucinogênicos e como veneno em flechas para caça (RODRIGUES 1980).

Posteriormente foram publicados vários trabalhos etnobotânicos e etnofarmacológicos envolvendo essas espécies, o que veio reforçar o interesse pela constituição química dessas plantas. Dentre as diversas indicações populares atribuídas às espécies dessa família destaca-se o uso como estimulante cerebral, cicatrizante, no tratamento de infecções dermatológicas ou estomacais, reumatismo, tumores, erisipela e 
doenças no trato respiratório (SCHULTES e HOLMSTED, 1971; GOTTLIEB, 1979; SCHULTES, 1985).

Os primeiros estudos fitoquímicos realizados com miristicáceas neotropicais surgiram na década de setenta, sendo conduzidos especialmente com a madeira do tronco e com as cascas de espécies de Virola e Iryanthera. Esses estudos levaram ao isolamento de compostos pertencentes às classes de diarilpropanóides, flavonóides, lignanas, $\gamma$-lactonas e alcalóides dos tipos $N, N$-dimetiltriptamina e $\beta$-carbolina, sendo a estes últimos atribuídas as propriedades alucinógenas e tóxicas propagadas por Schultes.

No início da década de oitenta, o interesse fitoquímico se direcionou aos metabólitos acumulados nos frutos dessas espécies, uma vez que este órgão acumula substâncias de defesa necessárias para a sua perpetuação. O resultado observado foi o registro de compostos pertencentes a outras classes, tais como policetídeos, tocotrienóides, flavonolignóides e uma grande variedade de neolignanas.

Ao analisar separadamente os dois gêneros mais estudados de miristicáceas neotropicais, é possível observar um acúmulo diferenciado entre seus principais constituintes. Flavonolignóides, tocotrienóis e $\gamma$-lactonas co-ocorrem com freqüência em espécies de Iryanthera, enquanto que policetídeos e diarilpropanóides estão presentes principalmente em espécies de Virola. Lignóides são predominantes no gênero Virola e os flavonóides se encontram bem distribuídos em ambos os gêneros (ROMOFF e YOSHIDA, 1997).

Atualmente existe registro para cerca de 230 constituintes químicos isolados de miristicáceas neotropicais, dentre os quais $50 \%$ correspondem a lignanas e neolignanas, o que faz destas as duas principais classes de metabólitos secundários da família Myristicaceae (ROMOFF e YOSHIDA, 1997; SARTORELLI et al., 1998; SILVA et al., 2001; NUNOMURA e YOSHIDA, 2002; LOPES et al., 2004; SILVA et al., 2007). 


\subsection{Atividade biológica de miristicáceas neotropicais}

Estudos realizados com miristicáceas neotropicais visando a descoberta de substâncias ativas conduziram ao isolamento de lignanas e neolignanas com atividades biológicas promissoras. De fato, a ação farmacológica dos lignóides é relevante e se encontra bem documentada na literatura, sendo a essa classe de compostos atribuída atividades antitumoral, fungistática e/ou fungicida, antioxidante, anti-HIV, cardiovascular, dentre inúmeras outras (McRAE e TOWERS, 1984).

Das folhas de $V$. surinamensis, usada tradicionalmente na quimioprofilaxia da esquistossomose (RODRIGUES, 1980), foram isoladas as neolignanas virolina (84) e surinamensina (85), ambas com efeito protetor contra a penetração de cercárias de Schistosoma mansoni no hospedeiro (BARATA et al., 1978).

O extrato diclorometânico dos galhos de $V$. surinamensis apresentou significativa atividade in vitro contra a forma tripomastigota de Trypanosoma cruzi. Desse extrato foram isoladas as neolignanas veraguensina (86) e grandisina (87), às quais foi atribuída a ação anti-chagásica observada (LOPES et al., 1998).

Dos frutos de $V$. calophylla foi isolado o ácido nor-di-hidroguaiarético (88), que além de intensa atividade antioxidante, possui ainda atividade antitumoral, larvicida contra $S$. mansoni e moluscicida contra Biomphalaria glabrata (YOSHIDA, 1995).

Do arilo de $V$. oleifera foram isoladas as lignanas 89 [rel-(7R,8S,8' $R)$-7-hidroxi3,4,3',4'-tetrametoxi-8,8'-lignana] e 90 (oleiferina G), que apresentaram moderada atividade contra o fungo fitopatogênico Cladosporium sphaerospermum $(25 \mu \mathrm{g})$ e boa atividade contra o C. cladosporioides $(10 \mu \mathrm{g})$, em ensaio de bioautografia (SARTORELLI et al., 1998).

Mais recentemente, a neolignana denominada guaiacina (14), isolada dos frutos de Iryanthera juruensis, apresentou significativa atividade inibitória de lipoperoxidação (> 95\% a 100 ppm), além de inibir fortemente a enzima ciclooxigenase COX-1 (75\% a 100 ppm) e apresentar fraca atividade para a COX-2 (<20\% a 100 ppm), sugerindo forte ação 
antioxidante, potencial uso como anti-hipertensivo e fraca atividade antiinflamatória (SILVA et al., 2007).<smiles>[R]c1cc([C@@H](O)[C@@H](C)Oc2ccc(/C=C/C)cc2OC)cc(OC)c1OC</smiles>

$\mathrm{R}=\mathrm{H}(\mathbf{8 4})$

$\mathrm{R}=\mathrm{OMe}(\mathbf{8 5})$

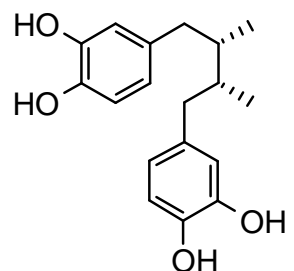

88<smiles>COc1ccc([C@H]2O[C@@H](c3ccc(OC)c(OC)c3)[C@H](C)[C@@H]2C)cc1OC</smiles>

86<smiles>[R]c1ccc(C[C@@H](C)[C@H](C)[C@H](O)c2ccc(OC)c(OC)c2)cc1OC</smiles>

$\mathrm{R}=\mathrm{MeO}(\mathbf{8 9})$

$\mathrm{R}=\mathrm{OH}(90)$<smiles>COc1cc([C@H]2O[C@@H](c3cc(OC)c(OC)c(OC)c3)C[C@@H]2C)cc(OC)c1OC</smiles>

87<smiles>COc1cc([C@H]2c3cc(O)c(OC)cc3C[C@@H](C)[C@H]2C)ccc1O</smiles>

14

Figura 2. Estruturas moleculares de lignóides ativos isolados de miristicáceas amazônicas.

Embora os lignóides quase sempre recebam os méritos pelo amplo espectro de ação biológica apresentado pelas miristicáceas neotropicais, muitas outras atividades biológicas observadas em extratos e frações de espécies de Virola e Iryanthera podem ser atribuídas aos flavonóides e/ou tocotrienóides, substâncias antioxidantes e com diversas outras atividades biológicas descritas (DAVINO et al., 1998; SILVA et al., 2001; SILVA et al., 2007).

Os flavonóides 7-hidroxi-flavanona (91) e 7-hidroxi-4'-metoxi-isoflavona (92), isolados das raízes de $V$. surinamensis, se mostraram 10 vezes mais ativos que o antibiótico nistatina, usado como controle positivo em ensaio de inibição de crescimento do fungo $C$. cladosporioides, evidenciando o papel ecofisiológico desses metabólitos na prevenção do tecido contra os microrganismos do solo (LOPES et al., 1999).

Das folhas de V. michelii, foi isolada a flavona titonina (3'-hidroxi-7,4'-dimetoxiflavona) (93), que juntamente com seus derivados metilado e acetilado, exibiu ação 
antiinflamatória em teste de edema de pata induzido por carragenina numa concentração de 10 mg/Kg (46, 53 e 78\% de inibição, respectivamente) (CARVALHO et al., 1999).

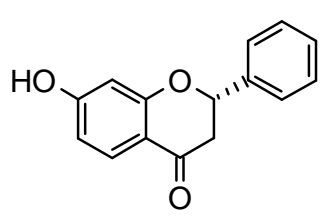

91

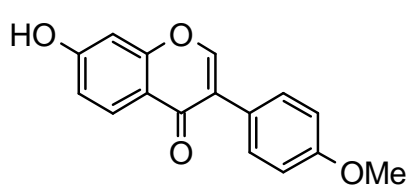

92<smiles>COc1ccc2c(=O)cc(-c3ccc(OC)c(O)c3)oc2c1</smiles>

93

Figura 3. Estruturas moleculares de flavonóides ativos isolados de miristicáceas amazônicas.

Fato interessante é a constatação da atividade antimalárica apresentada por extratos de algumas miristicáceas neotropicais. O extrato hidroalcoólico das cascas de Iryanthera leavis mostrou atividade in vivo contra Plasmodium berghei, reduzindo a parasitemia em $59 \%$ numa concentração de $100 \mathrm{mg} / \mathrm{Kg}$. De acordo com MUNÕZ et al. (2000), tal atividade pode estar associada à presença de chalconas e derivados, compostos antimaláricos em potencial.

Recentemente foi reportada a atividade in vitro contra $P$. falciparum do extrato diclorometânico das cascas de Virola calophylla $\left(\mathrm{IC}_{50}=4,3 \mu \mathrm{g} / \mathrm{mL}\right)(\mathrm{ROUMY}$ et al., 2007).

\section{3 Óleos essenciais na família Myristicaceae}

Por apresentar elevado valor econômico e aplicação medicinal, o óleo essencial das amêndoas de Myristica fragrans (noz-moscada) é o mais conhecido da família Myristicaceae e se caracteriza pela predominância de monoterpenos e fenilpropanóides, especialmente miristicina. Estudos sobre a composição química dos óleos voláteis das folhas de $M$. malabarica e Gymnacrathera canarica, bem como das cascas das espécies Staudtia gabonensis e Pycnanthus angolensis, revelaram abundância de hidrocarbonetos sesquiterpênicos (SABULAL et al., 2007; SIMIC et al., 2006; AGNANIET et al., 2004). O óleo 
volátil das folhas de $P$. angolensis mostrou-se rico em sesquiterpenos oxigenados, sendo o espatulenol (82\%) o principal constituinte identificado (SIMIC et al., 2006).

Poucas miristicáceas brasileiras foram examinadas com relação à produção e ao teor de óleo essencial. A análise do óleo volátil das folhas de $V$. surinamensis revelou a predominância do monoterpeno limoneno e do fenilpropanóide elemicina (LOPES et al., 1997), enquanto que o óleo obtido das folhas frescas de $V$. michelii apresentou abundância de hidrocarbonetos sesquiterpênicos e a ausência de fenilpropanóides, sendo o biciclogermacreno (36,6 \%) o principal componente identificado (TORRES et al., 2005).

De acordo com Lopes et al. (1999), os índios Waiãpi, oeste do Amapá, tratam os doentes acometidos pela malária com inalação do vapor proveniente das folhas de $V$. surinamensis coletadas na estação chuvosa da região amazônica. O estudo do óleo essencial das folhas dessa espécie, coletadas em diferentes estações do ano e horas do dia, apresentou variações sazonal e circadiana de seus constituintes, sendo observada a prevalência de sesquiterpenos no período de chuva. Ensaio antimalárico conduzido com o óleo essencial das plântulas dessa espécie apresentou $100 \%$ de inibição do desenvolvimento da fase de trofozoíta para o estágio de esquizonte do $P$. falciparum, causando a morte do parasito, sendo o nerolidol identificado como um dos compostos ativos.

\subsection{Revisão bibliográfica das espécies estudadas}

Embora todas as miristicáceas sejam caracterizadas pela presença marcante de lignanas e neolignanas, a ocorrência de determinadas classes de compostos parece ser restrita a alguns gêneros dessa família. Ainda que diversos estudos com espécies pertencentes a esta família tenham sido desenvolvidos, os mesmos foram conduzidos de maneira heterogênea em relação ao material vegetal de partida e às técnicas de isolamento. A realização de um estudo simultâneo de espécies pertencentes a diferentes gêneros de 
Myristicaceae pode levar a uma análise comparativa mais conclusiva, no que se refere à distribuição dos metabólitos comumente encontrados nessa família.

Diante do exposto acima, o presente trabalho foi conduzido com as espécies Virola pavonis (A. DC.) A. C. Sm, Iryanthera juruensis Warburg e Osteophloeum platyspermum (Spruce ex A. DC.) Warburg. Essas espécies já foram estudadas anteriormente e a revisão bibliográfica desses trabalhos se encontra nas seções a seguir.

\subsubsection{Virola pavonis (A. DC.) A. C. Sm.}

A espécie $V$. pavonis é uma árvore que pode atingir até $30 \mathrm{~m}$ de altura, muito comum em mata de terra firme, podendo às vezes ser encontrada em caatingas, mata pantanosa e igapós. No Brasil esta espécie se distribui pelos estados do Acre, Amazonas, Mato Grosso, Pará e Rondônia, podendo também ser encontrada no Equador, Peru, Venezuela e Colômbia, onde é conhecida como ve-ri-que pelos índios Karijona (SCHULTES, 1971; VAN ROOSMALEN, 1996).

Essa espécie está morfologicamente associada à $V$. carinata, sendo distinta desta por seu habitat e pelas características estruturais de seus frutos. Além das semelhanças morfológicas, estas espécies se relacionam ainda do ponto de vista químico, uma vez que muitos compostos isolados originalmente de $V$. carinata, foram posteriormente encontrados em tecidos de V. pavonis (MARQUES et al., 1992).

De acordo com Rodrigues (1980), a madeira dessa espécie pode ser usada como sucedânea da V. surinamensis na confecção de laminados e compensados.

Estudos fitoquímicos previamente conduzidos com a madeira e as cascas dessa espécie resultaram no isolamento de diarilpropanóides (94 e 95) e de neolignanas do tipo benzodioxânicas (96 e 97). De suas folhas foram isoladas neolignanas dos tipos benzodioxânica (98), 8.O.4'-oxineolignana (99), tetra-hidrofurânica (100) e um fenilpropanóide (101). Em seus frutos foram encontradas neolignanas benzodioxânicas (102 e 103), benzofurânicas (1 e 2) e ariloxiarilpropânicas (104 e 13). 
Das folhas de um espécime identificado como Virola aff. pavonis, coletado na Colômbia, foram isoladas e identificadas neolignanas arilnaftalênicas (105-107), ariltetralínicas (108 e 109), uma lignana ariltetralônica (110), lignanas dibenzilbutânicas (111 e 112) e uma seco-ciclolignandiona (113) (Tabela 1.1). 
Tabela 1 - Constituintes químicos previamente isolados de $V$. pavonis.

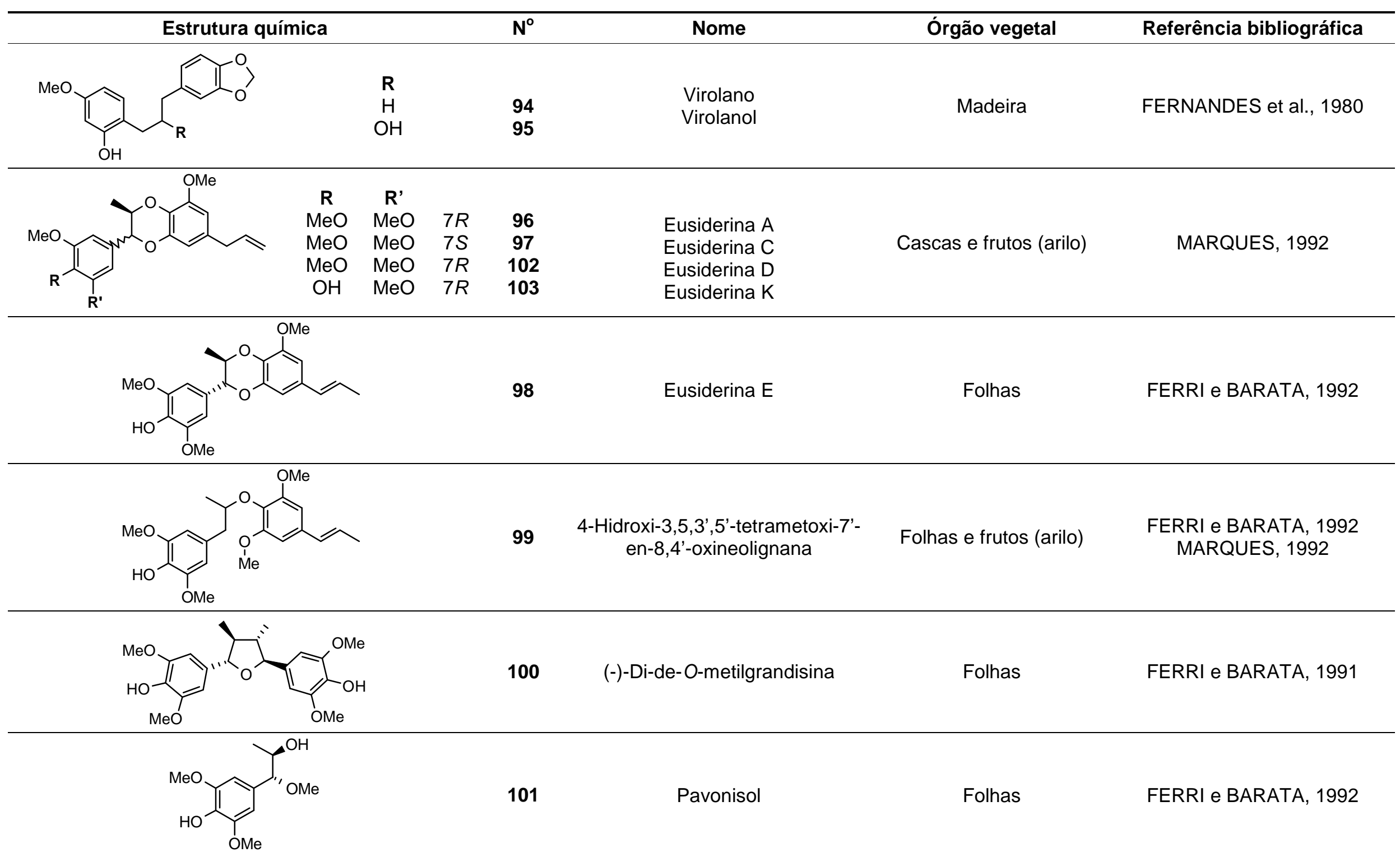


(continuação) Tabela 1 - Constituintes químicos previamente isolados de $V$. pavonis.

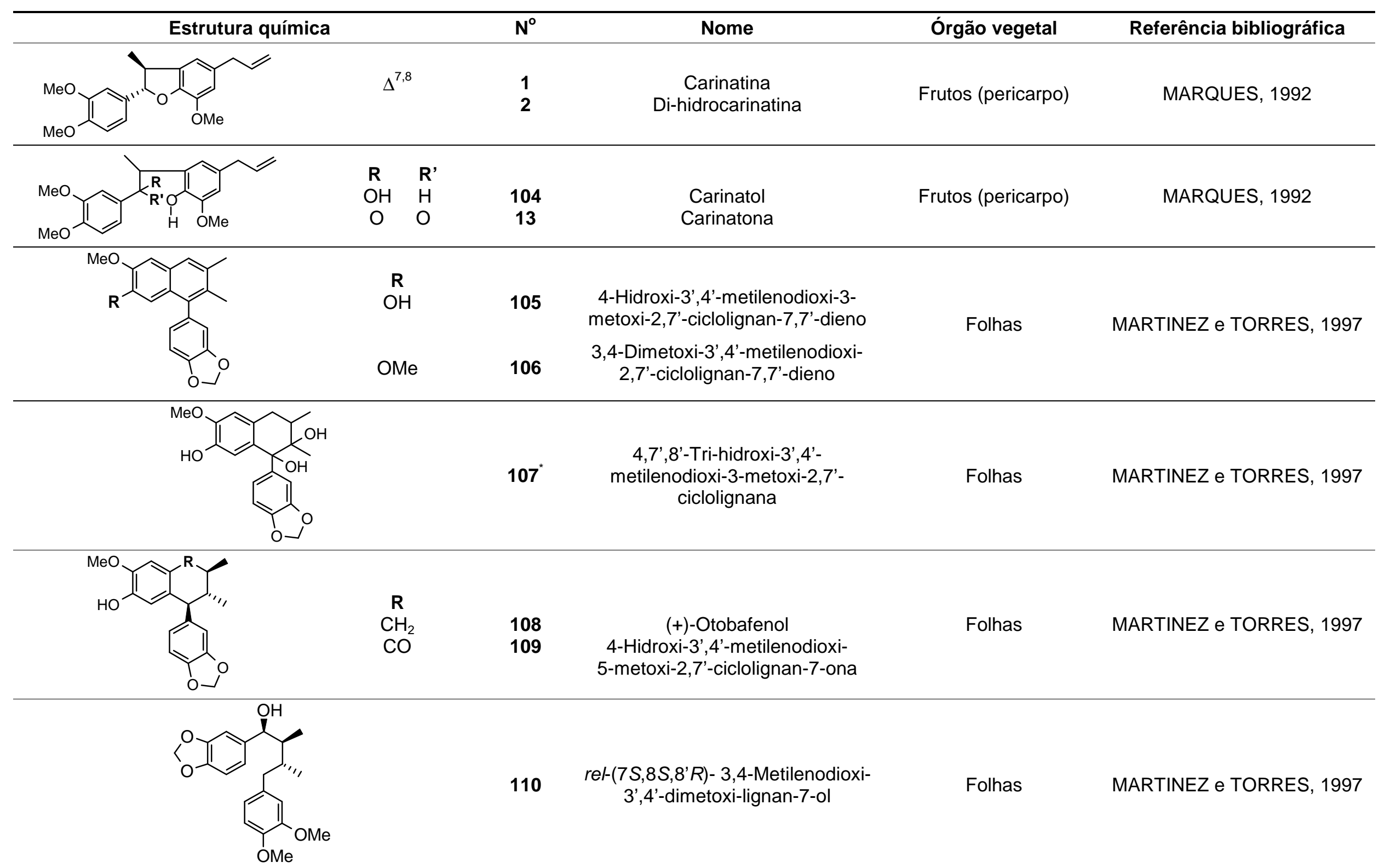


(continuação) Tabela 1 - Constituintes químicos previamente isolados de V. pavonis.

\begin{tabular}{|c|c|c|c|c|c|}
\hline Estrutura química & & $\mathbf{N}^{\circ}$ & Nome & Órgão vegetal & Referência bibliográfica \\
\hline $\mathbf{R}$ & $\begin{array}{c}\mathbf{R} \\
\mathrm{OH} \\
\mathrm{OMe}\end{array}$ & $\begin{array}{l}111 \\
112\end{array}$ & $\begin{array}{c}\left(8 S, 8^{\prime} R\right)-4 \text { '-Hidroxi-3,4- } \\
\text { metilenodioxi-3'-metoxi-7-oxo-8,8'- } \\
\text { lignana } \\
\text { (8S,8'R)- } \\
\text { dimetoxi-Metilenodioxi-3', } 4 \text { '- }\end{array}$ & Folhas & MARTINEZ e TORRES, 1997 \\
\hline & & $113^{*}$ & $\begin{array}{l}\text { 4-Hidroxi-3',4'-metilenodioxi- } \\
\text { 5-metoxi-7',8'-seco-2,7'- } \\
\text { ciclolignan-7',8'-diona }\end{array}$ & Folhas & MARTINEZ e TORRES, 1997 \\
\hline
\end{tabular}

* Configuração indeterminada. 


\subsubsection{Iryanthera juruensis Warburg}

A espécie Iryanthera juruensis é comumente encontrada na Bolívia, Colômbia, Equador, Guianas, Venezuela, Peru e Brasil, onde é popularmente conhecida como ucuubarana e especialmente encontrada nos estados do Acre, Amazonas, Mato Grosso, Pará, Rondônia e Roraima (VAN ROOSMALEN et al., 1996).

De acordo com informações etnobotânicas, a casca interna e a seiva dessa espécie apresentam bastante eficácia no tratamento de infecções causadas por fungos (SCHULTES, 1985).

Estudos realizados anteriormente com a madeira do tronco dessa espécie resultaram no isolamento e na identificação de uma flavana (114) e de $\gamma$-lactonas (115 e 116). De seus frutos foram isoladas neolignanas dos tipos tetra-hidrofurânicas (8 e 10) e ariltetralínicas (14 e 117), uma série de ácidos $\omega$-arilalcanóicos (118-120), tocotrienóides (16 e 121), plastoquinonas (122 e 123) e um ácido juruenólico (124). Mais recentemente, algumas 5desoxiflavonas $(\mathbf{9 3}, \mathbf{1 2 5}-\mathbf{1 2 8})$ foram obtidas das folhas dessa espécie, enquanto que de suas cascas foram isoladas as di-hidrochalconas 129 e 130 (Tabela 2).

Além da guaiacina (14), os compostos 16, 93, 127 e 128 apresentaram resultados promissores frente ao ensaio de lipoperoxidação. As 5-desoxiflavonas também inibiram as enzimas COX-1 e COX-2 cerca de 50-65\% na concentração de 100 ppm, enquanto que os compostos 118-120 e 124 apresentaram fraca atividade contra essas enzimas (SILVA et al., 2007). 
Tabela 2 - Constituintes químicos previamente isolados de I. juruensis.

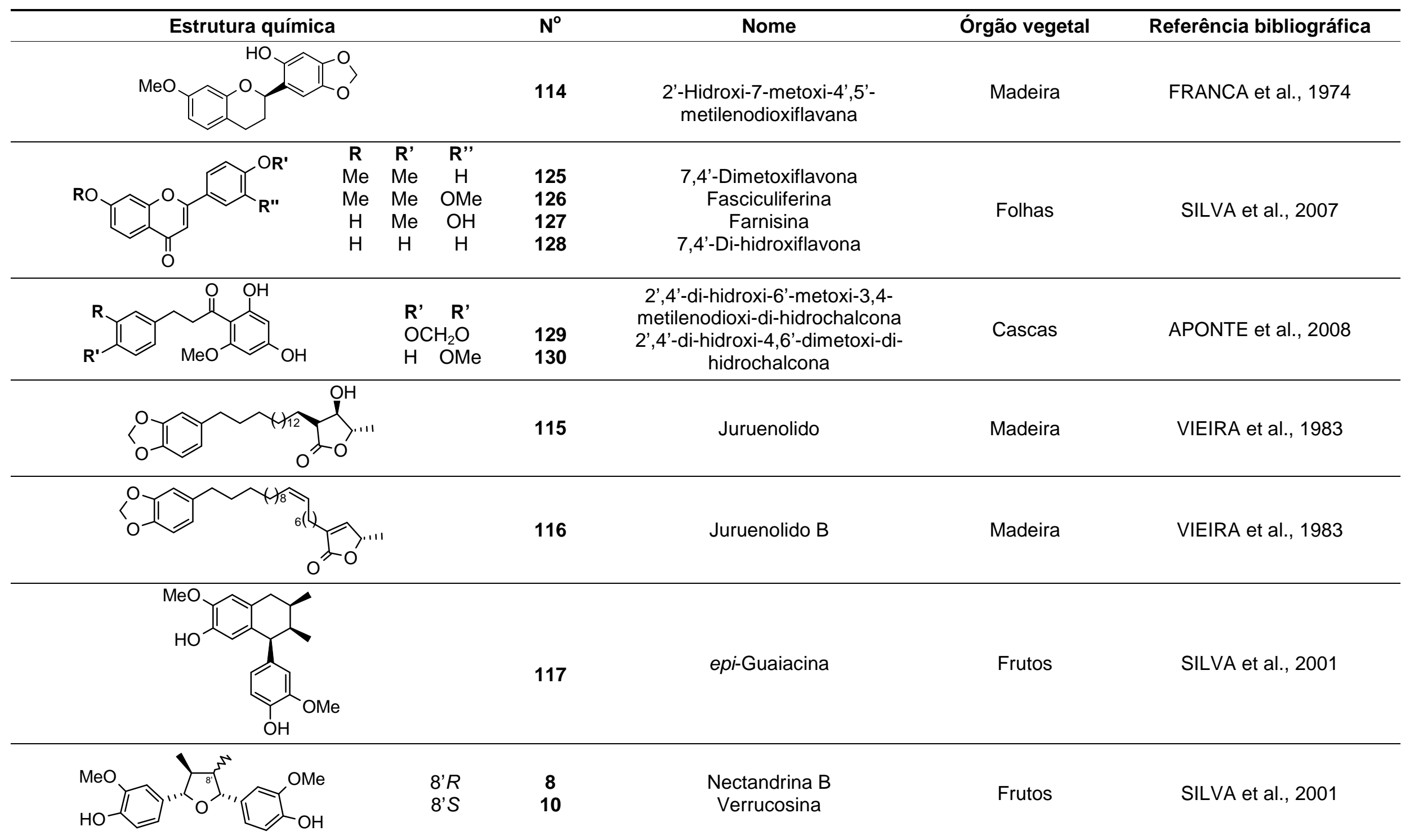


(continuação) Tabela 2 - Constituintes químicos previamente isolados de I. juruensis.

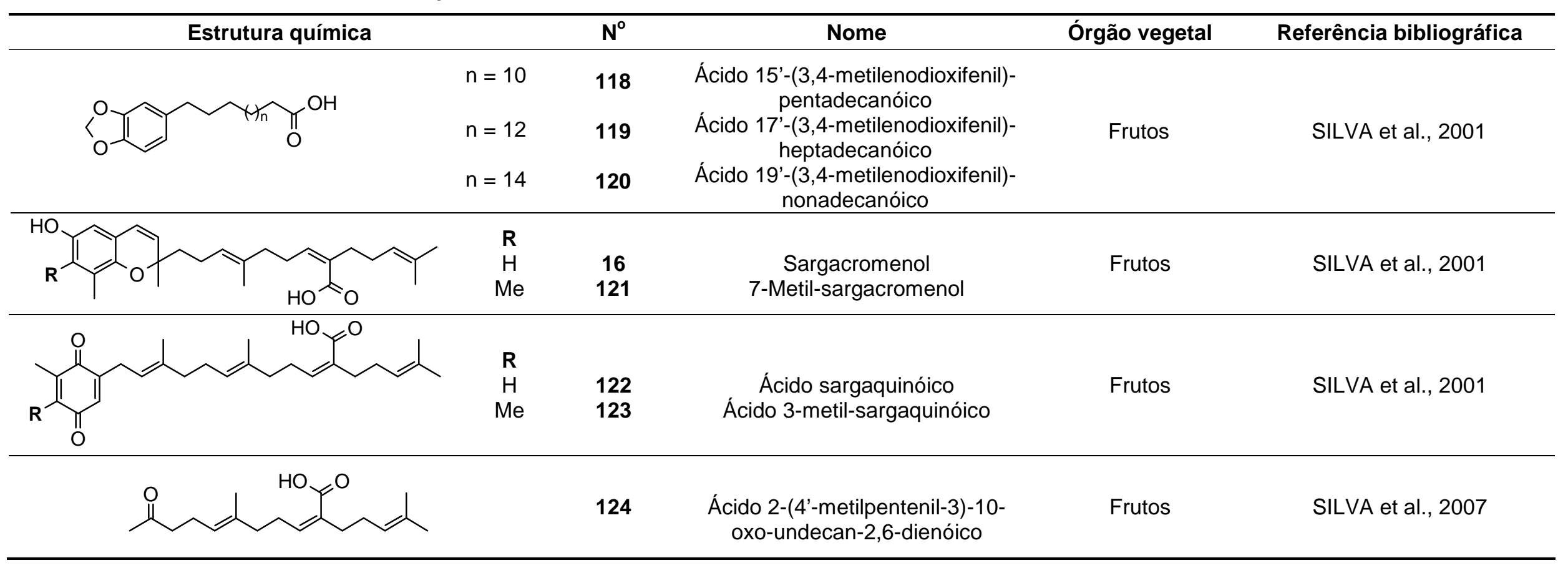




\subsubsection{Osteophloeum platyspermum (Spruce ex A. DC.) Warburg}

O gênero Osteophloeum compreende apenas duas espécies arbóreas, dentre as quais somente a O. platyspermum ocorre no Brasil, sendo especialmente encontrada nos estados do Acre, Amazonas, Pará e Roraima (VAN ROOSMALEN et al., 1996).

Segundo Schultes (1985), a inalação da fumaça gerada pela queima das folhas dessa espécie é tradicionalmente usada para aliviar os sintomas da asma. Os índios Makú, do rio Uneiuxi, costumavam beber a seiva dessa árvore para combater gripes e resfriados.

Estudos realizados previamente com diferentes órgãos dessa espécie revelaram a presença de flavonóides (131 e 132) na madeira do tronco, bem como de sesquiterpenos (64 e 133) e diterpenos $(\mathbf{8 0}, \mathbf{8 2}, 134$ e 135) nas folhas. De seus frutos foram isoladas diversas neolignanas $(14,108,136$ e 137) (Tabela 3). 
Tabela 3 - Constituintes químicos previamente isolados de O. platyspermum.

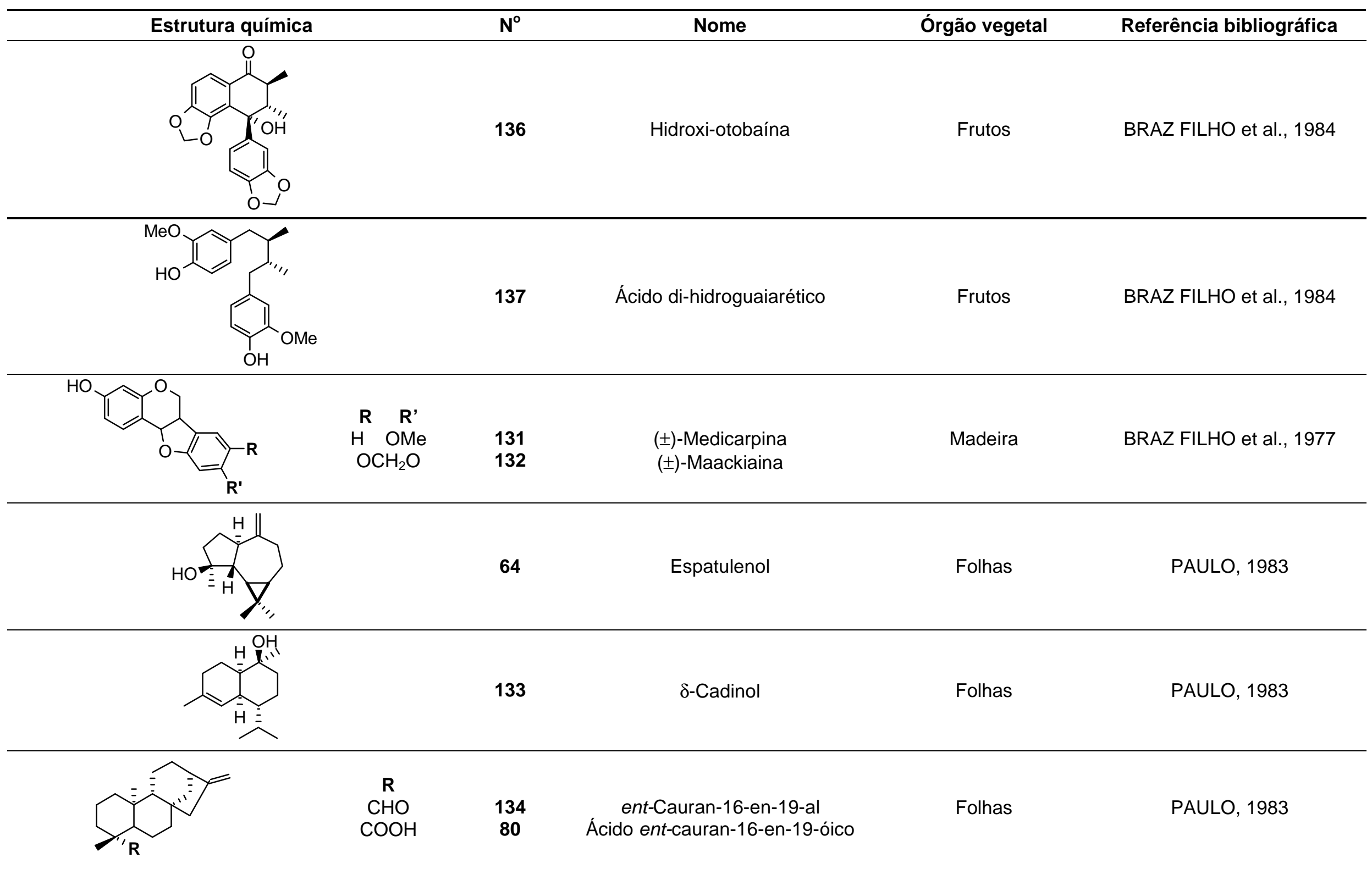


(continuação) Tabela 3 - Constituintes químicos previamente isolados de O. platyspermum.

\begin{tabular}{|c|c|c|c|c|}
\hline Estrutura química & $\mathbf{N}^{\circ}$ & Nome & Órgão vegetal & Referência bibliográfica \\
\hline & 135 & $\begin{array}{c}\text { Eperu-13-en-8ß,15-diol } \\
\text { (ent-13-labdadieno-8,15-diol) }\end{array}$ & Folhas & PAULO, 1983 \\
\hline
\end{tabular}




\section{OBJETIVOS}

Isolar e identificar os metabólitos secundários majoritários acumulados nos frutos maduros das espécies Virola pavonis (A. DC.) A. C. Sm, Iryanthera juruensis Warburg e Osteophloeum platyspermum (Spruce ex A. DC.) Warburg.

Identificar os constituintes químicos do óleo essencial obtido das folhas e dos pericarpos das espécies supracitadas.

Realizar ensaios biológicos preliminares para a avaliação do potencial antimalárico e leishmanicida dos lignóides isolados. 


\section{PROCEDIMENTO EXPERIMENTAL}

\subsection{Especificação de materiais e métodos}

Foram utilizados solventes de grau técnico previamente destilados nas extrações, partições e nos sistemas cromatográficos.

As análises por CCDC foram realizadas em cromatoplacas de alumínio com gel de sílica 60 com indicador de fluorescência $F_{254}$ da Merck. As placas foram visualizadas utilizando luz ultravioleta (UV 254 e 366 nm) e reveladas com solução de ácido sulfúrico $25 \%$, seguido de aquecimento.

Os experimentos de CCDP foram realizados em cromatoplacas de tamanho $20 \times 20$ $\mathrm{cm}$ e espessura do adsorvente de $1,0 \mathrm{~mm}$. Seis cromatoplacas foram preparadas usando 50 g de gel de sílica $60 \mathrm{PF}_{254}$ da Merck e cerca de $150 \mathrm{~mL}$ de água destilada.

Os fracionamentos por $\mathrm{CC}$ à pressão atmosférica foram realizados utilizando diferentes fases estacionárias: gel de sílica $60(0,063$ - 0,200 mm) da Merck, Sephadex LH20 e sílica de fase reversa.

Os espectros de $\mathrm{RMN}$ de ${ }^{1} \mathrm{H}$ e ${ }^{13} \mathrm{C}$ foram registrados nos espectrômetros Bruker AC200 e Varian INOVA 200 de 4,7 Tesla, operando a 200 e $50 \mathrm{MHz}$, respectivamente, e Varian DPX-300 de 7,05 Tesla, operando a 300 e $75 \mathrm{MHz}$, respectivamente. As amostras analisadas por RMN foram dissolvidas em $\mathrm{CDCl}_{3}, \mathrm{CD}_{3} \mathrm{OD}$ e DMSO- $d_{6}$ da Aldrich ou CIL.

Os espectros de massa das substâncias isoladas foram obtidos em sistema de CGEM da Shimadzu, modelo 14B/QP5050A, com analisador tipo quadrupolo e ionização por impacto eletrônico a 70 eV, ou através do sistema de LC-EM da Bruker, modelo Daltonics Esquire 3000 Plus, com analisador tipo íon trap, por injeção direta. Ambos os instrumentos operando em baixa resolução.

As análises dos óleos voláteis foram realizadas no Centro de Biotecnologia da Amazônia, sendo efetuadas em cromatógrafo a gás acoplado a espectrômetro de massas da Shimadzu, modelos CG-2010 e QP-2010, respectivamente. Foi usada coluna capilar DB- 
5MS (25 m x 0,25 mm e filme de 0,25 $\mu \mathrm{m}$ ) e hélio, como gás de arraste. A injeção foi feita no modo split na razão de $1 / 20$, com temperatura do injetor de $240{ }^{\circ} \mathrm{C}$ e fluxo de $1 \mathrm{~mL} / \mathrm{min}$, sendo injetado o volume de $1 \mu \mathrm{L}$ de solução da amostra. A programação da temperatura em cada análise foi de $100{ }^{\circ} \mathrm{C}(1 \mathrm{~min})$, com incremento de $3{ }^{\circ} \mathrm{C} / \mathrm{min}$ até $115^{\circ} \mathrm{C}$, seguido de incremento de $1^{\circ} \mathrm{C} / \mathrm{min}$ até $135^{\circ} \mathrm{C}$ e posterior incremento de $10^{\circ} \mathrm{C} / \mathrm{min}$ até $240^{\circ} \mathrm{C}$.

\subsection{Procedimento fitoquímico}

\subsubsection{Coleta e identificação do material vegetal}

Frutos maduros de Iryanthera juruensis Warburg foram coletados em março de 2003, no campus da Universidade Federal do Amazonas (UFAM), enquanto que os frutos das espécies Virola pavonis (A. DC.) A. C. Sm. e Osteophloeum platyspermum (Spruce ex A. DC.) Warburg foram coletados na Reserva Florestal Adolpho Ducke (Manaus), em março de 2004. Os espécimes coletados foram identificados pelo botânico José Ferreira Ramos e uma exsicata de cada um desses indivíduos se encontra depositada no herbário do Instituto Nacional de Pesquisas da Amazônia (INPA) sob as respectivas numerações: 213356, 214917 e 214918.

\subsubsection{Obtenção dos extratos}

Os frutos foram separados manualmente em pericarpo, arilo, tegumento e amêndoas. Em seguida, cada uma dessas partes foi separadamente seca à sombra, moída e extraída por maceração a frio. O processo de extração foi inicialmente realizado com hexanos e subsequentemente com etanol, por um período total de 14 dias, sendo o respectivo solvente trocado após 7 dias de maceração. Os extratos hexânicos e etanólicos foram obtidos eliminando-se os solventes em evaporador rotatório sob pressão reduzida (Esquema 1). Na Tabela 4 se encontram as massas dos extratos brutos obtidos, bem como as quantidades de material vegetal de partida. 


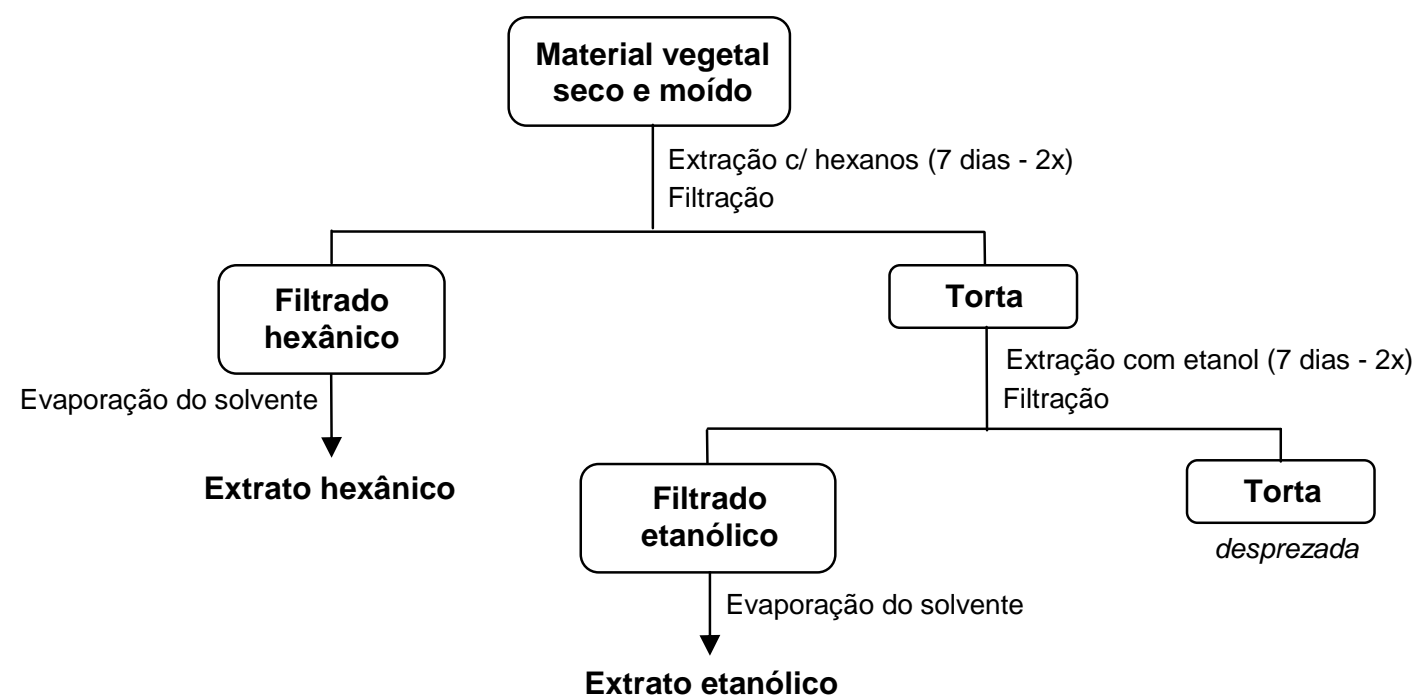

Esquema 1. Obtenção dos extratos hexânicos e etanólicos.

Tabela 4 - Quantidade do material vegetal de partida e massas dos extratos hexânicos e etanólicos obtidos dos frutos estudados.

\begin{tabular}{ccccc}
\hline Espécie & Parte do fruto & $\begin{array}{c}\text { Material } \\
\text { vegetal } \mathbf{( g )}\end{array}$ & $\begin{array}{c}\text { Extrato } \\
\text { hexânico } \mathbf{( g )}\end{array}$ & $\begin{array}{c}\text { Extrato } \\
\text { etanólico (g) }\end{array}$ \\
\hline \multirow{4}{*}{ I. juruensis } & Pericarpo & - & - & - \\
& Arilo & 8,20 & 3,94 & 1,60 \\
& Tegumento & 13,5 & 3,69 & 0,560 \\
& Amêndoas & 38,5 & 4,76 & 7,14 \\
\hline \multirow{4}{*}{ V. pavonis } & Pericarpo & 48,4 & 0,240 & 5,46 \\
& Arilo & 47,6 & 17,7 & 9,16 \\
& Tegumento & 16,3 & 0,550 & 0,650 \\
& Amêndoas & 145 & 60,0 & 14,4 \\
\hline \multirow{5}{*}{ O. platyspermum } & Pericarpo & 311 & 29,5 & 67,6 \\
& Arilo & 68,4 & 32,2 & 10,8 \\
& Tegumento & 155 & 6,80 & 3,42 \\
& Amêndoas & 121 & 68,2 & 14,3 \\
\hline
\end{tabular}

\subsubsection{Partição dos extratos}

Os extratos hexânicos foram ressuspendidos em metanol:água 9:1 e as soluções resultantes foram extraídas por três vezes com hexanos. As fases hexânicas e metanólicas foram então concentradas em evaporador rotatório fornecendo os respectivos resíduos (Esquema 2). As massas dos resíduos obtidos se encontram na Tabela 5. 


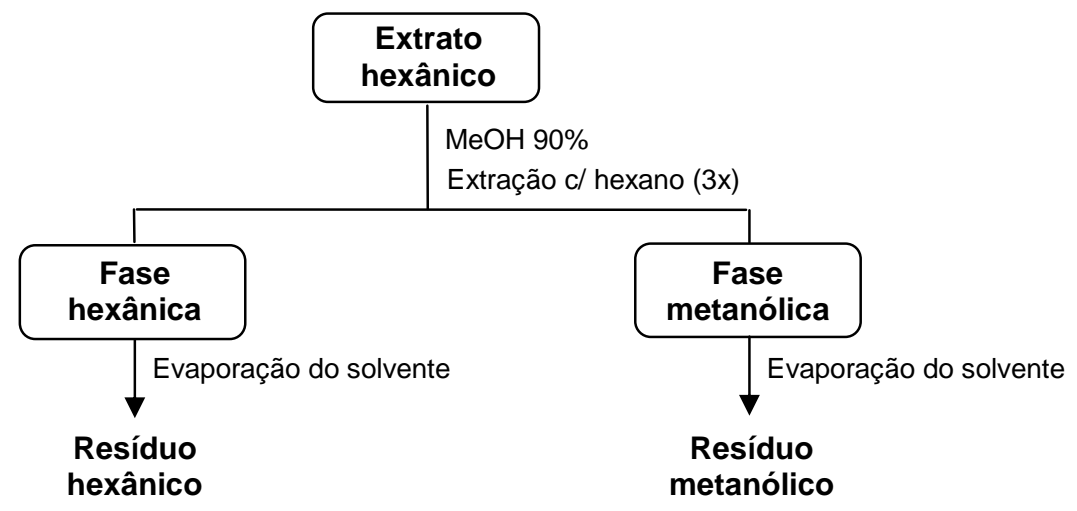

Esquema 2. Partição dos extratos hexânicos.

Tabela 5 - Massas dos resíduos provenientes da partição dos extratos hexânicos das espécies estudadas.

\begin{tabular}{cccc}
\hline Espécie & Parte do fruto & $\begin{array}{c}\text { Resíduo } \\
\text { hexânico } \mathbf{( g )}\end{array}$ & $\begin{array}{c}\text { Resíduo } \\
\text { metanólico (g) }\end{array}$ \\
\hline \multirow{3}{*}{ I. juruensis } & arilo & 3,35 & 0,59 \\
& tegumento & 2,91 & 0,72 \\
& amêndoa & 4,30 & 0,41 \\
\hline \multirow{3}{*}{ V. pavonis } & pericarpo & 0,16 & 0,08 \\
& arilo & 14,0 & 2,85 \\
& tegumento & 0,53 & 0,01 \\
& amêndoa & 57,5 & 1,21 \\
\hline \multirow{3}{*}{ O. platyspermum } & pericarpo & 65,5 & 0,60 \\
& arilo & 6,42 & 0,13 \\
& tegumento & 31,6 & 0,67 \\
& amêndoa & 28,0 & 1,76 \\
\hline
\end{tabular}

Os extratos etanólicos também foram ressuspendidos em metanol:água 9:1 e as respectivas suspensões resultantes foram extraídas com hexanos por três vezes. Em seguida, foi adicionada água destilada suficiente às fases hidroalcoólicas resultantes para torná-las uma solução de metanol:água 7:3. Estas novas soluções foram extraídas por três vezes com clorofórmio. Mais água destilada foi adicionada as fases hidroalcólicas tornandoas metanol:água 1:1, estas foram então extraídas com acetato de etila por três vezes. As soluções resultantes das extrações foram concentradas em evaporador rotatório fornecendo os respectivos resíduos. As massas desses resíduos se encontram na Tabela 6. 


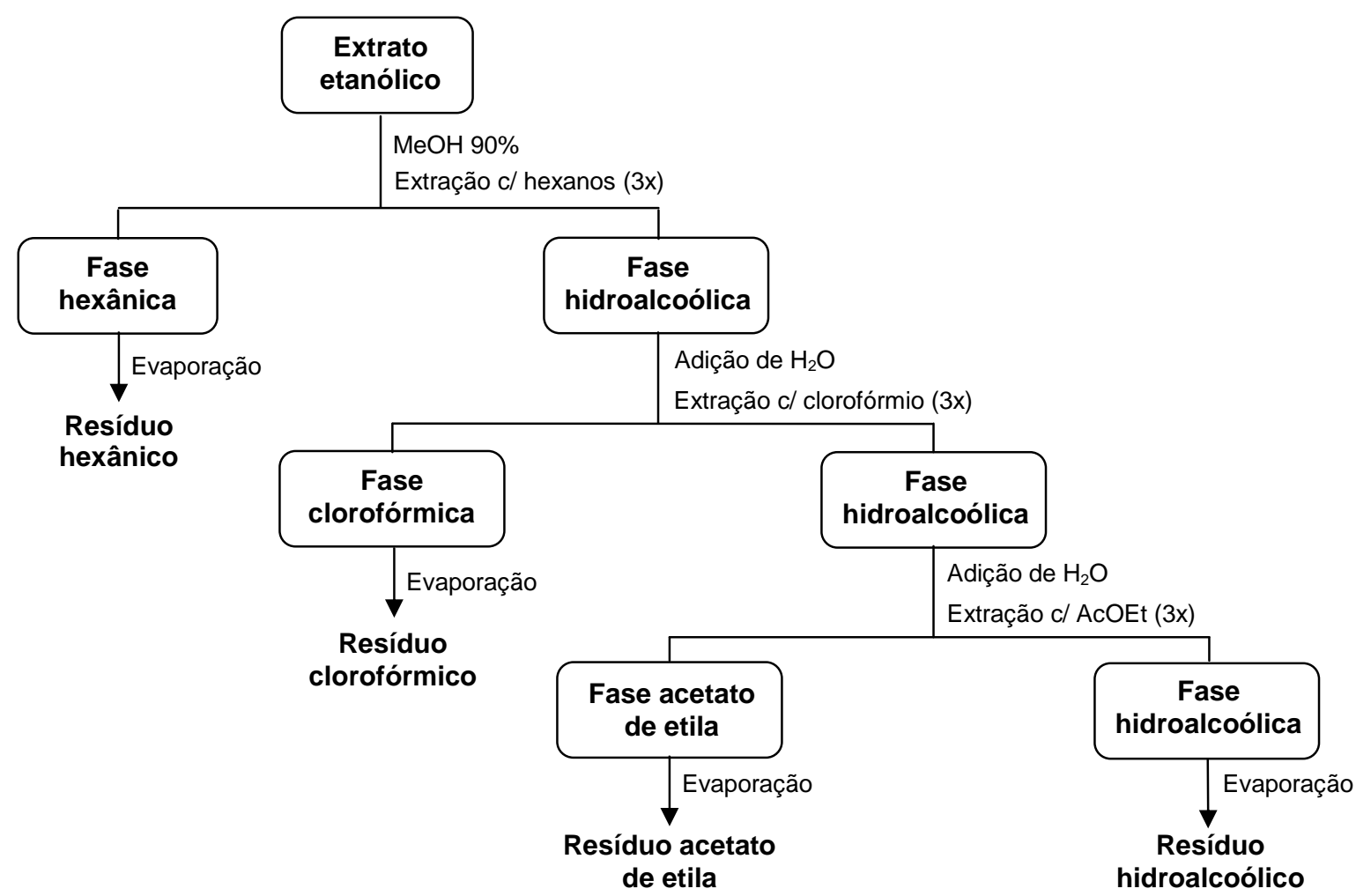

Esquema 3. Partição dos extratos etanólicos das espécies estudadas.

Tabela 6 - Massas dos resíduos provenientes da partição dos extratos etanólicos das espécies em estudo.

\begin{tabular}{cccccc}
\hline Espécie & $\begin{array}{c}\text { Parte do } \\
\text { fruto }\end{array}$ & $\begin{array}{c}\text { Resíduo } \\
\text { hexânico }\end{array}$ & $\begin{array}{c}\text { Resíduo } \\
\text { clorofórmico } \\
\text { gramas (g) }\end{array}$ & $\begin{array}{c}\text { Resíduo } \\
\text { acetato de etila }\end{array}$ & $\begin{array}{c}\text { Resíduo } \\
\text { metanólico }\end{array}$ \\
\hline \multirow{3}{*}{ I. juruensis } & arilo & 0,35 & 0,96 & 0,26 & 0,04 \\
& tegumento & 0,05 & 0,19 & 0,27 & 0,01 \\
& amêndoa & 2,41 & 3,38 & 1,19 & 0,05 \\
\hline \multirow{4}{*}{ V. pavonis } & pericarpo & 0,17 & 0,50 & 0,13 & 4,28 \\
& arilo & 1,16 & 2,37 & 0,37 & 1,08 \\
& tegumento & 0,03 & 0,31 & 0,08 & 0,22 \\
& amêndoas & 0,99 & 2,52 & 0,37 & 10,5 \\
\hline \multirow{4}{*}{ O. platyspermum } & pericarpo & 14,7 & 18,0 & 30,3 & 0,56 \\
& arilo & 7,10 & 5,07 & 2,04 & 0,07 \\
& tegumento & 0,33 & 1,14 & 0,53 & 0,92 \\
& amêndoas & 2,96 & 9,66 & 1,71 & 0,50 \\
\hline
\end{tabular}

3.2.4 Fracionamento dos resíduos e isolamento de substâncias

Os resíduos gerados pela partição foram submetidos à análise por CCDC, em diferentes sistemas, e RMN de ${ }^{1} \mathrm{H}$, que revelaram uma grande diferença de composição química entre as três espécies escolhidas para o estudo. As frações que apresentaram 
maior massa, sinais de compostos aromáticos no espectro de RMN de ${ }^{1} \mathrm{H}$ e/ou menor complexidade cromatográfica em CCDC foram fracionadas para a obtenção de substâncias puras.

Os Esquemas 4 a 9 mostram as condições usadas no isolamento das substâncias obtidas neste trabalho.

3.2.5 Fracionamento do resíduo clorofórmico do arilo de $V$. pavonis

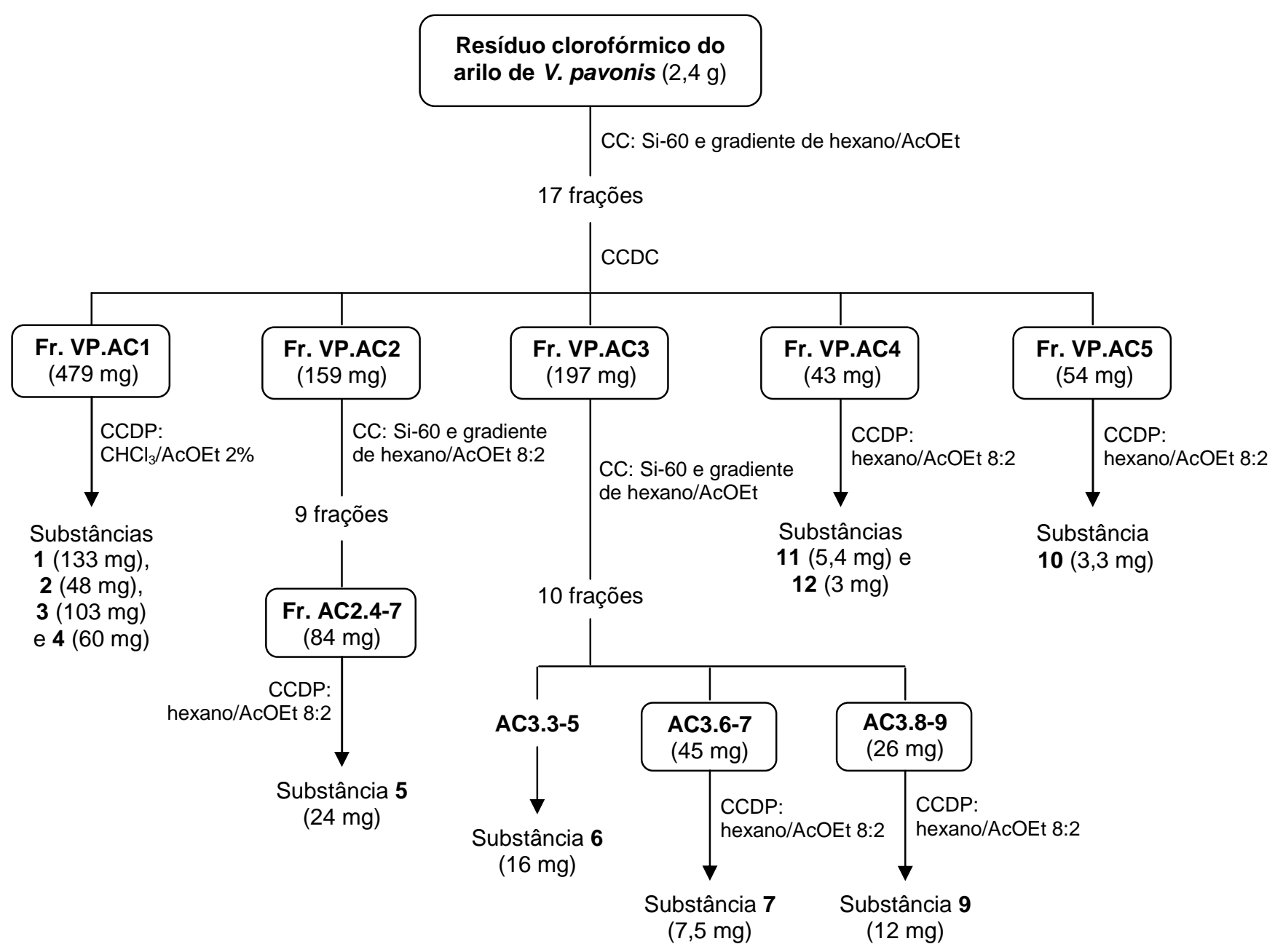

Esquema 4. Isolamento das substâncias 1, 2, 3, 4, 5, 6, 7, 9, 10, 11 e 12. 
3.2.6 Fracionamento do resíduo clorofórmico do pericarpo de $V$. pavonis

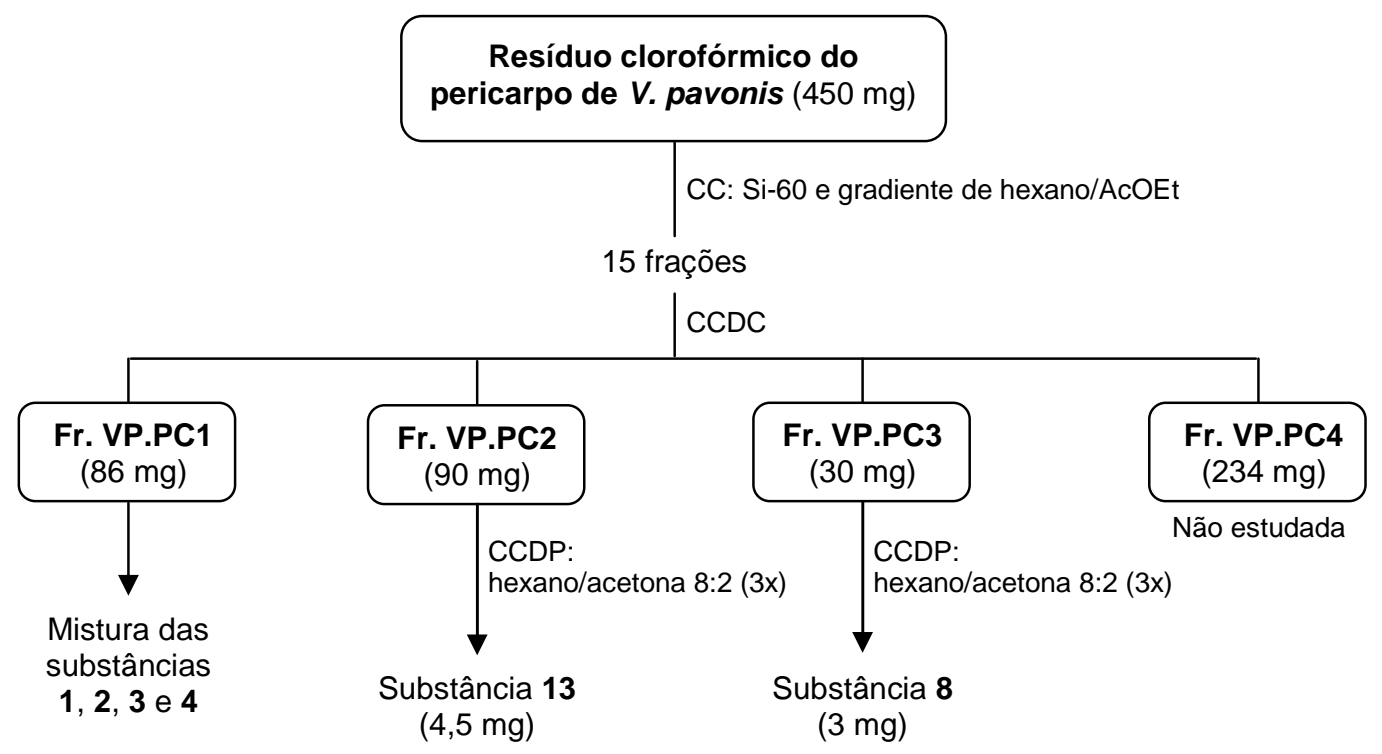

Esquema 5. Isolamento das substâncias 8 e 13.

3.2.7 Fracionamento do resíduo de acetato de etila do arilo de $V$. pavonis

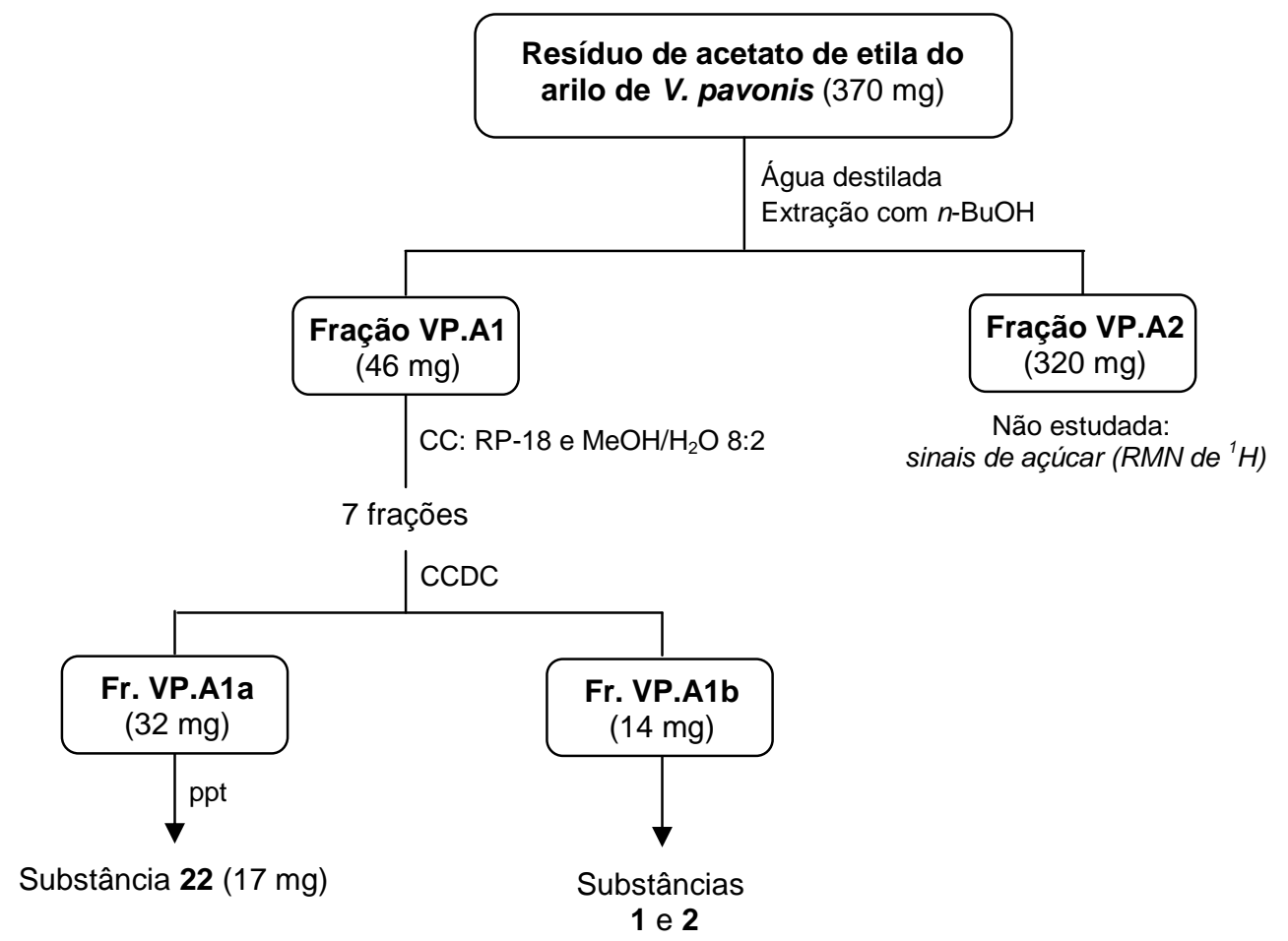

Esquema 6. Isolamento da substância 22. 
3.2.8 Fracionamento do resíduo clorofórmico do arilo de I. juruensis

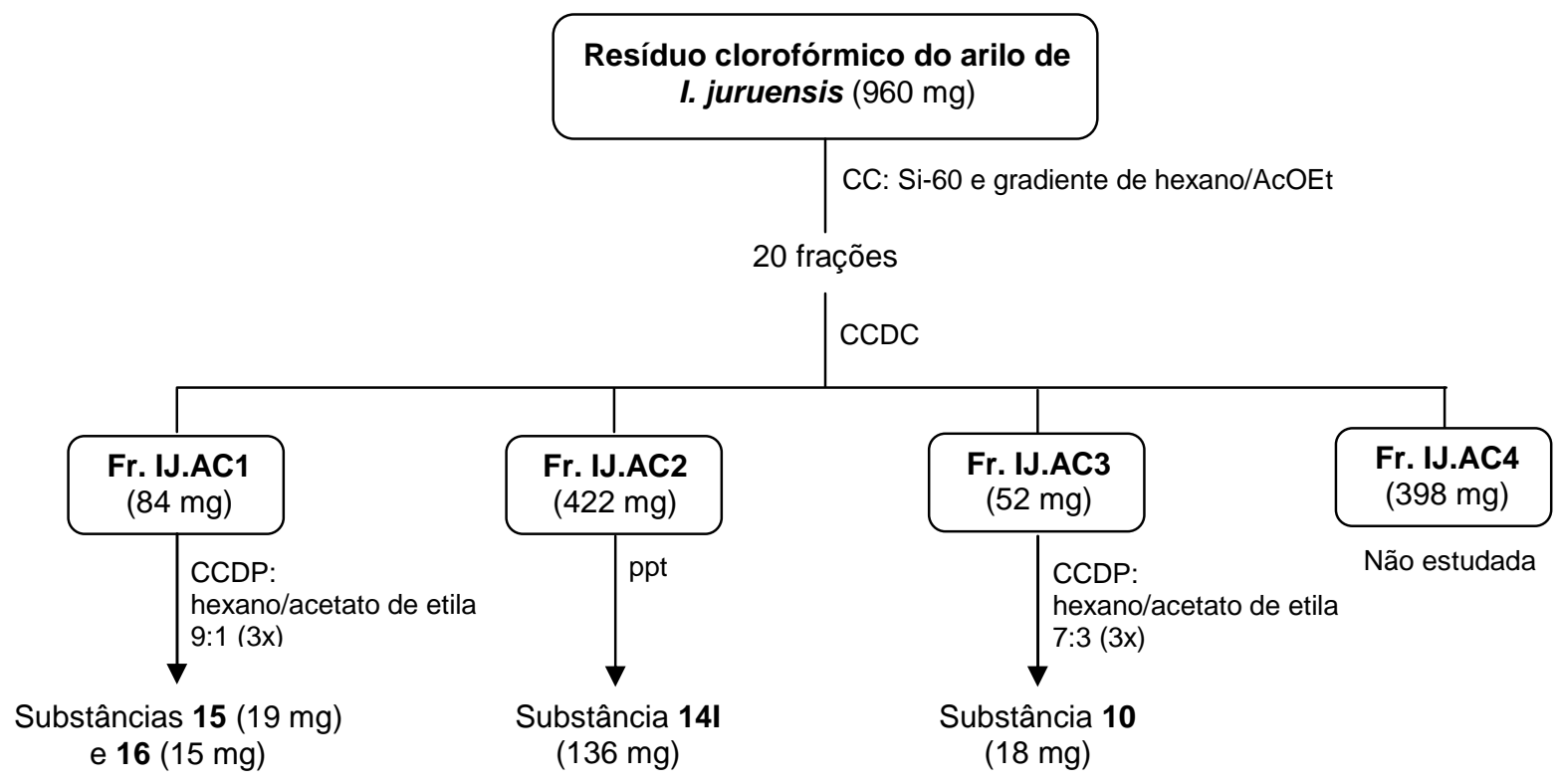

Esquema 7. Isolamento das substâncias 10, 14, 15 e 16.

3.2.9 Fracionamento do resíduo clorofórmico do pericarpo de O. platyspermum

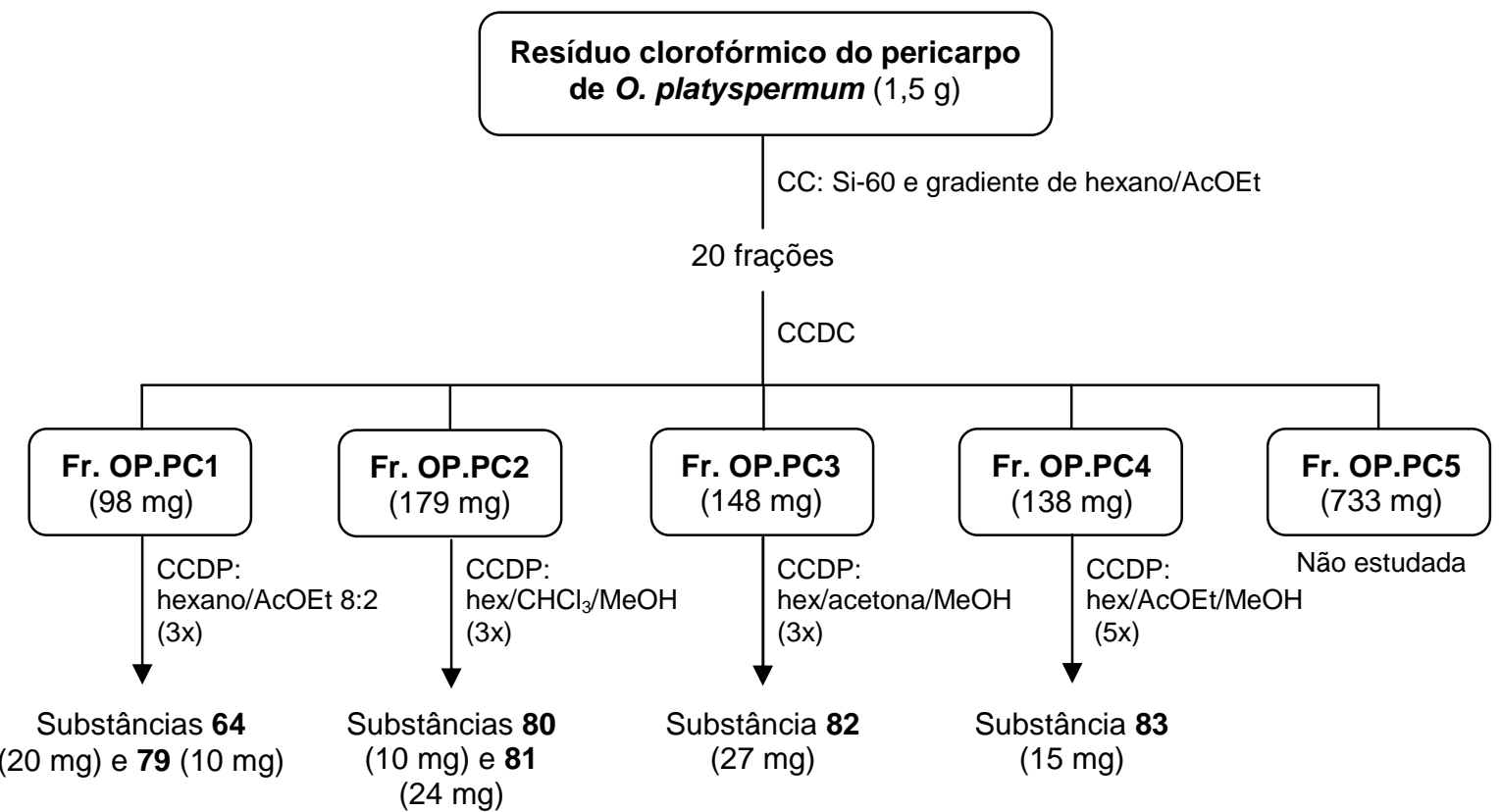

Esquema 8. Isolamento das substâncias 64, 79, 80, 81, 82 e 83. 
3.2.10 Fracionamento do resíduo acetato do tegumento de O. platyspermum

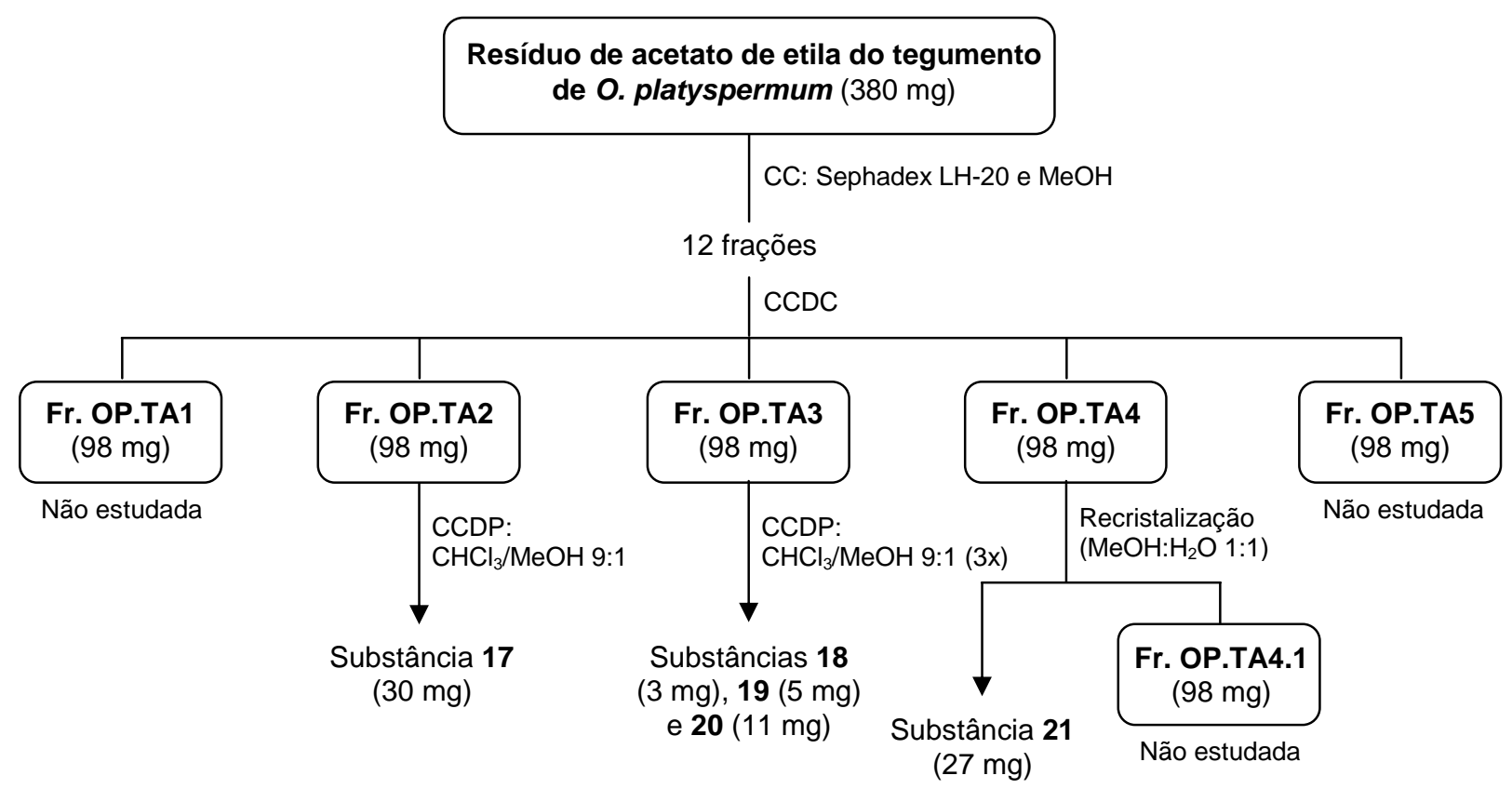

Esquema 9. Isolamento das substâncias 17, 18, 19, 20 e 21.

\subsection{Extração do óleo essencial}

A extração dos óleos essenciais foi feita com os mesmos espécimes citados na seção 3.2.1, sendo uma nova coleta realizada entre os meses de janeiro e fevereiro de 2008

As folhas e os pericarpos das espécies estudadas foram secos a temperatura ambiente e submetidos à destilação por arraste a vapor d'água, em aparelho tipo Clevenger, por um período de 3 horas. Os óleos voláteis obtidos foram secos com $\mathrm{Na}_{2} \mathrm{SO}_{4}$ anidro e uma solução de $1 \%$ de cada óleo dissolvido em hexano foi, separadamente, analisada por CGEM.

A identificação dos componentes foi feita por comparação de seus respectivos índices de Kováts, em relação a uma série homóloga de n-alcanos, e do padrão de 
fragmentação observado nos espectros de massa com dados da literatura e da biblioteca eletrônica Wiley (MCLAFFERTY e STAUFFER, 1989).

\subsection{Avaliação da atividade antimicrobiana}

O ensaio de avaliação da atividade antimicrobiana foi realizado na Faculdade de Ciências Farmacêuticas, da Universidade de São Paulo, pelo biólogo Marcos Lima, sob a coordenação do Dr. Paulo Roberto H. Moreno.

Os óleos voláteis foram avaliados pelo método de microdiluição em caldo, frente aos microrganismos Staphylococcus aureus subsp. aureus (ATCC 25923) (Gram-positiva), Escherichia coli (ATCC 25922), Pseudomonas aeruginosa (ATCC 9027) (Gram-negativas) e Candida albicans (ATCC 10231) (levedura).

As bactérias foram incubadas em meio ATS (Agar Triptose Soja) a $37^{\circ} \mathrm{C}$, enquanto que o fungo foi cultivado em meio ADS (Agar Dextrose de Sabouraud) a $25^{\circ} \mathrm{C}$.

As amostras foram dissolvidas em solução de metanol:DMSO 1:1 (v/v), na proporção de 1:4 de modo que a concentração final do óleo em cada poço fosse de $3,125 \mu \mathrm{L} / \mathrm{mL}$.

Soluções de $1 \mathrm{mg} / \mathrm{mL}$ dos antibióticos cloranfenicol, amicacina e nistatina foram empregadas como controles positivos com os microrganismos $S$. aureus e E. coli, $P$. aeruginosa e C. albicans, respectivamente. O ensaio consistiu na inoculação de $10 \mu \mathrm{L}$ de amostra, ou controle, em $190 \mu \mathrm{L}$ do meio de cultura com concentração ajustada para $2 \times 10^{3}$ UFC/mL em cada poço da microplaca.

As placas foram incubadas em estufa bacteriológica por 24 horas na temperatura de $37^{\circ} \mathrm{C}$ nos ensaios com as bactérias, e por 48 horas na temperatura de $25^{\circ} \mathrm{C}$ no ensaio conduzido com o fungo. Após o período de incubação, as microplacas foram lidas em espectrofotômetro de ELISA (SLT Spectra) no comprimento de onda de $630 \mathrm{~nm}$ (LENCZEWSKI et al., 1996; MATILA, 1987; SALIE et al., 1996; WILLINGER et al., 2000; DEVIENNE et al. 2002). 


\subsection{Avaliação da atividade antimalárica}

O ensaio de avaliação da atividade antimalárica foi realizada no Laboratório de Cultivo de Plasmodium falciparum e Testes de Atividade Antiplasmodial, da Fundação de Medicina Tropical do Amazonas, coordenado pelo Dr. Pedro Paulo R. Vieira.

As substâncias foram dissolvidas em DMSO na concentração estoque de $5 \mathrm{mg} / \mathrm{mL}$ e posteriormente diluídas no meio completo para obtenção das concentrações teste de 50 e $2,5 \mu \mathrm{g} / \mathrm{mL}$, sendo cada concentração testada em triplicata.

\subsubsection{Cultivo in vitro de Plasmodium falciparum}

A cepa multiresistente K1 de P. falciparum (MRA-159, MR4, ATCC Manassas, Virginia) foi mantida em cultivo contínuo segundo a técnica desenvolvida por TRAGER e JENSEN (1976), que se baseia no desenvolvimento laboratorial dos estágios eritrocitários dessa espécie parasitária.

Após o descongelamento da cepa, os parasitas foram cultivados em garrafas de poliestireno hermeticamente fechadas, mantidas a $37^{\circ} \mathrm{C}$, numa atmosfera de baixa tensão de oxigênio, às quais foi adicionada suspensão de eritrócitos suficiente para a obtenção de $500 \mu \mathrm{L}$ de sangue parasitado (suspensão de eritrócitos tipo $A^{+}$a $5 \%(v / v)$ em um hematócrito de 50\%) e 4,5 mL de solução composta pelo meio RPMl 1640 suplementado com $32 \mathrm{mM}$ de $\mathrm{NaHCO}_{3}, 25 \mathrm{mM}$ Hepes $\left(\mathrm{C}_{6} \mathrm{H}_{18} \mathrm{~N}_{2} \mathrm{O}_{4} \mathrm{~S}\right), 12 \mathrm{mM}$ TES (ácido sulfônico- $\mathrm{N}$ tris[hidroximetil]-metil-2-aminoetano), $37 \mathrm{mM}$ hipoxantina, $2 \mathrm{mM}$ glutamina, $10 \mathrm{mM}$ glicose e $10 \%$ de plasma humano tipo $\mathrm{A}^{+}$.

A troca do meio RPMI suplementado com plasma humano inativado, foi feita diariamente. A adição de suspensão de hemácias não parasitadas foi feita em períodos de 48 horas, sempre que se observou o predomínio de esquizontes e/ou parasitemia maior do que $2 \%$. O acompanhamento do crescimento parasitário também foi feito a cada 24 horas, durante o procedimento de troca do meio de cultura e adição da mistura de gases para a obtenção da atmosfera de baixa tensão de oxigênio. 
A contagem de parasitas viáveis foi realizada pela observação de estendidos hematológicos corados pelo método panótico. A parasitemia foi calculada na forma de percentual de formas eritrocíticas viáveis observadas durante a contagem de 1000 hemácias.

\subsubsection{Teste in vitro para avaliação da inibição do crescimento do $P$. falciparum}

Os parasitas foram primeiramente sincronizados para o estágio trofozoíta na forma de anel por tratamento com sorbitol (LAMBROS e VANDERBERG, 1979). Um volume de 20 $\mu \mathrm{L}$ de cada solução estoque $(5 \mathrm{mg} / \mathrm{mL})$ foi transferido para microtubos contendo o meio de cultura completo. Destes microtubos foram retiradas alíquotas de $150 \mu \mathrm{L}$, as quais foram transferidas para cada poço de microplacas contendo 96 poços cada. Em seguida, a estes poços foram acrescentados $100 \mu \mathrm{L}$ de sangue parasitado, obtendo-se um volume final de $250 \mu \mathrm{L}$. Foi utilizada uma parasitemia inicial de 1-2\% e hematócrito de $3 \%$.

As placas foram deixadas em repouso na ausência de luz direta (para evitar possíveis resultados falso-positivos devido a geração de compostos fototóxidos) a $37^{\circ} \mathrm{C}$, em atmosfera a $5 \%$ de $\mathrm{CO}_{2}, 5 \%$ de $\mathrm{O}_{2}$ e $90 \%$ de $\mathrm{N}_{2}$.

A atividade antiplasmódica foi avaliada após 24 horas e a parasitemia em cada poço foi determinada pelo exame do esfregaço sanguíneo corado pelo método do panótico em microscópio óptico, com objetiva de 100x. A parasitemia é expressa em porcentagem de formas eritrocíticas viáveis observadas durante a contagem de 3000 hemácias (ANDRADENETO et al., 2003).

A porcentagem de inibição do crescimento dos parasitas foi determinada pela comparação com os controles de crescimento sem amostra, de acordo com a relação abaixo.

\footnotetext{
$\%$ inibição $=($ parasitemia do controle - parasitemia com amostra $) \times 100$ 


\subsection{Avaliação da atividade leishmanicida}

O ensaio de avaliação da atividade leishmanicida foi realizada no Instituto de Medicina Tropical de São Paulo, pelo grupo do professor Dr. Ângelo Lindoso.

Foram utilizadas formas promastigotas de Leishmania amazonensis (WHO/BR/00/LT0016 - cutânea), L. braziliensis (MHOM/BR/75/M2903 - mucocutânea) e L. chagasi (MHOM/BR/72/cepa 46 - visceral), às quais foram mantidas em meio líquido M199 suplementado com soro fetal bovino e $2 \%$ de urina humana a $26{ }^{\circ} \mathrm{C}$.

$2 \mathrm{mg}$ de cada amostra foram dissolvidas em solução de DMSO (100 $\mu \mathrm{L})$ e meio de cultura $(1900 \mu \mathrm{L})$ e filtradas em membrana esterilizante de $0,22 \mathrm{~mm}$.

Cerca de $1 \times 10^{7}$ células promastigotas foram separadamente incubadas em placas de 24 poços a $26{ }^{\circ} \mathrm{C}$ por $72 \mathrm{~h}$ na presença de concentrações crescentes da amostra testada $(10,50,100$ e $200 \mu \mathrm{g} / \mathrm{mL})$. O volume final de cada poço foi de $1 \mathrm{~mL}$ e o período de incubação consistiu de 3 dias.

No terceiro dia de incubação, período no qual os parasitas se encontram na fase estacionária de crescimento, procedeu-se a contagem do número de células em cada poço com o auxílio de câmara de Neubauer. O controle foi feito usando-se a curva de crescimento do parasita (controle negativo). Os valores de $\mathrm{IC}_{50}$ foram estimados a partir dos gráficos de inibição dose-resposta usando-se o programa Prisma 3.0. 


\section{RESULTADOS E DISCUSSÃO}

\subsection{Caracterização estrutural das substâncias isoladas}

\subsubsection{Lignanas e neolignanas}

Os lignóides constituem uma importante classe de produtos naturais, cujos compostos possuem esqueleto formado pelo grupo fenilpropânico $\left(\mathrm{C}_{6}-\mathrm{C}_{3}\right)$. A grande maioria dos lignóides pertence ao grupo das lignanas e das neolignanas, que são dímeros oxidativos de unidades fenilpropânicas (GOTTLIEB e YOSHIDA, 1984).

Com base na origem biogenética das substâncias, Gottlieb (1978) definiu o termo lignana como dímeros de ácidos cinâmicos e/ou álcoois cinamílicos, enquanto que o termo neolignana incluiria os dímeros de propenilfenóis e de alilfenóis. Dessa forma, as lignanas apresentariam o carbono 9 da cadeia lateral oxigenado, enquanto que as neolignanas estariam isentas de oxigênio nesse carbono.

Fundamentada somente nas características estruturais dos compostos e desconsiderando a definição introduzida por Gottlieb no que se refere à oxigenação do carbono 9 da cadeia lateral, atualmente a IUPAC recomenda o uso do termo lignana para os dímeros de unidades $\mathrm{C}_{6}-\mathrm{C}_{3}$ ligadas pelos carbonos 8,8' de suas respectivas cadeias laterais, enquanto que o termo neolignana é reservado para designar os dímeros unidos por outras posições diferentes das 8,8'. Aceitando-se ainda algumas variações dessas terminações, como o termo oxineolignana, usado para os dímeros nos quais um átomo de oxigênio proporciona a união entre as duas unidades $\mathrm{C}_{6}-\mathrm{C}_{3}$ (MOSS, 2000).

A Figura 4 apresenta os esqueletos dos lignóides mais comumente encontrados nas miristicáceas neotropicais, juntamente com suas respectivas denominações usual e sistemática. Em geral, um dos anéis aromáticos, ou ambos, é oxisubstituído nas posições 3 e 4 e representados pelas unidades guaiacila (4-hidroxi-3-metoxi-fenil), veratrila $(3,4-$ dimetoxi-fenil), catequila (3,4-di-hidroxi-fenil) e piperonila (3,4-metilenodioxi-fenil), podendo 
ocorrer ainda as trissubstituições nas posições 3,4 e 5 , o que origina as unidades tri-Ometilpirogalila (3,4,5-trimetoxi-fenil) e 3-hidroxi(ou metoxi)-4,5-metilenodioxi-fenil.

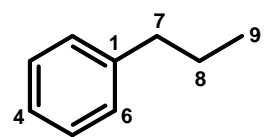

Grupo fenilpropânico<smiles>CCCc1ccc2c(c1)C(C)C(c1ccccc1)O2</smiles>

Benzofurano 4',7-epóxi-8,3'-neolignana

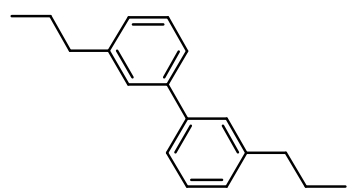

Bifenílica 3,3'-neolignana

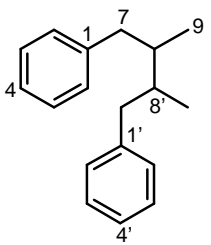

Diarilbutano (usual) 8,8'-lignana (IUPAC, 2000)<smiles>CCCc1ccc2c(c1)OC(c1ccccc1)C(C)O2</smiles>

Benzodioxano 3',7-epóxi-8,4'-oxineolignana<smiles>CC1C(c2ccccc2)OC(c2ccccc2)C1C</smiles>

Tetraidrofurano 7,7'-epóxilignana<smiles>CC1Cc2ccccc2C(c2ccccc2)C1C</smiles>

Ariltetralina

2,7'-ciclolignana<smiles>CCCc1ccc(OC(C)Cc2ccccc2)cc1</smiles>

Ariloxiarilpropano 8,4'-oxineolignana<smiles>c1ccc(C2OCC3C(c4ccccc4)OCC23)cc1</smiles>

Furofurano 7,9':7',9-diepóxilignana

Figura 4. Esqueleto básico de lignóides comumente encontrados em miristicáceas neotropicais.

\subsubsection{Substâncias 1 e 2}

Os espectros de RMN de ${ }^{1} \mathrm{H}$ das substâncias 1 e 2 (Espectros 1 e 2, p. 108 e 109) apresentam absorções características de neolignanas benzofurânicas. Em ambos os espectros são observados sinais de hidrogênios vinílicos terminais $(\delta 5,19-5,09)$ e vinílico metínico $(\delta 6,06)$, que juntamente com o dubleto em $3,49 \mathrm{ppm}(J=6,6 \mathrm{~Hz}, 2 \mathrm{H})$, caracterizam um grupo alila. Observa-se ainda um singleto em $\delta 2,43(3 \mathrm{H})$, atribuído ao grupo metila ligado a carbono insaturado do anel furânico (C-8).

A substância 1 apresenta sinais correspondentes a três grupos metoxilas $(\delta 4,03$, 3,99 e 3,94), enquanto que 2 apresenta sinais para duas metoxilas (4,03 e 3,99 ppm) e um 
singleto em $\delta 5,31$, típico de hidroxila fenólica, evidenciando a única diferença entre estas substâncias.

Os espectros de RMN de ${ }^{13} \mathrm{C}$ de ambas as substâncias (Espectros 3 e 4, p. 110 e 111) também apresentam algumas semelhanças e confirmam a presença do grupo alila ( $\delta$ 40,$6 ; 138,0$ e 115,6), do anel benzofurânico $(\delta 151,3 \pm 0,1 ; 110,15 \pm 0,15 ; 135,1 ; 109,75 \pm 0,25$; $144,7 ; 141,5 ; 124,05 \pm 0,25$ e 111,0$)$, da metila em C-8 $(9,6$ ppm), bem como dos grupos metoxilas $(\delta 56 \pm 0,1)$. A substituição do grupo metoxila pela hidroxila em C-4 na substância 2, causa proteção dos carbonos 3 e 4 e desproteção de C-5 e C-6. A atribuição dos carbonos da substância 2 foi feita com base no padrão descrito na literatura para a unidade guaiacila e através de seu espectro HETERO-COSY (Espectro 5, p. 112), uma vez que a literatura carece desses dados para uma comparação direta.

Os espectros de massas de 1 e 2 (Espectros 6A e 6B, p. 113) apresentaram, respectivamente, os picos $\mathrm{m} / \mathrm{z} 338$ e $\mathrm{m} / \mathrm{z} 324$ como íon molecular e pico base. A diferença de 14 u.m.a. $\left(\mathrm{CH}_{2}\right)$ entre essas substâncias também confirma a única diferença entre ambas, conforme verificado em seus respectivos espectros de ressonância. Todos os dados observados estão de acordo com os descritos na literatura para as neolignanas carinatina e carinatidina (Figura 5), ambas isoladas originalmente de V. carinata.

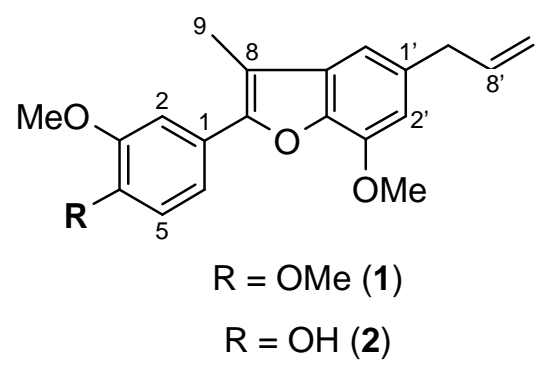

Figura 5. Estrutura molecular das neolignanas carinatina (1) e carinatidina (2). 
Tabela 7 - Dados de RMN de ${ }^{1} \mathrm{H}$ e ${ }^{13} \mathrm{C}$ de 1 e $2\left(\mathrm{CDCl}_{3}, 4,7 \mathrm{~T}\right)$ e dados de RMN de ${ }^{13} \mathrm{C}$ da carinatina.

\begin{tabular}{|c|c|c|c|c|c|}
\hline \multirow{2}{*}{ Posição } & \multicolumn{2}{|c|}{$\begin{array}{c}\mathrm{T} H \\
\delta(\mathrm{ppm}), \text { multiplicidade, } J(\mathrm{~Hz})\end{array}$} & \multicolumn{3}{|c|}{$\begin{array}{l}{ }^{13} \mathbf{C} \\
\delta(\mathrm{ppm})\end{array}$} \\
\hline & 1 & 2 & 1 & $\begin{array}{c}\text { Carinatina } \\
\text { (Marques, 1992) }\end{array}$ & 2 \\
\hline 1 & - & - & 133,0 & 133,1 & 133,0 \\
\hline 2 & $7,36-7,33(m)$ & $7,33-7,25(\mathrm{~m})$ & 107,5 & 108,1 & 107,5 \\
\hline 3 & - & - & 148,9 & 149,2 & 146,6 \\
\hline 4 & - & - & 148,9 & 149,2 & 145,7 \\
\hline 5 & $6,96(d, 9,0)$ & $6,99(d, 7,9)$ & 110,9 & 110,9 & 114,4 \\
\hline 6 & $7,33-7,37(m)$ & $7,33-7,25(m)$ & 119,9 & 120,0 & 120,6 \\
\hline 7 & - & - & 151,2 & 151,3 & 151,4 \\
\hline 8 & - & - & 110,3 & 110,6 & 110,0 \\
\hline 9 & $2,43(s)$ & $2,41(s)$ & 9,6 & 9,3 & 9,6 \\
\hline 1 & - & - & 135,1 & 135,2 & 135,1 \\
\hline $2^{\prime}$ & $6,65(s l)$ & $6,64(s l)$ & 110,0 & 110,1 & 109,5 \\
\hline 3 & - & - & 144,7 & 144,7 & 144,7 \\
\hline $4^{\prime}$ & - & - & 141,5 & 141,6 & 141,4 \\
\hline $5^{\prime}$ & - & - & 124,3 & 124,5 & 123,8 \\
\hline 6 & $6,94(d, 1,2)$ & $6,93(s)$ & 111,1 & 111,6 & 111,0 \\
\hline $7^{\prime}$ & $3,49(d, 7,0)$ & $3,48(d, 6,6)$ & 40,6 & 40,6 & 40,6 \\
\hline 8' & $\begin{array}{c}6,06 \\
(d d t, 6,6 ; 10,1 \text { e } 16,7)\end{array}$ & $\begin{array}{c}6,02 \\
(d d t, 6,6 ; 10,1 \text { e } 16,7)\end{array}$ & 138,0 & 137,9 & 138,0 \\
\hline $9^{\prime}$ & $5,19-5,09(m)$ & $5,18-5,07(m)$ & 115,6 & 115,3 & 115,6 \\
\hline MeO-3 & $3,99(s)$ & $3,98(s)$ & 56,1 & 56,2 & 56,1 \\
\hline $\mathrm{MeO}-4$ & $3,94(s)$ & - & 56,0 & 56,0 & - \\
\hline $\mathrm{OH}-4$ & - & $5,77(s)$ & - & - & - \\
\hline MeO-3' & $4,03(s)$ & $4,02(s)$ & 55,9 & 55,9 & 56,1 \\
\hline
\end{tabular}

\subsubsection{Substâncias 3 e 4}

As substâncias 3 e 4 também apresentam espectros de $\mathrm{RMN}$ de ${ }^{1} \mathrm{H}$ e ${ }^{13} \mathrm{C}$ semelhantes entre si, sendo a única diferença entre elas os substituintes de um dos anéis aromáticos.

Algumas absorções características de neolignanas di-hidrobenzofurânicas são observadas em ambos os espectros tais como um dubleto em $\delta 5,09(\mathrm{~J}=9,6 \mathrm{~Hz})$, referente ao hidrogênio oximetínico, um multipleto centralizado em 3,46 ppm, atribuído ao H-8 e um dubleto em $\delta 1,38(J=6,9 \mathrm{~Hz})$, referente ao grupo metila na posição 9. Observa-se ainda o conjunto de sinais típicos do grupamento alila e singletos referentes a metoxilas. O espectro de $\mathrm{RMN}$ de ${ }^{1} \mathrm{H}$ de 3 mostra sinais referentes a três metoxilas distintas $(3,90,3,89$ e 3,88 
ppm), enquanto que o espectro de 4 apresenta apenas duas metoxilas (3,90 e 3,88 ppm), juntamente com um sinal de hidroxila fenólica em $\delta$ 5,64 (Espectros 7 e 8, p. 114 e 115).

$\mathrm{O}$ espectro de RMN de ${ }^{13} \mathrm{C}$ de ambas as substâncias (Espectro 9 e 10, p. 116 e 117) confirmam a presença do grupamento alila, do carbono oxibenzílico (93,6 ppm, C-7), bem como do carbono metínico C-8 e da metila ligada a um carbono terciário saturado $(\delta 17,4$, C9). A existência do grupo hidroxila em C-4 de um dos anéis aromáticos da substância 4 é ainda verificada pela proteção dos sinais referentes a C-3 e C-4, acompanhada pela desproteção de C-5 e C-6.

Os espectros de RMN e de EM (Espectros 11A e 11B, p. 118) obtidos para 3 (340 $\left.[\mathrm{M}]^{\bullet+}\right)$ e $4\left(326[\mathrm{M}]^{*+}\right)$ são consistentes com os registrados na literatura para as neolignanas di-hidrocarinatina e di-hidrocarinatidina, ambas também isoladas originalmente de $V$. carinata. A determinação da configuração relativa foi baseada na análise da constante de acoplamento de $\mathrm{H}-7(\mathrm{~J}=9,8 \mathrm{~Hz})$, que indica uma relação trans entre a metila ligada a C-8 e o anel aromático em C-7.

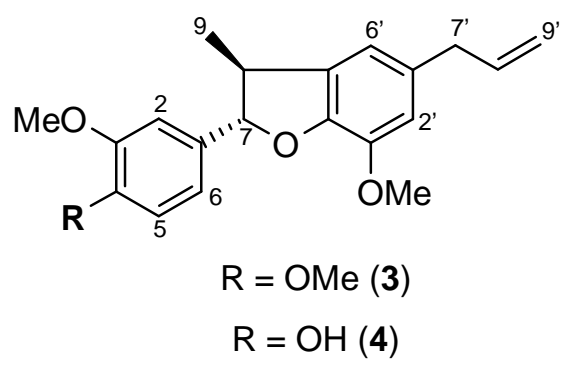

Figura 6. Estruturas moleculares da di-hidrocarinatina (3) e da di-hidrocarinatidina (4). 
Tabela 8 - Dados de RMN de ${ }^{1} \mathrm{H}$ e ${ }^{13} \mathrm{C}$ de 3 e $4\left(\mathrm{CDCl}_{3}, 4,7 \mathrm{~T}\right)$ e dados de $\mathrm{RMN}$ de ${ }^{13} \mathrm{C}$ da dihidrocarinatina e da di-hidrocarinatidina.

\begin{tabular}{|c|c|c|c|c|c|c|}
\hline \multirow[b]{2}{*}{ Posição } & \multicolumn{2}{|c|}{$\begin{array}{c}\text { 'H } \\
\delta(\mathrm{ppm}), \text { multiplicidade, } J(\mathrm{~Hz})\end{array}$} & \multicolumn{4}{|c|}{$\begin{array}{l}{ }^{13} \mathbf{C} \\
\delta(\mathrm{ppm})\end{array}$} \\
\hline & 3 & 4 & 3 & $\begin{array}{c}\text { Di- } \\
\text { hidrocarinatina } \\
\text { (Marques, 1992) }\end{array}$ & 4 & $\begin{array}{c}\text { Di- } \\
\text { hidrocarinatidina } \\
\text { (Marques, 1992) }\end{array}$ \\
\hline 1 & - & - & 137,9 & 137,7 & 132,2 & 132,2 \\
\hline 2 & $7,00-6,95(m)$ & $6,99-6,91(m)$ & 109,5 & 109,4 & 108,9 & 108,9 \\
\hline 3 & - & - & 149,1 & 149,1 & 146,7 & 146,6 \\
\hline 4 & - & - & 149,1 & 149,0 & 145,7 & 145,7 \\
\hline 5 & $6,85(d, 7,9)$ & $6,99-6,91(m)$ & 110,7 & 110,7 & 114,0 & 114,0 \\
\hline 6 & $7,00-6,95(m)$ & $6,99-6,91(m)$ & 119,3 & 119,2 & 119,9 & 119,9 \\
\hline 7 & $5,11(d, 9,7)$ & $5,09(d, 9,8)$ & 93,6 & 93,5 & 93,7 & 93,7 \\
\hline 8 & $3,51-3,43(m)$ & $3,50-3,45(m)$ & 45,7 & 45,6 & 45,8 & 45,7 \\
\hline 9 & $1,38(d, 6,6)$ & $1,38(d, 6,8)$ & 17,5 & 17,4 & 17,4 & 17,4 \\
\hline $1^{\prime}$ & - & - & 133,1 & 133,1 & 133,5 & 133,5 \\
\hline $2^{\prime}$ & $6,62(s)$ & $6,62(s)$ & 111,8 & 111,8 & 111,8 & 111,8 \\
\hline 3 & - & - & 145,1 & 145,0 & 144,0 & 144,0 \\
\hline $4^{\prime}$ & - & - & 144,1 & 144,0 & 108,9 & 109,1 \\
\hline 5 & - & - & 133,5 & 133,5 & 133,2 & 133,5 \\
\hline 6 & $6,64(s)$ & $6,64(s)$ & 115,6 & 115,6 & 115,6 & 115,6 \\
\hline $7^{\prime}$ & $3,37(d, 6,6)$ & $3,37(d, 6,8)$ & 40,2 & 40,1 & 40,2 & 40,2 \\
\hline $8^{\prime}$ & $\begin{array}{c}5,99 \\
(d d t, 6,6 ; 10,1 \text { e } 17,1)\end{array}$ & $\begin{array}{c}5,98 \\
(d d t, 6,6 ; 10,1 \text { e } 17,1)\end{array}$ & 137,9 & 137,8 & 137,9 & 137,9 \\
\hline $9^{\prime}$ & $5,16-5,06(m)$ & $5,17-5,06(m)$ & 115,6 & 115,5 & & 115,6 \\
\hline $\mathrm{MeO}-3$ & $3,89(s)$ & $3,89(s)$ & 55,9 & 55,9 & 55,9 & 56,0 \\
\hline $\mathrm{MeO}-4$ & $3,89(s)$ & - & 55,9 & 55,9 & - & - \\
\hline $\mathrm{HO}-4$ & - & 5,31 & - & - & - & - \\
\hline MeO-3' & $3,89(s)$ & $3,89(s)$ & 55,9 & 55,9 & 55,9 & 56,0 \\
\hline
\end{tabular}

\subsubsection{Substância 5}

$\mathrm{O}$ espectro de RMN de ${ }^{1} \mathrm{H}$ da substância 5 (Espectro 12, p. 119) apresenta dois dubletos em $\delta 6,76$ e $\delta 6,74$, ambos com $J=2,2 \mathrm{~Hz}$, o que sugere a presença de um anel aromático 1,3,4,5-tetrassubstituído. Observa-se ainda o conjunto de sinais característico do grupamento alila (5,99; 5,09 e 3,37 ppm) e um singleto em $\delta 3,92$.

Em seu espectro de RMN de ${ }^{13} \mathrm{C}$ (Espectro 13, p. 120) é possível observar a presença de 10 carbonos distintos, que confirmam a presença do grupo alila (39,9, 137,6 e 115,7 ppm), do grupo metoxila (56 ppm) e do anel aromático. 
A comparação dos dados de RMN e de EM (326 [M] ${ }^{*+}$ ) da substância 5 (Espectro 14, p. 121) com os descritos na literatura para a neolignana denominada desidro-dieugenol, permite concluir que se tratam do mesmo composto.

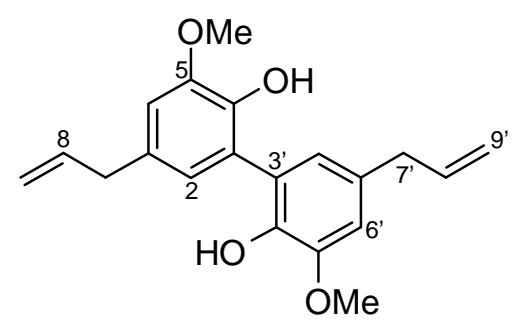

Figura 7. Estrutura molecular do desidro-dieugenol.

Tabela 9 - Dados de RMN de ${ }^{1} \mathrm{H}$ e ${ }^{13} \mathrm{C}$ da substância $5\left(\mathrm{CDCl}_{3}, 4,7 \mathrm{~T}\right)$ e dados de $\mathrm{RMN}$ de ${ }^{13} \mathrm{C}$ do desidro-dieugenol.

\begin{tabular}{|c|c|c|c|}
\hline \multirow{2}{*}{ Posição } & \multirow{2}{*}{$\begin{array}{c}{ }^{1} \mathbf{H} \\
\delta(\mathrm{ppm}), \text { multiplicidade, } \boldsymbol{J}(\mathrm{Hz}) \\
5 \\
\end{array}$} & \multicolumn{2}{|c|}{$\begin{array}{c}{ }^{13} \mathbf{C} \\
\delta(\text { ppm) }\end{array}$} \\
\hline & & 5 & $\begin{array}{c}\text { Desidro-dieugenol } \\
\text { (SUAREZ et al., 1983) }\end{array}$ \\
\hline $1 / 1^{\prime}$ & - & 131,9 & 131,9 \\
\hline $2 / 2$ & $6,74(d, 2,2)$ & 123,1 & 123,3 \\
\hline $3 / 3$ & - & 124,4 & 124,5 \\
\hline $4 / 4$ & - & 140,8 & 141,1 \\
\hline $5 / 5^{\prime}$ & - & 147,2 & 147,3 \\
\hline $6 / 6$ & $6,76(d, 2,2)$ & 110,6 & 110,8 \\
\hline $7 / 7$ & $3,37(d, 6,6)$ & 39,9 & 40,0 \\
\hline $8 / 8$ & $5,97(d d t, 6,9 ; 10,2$ e 17,1$)$ & 137,6 & 137,7 \\
\hline $9 / 9^{\prime}$ & $5,17-5,05(m)$ & 115,7 & 115,7 \\
\hline $\mathrm{MeO}-5 / 5^{\prime}$ & $3,92(s)$ & 56,0 & 56,1 \\
\hline
\end{tabular}

\subsubsection{Substâncias 6, 7, 8, 9 e 10}

Os espectros de RMN de ${ }^{1} \mathrm{H}$ e ${ }^{13} \mathrm{C}$ das substâncias 6, 7, 8, 9 e 10 apresentam absorções típicas de lignanas tetra-hidrofurânicas com as estereoquímicas relativas aos carbonos 7, 8, 8' e 7' mostradas na figura abaixo. 


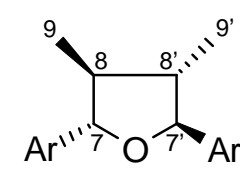

trans, trans, trans

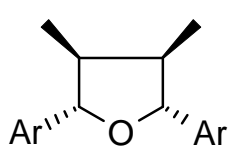

trans, cis, trans

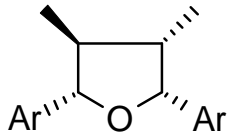

trans, trans, cis

Figura 8. Estereoquímica relativa das lignanas tetra-hidrofurânicas isoladas.

As estereoquímicas trans, cis, trans e trans, trans, trans conferem elementos de simetria às moléculas, impedindo a distinção dos hidrogênios oxibenzílicos (7/7'), metínicos $\left(8 / 8^{\prime}\right)$ e metílicos $\left(9 / 9^{\prime}\right)$, enquanto que na estereoquímica trans, trans, cis os sinais referentes aos prótons 7/7', 8/8' e 9/9' são diferentes entre si, uma vez que os grupos arílicos em cis possuem rotação restrita acarretando a proteção anisotrópica de H-9' e a desproteção de H7’ (HATTORI et al., 1987; LOPES, 1997).

No espectro de RMN de ${ }^{1} \mathrm{H}$ das substâncias 6, 7 e 8 (Espectros 15-17, p. 122-124) são observados sinais em $\delta 1,04 \pm 0,01$ (d, H-9/9'), $\delta 2,34\left(m, \mathrm{H}-8 / 8^{\prime}\right)$ e em $\delta 4,51 \pm 0,02(d, \mathrm{H}-$ 7/7'), absorções estas condizentes com a estereoquímica trans, cis, trans. A substância 9 (Espectro 18, p. 125) apresenta sinal referente a $\mathrm{H}-7 / 7^{\prime}$ mais desprotegido e $\mathrm{H}-8 / 8^{\prime}$ mais protegido, em relação aos compostos anteriores (6, 7 e 8), o que sugere a ocorrência da configuração trans, trans, trans. A observação de dois dubletos em $\delta$ 0,67 (H-9') e $\delta 1,06(\mathrm{H}-$ 9), dois multipletos centrados em 2,26 ppm ( $\mathrm{H}-8)$ e 1,76 ppm ( $\mathrm{H}-8$ ') e os dois dubletos em $\delta$ $5,11(\mathrm{H}-7)$ e $\delta 4,40\left(\mathrm{H}-7^{\prime}\right)$ no espectro de RMN de ${ }^{1} \mathrm{H}$ da substância 10 (Espectro 19, p. 126) evidencia a estereoquímica trans, trans, cis.

Os sinais de $\mathrm{RMN}$ de ${ }^{13} \mathrm{C}$ de $\mathrm{C}-7 / 7$ ', C-8/8' e C-9/9' também proporcionam informações diagnósticas sobre a configuração relativa de lignanas tetra-hidrofurânicas. Os sinais de C-8 e C-8' aparecem em cerca de 44, 51 e 46-48 ppm, enquanto que C-9 e C-9' ressonam em 13, 14 e 15 ppm para as formas trans, cis, trans; trans, trans, trans e trans, trans, cis, respectivamente. Nas duas primeiras formas, os carbonos C-7/7', C-8/8' e C-9/9' absorvem na mesma região, enquanto que na última, esses carbonos passam a ressonar em regiões distintas (HATTORI et al., 1987) (Espectros 20-24, p. 127-131). 
A comparação dos dados de RMN e EM (Espectros 25A-25E, p. 132) das substâncias $\mathbf{6}$, 7, 8, 9 e 10 com os descritos na literatura permitiu identificá-las como sendo as lignanas galgravina, nectandrina A, nectandrina B, galbelgina e verrucosina, respectivamente. Embora tais lignanas sejam muito comuns em miristicáceas amazônicas, este é primeiro relato sobre a sua ocorrência em $V$. pavonis.

Tabela 10 - Dados de RMN de ${ }^{1} \mathrm{H}$ das substâncias 6, 7, 8, 9 e $10\left(\mathrm{CDCl}_{3}, 4,7 \mathrm{~T}\right)$.

\begin{tabular}{|c|c|c|c|c|c|}
\hline \multirow{2}{*}{$\mathbf{H}$} & \multicolumn{5}{|c|}{$\delta$ (ppm), multiplicidade, $J(\mathrm{~Hz})$} \\
\hline & 6 & 7 & 8 & 9 & 10 \\
\hline $7 / 7$ & $4,53(d, 6,3)$ & $4,67(d, 9,2)$ & $\begin{array}{l}4,52(d, 6,3) \\
4,51(d, 6,3)\end{array}$ & $4,49(d, 6,1)$ & $\begin{array}{l}5,11(d, 8,3) \\
4,40(d, 9,2)\end{array}$ \\
\hline $8 / 8^{\prime}$ & $2,34(m)$ & $1,79(m)$ & $2,34(m)$ & 2,33 (m) & $\begin{array}{l}2,26(m) \\
1,76(m)\end{array}$ \\
\hline $9 / 9$ & $1,05(d, 6,6)$ & $1,05(d, 6,2)$ & $\begin{array}{l}1,05(d, 6,6) \\
1,04(d, 6,6)\end{array}$ & $1,03(d, 6,6)$ & $\begin{array}{l}1,06(d, 6,6) \\
0,66(d, 7,0)\end{array}$ \\
\hline Ar-H & $6,99-6,85(m)$ & $7,0-6,83(m)$ & $6,99-6,85(m)$ & $7,04-6,85(m)$ & $7,05-6,80(m)$ \\
\hline $\mathrm{MeO}-3$ & $3,89(s)$ & $3,92(s)$ & $3,89(s)$ & $3,88(s)$ & $3,91(s)$ \\
\hline $\mathrm{MeO}-4$ & $3,88(s)$ & $3,86(s)$ & $3,88(s)$ & - & - \\
\hline MeO-3' & $3,89(s)$ & $3,92(s)$ & $3,89(s)$ & $3,88(s)$ & $3,85(s)$ \\
\hline MeO-4' & $3,88(s)$ & $3,86(s)$ & - & - & - \\
\hline $\mathrm{OH}-4$ & - & - & - & $5,59(s)$ & $5,63(s)$ \\
\hline $\mathrm{OH}-4$ & - & - & $5,59(s)$ & $5,59(s)$ & $5,63(s)$ \\
\hline
\end{tabular}<smiles>[R]c1ccc([C]2O[C@@H](c3ccc([R])c(OC)c3)[C@H](C)[C@H]2C)cc1OC</smiles>

$\mathrm{R}=\mathrm{MeO}, \mathrm{R}^{\prime}=\mathrm{MeO}(\mathbf{6})$

$\mathrm{R}=\mathrm{MeO}, \mathrm{R}^{\prime}=\mathrm{OH}(\mathbf{7})$

$\mathrm{R}=\mathrm{OH}, \mathrm{R}^{\prime}=\mathrm{OH}(\mathbf{8})$<smiles>COc1ccc([C@H]2O[C@@H](c3ccc(OC)c(OC)c3)[C@H](C)[C@H]2C)cc1OC</smiles><smiles>COc1cc([C@H]2O[C@@H](c3ccc(O)c(OC)c3)[C@H](C)[C@@H]2C)ccc1O</smiles>

Figura 9. Estruturas moleculares das neolignanas tetra-hidrofurânicas isoladas. 
Tabela 11 - Dados de RMN de ${ }^{13} \mathrm{C}$ das substâncias 6, 7, 8, 9 e 10 e das neolignanas galgravina, galbelgina, nectandrina A, nectandrina B e verrucosina $\left(\mathrm{CDCl}_{3}, 4,7 \mathrm{~T}\right)$.

\begin{tabular}{|c|c|c|c|c|c|c|c|c|c|c|}
\hline \multirow[b]{2}{*}{ C } & \multicolumn{10}{|c|}{$\delta$ (ppm) } \\
\hline & 6 & $\begin{array}{l}\text { Galgravina } \\
\text { (FONSECA } \\
\text { et al., 1979) }\end{array}$ & 7 & $\begin{array}{c}\text { Nectandrina A } \\
\text { (SHIMOMURA } \\
\text { et al., 1988) }\end{array}$ & 8 & $\begin{array}{c}\text { Nectandrina B } \\
\text { (HATTORI et } \\
\text { al., 1987) }\end{array}$ & 9 & $\begin{array}{c}\text { Galbelgina } \\
\text { (PAULO, 1983) }\end{array}$ & 10 & $\begin{array}{c}\text { Verrucosina } \\
\text { (HATTORI et } \\
\text { al., 1987) } \\
\end{array}$ \\
\hline 1 & 134,7 & 134,6 & 134,8 & 134,8 & 134,2 & 134,1 & 134,9 & 134,1 & 133,2 & 132,8 \\
\hline 2 & 109,6 & 109,6 & 109,7 & 109,8 & 109,1 & 109,2 & 109,1 & 108,4 & 109,4 & 109,5 \\
\hline 3 & 148,9 & 148,7 & 148,9 & 148,9 & 146,4 & 146,4 & 149,0 & 148,1 & 146,5 & 146,5 \\
\hline 4 & 148,4 & 148,2 & 148,4 & 148,3 & 145,0 & 145,0 & 148,5 & 147,6 & 145,2 & 145,2 \\
\hline 5 & 110,9 & 110,8 & 110,9 & 111,1 & 114,1 & 114,1 & 110,8 & 110,1 & 114,2 & 114,1 \\
\hline 6 & 118,5 & 118,4 & 118,5 & 118,5 & 119,3 & 119,2 & 118,6 & 117,7 & 119,3 & 119,3 \\
\hline 7 & 87,2 & 87,1 & 87,2 & $87,2^{a}$ & 87,3 & 87,2 & 88,3 & 87,3 & 87,3 & 87,3 \\
\hline 8 & 44,3 & 44,3 & 44,2 & $44,2^{b}$ & 44,3 & 44,2 & 50,9 & 50,1 & 47,7 & 47,8 \\
\hline 9 & 12,9 & 12,9 & 12,8 & 12,8 & 12,9 & 12,8 & 13,8 & 13,1 & 14,9 & 14,9 \\
\hline $1^{\prime}$ & 134,7 & 134,6 & 134,1 & 134,1 & 134,2 & 134,1 & 134,9 & 134,1 & 132,7 & 132,2 \\
\hline 2' & 109,6 & 109,6 & 109,1 & 109,1 & 109,1 & 109,2 & 109,1 & 108,4 & 109,7 & 109,8 \\
\hline $3^{\prime}$ & 148,9 & 148,7 & 146,4 & 146,5 & 146,4 & 146,4 & 149,0 & 148,1 & 146,2 & 146,2 \\
\hline $4^{\prime}$ & 148,4 & 148,2 & 145,0 & 145,0 & 145,0 & 145,0 & 148,5 & 147,6 & 144,7 & 144,6 \\
\hline $5^{\prime}$ & 110,9 & 110,8 & 114,1 & 114,1 & 114,1 & 114,1 & 110,8 & 110,1 & 113,8 & 113,8 \\
\hline $6^{\prime}$ & 118,5 & 118,4 & 119,2 & 119,2 & 119,3 & 119,2 & 118,6 & 117,7 & 119,9 & 119,9 \\
\hline $7^{\prime}$ & 87,2 & 87,1 & 87,3 & $87,3^{a}$ & 87,3 & 87,2 & 88,3 & 87,3 & 83,1 & 83,1 \\
\hline $8^{\prime}$ & 44,3 & 44,3 & 44,3 & $44,3^{b}$ & 44,3 & 44,2 & 50,9 & 50,1 & 45,9 & 46,0 \\
\hline $9^{\prime}$ & 12,9 & 12,9 & 12,9 & 12,9 & 12,9 & 12,8 & 13,8 & 13,1 & 14,9 & 15,0 \\
\hline MeO-3 & 55,8 & 55,8 & 55,8 & 55,7 & 55,8 & 55,8 & 55,8 & 55,8 & 55,8 & 55,8 \\
\hline $\mathrm{MeO}-4$ & 55,8 & 55,8 & 55,9 & 55,9 & - & - & - & - & - & - \\
\hline MeO-3' & 55,8 & 55,8 & 55,8 & 55,7 & 55,8 & 55,8 & 55,8 & 55,8 & 55,8 & 55,8 \\
\hline MeO-4' & 55,8 & 55,8 & - & - & - & - & - & - & - & - \\
\hline
\end{tabular}

a,b Atribuições permutáveis. 


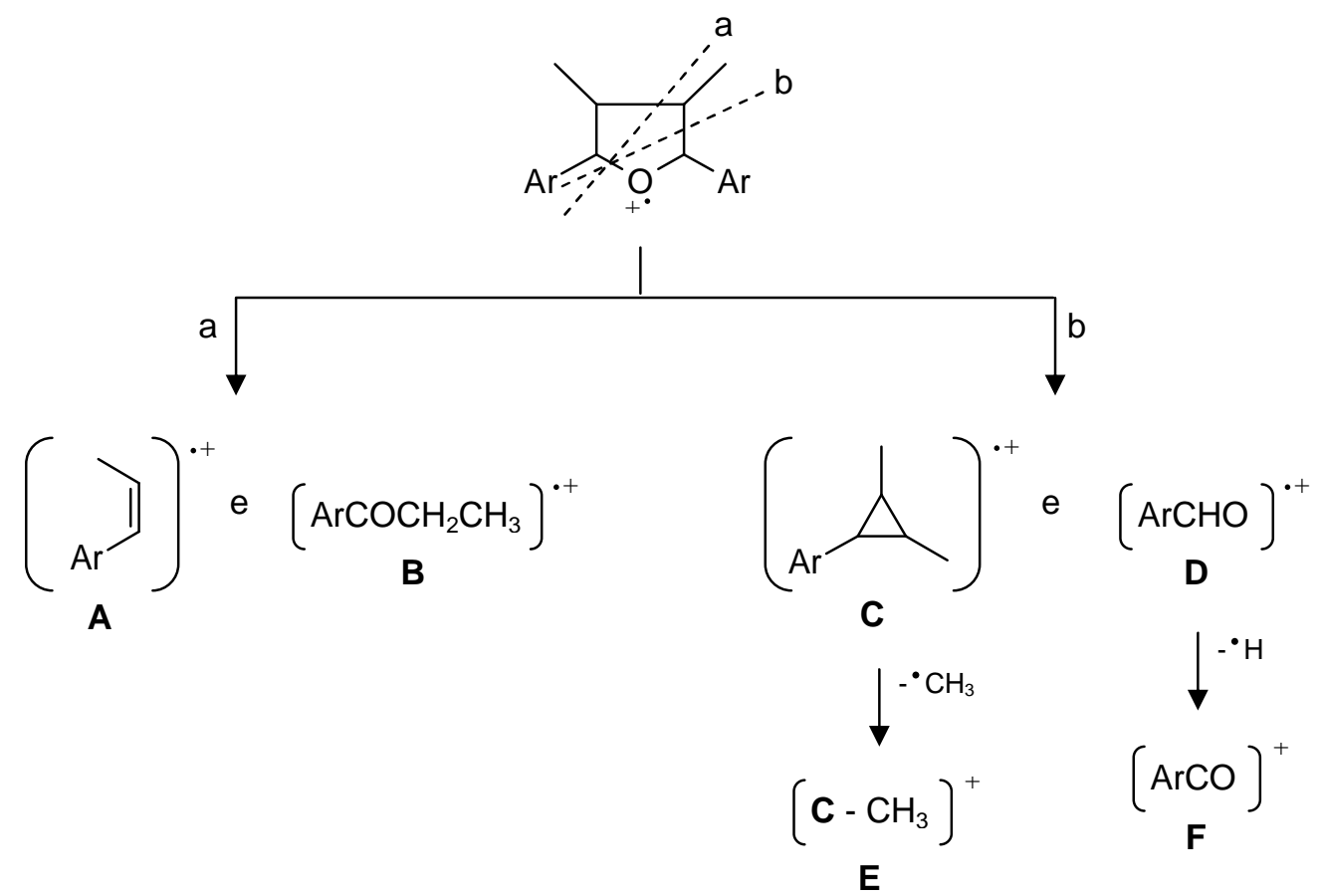

Figura 10. Padrão de fragmentação das lignanas tetra-hidrofurânicas de acordo com Hattori et al. (1987).

Tabela 12 - Fragmentos de massa das lignanas tetra-hidrofurânicas isoladas.

\begin{tabular}{cccccccc}
\hline \multirow{2}{*}{ Substância } & \multicolumn{7}{c}{$\boldsymbol{m} / \mathbf{z}$ (int. rel. \%) } \\
\cline { 2 - 8 } & {$\left[\mathbf{M}^{\bullet+}\right]$} & $\mathbf{A}$ & $\mathbf{B}$ & $\mathbf{C}$ & $\mathbf{D}$ & $\mathbf{E}$ & $\mathbf{F}$ \\
\hline $\mathbf{6}$ & $372(24)$ & $178(13)$ & $194(4)$ & $206(100)$ & $166(4)$ & $191(61)$ & $165(20)$ \\
$\mathbf{7}$ & $372(20)$ & $178(44)$ & $194(20)$ & $206(100)$ & $166(2)$ & $191(74)$ & $165(7)$ \\
$\mathbf{8}$ & $358(34)$ & $178(16)$ & $194(9)$ & $206(81)$ & $166(16)$ & $191(66)$ & $165(9)$ \\
$\mathbf{9}$ & $344(7)$ & $164(9)$ & $180(3)$ & $192(100)$ & $152(5)$ & $177(56)$ & $151(47)$ \\
$\mathbf{1 0}$ & $344(7)$ & $164(18)$ & $180(10)$ & $192(100)$ & $152(14)$ & $177(54)$ & $151(44)$ \\
\hline
\end{tabular}

\subsubsection{Substâncias 11 e 12}

Através da análise de seus respectivos espectros de $\mathrm{RMN}$ de ${ }^{1} \mathrm{H}$ e ${ }^{13} \mathrm{C}$, as substâncias 11 e 12 foram identificadas como sendo as formas eritro e treo, respectivamente, da neolignana denominada 1'-alil-7-hidroxi-3,4,3'-trimetoxi-8,4'oxineolignana (MOSS, 2000).

Os espectros de RMN de ${ }^{1} \mathrm{H}$ de ambas as substâncias (Espectros 26 e 27, p. 133 e 134) apresentam absorções referentes ao grupamento alila e a três grupos metoxilas distintos, juntamente com sinais na região entre $7,00-6,72$ ppm, integrando para seis 
hidrogênios. A distinção entre ambas é feita pelos deslocamentos químicos dos hidrogênios 7, 8 e 9, que em 11 absorvem em $\delta 4,84(d, J=2,6 \mathrm{~Hz}), \delta 4,33(m)$, e $\delta 1,18(d, J=6,6 \mathrm{~Hz})$, enquanto que em 12 os mesmos se encontram mais protegidos, ressonando em $\delta 4,64(d, J$ $=8,3 \mathrm{~Hz}), \delta 4,06(m)$ e $\delta 1,17(d, J=6,1 \mathrm{~Hz})$, respectivamente.

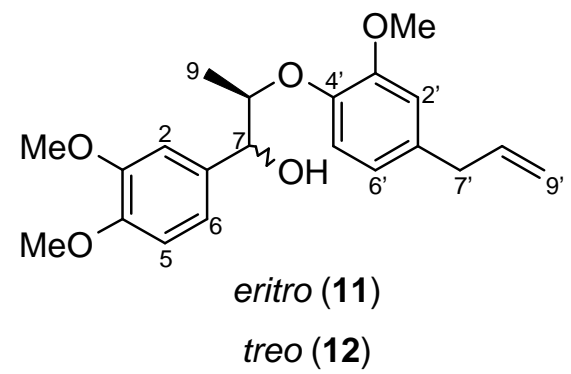

Figura 11. Estrutura molecular das formas diastereoisoméricas da oxineolignana isolada.

De acordo com BRAGA et al. (1984) tanto a estereoquímica, quanto a conformação mais provável das substâncias 11 e 12 podem ser deduzidas pela análise de seus respectivos espectros de $\mathrm{RMN}$ de ${ }^{1} \mathrm{H}$. Levando-se em consideração a existência de uma ligação de hidrogênio intramolecular entre a hidroxila benzílica e o oxigênio do grupo arilóxi, os rotâmeros A, B e C (Figura 12) são os únicos que poderiam contribuir significativamente para as conformações destes éteres arílicos. As constantes de acoplamento $J_{7,8}$ de 3 e $8 \mathrm{~Hz}$ são consistentes com ângulos diedros de $60^{\circ}$ e $180^{\circ}$ entre $\mathrm{H}-7$ e $\mathrm{H}-8$, para as formas eritro e treo, respectivamente, o que permite associar o confôrmero $\mathrm{C}$ com o maior valor de $J$ para a forma treo, e os confôrmeros A e/ou B para a forma eritro.

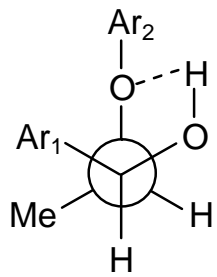

A

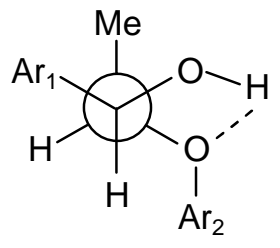

B

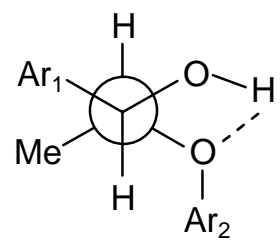

C

Figura 12. Conformações possíveis para as formas diastereoisoméricas de 8,4'-oxineolignanas. 
Embora não se tenha dúvidas sobre a identificação da substância 12 como sendo a forma treo da oxineolignana supracitada, obteve-se um espectro HETERO-COSY (Espectro 30, p. 137) para a atribuição da parte alifática da mesma, uma vez que foi observada uma ligeira divergência entre os dados obtidos e àqueles descritos na literatura.

A forma eritro já tinha sido isolada do arilo de $M$. fragrans, enquanto que a forma treo foi sintetizada por Braga et al. (1984). Este é o primeiro relato sobre a obtenção da forma treo como produto natural, sendo ambas neolignanas isoladas pela primeira vez da espécie V. pavonis.

A ocorrência de 8,4'-oxineolignanas como produto natural é relativamente pequena e tais lignóides têm sido isolados quase que exclusivamente de miristicáceas. Em estudos anteriores as substâncias 11 e 12 apresentaram significativa atividade contra fungos dermatófitos, sendo a forma eritro mais ativa (ZACCHINO et al., 1997).

Tabela 13 - Dados de RMN de ${ }^{1} \mathrm{H}$ e ${ }^{13} \mathrm{C}\left(\mathrm{CDCl}_{3}, 4,7 \mathrm{~T}\right)$ de 11 e 12 e RMN de ${ }^{13} \mathrm{C}$ das formas eritro e treo (BRAGA et al., 1984).

\begin{tabular}{|c|c|c|c|c|c|c|}
\hline \multirow[t]{2}{*}{ Posição } & \multicolumn{2}{|c|}{$\frac{{ }^{1} \mathrm{H}}{\delta(\mathrm{ppm}), \text { multiplicidade, } \boldsymbol{J}(\mathrm{Hz})}$} & \multicolumn{4}{|c|}{$\begin{array}{c}{ }^{13} \mathrm{C} \\
\delta(\mathrm{ppm})\end{array}$} \\
\hline & 11 & 12 & 11 & eritro & 12 & treo \\
\hline 1 & - & - & 132,5 & 132,4 & 132,6 & 132,3 \\
\hline 2 & $7,00-6,75(\mathrm{~m})$ & $6,97-6,72(m)$ & 110,7 & 110,4 & 110,8 & 110,3 \\
\hline 3 & - & - & 148,1 & 147,8 & 148,8 & 148,2 \\
\hline 4 & - & - & 151,4 & 150,9 & 150,7 & 150,0 \\
\hline 5 & $7,00-6,75(m)$ & $6,97-6,72(m)$ & 109,4 & 109,2 & 109,9 & 109,6 \\
\hline 6 & $7,00-6,75(m)$ & $6,97-6,72(m)$ & 121,1 & 120,7 & 120,8 & 120,3 \\
\hline 7 & $4,84(d, 2,6)$ & $4,64(d, 8,3)$ & 73,4 & 73,3 & 78,4 & 77,5 \\
\hline 8 & $4,33(m)$ & $4,06(m)$ & 82,5 & 81,8 & 84,4 & 82,8 \\
\hline 9 & $1,18(d, 6,6)$ & $1,17(d, 6,1)$ & 13,5 & 13,2 & 17,1 & 16,2 \\
\hline 1 & - & - & 135,5 & 134,9 & 135,3 & 134,3 \\
\hline 2 & $7,00-6,75(m)$ & $6,97-6,72(m)$ & 112,4 & 112,2 & 112,4 & 111,9 \\
\hline 3 & - & - & 148,8 & 148,5 & 148,8 & 148,4 \\
\hline $4^{\prime}$ & - & - & 144,7 & 144,6 & 146,0 & 145,3 \\
\hline 5 & $7,00-6,75(m)$ & $6,97-6,72(m)$ & 118,4 & 118,2 & 119,2 & 118,2 \\
\hline 6 & $7,00-6,75(m)$ & $6,97-6,72(m)$ & 119,9 & 119,2 & 120,0 & 119,3 \\
\hline $7^{\prime}$ & $3,37(d, 7,0)$ & $3,37(d, 6,6)$ & 39,9 & 39,6 & 39,9 & 39,3 \\
\hline $8^{\prime}$ & $\begin{array}{c}5,98 \\
(d d t, 16,6 ; 10,3 \text { e } 6,6)\end{array}$ & $\begin{array}{c}5,95 \\
(d d t, 16,6 ; 10,5 \text { e } 6,6)\end{array}$ & 137,2 & 137,0 & 137,4 & 136,8 \\
\hline $9^{\prime}$ & $5,16-5,07(m)$ & $5,15-5,07(m)$ & 115,9 & 115,5 & 115,9 & 115,2 \\
\hline $\mathrm{MeO}$ & 3,$90 ; 3,89 ; 3,88$ & 3,$91 ; 3,89 ; 3,88(s)$ & 55,8 & 55,5 & $\begin{array}{l}55,7 \\
55,9\end{array}$ & 55,2 \\
\hline
\end{tabular}




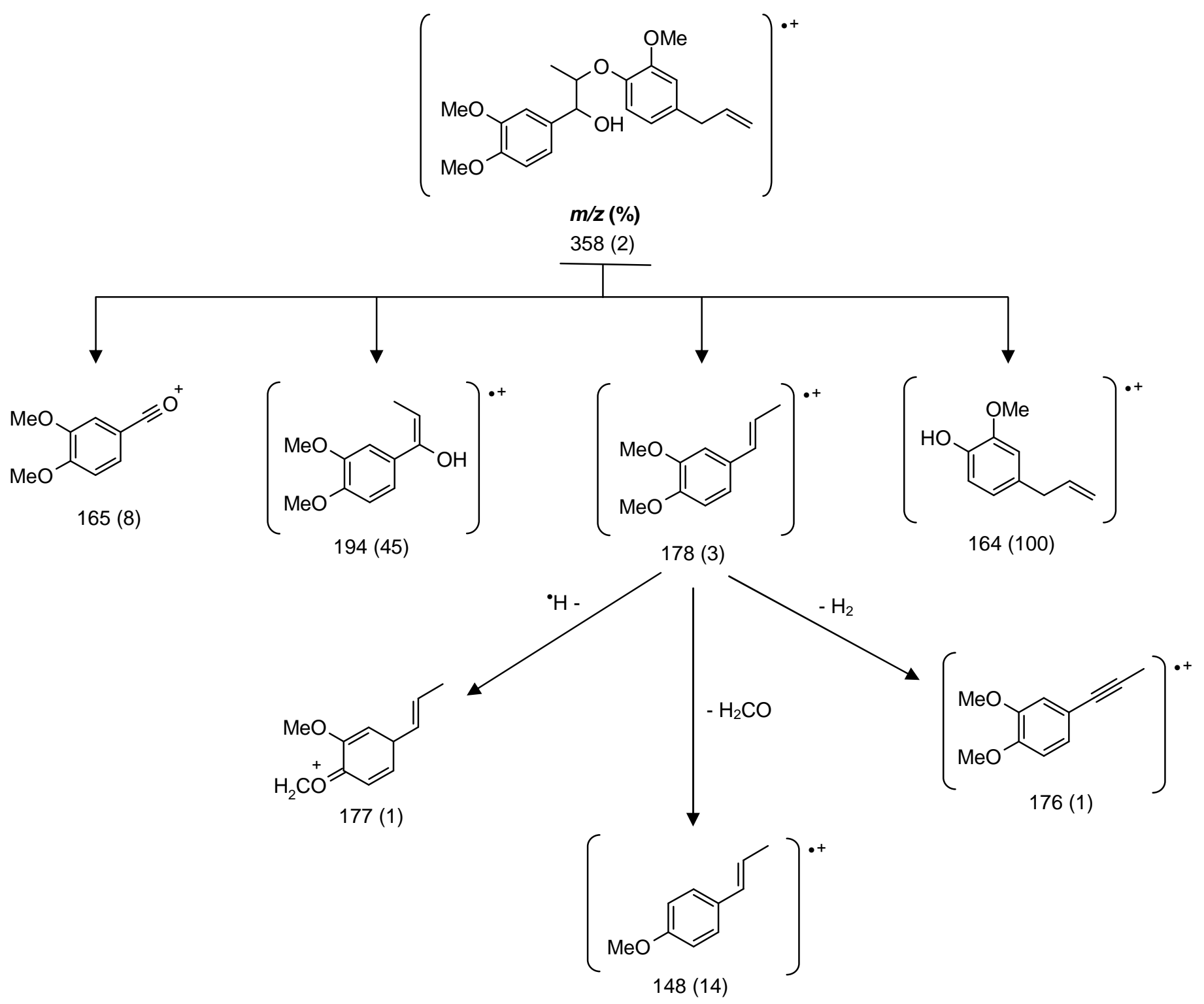

Figura 13. Proposta de fragmentação das oxineolignanas 11 e 12.

\subsubsection{Substância 13}

A substância 13 foi identificada como sendo a neolignana denominada carinatona, isolada originalmente de $V$. carinata. $\mathrm{O}$ espectro de $\mathrm{RMN}$ de ${ }^{1} \mathrm{H}$ dessa substância (Espectro 32 , p. 139) apresenta o conjunto de sinais característicos do grupo alila $(3,23 ; 5,87$ e 5,00 ppm), dois singletos em $\delta 3,89$ e $\delta 3,87$, correspondentes a grupos metoxilas, juntamente com um singleto em 5,31 ppm, típico de hidroxila fenólica. A observação de um dubleto em $1,47 \mathrm{ppm}(\mathrm{J}=6,6 \mathrm{~Hz})$ e de um quarteto em $5,06 \mathrm{ppm}(J=6,9 \mathrm{~Hz})$ sugere a presença de um grupo metila secundário adjacente a um grupo carbonila. O padrão de substituição dos dois 
anéis aromáticos foi determinado pela a observação de dois dubletos centrados em $\delta 6,53 \mathrm{e}$ $\delta 6,56 \mathrm{com} J=2 \mathrm{~Hz}$ cada, que indicam uma orientação meta para H-2' e H-6', juntamente com os sinais em $\delta 6,82(d, J=8,7 \mathrm{~Hz}), \delta 7,62(d, J=2,1 \mathrm{~Hz})$ e $\delta 7,73(d d, J=2,1$ e $8,4 \mathrm{~Hz})$ que evidenciam um sistema $A B X$ para $\mathrm{H}-5, \mathrm{H}-2$ e $\mathrm{H}-6$, respectivamente, do outro anel. $A$ substância 13 foi identificada apenas por comparação dos dados de RMN de ${ }^{1} \mathrm{H}$, não sendo possível a obtenção dos espectros de $\mathrm{RMN}$ de ${ }^{13} \mathrm{C}$ e massas por motivo de decomposição da substância.<smiles>C=CCc1cc(OC)c(O)c(C(C)C(=O)c2ccc(OC)c(OC)c2)c1</smiles>

Figura 14. Estrutura molecular da carinatona.

Tabela 14 - Dados de RMN de ${ }^{1} \mathrm{H}$ de 13 e da carinatona $\left(\mathrm{CDCl}_{3}, 7,05 \mathrm{~T}\right)$.

\begin{tabular}{|c|c|c|}
\hline \multirow{2}{*}{ Posição } & \multicolumn{2}{|c|}{$\begin{array}{c}{ }^{1} \mathrm{H} \\
\delta(\mathrm{ppm}), \text { multiplicidade, } J(\mathrm{~Hz})\end{array}$} \\
\hline & 13 & $\begin{array}{c}\text { Carinatona } \\
\text { (KAWANISHI et al., 1982) }\end{array}$ \\
\hline 2 & $7,62(d, 2,1)$ & $7,61(d, 1,9)$ \\
\hline 5 & $6,82(d, 8,7)$ & $6,80(d, 8,6)$ \\
\hline 6 & $7,73(d d, 2,1$ e 8,4$)$ & $7,72(d d, 1,9$ e 8,6$)$ \\
\hline 8 & $5,06(q, 6,9)$ & $5,03(q, 6,8)$ \\
\hline 9 & $1,47(d, 6,6)$ & $1,46(d, 6,8)$ \\
\hline $2^{\prime}$ & $6,53(d, 2,0)$ & $6,53(d, 2,0)$ \\
\hline 6 & $6,56(d, 2,1)$ & $6,55(d, 2,0)$ \\
\hline $7^{\prime}$ & $3,23(d, 6,6)$ & $3,22(d t, 1,6$ e 6,7$)$ \\
\hline $8^{\prime}$ & $5,87(m)$ & $\begin{array}{c}5,86 \\
(d d t, 6,7 ; 9,2 \text { e } 17,0)\end{array}$ \\
\hline $9^{\prime}$ & $5,03-4,97(m)$ & $\begin{array}{c}4,99 \\
(d d t, 1,6 ; 2,0 \text { e } 17,0)\end{array}$ \\
\hline $\mathrm{MeO}-3$ & $3,89(s)$ & $3,88(s)$ \\
\hline $\mathrm{MeO}-4$ & $3,87(s)$ & $3,85(s)$ \\
\hline $\mathrm{MeO}-5^{\prime}$ & $3,89(s)$ & $3,88(s)$ \\
\hline $\mathrm{OH}-4$ & $5,31(s)$ & $5,92(s)$ \\
\hline
\end{tabular}




\subsubsection{Substância 14}

O espectro de RMN de ${ }^{1} \mathrm{H}$ da substância 14 (Espectro 33, p. 140) apresenta dois dubletos em $\delta 0,85(J=6,2 \mathrm{~Hz}, 3 \mathrm{H})$ e $\delta 1,07(J=6,2 \mathrm{~Hz}, 3 \mathrm{H})$, um dubleto em 3,37 ppm $(J=$ $10,3 \mathrm{~Hz})$ atribuível a um próton dibenzílico, dois duplos dubletos centrados em $\delta 2,75(\mathrm{~J}=$ 4,4 e $15,8 \mathrm{~Hz})$ e $\delta 2,59(\mathrm{~J}=10,1$ e $15,8 \mathrm{~Hz})$, que juntamente com as absorções observadas na região aromática sugerem a presença de uma neolignana ariltetralínica.

O padrão de substituição dos anéis aromáticos foi definido através da análise das constantes de acoplamento observadas para os sinais na região de 6,85-6,54 ppm. O duplo dubleto em 6,63 ppm $(J=8,34 \mathrm{~Hz}$ e $1,76 \mathrm{~Hz})$ foi atribuído a $\mathrm{H}-6$ ', enquanto que os dubletos centrados em $\delta 6,83(J=8,34 \mathrm{~Hz})$ e $\delta 5,55(J=2,2 \mathrm{~Hz})$ foram atribuídos respectivamente aos hidrogênios 5' e 2' do anel C. O singleto em 6,25 ppm (1H) foi atribuído ao H-3, uma vez que este se encontra protegido através do efeito anisotrópico exercido pelo anel C.

O espectro de RMN de ${ }^{1} \mathrm{H}$ mostrou ainda dois singletos em 5,48 ppm e 5,28 ppm, atribuíveis aos dois prótons hidroxílicos presente nesta neolignana.

A constante de acoplamento de 10,3 Hz entre H-7' e H-8' sugere uma relação trans entre estes prótons e a proteção de H-3 define a posição do anel $\mathrm{C}$ em equatorial. Estas observações aliadas à comparação dos deslocamentos químicos dos prótons metílicos com dados da literatura definem as relações trans-trans e a conformação pseudo-equatorial dos substituintes do anel cicloexânico desta molécula.

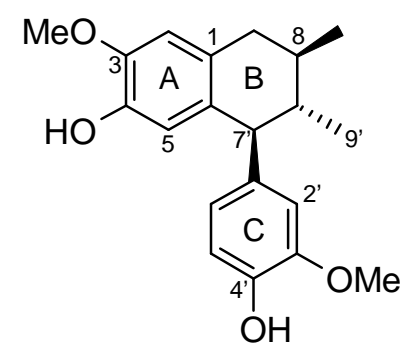

Figura 15. Estrutura molecular da guaiacina. 
O espectro de massas de 14 (Espectro 36, p. 143) apresentou pico do íon molecular $[\mathrm{M}]^{++} 328 \mathrm{~m} / \mathrm{z}$, que também é correspondente ao pico base, juntamente com as fragmentações mostradas na Figura 15.

Os dados de RMN de ${ }^{1} \mathrm{H}$ e de EM dessa substância são condizentes com os descritos na literatura para a neolignana denominada guaiacina, que já havia sido isolada de I. juruensis.

Tabela 15 - Dados de RMN de ${ }^{1} \mathrm{H}$ e ${ }^{13} \mathrm{C}$ de 14 e da guaiacina $\left(\mathrm{CDCl}_{3}, 4,7 \mathrm{~T}\right)$.

\begin{tabular}{|c|c|c|c|c|}
\hline \multirow{2}{*}{ Posição } & \multicolumn{2}{|c|}{$\begin{array}{c}\text { 'H } \\
\delta(\mathrm{ppm}), \text { multiplicidade, } J(\mathrm{~Hz})\end{array}$} & \multirow{2}{*}{$\begin{array}{l}{ }_{\delta}^{13} \mathbf{C p} \\
\delta(p m)\end{array}$} & \multirow{2}{*}{ HETERO-COSY } \\
\hline & 14 & $\begin{array}{c}\text { Guaiacina } \\
\text { (LOPES, 1997) }\end{array}$ & & \\
\hline 1 & - & - & 128,4 & \\
\hline 2 & $6,54(s)$ & $6,46(s)$ & 110,0 & 110,0 \\
\hline 3 & - & - & 143,9 & \\
\hline 4 & - & - & 143,3 & \\
\hline 5 & $6,26(s)$ & $6,18(s)$ & 115,5 & 115,5 \\
\hline 6 & - & - & 133,5 & \\
\hline $7 a x$. & $2,59(d d, 10,1$ e 15,8$)$ & $2,53(d d, 10,8$ e 15,5$)$ & 39.1 & 39.1 \\
\hline 7eq. & $2,75(d d, 4,4$ e 15,8$)$ & $2,66(d d, 4,5$ e 15,8$)$ & 39,1 & 39,1 \\
\hline 8 & $1,69-1,48(m)$ & $1,5(m)$ & 43,7 & 43,7 \\
\hline 9 & $1,07(d, 6,2)$ & $1,0(d, 6,1)$ & 20,0 & 20,0 \\
\hline $1^{\prime}$ & - & - & 138,3 & \\
\hline $2^{\prime}$ & $6,55(d, 2,2)$ & $6,48(d, 2,7)$ & 111,5 & 111,5 \\
\hline 3' & - & - & 146,5 & \\
\hline $4^{\prime}$ & - & - & 144,6 & \\
\hline $5^{\prime}$ & $6,83(d, 8,34)$ & $6,74(d, 8,0)$ & 113,9 & 113,9 \\
\hline $6{ }^{\prime}$ & $6,63(d d, 1,76$ e 8,34$)$ & $6,56(d d, 2,7$ e 8,0$)$ & 122,5 & 122,5 \\
\hline $7^{\prime}$ & $3,37(d, 10,3)$ & $3,28(d, 10,3)$ & 54,2 & 54,2 \\
\hline $8^{\prime}$ & $1,69-1,48(m)$ & $1,3(m)$ & 35,6 & 35,6 \\
\hline $9^{\prime}$ & $0,85(d, 6,2)$ & $0,78(d, 6,1)$ & 17,2 & 17,2 \\
\hline MeO-3 & $3,82(s)$ & & 55,8 & 55,8 \\
\hline MeO-3' & $3,84(s)$ & 3,$77 ; 3,74(s)$ & 55,9 & 55,9 \\
\hline $\mathrm{OH}$ & $5,28(s)$ & - & - & \\
\hline $\mathrm{OH}$ & $5,48(s)$ & - & - & \\
\hline
\end{tabular}




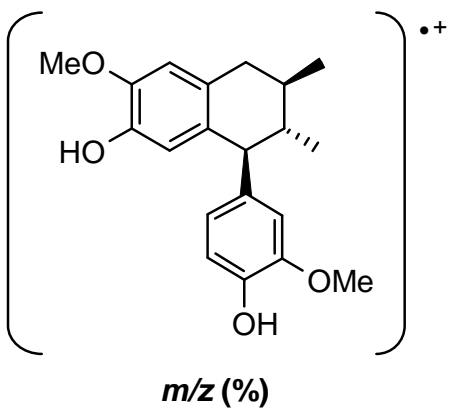

$328(100)$

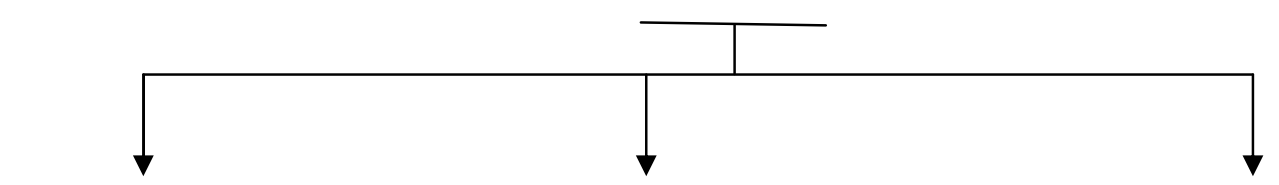<smiles>[C+]c1ccc(O)c(OC)c1</smiles><smiles>COc1ccccc1O</smiles>

$136(14)$<smiles>COc1cc2c(cc1O)CC(C)C(C)=C2</smiles>

$204(40)$

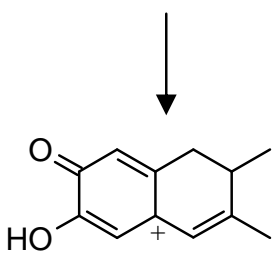

$189(32)$

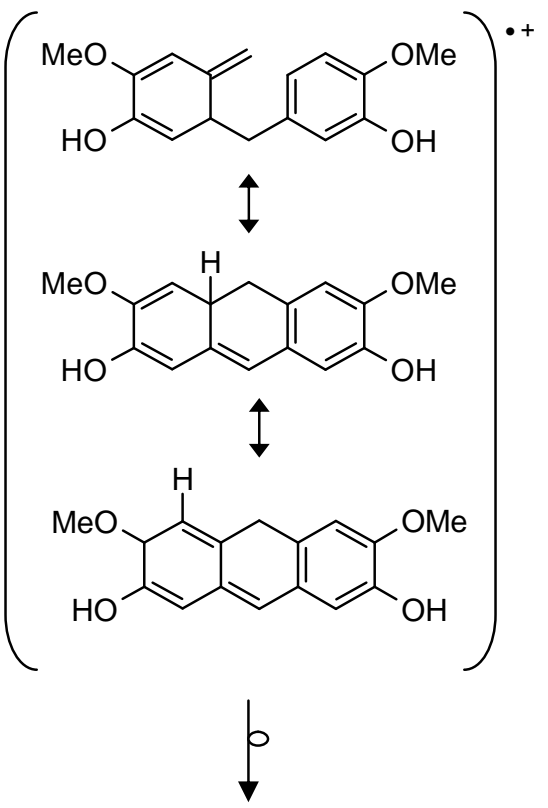<smiles></smiles>

$271(43)$<smiles>CCCCCCCCCO</smiles><smiles>COc1cc2c(cc1O)C=C1C=C(O)[CH+]C=C1C2</smiles>

Figura 16. Proposta de fragmentação da neolignana guaiacina de acordo com Lopes (1997). 


\subsubsection{Tocotrienóides}

Os tocotrienóides (ou tocotrienóis) são compostos isoprenóides que, juntamente com os tocoferóis, constituem a família da vitamina E. Estruturalmente, esses compostos são formados por um anel cromano e uma cadeia lateral na posição C-2, que nos tocoferóis ocorre como uma cauda fitila saturada, e nos tocotrienóis aparece como uma cadeia isoprenóide insaturada. A atividade antioxidante desses compostos é bem reconhecida (THERIAULT et al., 1999).

A ocorrência de tocotrienóis na família Myristicaceae tem sido relatada nos frutos de algumas espécies de Iryanthera e Pycnanthus (VIEIRA, et al., 1983; FORT et al., 2000; SILVA et al., 2001).

\subsubsection{Substâncias 15 e 16}

Em ambos os espectros de RMN de ${ }^{1} \mathrm{H}$ das substâncias 15 e 16 (Espectros 37 e 38, p. 144 e 145) são observados dois dubletos em $\delta 6,23 \pm 0,02$ e $\delta 5,56 \pm 0,02$ acoplados entre si $(J=9,8 \mathrm{~Hz})$, característicos dos hidrogênios 3 e 4, respectivamente, dos anéis cromenos

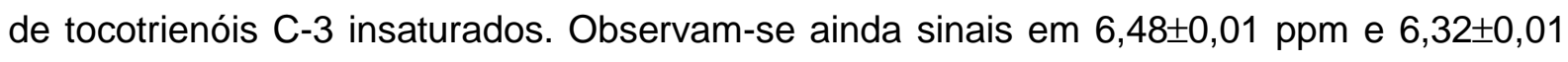
ppm, que no espectro de 15 aparecem como dois singletos largos e no espectro de 16 ocorrem como dois dubletos com $J=3 \mathrm{~Hz}$, que caracterizam o anel cromeno de $\delta$ tocotrienóis (6,8-dissubstituídos).

Multipletos centralizados em 5,10 ppm, referente a prótons olefínicos, e 2,05 ppm, correspondente a grupos metilênicos alílicos, são verificados em ambos os espectros. No espectro de hidrogênio de 15 são observados cinco singletos $(\delta 1,36, \delta 1,55, \delta 1,57, \delta 1,67$ e $\delta 2,12)$, enquanto que no espectro de 16 observam-se apenas quatro singletos $(\delta 1,36, \delta$ $1,58, \delta 1,68$ e $\delta 2,14)$ e um tripleto em 5,99 ppm $(J=7,2 \mathrm{~Hz})$, típico de hidrogênio vinílico vizinho à carbonila $\left(\mathrm{H}-7^{\prime}\right)$.

A diferença entre essas substâncias é ainda evidenciada pela análise de seus respectivos espectros de $\mathrm{RMN}$ de ${ }^{13} \mathrm{C}$ (Espectros 39 e 40, p. 146 e 147). É possível 
confirmar a presença de uma função ácida em 16 (172,9ppm), a qual está ausente na substância 15.

A comparação com dados da literatura, juntamente com a análise de seus respectivos EM (Espectros 41A e 41B, p.148) possibilitaram a identificação das substâncias 15 e 16 como sendo os tocotrienóis sargaol e sargacromenol, respectivamente. O sargacromenol já havia sido isolado anteriormente dos frutos de $I$. juruensis, porém este é o primeiro relato sobre a ocorrência do sargaol como metabólito secundário dessa espécie.

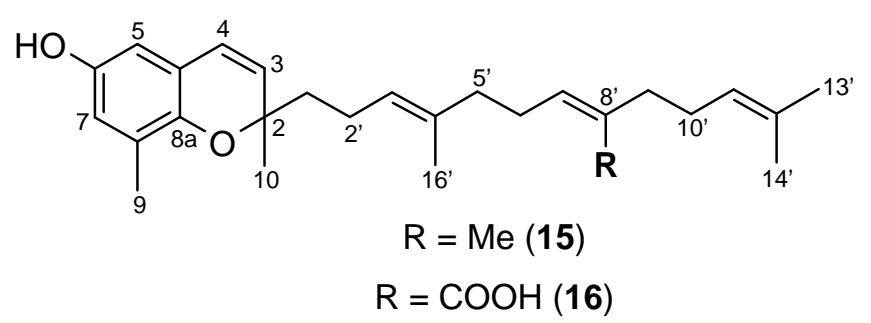

Figura 17. Estrutura molecular do sargaol (15) e do sargacromenol (16). 
Tabela 16 - Dados de RMN de ${ }^{1} \mathrm{H}$ e ${ }^{13} \mathrm{C}$ das substâncias 15 e $16\left(\mathrm{CDCl}_{3}, 4,7 \mathrm{~T}\right)$ e dados de $\mathrm{RMN}$ de ${ }^{13} \mathrm{C}$ do sargaol e do sargacromenol.

\begin{tabular}{|c|c|c|c|c|c|c|}
\hline \multirow[b]{2}{*}{ Posição } & \multicolumn{2}{|c|}{${ }^{1} \mathrm{H}(\mathrm{ppm})$, multiplicidade, $J(\mathrm{~Hz})$} & \multicolumn{4}{|c|}{${ }^{13} \mathrm{C}(\mathrm{ppm})$} \\
\hline & 15 & 16 & 15 & $\begin{array}{c}\text { Sargaol } \\
\text { (NUMATA, 1992) }\end{array}$ & 16 & $\begin{array}{l}\text { Sargacromenol } \\
\text { (SEO et al., 2007) }\end{array}$ \\
\hline 2 & - & - & 77,8 & 77,9 & 77,8 & 77,7 \\
\hline 3 & $5,56(d, 9,6)$ & $5,58(d, 9,8)$ & 130,6 & 130,8 & 130,6 & 130,5 \\
\hline 4 & $6,23(d, 9,6)$ & $6,25(d, 9,6)$ & 122,9 & 122,9 & 122,9 & 122,8 \\
\hline $4 a$ & - & - & 121,3 & 121,4 & 121,3 & 121,2 \\
\hline 5 & $6,33(s)$ & $6,33(d, 3)$ & 110,3 & 110,3 & 110,3 & 110,3 \\
\hline 6 & - & - & 148,6 & 148,8 & 148,6 & 148,5 \\
\hline 7 & $6,48(s)$ & $6,48(d, 2,8)$ & 117,1 & 117,1 & 117,1 & 117,0 \\
\hline 8 & - & - & 126,3 & 126,4 & 126,3 & 126,2 \\
\hline $8 a$ & - & - & 144,8 & 145,0 & 144,8 & 144,6 \\
\hline 9 & $2,12(s)$ & $2,15(s)$ & 15,5 & 15,5 & 15,7 & 15,8 \\
\hline 10 & $1,36(s)$ & $1,36(s)$ & 26,0 & 25,9 & 25,9 & 26,0 \\
\hline $1^{\prime}$ & & $1,63(m)$ & 40,7 & 40,9 & 40,8 & 40,8 \\
\hline 2 & & $2,06-2,27(m)$ & 22,6 & 22,6 & 22,6 & 22,7 \\
\hline 3 & $5,10(m)$ & $5,06-5,17(m)$ & 124,9 & 124,2 & 124,9 & 124,8 \\
\hline $4^{\prime}$ & - & - & 134,3 & 136,0 & 134,3 & 134,2 \\
\hline 5 & & $2,06-2,27(m)$ & 39,1 & 39,7 & 39,1 & 39,1 \\
\hline 6 & & $2,59(q, 7,4)$ & 28,0 & 26,8 & 28,1 & 28,2 \\
\hline 7 & $5,10(m)$ & $5,99(t, 7,2)$ & 123,6 & 124,1 & 145,5 & 145,4 \\
\hline 8 & - & - & 134,4 & 135,2 & 130,5 & 130,4 \\
\hline $9^{\prime}$ & & $5,11(m)$ & 34,5 & 39,7 & 34,5 & 34,6 \\
\hline $10^{\prime}$ & & $2,06-2,27(m)$ & 27,8 & 26,6 & 27,8 & 27,9 \\
\hline $11^{\prime}$ & $5,10(\mathrm{~m})$ & $5,06-5,17(m)$ & 123,5 & 124,4 & 123,4 & 123,3 \\
\hline $12^{\prime}$ & - & - & 132,2 & 131,3 & 132,2 & 132,1 \\
\hline $13^{\prime}$ & $1,67(s)$ & $1,68(s)$ & 25,9 & 25,7 & 25,6 & 25,7 \\
\hline $14^{\prime}$ & $1,58(s)$ & $1,58(s)$ & 17,7 & 17,7 & 17,7 & 17,8 \\
\hline $15^{\prime}$ & $1,58(s)$ & - & 15,7 & 16,0 & 172,9 & 172,9 \\
\hline 16 & $1,58(s)$ & $1,58(s)$ & 15,7 & 15,9 & 15,5 & 15,6 \\
\hline
\end{tabular}




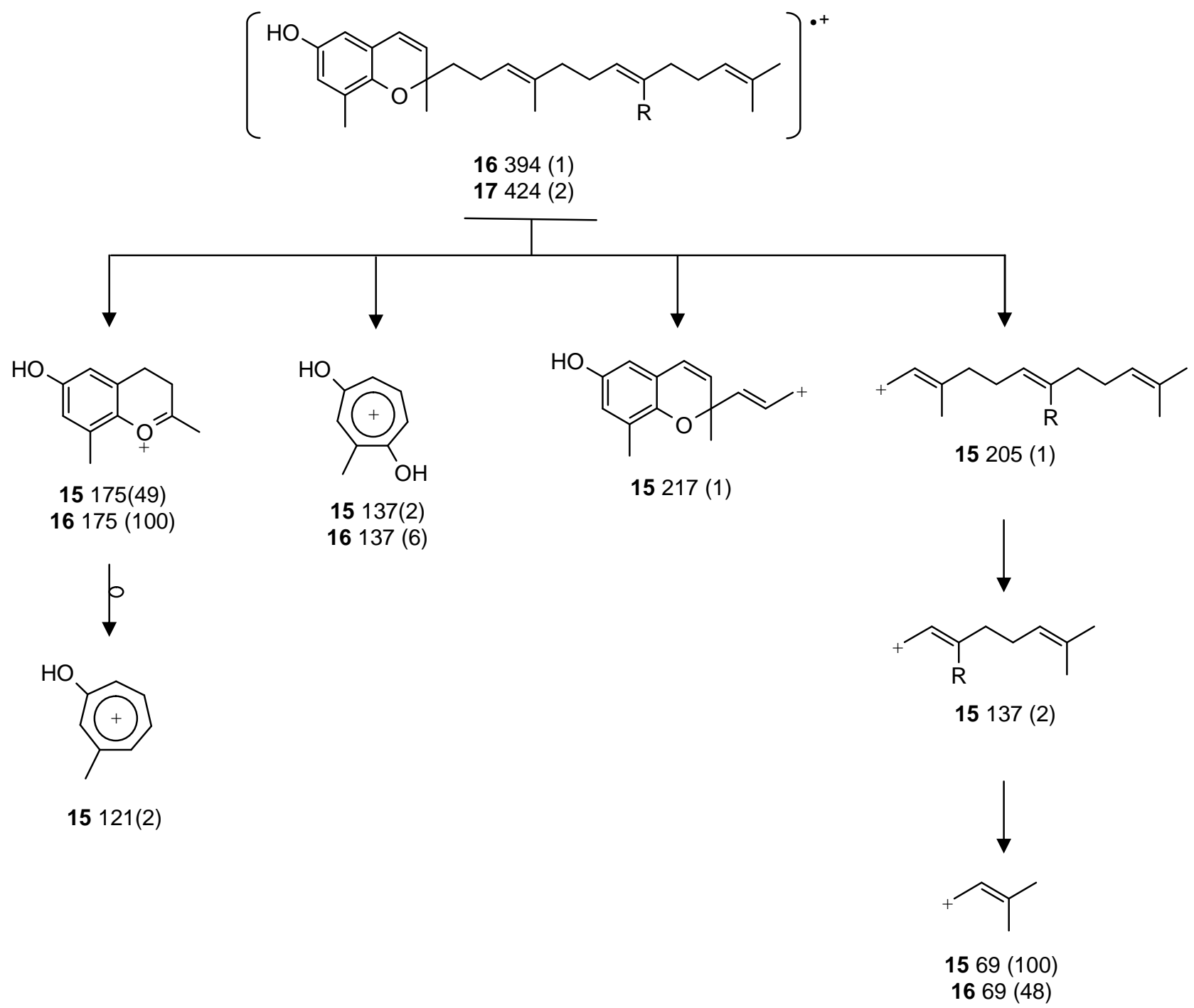

Figura 18. Proposta de fragmentação para os tocotrienóides 15 e 16.

\subsubsection{Terpenóides}

Os terpenos são derivados da condensação de unidades do isopreno e se classificam de acordo com o número dessas unidades presentes no esqueleto carbônico. Esta classe de compostos está amplamente distribuída na natureza, especialmente no reino vegetal, e apresentam estruturas cíclicas ou acíclicas que resultam de transformações das cadeias isoprênicas que lhe dão origem. Estas transformações compreendem um grande número de reações, tais como reduções, oxidações, ciclizações, rupturas de anel ou rearranjo, as quais conferem uma enorme diversidade estrutural a estes metabólitos. 
A ocorrência de terpenóides não é comum na família Myristicaceae, sendo o isolamento de mono e sesquiterpenos relatado somente para o gênero Osteophloeum.

\subsubsection{Substância 64}

O espectro de RMN de ${ }^{1} \mathrm{H}$ da substância 64 (Espectro 42, p. 149) apresenta dois singletos em $\delta 4,67$ e $\delta 4,69$ ppm, referentes a hidrogênios de ligação dupla exocíclica, além de três singletos em 1,04, 1,06 e 1,28 ppm, sendo os dois primeiros referentes a grupos metílicos ligados a átomos de carbono quaternário e o último indicativo de grupo metílico ligado a carbono quaternário carbinólico. Observa-se ainda um duplo dubleto em $\delta 0,47(\mathrm{~J}=$ 9,3 e $11 \mathrm{~Hz}$ ), sinal este bastante protegido em relação aos demais hidrogênios da molécula e que é típico do hidrogênio H-6 de sesquiterpenos com esqueleto aromadendrano, devido à tensão observada no anel de três membros.

No espectro de RMN de ${ }^{13} \mathrm{C}$ dessa substância (Espectro 43, p. 150), verifica-se a presença de 15 átomos de carbono distintos, os quais confirmam a presença da ligação dupla terminal (153,4 e 106,3 ppm), do carbono carbinólico quaternário $(\delta 80,9)$ e do esqueleto aromadendrano. A partir da comparação dos dados de RMN com aqueles disponíveis na literatura, foi possível identificar a substância 64 como sendo o espatulenol.

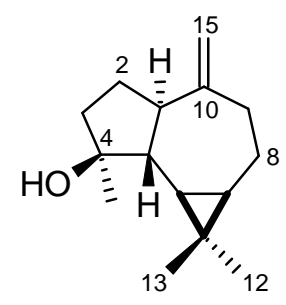

Figura 19. Estrutura molecular do espatulenol. 
Tabela 17 - Dados de RMN de ${ }^{1} \mathrm{He}$ e ${ }^{13} \mathrm{C}$ de $64\left(\mathrm{CDCl}_{3}, 4,7 \mathrm{~T}\right)$ e dados de RMN de ${ }^{13} \mathrm{C}$ do espatulenol.

\begin{tabular}{cccc}
\hline \multirow{2}{*}{ Posição } & ${ }^{1} \mathbf{H}$ (ppm), multiplicidade, $\mathbf{J}(\mathbf{H z})$ & \multicolumn{2}{c}{${ }^{\mathbf{1 3}} \mathbf{C} \mathbf{~ ( p p m )}$} \\
\cline { 2 - 4 } & $\mathbf{6 4}$ & $\mathbf{6 4}$ & $\begin{array}{c}\text { Espatulenol } \\
\text { (IWABUCHI et al., 1989) }\end{array}$ \\
\hline 1 & $2,41(d d, 6,0$ e 14,0) & 54,3 & 54,3 \\
2 & & 24,7 & 24,8 \\
3 & & 41,7 & 41,7 \\
4 & - & 80,9 & 81,0 \\
5 & & 53,4 & 53,4 \\
6 & $0,47(d d, 9,3$ e 11,0) & 27,4 & 27,5 \\
7 & $0,72(d d d, 6,2,9,2$ e 11,2) & 26,7 & 26,7 \\
8 & & 29,9 & 29,9 \\
9 & & 38,8 & 38,8 \\
10 & - & 153,4 & 153,4 \\
11 & & 20,2 & 20,2 \\
12 & $1,04(s)$ & 28,6 & 28,6 \\
13 & $1,06(s)$ & 16,3 & 16,3 \\
14 & $1,28(s)$ & 26,0 & 26,0 \\
15 & $4,67(s)$ e 4,69 (s) & 106,3 & 106,2 \\
\hline
\end{tabular}

\subsubsection{Substância 79}

No espectro de RMN de ${ }^{1} \mathrm{H}$ de 79 (Espectro 44, p. 151) observam-se dois singletos em 4,74 e 5,02 ppm, típicos de hidrogênios olefínicos terminais, e sinais em $\delta 3,72(t, J=9,8$ $\mathrm{Hz}$ ) e em $\delta 3,46(d d, J=4,8$ e 11,4 Hz), cujas regiões de absorção sugerem a presença de hidrogênios metínicos carbinólicos. Observam-se ainda um singleto em $\delta \quad 0,70$ e dois dubletos em 0,95 e $0,87 \mathrm{ppm}(J=7,0 \mathrm{~Hz})$, que juntamente com o multipleto centrado em 1,28 ppm caracterizam um grupo isopropila.

$\mathrm{O}$ espectro de RMN de ${ }^{13} \mathrm{C}$ de 79 (Espectro 45, p. 152) também apresenta 15 absorções distintas, que ao serem confrontadas com dados descritos na literatura permitiu identificá-la como sendo o sesquiterpeno ent-4(15)-eudesmeno-1 $\beta, 6 \alpha$-diol. 


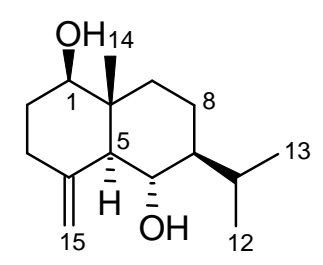

Figura 20. Estrutura molecular do ent-4(15)-eudesmeno-1 $\beta, 6 \alpha$-diol.

Tabela 18 - Dados de RMN de ${ }^{1} \mathrm{H}$ e ${ }^{13} \mathrm{C}$ de $79\left(\mathrm{CDCl}_{3}, 4,7 \mathrm{~T}\right)$ e RMN de ${ }^{13} \mathrm{C}$ do ent-4(15)eudesmeno-1 $\beta, 6 \alpha$-diol.

\begin{tabular}{cccc}
\hline \multirow{2}{*}{ Posição } & ${ }^{\mathbf{1}} \mathbf{H}$ (ppm), multiplicidade, $\boldsymbol{J}(\mathbf{H z})$ & \multicolumn{2}{c}{${ }^{\mathbf{1 3} \mathbf{C}(\mathbf{p p m})}$} \\
\cline { 2 - 4 } & $\mathbf{7 9}$ & $\mathbf{7 9}$ & $\begin{array}{c}\text { ent-4(15)-eudesmeno-1 } \mathbf{\beta}, \mathbf{6} \alpha \text {-diol } \\
\text { (NAGASHIMA et al., 2005) }\end{array}$ \\
\hline 1 & $3,46(d d, 4,8$ e 11,4) & 79,0 & 79,1 \\
2 & & 31,9 & 32,0 \\
3 & - & 35,0 & 35,1 \\
4 & $1,75(d, 10,1)$ & 146,2 & 146,3 \\
5 & $3,72(t, 9,8)$ & 55,8 & 55,9 \\
6 & $1,20-1,34(m)$ & 67,0 & 67,0 \\
7 & & 49,3 & 49,4 \\
8 & & 18,1 & 18,2 \\
9 & - & 36,2 & 36,3 \\
10 & $2,38-2,14(m)$ & 41,7 & 41,7 \\
11 & $0,95(d, 7,0)$ & 25,9 & 26,0 \\
12 & $0,87(d, 7,0)$ & 21,1 & 21,1 \\
13 & $0,70(s)$ & 16,1 & 16,2 \\
14 & $4,75(s)$ e $5,02(s)$ & 11,6 & 11,6 \\
15 & & 107,8 & 107,8 \\
\hline
\end{tabular}

\subsubsection{Substâncias 80 e 81}

Os espectros de RMN de ${ }^{1} \mathrm{H}$ de ambas as substâncias 80 e 81 (Espectros 46 e 47, p. 153 e 154) mostram dois singletos em torno de 1,24 e 0,95 ppm, característicos de grupos metila quaternários, além de uma série de sinais correspondentes a hidrogênios alifáticos na região entre 2,63 e 0,70 ppm. No espectro de 80 observam-se ainda dois singletos largos em 4,74 e 4,79 ppm, típicos de prótons metilênicos exocíclicos, enquanto que o espectro de 81 apresenta um dubleto centrado em $\delta 3,41(J=7,5 \mathrm{~Hz})$, correspondente a hidrogênios carbinólicos. 
Os espectros de RMN de ${ }^{13} \mathrm{C}$ dessas substâncias (Espectros 48 e 49, p. 155 e 156) apresentam 20 absorções distintas, dentre as quais o sinal em torno de $\delta 183$ sugere a presença de uma função ácida em ambas as moléculas. Os sinais em $\delta$ 155,9 e $\delta$ 102,9, observados no espectro de $\mathbf{8 0}$, confirmam a presença da ligação dupla exocíclica nessa substância, enquanto que o sinal em $\delta$ 67,4 comprova a existência de um carbono carbinólico em 81. Os demais sinais observados são típicos de esqueleto diterpênico do tipo ent-caurânico e estão condizentes com os descritos na literatura para os ácidos entcaurenóico (ácido ent-caur-16-en-19-óico) e 17-hidróxi-16 $\alpha$-ent-cauran-19-óico, respectivamente. Este último sendo isolado pela primeira vez de O. platyspermum.
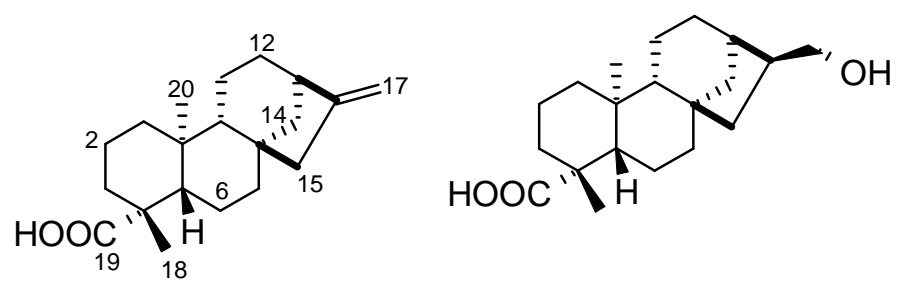

Figura 21. Estruturas moleculares dos ácidos ent-caur-16-en-19-óico (80) e 17-hidroxi-16 $\alpha$-entcauran-19-óico (81).

Tabela 19 - Dados de RMN de ${ }^{1} \mathrm{H}$ das substâncias 80 e $81\left(\mathrm{CDCl}_{3}, 4,7 \mathrm{~T}\right)$.

\begin{tabular}{ccc}
\hline \multirow{2}{*}{ Posição } & \multicolumn{2}{c}{$\delta(\mathbf{p p m})$, multiplicidade, $\boldsymbol{J}(\mathbf{H z})$} \\
\cline { 2 - 3 } & $\mathbf{8 0}$ & $\mathbf{8 1}$ \\
\hline 17 & $4,74(s)$ & $3,41(d, 7,5)$ \\
18 & $4,79(s)$ & $1,23(s)$ \\
20 & $1,24(s)$ & $0,94(s)$ \\
\hline
\end{tabular}

A localização do grupo carboxila em posição axial trans em relação ao átomo de hidrogênio H-5 baseou-se no deslocamento químico de C-5 $\left(\delta_{C} 56,4\right)$. Quando esta função se encontra na posição equatorial cis em relação a $\mathrm{H}-5$, o deslocamento químico de C-5 ocorre em torno de 50 ppm devido aos efeitos $\gamma$ dos átomos de oxigênio do grupo carboxila. Os deslocamentos químicos do carbono quaternário C-4 e dos metílicos $\mathrm{CH}_{3}-18, \mathrm{CH}_{3}-19$ e 
$\mathrm{CH}_{3}-20$ também foram considerados nesta dedução estereoquímica, os quais ocorrem em $\delta$ $47,6, \delta 185,0, \delta 17,8$ e $\delta 16,1$, respectivamente, no epímero $4 \beta$ de 80 (VELANDIA et al., 1998).

O ácido 81 é frequentemente isolado em mistura com seu epímero $16 \beta$ de espécies de Annona. A distinção entre ambos é feita pela análise dos deslocamentos químicos de $\mathrm{H}$ 17 e C-17, que em $16 \alpha$ absorvem em 3,40 ppm ( $d, J=7,0 \mathrm{~Hz})$ e 67,4 ppm, enquanto que no epímero $16 \beta$ os mesmos ocorrem em $3,72 \mathrm{ppm}(d, J=7,0 \mathrm{~Hz})$ e $64,2 \mathrm{ppm}$, devido ao efeito anisotrópico do anel $\mathrm{C}$ ent-caurânico, que protege $\circ \mathrm{H}-17$ de $16 \alpha$ e desprotege $0 \mathrm{H}-17$ de $16 \beta$ (YANG et al., 2002).

Tabela 20 - Dados de RMN de ${ }^{13} \mathrm{C}$ de 80 e $81\left(\mathrm{CDCl}_{3}, 4,7 \mathrm{~T}\right)$ e dos ácidos ent-caurenóico e 17-hidroxi-16 $\alpha$-ent-cauran-19-óico.

\begin{tabular}{ccccc}
\hline & \multicolumn{3}{c}{${ }^{13} \mathbf{C}$ (ppm) } \\
\cline { 2 - 5 } Posição & $\mathbf{8 0}$ & $\begin{array}{c}\text { Ác. caurenóico } \\
\text { (LU et al., 1995) }\end{array}$ & $\mathbf{8 1}$ & $\begin{array}{c}\text { Ác. 17-hidroxi-16 } \alpha- \\
\text { ent-cauran-19-óico } \\
\text { (WU et al., 1996) }\end{array}$ \\
\hline 1 & 41,3 & 41,3 & 41,6 & 42,0 \\
2 & 19,1 & 19,1 & 19,1 & 19,1 \\
3 & 39,6 & 39,7 & 37,2 & 37,2 \\
4 & 43,7 & 43,7 & 44,7 & 44,7 \\
5 & 55,1 & 55,1 & 56,9 & 56,9 \\
6 & 21,8 & 21,8 & 22,4 & 22,4 \\
7 & 40,7 & 40,7 & 40,7 & 40,7 \\
8 & 44,2 & 44,2 & 43,7 & 43,7 \\
9 & 57,0 & 57,1 & 55,3 & 55,3 \\
10 & 39,6 & 39,7 & 39,6 & 39,6 \\
11 & 18,4 & 18,4 & 18,9 & 18,9 \\
12 & 33,1 & 33,1 & 31,4 & 31,4 \\
13 & 43,8 & 43,9 & 38,1 & 38,1 \\
14 & 37,8 & 37,8 & 37,8 & 37,8 \\
15 & 48,9 & 49,0 & 45,0 & 45,0 \\
16 & 155,9 & 155,9 & 43,3 & 43,1 \\
17 & 103,0 & 103,0 & 67,5 & 67,4 \\
18 & 29,0 & 29,0 & 28,9 & 28,9 \\
19 & 183,4 & 183,8 & 183,6 & 183,7 \\
20 & 15,6 & 15,6 & 15,6 & 15,5 \\
\hline
\end{tabular}




\subsubsection{Substâncias 82 e 83}

Os espectros de RMN de ${ }^{1} \mathrm{H}$ de ambas as substâncias (Espectros 50 e 51, p. 157 e 158) apresenta três singletos em $\delta 0,69, \delta 0,77$ e $\delta 0,99$, correspondentes a grupos metílicos quaternários, juntamente com um duplo dubleto centrado em 3,27 ppm $(J=4,4$ e $11 \mathrm{~Hz})$ e singletos em 4,53 e 4,84 ppm, que se referem a hidrogênios metilênicos exocíclicos. No espectro de 82 verifica-se ainda um dubleto em $\delta 4,15$ e um multipleto em $\delta 5,40$, estes ausentes no espectro de 83. Uma outra diferença entre os espectros dessas substâncias reside na presença de um singleto em 1,67 ppm em 82 e de um singleto em 2,17 ppm em 83.

Nos espectros de RMN de ${ }^{13} \mathrm{C}$ dessas substâncias (Espectros 52 e 53, p. 159 e 160) verificam-se 20 sinais distintos, cujos deslocamentos químicos evidenciam a existência de um esqueleto ent-labdânico oxigenado em C-3 e com insaturações nas posições C-8/C-17 (ligação dupla exocíclica) e C-13/C-14. O sinal $\delta$ 59,4 sugere a presença de um carbono carbinólico primário em $\mathbf{8 2}$, enquanto que a absorção em 171,2 ppm sugere a existência de uma função ácida conjugada a uma ligação dupla em 83. Em ambos os espectros verifica-se ainda um sinal em 78,9 ppm, que pode ser atribuído a um carbono carbinólico secundário.

A comparação dos dados de ressonância com os descritos na literatura permitiu identificar as substâncias 82 e 83 como sendo ent-8(17),13E-labdadieno-3 $\alpha, 15$-diol e do ácido 3 $\alpha$-hidroxi-ent-8(17),13E-labdadieno-15-óico, respectivamente. Este é o primeiro relato sobre a ocorrência de 83 em O. platyspermum.

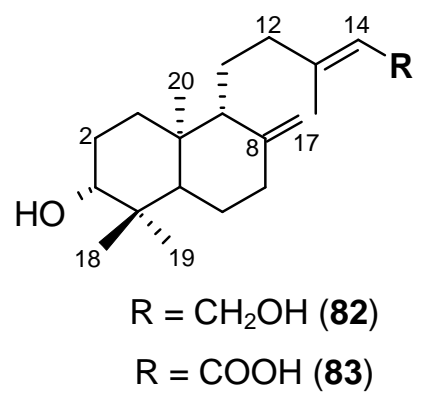

Figura 22. Estrutura molecular das substâncias 82 e 83. 
Tabela 21 - Dados de RMN de ${ }^{1} \mathrm{H}$ das substâncias 82 e $83\left(\mathrm{CDCl}_{3}, 4,7 \mathrm{~T}\right)$.

\begin{tabular}{ccc}
\hline \multirow{2}{*}{ Posição } & \multicolumn{3}{c}{$\mathbf{H}$} \\
\cline { 2 - 3 } & $\mathbf{8 2}(\mathbf{p p m})$, multiplicidade, $\boldsymbol{J}(\mathbf{H z})$ \\
\hline 3 & $3,26(d d, 4,6$ e 11$)$ & $\mathbf{8 3}$ \\
14 & $5,40(t, 7,0)$ & $3,27(d d, 4,4$ e 11$)$ \\
15 & $4,15(d, 6,9)$ & $5,67(s)$ \\
16 & $1,67(s)$ & - \\
17 & $4,53(s)$ e $4,84(s)$ & $2,17(s)$ \\
18 & $0,99(s)$ & $4,52(s)$ e $4,88(s)$ \\
19 & $0,77(s)$ & $1,00(s)$ \\
20 & $0,69(s)$ & $0,78(s)$ \\
\hline
\end{tabular}

O posicionamento da hidroxila em $3 \alpha$ nas substâncias 82 e 83 é corroborado pela análise da multiplicidade de $\mathrm{H}-3 \beta(d d, J=4,6$ e $11 \mathrm{~Hz})$, uma vez que nos epímeros $3 \beta$ observa-se um tripleto em torno de $\delta 3,44(J=3 \mathrm{~Hz})$ para $\mathrm{H}-3 \alpha$.

Tabela 22 - Dados de RMN de ${ }^{13} \mathrm{C}$ de $82\left(\mathrm{CDCl}_{3}, 4,7 \mathrm{~T}\right), 83\left(\mathrm{CDCl}_{3}, 705 \mathrm{~T}\right)$, ent-8(17),13Elabdadieno-3 $\alpha, 15$-diol e do ácido $3 \alpha$-hidroxi-ent-8(17),13E-labdadieno-15-óico.

\begin{tabular}{|c|c|c|c|c|}
\hline \multirow[b]{2}{*}{ Posição } & \multicolumn{4}{|c|}{${ }^{13} \mathrm{C}$ (ppm) } \\
\hline & 82 & $\begin{array}{l}\text { ent-8(17),13E- } \\
\text { labdadieno-3a,15-diol } \\
\text { (KONISHI et al., 1996) }\end{array}$ & 83 & $\begin{array}{l}\text { Ac. } 3 \alpha \text {-hidroxi-ent-8(17),13E- } \\
\text { labdadieno-15-oico } \\
\text { (ZDERO et al., 1992) }\end{array}$ \\
\hline 1 & 37,0 & 37,0 & 37,3 & 37,1 \\
\hline 2 & 27,9 & 27,9 & 28,0 & 27,8 \\
\hline 3 & 78,8 & 78,8 & 78,9 & 78,9 \\
\hline 4 & 39,1 & 39,1 & 39,3 & 39,2 \\
\hline 5 & 54,6 & 54,5 & 54,8 & 54,7 \\
\hline 6 & 24,0 & 24,0 & 24,2 & 24,0 \\
\hline 7 & 38,3 & 38,3 & 38,3 & 38,2 \\
\hline 8 & 147,9 & 147,9 & 147,8 & 147,7 \\
\hline 9 & 59,4 & 56,0 & 56,1 & 56,0 \\
\hline 10 & 39,3 & 39,3 & 39,6 & 39,5 \\
\hline 11 & 21,9 & 21,9 & 21,8 & 21,7 \\
\hline 12 & 38,1 & 38,1 & 40,1 & 40,0 \\
\hline 13 & 140,4 & 140,4 & 163,9 & 163,7 \\
\hline 14 & 123,1 & 123,0 & 114,9 & 114,9 \\
\hline 15 & 59,4 & 59,4 & 171,2 & 171,4 \\
\hline 16 & 16,3 & 16,3 & 19,4 & 19,2 \\
\hline 17 & 106,7 & 106,7 & 107,0 & 106,9 \\
\hline 18 & 28,3 & 28,2 & 28,5 & 28,3 \\
\hline 19 & 15,4 & 15,4 & 15,6 & 15,4 \\
\hline 20 & 14,5 & 14,5 & 14,7 & 14,6 \\
\hline
\end{tabular}


4.1.4 Derivados do ácido cinâmico

\subsubsection{Substância 17}

A análise dos espectros de RMN de ${ }^{1} \mathrm{H}$ e ${ }^{13} \mathrm{C}$ da substância 17 (Espectros 54 e 55, p. 161 e 162) permitiu caracterizá-la como sendo o ácido cis-cafêico. A observação de dois dubletos centrados em $\delta 6,18$ e $\delta 8,11$ (1H cada) com constantes de acoplamento de $6 \mathrm{~Hz}$ sugere a presença do sistema cis-alceno, uma vez que o isômero trans apresenta constante em torno de $10 \mathrm{~Hz}$. Além disso, os sinais em 6,77 ppm (d, $J=2,2 \mathrm{~Hz}), 7,83(d, J=8,6 \mathrm{~Hz})$ e $6,86(d d, J=2,2$ e $8,8 \mathrm{~Hz}$ ) sugerem a presença de um anel aromático 1,3,4-trissubstituído. Os sinais verificados no espectro de RMN de ${ }^{13} \mathrm{C}$ dessa substância confirmam a estrutura proposta.

Embora existam relatos na literatura sobre a ocorrência dos isômeros cis de fenilpropanóides como produto natural (WONG et al., 2005), acredita-se que a substância 17 tenha sido formada a partir da isomerização por luz do ácido trans-cafêico.<smiles>O=C(O)/C=C\c1ccc(O)c(O)c1</smiles>

Figura 23. Estrutura molecular do ácido cis-cafêico.

Tabela 23 - Dados de RMN de ${ }^{1} \mathrm{H}$ e ${ }^{13} \mathrm{C}\left(\mathrm{DMSO}_{-} \mathrm{d}_{6}, 4,7 \mathrm{~T}\right)$ da substância 17.

\begin{tabular}{ccc}
\hline Posição & $\delta(\mathbf{p p m})$, multiplicidade, $\boldsymbol{J}(\mathbf{H z})$ & ${ }^{13} \mathbf{C}$ \\
\hline 1 & - & 116,6 \\
2 & $6,77(d, 2,2)$ & 102,5 \\
3 & - & 158,2 \\
4 & - & 156,1 \\
5 & $7,83(d, 8,6)$ & 126,7 \\
6 & $6,86(d d, 2,2$ e 8,8) & 115,8 \\
7 & $8,11(d, 6,0)$ & 164,4 \\
8 & $6,17(d, 6,2)$ & 112,1 \\
9 & - & 175,8 \\
\hline
\end{tabular}




\subsubsection{Flavonóides}

Os flavonóides constituem um dos grupos de compostos polifenólicos mais diversificados entre os produtos de origem natural, apresentando como esqueleto básico dois núcleos aromáticos conectados por uma ponte de três átomos de carbono $\left(\mathrm{C}_{6}-\mathrm{C}_{3}-\mathrm{C}_{6}\right)$. Os diferentes tipos de flavonóides variam de acordo com o estado de oxidação da unidade $\mathrm{C}_{3}$. Em geral, os flavonóides de origem natural apresentam-se oxigenados, sendo que um grande número ocorre conjugado com açúcares (ZUANAZZI, 2001; VALDERRAMA, 2000).

A presença de flavonóides na família Myristicaceae é menos comum do que em outras famílias de Angiospermas, porém a ocorrência de certas classes de flavonóides é típica de alguns gêneros e pode ser usada para estabelecer relações quimiotaxonômicas. Os tipos de flavonóides frequentemente encontrados nas miristicáceas incluem chalconas, flavanonas, flavonas, dihidroflavonóis, flavonóis, flavanas, 3-flavonóis, 1,3-diarilpropanos (virolanos), 1,3-diaril-2-propanóis (virolanóis), dihidrochalconas, isoflavonas e pterocarpanos (VALDERRAMA, 2000).

A ocorrência de dihidrochalconas e flavonolignóides, também denominados irianterinas, é uma característica quimiotaxonômica do gênero Iryanthera.

\subsubsection{Substância 18}

O espectro de RMN de ${ }^{1} \mathrm{H}$ da substância 18 (Espectro 56, p. 163) mostra dois dubletos em $\delta 7,95(8,8 \mathrm{~Hz})$ e $\delta 6,26(2,6 \mathrm{~Hz})$, que juntamente com o duplo dubleto centrado em $\delta$ 6,39 (2,6 e 8,8 Hz) caracterizam um anel aromático 1,2,4-trissubstituído. Observam-se ainda dois dubletos em 7,62 ppm $(8,8 \mathrm{~Hz})$ e $6,84 \mathrm{ppm}(8,8 \mathrm{~Hz})$, e dois dubletos em 7,78 ppm e 7,60 ppm, cujas constantes de acoplamento $(15 \mathrm{~Hz})$ sugerem a presença de uma ligação dupla trans.

O espectro de RMN de ${ }^{13} \mathrm{C}$ dessa substância (Espectro 57, p. 164) apresenta treze carbonos distintos, dentre os quais os sinais em $\delta 145,6, \delta 118,8$ e $\delta 193,6$ caracterizam os carbonos $\beta$, $\alpha$ e $\beta$ ', respectivamente, de chalconas. Comparando-se os valores dos demais 
sinais observados no espectro de $\mathbf{1 8}$ com os descritos na literatura, foi possível identificá-la como sendo a chalcona denominada isoliquiritigenina (2',4,4'-tri-hidroxi-chalcona).<smiles>O=C(C=Cc1ccc(O)cc1)c1ccc(O)cc1O</smiles>

Figura 24. Estrutura molecular da isoliquiritigenina.

Tabela 24 - Dados de RMN de ${ }^{1} \mathrm{H}\left(\mathrm{CD}_{3} \mathrm{OD}, 4,7 \mathrm{~T}\right)$ e ${ }^{13} \mathrm{C}\left(\mathrm{CD}_{3} \mathrm{OD}, 7,05 \mathrm{~T}\right)$ da substância 18 e $\mathrm{RMN}$ de ${ }^{13} \mathrm{C}$ da isoliquiritigenina.

\begin{tabular}{cccc}
\hline \multirow{2}{*}{ Posição } & ${ }^{\mathbf{1}} \mathbf{H}(\mathbf{p p m})$, multiplicidade, $\boldsymbol{J}(\mathbf{H z})$ & \multicolumn{1}{c}{${ }^{\mathbf{3}} \mathbf{C}(\mathbf{p p m})$} \\
\cline { 2 - 4 } & $\mathbf{1 8}$ & $\mathbf{1 8}$ & $\begin{array}{c}\text { Isoliquiritigenina } \\
\text { (VEITCH et al., 2003) }\end{array}$ \\
\hline 1 & - & 127,7 & 128,0 \\
2 e 6 & $7,62(d, 8,8)$ & 132,1 & 131,8 \\
3 e 5 & $6,84(d, 8,8)$ & 117,6 & 117,0 \\
4 & - & 161,7 & 161,7 \\
$\beta$ & $7,78(d, 15,4)$ & 145,6 & 145,5 \\
$\alpha$ & $7,60(d, 15,0)$ & 118,8 & 118,5 \\
$\beta^{\prime}$ & - & 193,6 & 193,4 \\
$1^{\prime}$ & - & 114,2 & 114,5 \\
$2^{\prime}$ & - & 167,6 & 167,4 \\
$3^{\prime}$ & $6,26(d, 2,6)$ & 104,0 & 104,1 \\
$4^{\prime}$ & - & 167,6 & 167,4 \\
$5^{\prime}$ & $6,39(d d, 2,6$ e 8,8$)$ & 109,6 & 109,6 \\
$6^{\prime}$ & $7,95(d, 8,8)$ & 133,4 & 133,4 \\
\hline
\end{tabular}

\subsubsection{Substâncias 19 e 20}

O espectro de RMN de ${ }^{1} \mathrm{H}$ das substâncias 19 e 20 (Espectros 58 e 59, p. 164 e 166) apresenta três duplos dubletos em $\delta 5,37 \pm 0,02, \delta 3,04 \pm 0,02$ e $\delta 2,58 \pm 0,01$, os quais caracterizam o anel $\mathrm{C}$ de uma flavanona. O padrão de substituição do anel $\mathrm{A}$ das flavanonas foi determinado pela observação de um dubleto em $7,45 \pm 0,15$ ppm, que juntamente com duplo dubleto em $6,45 \pm 0,03$ ppm e o dubleto em $6,24 \pm 0,03$ ppm sugere um sistema $A B X$. $A$ diferença entre as duas substâncias reside na substituição do anel B das mesmas, uma vez 
que 19 não possui este anel substituído, enquanto que 20 apresenta grupos hidroxilas nas posições 3' e 4'.

O padrão de substituição dessas substâncias também é evidenciado por seus respectivos espectros de $\mathrm{RMN}$ de ${ }^{13} \mathrm{C}$ (Espectros 60 e 61, p. 167 e 168). A substância 19 apresenta apenas 12 carbonos, uma vez que a existência de dois planos de simetria no anel B desta molécula faz com que haja coincidência da região de absorção dos carbonos 1'/4', 2'/6' e 3'/5'. O que não é observado no espectro de 20 , no qual é possível verificar 15 absorções distintas. Os espectros de massa obtidos por ESI/EM (Espectros 62A e 62B, p. 169), juntamente com a comparação dos dados de RMN com os descritos na literatura permitiu identificar as substâncias 19 e 20 como sendo a liquiritigenina e a butina, respectivamente. Tais flavanonas ainda não haviam sido isoladas de O. platyspermum.<smiles>[R]c1cc(C2CC(=O)c3ccc(O)cc3O2)ccc1[R]O</smiles>

Figura 25. Estruturas moleculares das substâncias 19 e 20.

Tabela 25 - Dados de RMN de ${ }^{1} \mathrm{H}$ das substâncias 19 e $20\left(\mathrm{CD}_{3} \mathrm{OD}, 4,7 \mathrm{~T}\right)$.

\begin{tabular}{ccc}
\hline \multirow{2}{*}{ Posição } & \multicolumn{2}{c}{$\delta(\mathbf{p p m})$, multiplicidade, $\boldsymbol{J}(\mathbf{H z})$} \\
\cline { 2 - 3 } & $\mathbf{1 9}$ & $\mathbf{2 0}$ \\
\hline 2 & $5,39(d d, 2,6$ e 12,7$)$ & $5,36(d d, 3,1$ e 12,6$)$ \\
3ax. & $3,06(d d, 12,7$ e 16,7$)$ & $3,02(d d, 12,8$ e 16,6$)$ \\
3eq. & $2,57(d d, 3,1$ e 16,7$)$ & $2,59(d d, 3,1$ e 16,8$)$ \\
5 & $7,30(d, 8,7)$ & $7,70(d, 8,8)$ \\
6 & $6,42(d d, 2,2$ e 8,7$)$ & $6,58-6,45(m)$ \\
8 & $6,24(d, 2,2)$ & $6,33(s)$ \\
$2^{\prime}$ & $7,58(d, 8,4)$ & $6,87(s)$ \\
$3^{\prime}$ & $6,77(d, 8,4)$ & - \\
$4^{\prime}$ & - & - \\
$5^{\prime}$ & $6,77(d, 8,4)$ & $6,73(s)$ \\
$6^{\prime}$ & $7,58(d, 8,4)$ & $6,73(s)$ \\
\hline
\end{tabular}


Tabela 26 - Dados de RMN de ${ }^{13} \mathrm{C}\left(\mathrm{CD}_{3} \mathrm{OD}, 4,7 \mathrm{~T}\right)$ das substâncias 19 e 20 e das flavanonas liquiritigenina e butina.

\begin{tabular}{ccccc}
\hline \multirow{2}{*}{ Posição } & \multicolumn{4}{c}{${ }^{\mathbf{1 3} \mathbf{C}(\mathbf{p p m})}$} \\
\cline { 2 - 5 } & $\mathbf{1 9}$ & $\begin{array}{c}\text { Liquiritigenina } \\
\text { (YOUSSEF et al., 1998) }\end{array}$ & $\mathbf{2 0}$ & $\begin{array}{c}\text { Butina } \\
\text { (TIAN et al., 2004) }\end{array}$ \\
\hline 2 & 81,0 & 81,0 & 81,0 & 81,1 \\
3 & 44,9 & 44,9 & 45,0 & 45,0 \\
4 & 193,5 & 193,5 & 193,5 & 193,5 \\
5 & 129,8 & 129,8 & 129,8 & 129,6 \\
6 & 111,9 & 111,7 & 112,2 & 112,0 \\
7 & 167,3 & 166,9 & 167,9 & 167,0 \\
8 & 103,9 & 103,8 & 103,9 & 103,6 \\
9 & 165,6 & 165,3 & 165,6 & 165,5 \\
10 & 114,8 & 114,9 & 114,7 & 115,0 \\
$1 '$ & 131,4 & 131,3 & 132,1 & 132,1 \\
2 & 129,0 & 129,0 & 114,6 & 114,7 \\
$3^{\prime}$ & 116,3 & 116,3 & 146,5 & 146,5 \\
4 & 159,0 & 156,8 & 146,8 & 146,8 \\
$5^{\prime}$ & 116,3 & 116,3 & 116,3 & 116,3 \\
$6 '$ & 129,0 & 129,0 & 119,2 & 119,2 \\
\hline
\end{tabular}

\subsubsection{Substância 21}

No espectro de RMN de ${ }^{1} \mathrm{H}$ da substância 21 (Espectro 63, p. 170) é possível observar um dubleto em $\delta 7,84(J=8,4 \mathrm{~Hz}, 1 \mathrm{H})$, um singleto largo 7,37 ppm $(2 \mathrm{H})$, juntamente com sinais não definidos na região entre $6,85-6,91$ ppm e um singleto em $\delta$ 6,59 $(1 \mathrm{H})$, sinal este característico do hidrogênio H-3 de flavonas.

O espectro de RMN de ${ }^{13} \mathrm{C}$ dessa substância (Espectro 64, p. 171) apresenta catorze sinais distintos, sendo que as absorções em $\delta 162,8$, $\delta$ 104,7 e $\delta 176,4$, confirmam a presença de uma flavona, uma vez que estas são as regiões de absorção dos carbonos 2, 3 e 4 , respectivamente, dessa classe de compostos. A comparação dos demais sinais de ${ }^{13} \mathrm{C}$ com os descritos na literatura, permitiu identificar a substância 21 como sendo a 3',4',7-trihidroxi-flavona. 
<smiles>O=c1cc(-c2ccc(O)c(O)c2)oc2cc(O)ccc12</smiles>

Figura 26. Estrutura molecular da 3',4',7-tri-hidroxi-flavona.

Tabela 27 - Dados de RMN de ${ }^{1} \mathrm{H}$ e ${ }^{13} \mathrm{C}$ (DMSO- $\left.d_{6}, 4,7 \mathrm{~T}\right)$ da substância 21 e da 3', 4',7-trihidroxi-flavona.

\begin{tabular}{|c|c|c|c|}
\hline \multirow[b]{2}{*}{ Posição } & \multirow{2}{*}{$\begin{array}{c}{ }^{1} \mathrm{H} \text { (ppm), multiplicidade, } J(\mathrm{~Hz}) \\
21\end{array}$} & \multicolumn{2}{|r|}{${ }^{13} \mathrm{C}$ (ppm) } \\
\hline & & 21 & $\begin{array}{l}\text { 3',4',7-tri-hidroxi-flavona } \\
\text { (CHAMSUKSAl et al., 1981) }\end{array}$ \\
\hline 2 & - & 162,8 & 163,0 \\
\hline 3 & $6,59(s)$ & 104,7 & 104,8 \\
\hline 4 & - & 176,4 & 176,6 \\
\hline 5 & $7,86(d, 9)$ & 126,7 & 126,2 \\
\hline 6 & $6,90(d d, 3$ e 9$)$ & 114,9 & 114,6 \\
\hline 7 & - & 162,8 & 162,8 \\
\hline 8 & $6,92(s)$ & 102,5 & 102,5 \\
\hline 9 & - & 157,6 & 157,6 \\
\hline 10 & - & 116,2 & 116,0 \\
\hline $1^{\prime}$ & - & 122,3 & 122,2 \\
\hline 2 & $7,37-7,39(m)$ & 113,4 & 113,2 \\
\hline 3 & - & 145,9 & 145,8 \\
\hline $4^{\prime}$ & - & 149,4 & 149,1 \\
\hline 5 & $7,37-7,39(m)$ & 116,3 & 116,2 \\
\hline $6^{\prime}$ & $7,37-7,39(m)$ & 118,7 & 118,2 \\
\hline
\end{tabular}

\subsubsection{Substância 22}

O espectro de RMN de ${ }^{1} \mathrm{H}$ da substância 22 (Espectro 65, p. 172) apresenta absorções típicas de um diidroflavonol glicosilado, no qual a ramnose é a unidade glicosílica.

A presença dos dubletos centrados em $\delta 5,23(J=9,7 \mathrm{~Hz})$ e $\delta 4,65(J=9,7 \mathrm{~Hz})$ é característica dos prótons H-3 e H-2 de diidroflavonóis, respectivamente. A observação de dois dubletos em 5,89 ppm $(J=1,74 \mathrm{~Hz})$ e $5,87 \mathrm{ppm}(J=1,76 \mathrm{~Hz})$, ambos correspondentes a um hidrogênio cada, caracterizam um anel aromático 1,3,4,5-tetrassubstituído. Observam- 
se ainda dois singletos em $\delta 6,87(1 \mathrm{H})$ e em $\delta 6,72(2 \mathrm{H})$, cujas atribuições são mostradas na Tabela 28.

A presença da ramnose é confirmada pela observação do dubleto em $\delta 1,03(\mathrm{~J}=$ 6,14 Hz, H-6"), juntamente com o singleto largo em 4,00 ppm ( $\mathrm{H}-1$ ") e o conjunto de sinais na região entre 3,06-3,91 ppm. Além disso, observa-se no espectro de $\mathrm{RMN}$ de ${ }^{13} \mathrm{C}$ dessa substância, as absorções em $\delta 17,9$ e $\delta 100,3$, que correspondem respectivamente ao grupo metílico e ao carbono anomérico da ramnose, cujos demais sinais são observados em torno de 70 ppm (4 sinais) (Espectro 66, p. 173). A configuração $\alpha$ da ramnose é sugerida pela observação do singleto largo em 4,00 ppm.

As absorções observadas em ambos os espectros de RMN da substância 22, juntamente com a observação do pico referente à molécula cationizada com $\mathrm{Na}(473,1$ u.m.a.) (Espectro 67, p. 174), são condizentes com os dados disponíveis na literatura para o composto conhecido como astilbina (3-O- $\alpha$-L-ramnosil di-hidroquercetina). A determinação da configuração relativa foi baseada nas constantes de acoplamento entre H-2 e H-3 (9,7 $\mathrm{Hz}$ ), o que indica uma relação trans entre eles.

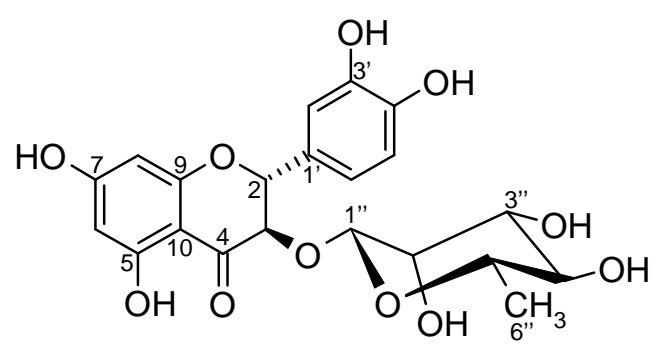

Figura 27. Estrutura molecular da astilbina.

O valor de $[\alpha]_{D}=-13,2$ (c. 0,76, metanol) encontrado para a substância 22 possibilita a identificação desse di-hidroflavonol como $(2 R, 3 R) 5,7,3^{\prime}, 4^{\prime}$-tetra-hidroxi-3- $\alpha$-O-ramnose (DU et al. 2005). 
Tabela 28 - Dados de RMN de ${ }^{1} \mathrm{H}$ e ${ }^{13} \mathrm{C}\left(\mathrm{DMSO}-d_{6}, 4,7 \mathrm{~T}\right)$ da substância 22 e da astilbina.

\begin{tabular}{|c|c|c|c|}
\hline \multirow[b]{2}{*}{ Posição } & \multirow{2}{*}{$\begin{array}{c}{ }^{1} \mathrm{H}(\mathrm{ppm}), \text { multiplicidade, } J(\mathrm{~Hz}) \\
23\end{array}$} & \multicolumn{2}{|c|}{${ }^{13} \mathrm{C}$ (ppm) } \\
\hline & & 23 & $\begin{array}{c}\text { Astilbina } \\
\text { (DU et al., 2005) }\end{array}$ \\
\hline 2 & $5,23(d, 9,7)$ & 81,7 & 81,5 \\
\hline 3 & $4,65(d, 9,7)$ & 75,8 & 75,6 \\
\hline 4 & - & 194,8 & 194,3 \\
\hline 5 & - & 163,6 & 163,4 \\
\hline 6 & $5,89(d, 1,7)$ & 96,2 & 96,1 \\
\hline 7 & - & 167,2 & 167,2 \\
\hline 8 & $5,87(d, 1,7)$ & 95,2 & 95,1 \\
\hline 9 & - & 162,4 & 162,1 \\
\hline 10 & - & 100,3 & 100,7 \\
\hline 11 & - & 127,1 & 127,0 \\
\hline 1 ' & - & 114,9 & 114,7 \\
\hline $2^{\prime}$ & $6,87(s)$ & 81,7 & 81,5 \\
\hline $3^{\prime}$ & - & 145,3 & 145,1 \\
\hline $4^{\prime}$ & - & 146,1 & 145,9 \\
\hline $5^{\prime}$ & $6,72(s)$ & 115,5 & 115,3 \\
\hline $6^{\prime}$ & $6,72(s)$ & 119,1 & 118,9 \\
\hline $1 "$ & $4,00(s)$ & 100,2 & 100,0 \\
\hline 2" & $3,40(d d, 3,1$ e 9,2$)$ & 70,3 & 70,1 \\
\hline 3" & $3,32(s)$ & 70,6 & 70,4 \\
\hline $4 "$ & $3,11(t)$ & 71,8 & 71,6 \\
\hline $5 "$ & $3,87(d d, 6,2$ e 9,2$)$ & 69,1 & 68,9 \\
\hline $6 "$ & $1,03(d, 6,2)$ & 17,9 & 17,7 \\
\hline
\end{tabular}

\subsection{Atividade antimalárica dos lignóides}

A malária é uma doença infecciosa causada por protozoários do gênero Plasmodium que constitui uma das enfermidades tropicais que mais afeta a população da África, e de algumas regiões da Ásia e das Américas Central e do Sul.

Conforme dados do Ministério da Saúde, estima-se que a malária mate mais de um milhão de pessoas no mundo, sendo crianças menores de cinco anos as principais vítimas. Cerca de 40 \% de toda a população mundial vive em zonas de risco, mas a maior incidência dos casos ocorre na África Subsahariana, que abrange os países de população negra situados ao sul do deserto do Saara. No Brasil a maior incidência da doença é na Amazônia Legal, onde se concentram 99,5 \% dos casos registrados no país. 
Devido à resistência de formas dos parasitos frente a medicamentos utilizados no tratamento da malária, na década passada, houve uma intensificação na busca por substâncias com ação antiplasmódica de origem natural, especialmente de plantas, que representam uma importante fonte de compostos biologicamente ativos e com diversidade estrutural, podendo fornecer protótipos para o desenvolvimento de novas drogas no combate à doença. Entre as diversas classes de metabólitos secundários que apresentam promissora atividade antimalárica, se encontra a dos lignóides (BILIA, 2006; DA SILVA FILHO et al., 2008).

Dentre os lignóides isolados neste trabalho, somente os relacionados na Tabela 29 foram submetidos ao ensaio de inibição de crescimento das cepas multiresistentes $\mathrm{K} 1$ de $P$. falciparum. Conforme pode ser observado, somente os compostos $\mathbf{3}$ e $\mathbf{4}$ foram ativos nas duas concentrações testadas, chamando atenção para o esqueleto di-hidrobenzofurânico. Embora estes sejam resultados interessantes e promissores, há a necessidade de investigações mais aprofundadas no futuro.

Tabela 29 - Porcentagem de inibição do crescimento in vitro da cepa K1 de $P$. falciparum frente às amostras testadas.

\begin{tabular}{|c|c|c|c|}
\hline \multirow{2}{*}{ Lignóides } & \multicolumn{2}{|c|}{ \% de inibição } & \multirow{2}{*}{$\begin{array}{l}\text { Classificação } \\
\text { da atividade }\end{array}$} \\
\hline & $50 \mu \mathrm{g} / \mathrm{mL}$ & $2,5 \mu \mathrm{g} / \mathrm{mL}$ & \\
\hline carinatina (1) & 56,0 & 14,4 & I \\
\hline carinatidina (2) & 46,2 & 35,4 & I \\
\hline diidrocarinatina (3) & 84,8 & 65,7 & $A$ \\
\hline diidrocarinatidina (4) & 82,9 & 58,4 & $A$ \\
\hline deidrodieugenol (5) & 43,7 & 0,0 & I \\
\hline galgravina (6) & 27,8 & 0,0 & I \\
\hline galbelgina (9) & 4,8 & 0,0 & I \\
\hline guaiacina (14) & 36,4 & 23,9 & I \\
\hline
\end{tabular}

Legenda: (A) ativa - 80 a 100\%; (PA) parcialmente ativa - 50 a 79\%; (I) inativa - <50\%.

Recentemente foi divulgada a moderada atividade antimalárica da lignana tetraidrofurânica calopeptina (138) e a inatividade das lignanas galgravina (6), nectandrina A (7) e nectandrina B (8), todas estas isoladas da laurácea Nectandra megapotamica (DA SILVA FILHO et al., 2008). 


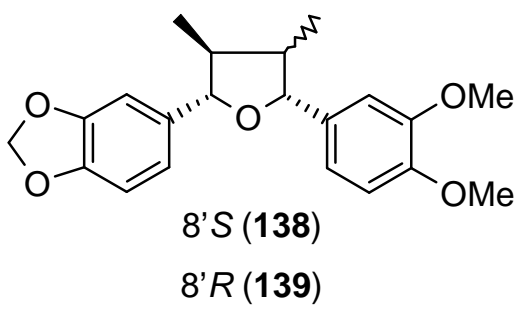

Figura 28. Estruturas moleculares da calopeptina e da machilina G.

\subsection{Atividade leishmanicida dos lignóides}

As leishmanioses são doenças parasitárias não contagiosas causadas por protozoários do gênero Leishmania, que constituem um grande problema de saúde pública. De acordo com a OMS, as leishmanioses podem ser classificadas em visceral, cutânea, mucocutânea e cutânea difusa, sendo as formas cutânea e mucocutânea as que prevalecem no Brasil.

A leishmaniose mucocutânea, também conhecida como Leishmaniose Tegumentar Americana (LTA), é causada pelo Leishmania braziliensis e apresenta ampla distribuição com registro de casos em todas as regiões brasileiras, enquanto que a leishmaniose cutânea, cujo agente etiológico é o L. amazonensis, se concentra em áreas de florestas primárias e secundárias da Amazônia Legal, ocorrendo ainda nos estados da Bahia, Goiás, Minas Gerais, São Paulo e Paraná (Ministério da Saúde, 2007).

A alta toxicidade, bem como o aparecimento de formas resistentes dos parasitos diante aos medicamentos atualmente empregados no tratamento das leishmanioses, aumenta a importância de pesquisas visando à descoberta de novos fármacos para o tratamento dessas doenças. A moderada atividade in vitro contra formas promastigotas e amastigotas de $L$. donovani apresentada pela surinamensina (85) tem estimulado a avaliação da atividade leishmanicida de lignóides (BARATA et al., 2000).

Segundo DA SILVA FILHO et al. (2008), as lignanas machilina G (139) e veraguensina (86) apresentaram atividade in vitro frente às formas promastigotas de $L$. 
donovani, ambas apresentando valores de $\mathrm{IC}_{50}$ e $\mathrm{IC}_{90}$ de 18 e $36 \mu \mathrm{g} / \mathrm{mL}$, respectivamente. Ainda de acordo com esses autores, os lignóides 6, 7 e 8 foram inativos.

Todos os lignóides isolados neste trabalho foram submetidos a teste de triagem frente às formas promastigotas de L. amazonensis, L. braziliensis e L. chagasi. Conforme mostrado na tabela abaixo, estes compostos não apresentaram atividade, com exceção das lignanas verrucosina (10) e guaiacina (14), que apresentaram valores de $\mathrm{IC}_{50}$ abaixo de 50 $\mu \mathrm{g} / \mathrm{mL}$ para a inibição de L. amazonensis, causadora da leishmaniose cutânea. Tais resultados estimulam a avaliação da atividade dessas duas substâncias frente às formas amastigotas de $L$. amazonensis, uma vez que são estas as formas clinicamente relevantes da doença.

Tabela 30 - Atividade leishmanicida in vitro dos lignóides isolados frente às formas promastigotas de Leishmania amazonensis, L. braziliensis e L. chagasi.

\begin{tabular}{cccc}
\hline \multirow{2}{*}{ Lignóides } & L. amazonensis & L. braziliensis & L. chagasi \\
\cline { 2 - 4 } & \multicolumn{3}{|c}{$\mathbf{C}_{50}(\mu \mathbf{g} / \mathbf{m L})$} \\
\hline carinatina (1) & $\geq 250$ & $\geq 250$ & $\geq 250$ \\
carinatidina (2) & 76 & $\geq 250$ & $\geq 250$ \\
diidrocarinatina (3) & 100 & $\geq 250$ & $\geq 250$ \\
diidrocarinatidina (4) & $\geq 250$ & $\geq 250$ & $\geq 250$ \\
deidrodieugenol (5) & 148 & 150 & $\geq 250$ \\
galgravina (6) & $\geq 250$ & $\geq 250$ & $\geq 250$ \\
nectandrina A (7) & $\geq 250$ & $\geq 250$ & $\geq 250$ \\
nectandrina B (8) & $\geq 250$ & $\geq 250$ & $\geq 250$ \\
galbelgina (9) & $\geq 250$ & $\geq 250$ & $\geq 250$ \\
verrucosina (10) & 27 & 100 & 170 \\
eritro (11) & 239 & 230 & $\geq 250$ \\
treo (12) & $\geq 250$ & $\geq 250$ & $\geq 250$ \\
guaiacina (14) & 45 & 98 & 184 \\
\hline
\end{tabular}

Embora os lignóides $\mathbf{1 0}$ e $\mathbf{1 4}$ tenham mostrado atividade promissora, é necessário realizar novos ensaios levando-se em consideração a reprodutibilidade dos resultados obtidos. 


\section{4 Óleos voláteis}

Conforme apresentado na Tabela 31, os rendimentos dos óleos essenciais obtidos das folhas e dos pericarpos das espécies em estudo variaram entre 0,005-0,39 \%. Os maiores rendimentos foram observados para os óleos de $O$. platyspermum, enquanto que a espécie $V$. pavonis apresentou um rendimento muito baixo em ambos os tecidos analisados.

Tabela 31 - Rendimento dos óleos essenciais das espécies em estudo.

\begin{tabular}{ccccc}
\hline Espécie & Parte da planta & $\begin{array}{c}\text { Material vegetal } \\
\text { seco }(\mathbf{g})\end{array}$ & Óleo volátil (mg) & Rendimento (\%) \\
\hline \multirow{2}{*}{ V. pavonis } & folhas & 138 & 31,6 & 0,02 \\
& pericarpos & 250 & 12,1 & 0,005 \\
\multirow{2}{*}{ I. juruensis } & folhas & 253 & 279 & 0,11 \\
\multirow{3}{*}{ O. platyspermum } & pericarpos & 246 & 126 & 0,05 \\
& folhas & 252 & 378 & 0,15 \\
& pericarpos & 261 & 1034 & 0,39 \\
\hline
\end{tabular}

Comparativamente, os óleos voláteis analisados apresentaram composição química distinta entre si. O. platyspermum forneceu óleos ricos em monoterpenos, enquanto que os sesquiterpenos foram predominantes nos espécimes de $I$. juruensis e $V$. pavonis.

Foram identificados 20 componentes tanto das folhas, quanto dos pericarpos de $\mathrm{V}$. pavonis, o que corresponde a 89,2 e $89,8 \%$ do total dos respectivos óleos. Dos compostos identificados das folhas dessa espécie, 70,5 \% correspondem a sesquiterpenos oxigenados, sendo o E-nerolidol (44,8 \%) e o $\alpha$-cadinol (21,2\%) os componentes majoritários. O óleo dos pericarpos de $V$. pavonis mostrou predominância de hidrocarbonetos sesquiterpênicos $(44,3 \%)$, embora tenha apresentado concentração expressiva de sesquiterpenos oxigenados (42,3\%). Ainda que o $\alpha$-cadinol (34,1\%) tenha sido detectado como um de seus componentes majoritários, o germacreno B (38,8\%) foi o constituinte mais abundante identificado nos pericarpos dessa espécie.

O óleo das folhas de I. juruensis mostrou-se constituído por 28 componentes, enquanto que 31 compostos foram identificados em seus pericarpos, o que corresponde a 
94,4 e $97,9 \%$, respectivamente, do total analisado. Os hidrocarbonetos sesquiterpênicos foram predominantes em ambos os óleos dessa espécie, embora a quantidade de monoterpenos e sesquiterpenos oxigenados também seja considerável em seus pericarpos. O $\beta$-cariofileno foi o principal componente detectado em ambos os tecidos (folhas: $57,0 \% \mathrm{e}$ pericarpos: $40,4 \%$, seguido do $\alpha$-humuleno $(12,1 \%)$ nas folhas e do linalool $(14,4 \%)$ nos pericarpos.

Das folhas de O. platyspermum foram detectados 33 compostos, dos quais $57,9 \%$ correspondem a hidrocarbonetos monoterpênicos e apenas 31,2 \% são referentes a sesquiterpenos. Os monoterpenos $\beta$-pineno (33,7 \%), $\alpha$-pineno $(8,9 \%)$ e limoneno $(8,8 \%)$ foram os principais componentes voláteis identificados nesse óleo. Dos 26 componentes identificados dos pericarpos dessa espécie, 72 \% são correspondentes a monoterpenos, sendo os monoterpenos oxigenados responsáveis por $42 \%$ desse total. Os principais constituintes identificados em seus pericarpos foram $\alpha$-terpineol (21,5\%), 4-terpineol (14,3 \%) e $\beta$-pineno $(9,9 \%)$.

Os únicos componentes detectados simultaneamente nos diferentes tecidos das espécies estudadas foram linalool, $\alpha$-epi-muurolol e $\alpha$-cadinol.

Fato interessante é ausência de fenilpropanóides nos óleos das espécies analisadas, uma vez que uma das características dos óleos essenciais de $V$. surinamensis é a presença da elemicina. Estudos sobre a ação antiinflamatória do óleo extraído das folhas dessa espécie têm demonstrado resultados satisfatórios, sendo a atividade observada atribuída a este fenilpropanóide (SANTOS, 2008). 
Tabela 32 - Composição química dos óleos voláteis das espécies em estudo.

\begin{tabular}{|c|c|c|c|c|c|c|c|}
\hline \multirow{2}{*}{ Composto } & \multirow{2}{*}{ IR } & \multicolumn{2}{|c|}{ V. pavonis } & \multicolumn{2}{|c|}{ I. juruensis } & \multicolumn{2}{|c|}{ O. platyspermum } \\
\hline & & folha & pericarpo & folha & pericarpo & folha & pericarpo \\
\hline$\alpha$-pineno (23) & 941 & - & - & 0,1 & 0,4 & 8,9 & 6,0 \\
\hline canfeno (24) & 948 & - & - & - & - & 0,2 & - \\
\hline$\beta$-pineno (25) & 980 & - & - & 0,3 & 0,7 & 33,7 & 9,9 \\
\hline mirceno (26) & 994 & 0,1 & - & 0,1 & 0,4 & 1,7 & 3,0 \\
\hline$\alpha$-felandreno (27) & 1005 & - & & - & 0,7 & - & - \\
\hline$\delta$-3-careno (28) & 1013 & - & - & - & - & 0,2 & 2,0 \\
\hline$\alpha$-terpineno (29) & 1020 & - & - & - & - & 0,4 & 1,1 \\
\hline$p$-cimeno $(\mathbf{3 0})$ & 1027 & - & - & - & 0,2 & 0,2 & 0,6 \\
\hline limoneno (31) & 1032 & - & - & 0,7 & 3,1 & 8,8 & 4,7 \\
\hline eucaliptol (32) & 1034 & - & - & - & - & - & 2,5 \\
\hline trans-ocimeno (33) & 1057 & - & - & - & - & 1,9 & - \\
\hline$\gamma$-terpineno $(\mathbf{3 4})$ & 1062 & 0,1 & - & - & - & 0,7 & 1,5 \\
\hline terpinoleno (35) & 1093 & - & - & - & - & 1,2 & 1,2 \\
\hline linalool (36) & 1100 & 1,2 & 2,8 & 0,1 & 14,4 & 0,2 & 1,9 \\
\hline$\alpha$-fenchol (37) & 1120 & 0,3 & - & - & - & - & 0,7 \\
\hline borneol (38) & 1175 & - & - & - & - & - & 1,1 \\
\hline 4-terpineol (39) & 1180 & - & - & - & 0,4 & 0,9 & 14,3 \\
\hline$\alpha$-terpineol (40) & 1191 & - & 0,3 & - & 1,2 & 4,6 & 21,5 \\
\hline nerol (41) & 1234 & - & - & - & 0,3 & - & - \\
\hline$\delta$-elemeno (42) & 1331 & - & - & 0,5 & - & 0,5 & - \\
\hline$\alpha$-cubebeno (43) & 1355 & 0,2 & - & 3,6 & 2,8 & 0,7 & 1,3 \\
\hline isoledeno (44) & 1377 & - & - & - & 0,4 & - & - \\
\hline$\beta$-cubebeno (45) & 1388 & - & - & 1,2 & - & - & - \\
\hline$\beta$-elemeno (46) & 1397 & - & - & 1,8 & 0,6 & 1,5 & - \\
\hline$\alpha$-gurjuneno (47) & 1399 & 2,6 & 1,1 & - & - & - & - \\
\hline$\beta$-cariofileno (48) & 1423 & - & - & 57,0 & 40,4 & 1,1 & - \\
\hline aromadendreno (49) & 1446 & 2,3 & 0,7 & 0,2 & - & - & - \\
\hline$\alpha$-humuleno (50) & 1458 & - & - & 12,1 & 8,6 & 0,4 & - \\
\hline trans-cadina-1(6),4-dieno (51) & 1480 & 1,7 & 0,8 & 0,4 & 0,7 & - & - \\
\hline$\gamma$-curcumeno $(52)$ & 1487 & 0,8 & - & - & - & - & - \\
\hline$\alpha$-amorfeno (53) & 1491 & - & - & 0,3 & - & 0,4 & - \\
\hline germacreno D (54) & 1496 & - & - & 3,0 & 1,8 & 3,5 & - \\
\hline$\beta$-selineno (55) & 1502 & 2,8 & - & - & - & 1,4 & - \\
\hline biciclogermacreno $(56)$ & 1512 & - & - & 4,7 & 0,6 & 3,6 & - \\
\hline isodauceno $(57)$ & 1514 & 2,1 & 0,8 & - & - & - & - \\
\hline$\beta$-bisaboleno (58) & 1516 & 2,5 & 0,6 & - & - & - & - \\
\hline$\beta$-curcumeno (59) & 1520 & 1,7 & 0,2 & 0,1 & - & 1,8 & 1,6 \\
\hline$\delta$-cadineno $(60)$ & 1529 & - & - & 2,5 & 3,2 & - & - \\
\hline zonareno $(61)$ & 1534 & - & - & 0,3 & 0,9 & - & - \\
\hline germacreno B (62) & 1571 & - & 38,8 & 1,0 & 0,6 & - & - \\
\hline E-nerolidol (63) & 1575 & 44,8 & - & - & - & - & - \\
\hline espatulenol (64) & 1588 & - & - & - & 0,8 & - & - \\
\hline óxido de cariofileno (65) & 1590 & - & - & 0,3 & 1,6 & 1,6 & 1,4 \\
\hline globulol (66) & 1607 & - & - & - & - & 3,7 & 1,9 \\
\hline guaiol (67) & 1610 & - & 0,2 & 0,6 & 0,7 & 1,8 & 3,5 \\
\hline 1-epi-cubenol (68) & 1634 & - & 0,2 & 0,7 & 2,3 & - & - \\
\hline$\gamma$-eudesmol (69) & 1645 & - & 0,5 & - & 0,7 & 0,8 & 4,7 \\
\hline$\alpha$-epi-cadinol (70) & 1649 & - & - & 0,6 & 1,8 & 1,2 & 1,6 \\
\hline$\alpha$-epi-muurolol (71) & 1653 & 0,3 & 0,6 & 0,4 & 1,4 & 1,0 & 1,0 \\
\hline$\alpha$-muurolol (72) & 1656 & - & - & 0,3 & 1,0 & 0,7 & 0,9 \\
\hline$\alpha$-eudesmol (73) & 1662 & 0,4 & 0,8 & 0,3 & - & 1,9 & 4,0 \\
\hline$\alpha$-cadinol (74) & 1665 & 21,2 & 34,1 & 1,2 & 4,9 & 3,6 & 3,6 \\
\hline epi- $\alpha$-bisabolol (75) & 1689 & 2,4 & 3,9 & - & - & - & - \\
\hline$\alpha$-bisabolol (76) & 1692 & 1,4 & 2,0 & - & - & - & - \\
\hline cis-farnesol (77) & 1693 & 0,3 & 0,9 & - & 0,3 & - & - \\
\hline n-heptadecano (78) & 1700 & - & 0,5 & - & - & - & - \\
\hline \multicolumn{2}{|c|}{ Hidrocarbonetos monoterpênicos } & 0,2 & - & 1,2 & 5,5 & 57,9 & 30 \\
\hline \multicolumn{2}{|c|}{ Monoterpenos oxigenados } & 1,2 & 3,1 & 0,1 & 16,3 & 5,7 & 42 \\
\hline \multicolumn{2}{|c|}{ Hidrocarbonetos sesquiterpênicos } & 16,7 & 43 & 88,7 & 60,6 & 14,9 & 2,9 \\
\hline \multicolumn{2}{|c|}{ Sesquiterpenos oxigenados } & 70,5 & 42,3 & 4,4 & 15,2 & 16,3 & 22.6 \\
\hline \multicolumn{2}{|l|}{ Total analisado } & 89,2 & 89,8 & 94,4 & 97,9 & 94,8 & 97,5 \\
\hline
\end{tabular}




\subsection{Atividade antimicrobiana dos óleos voláteis}

A Tabela 33 apresenta o resultado da avaliação do potencial antimicrobiano dos óleos voláteis extraídos de I. juruensis e O. platyspermum. A espécie $V$. pavonis forneceu baixo rendimento de óleos essenciais e por isso estes não foram submetidos ao ensaio.

Nenhum dos óleos avaliados apresentou resultado perante a bactéria Pseudomonas aeruginosa. O óleo essencial dos pericarpos de I. juruensis apresentou um melhor potencial antifúngico (contra Candida albicans) do que antibacteriano, uma vez que Staphylococcus aureus é uma bactéria bastante suscetível à maioria dos óleos essenciais testados.

Como esperado, o óleo obtido dos pericarpos de 0 . platyspermum se mostrou especialmente ativo frente às cepas de Escherichia coli, uma vez que este se caracteriza pela alta concentração dos monoterpenos oxigenados 4-terpineol $(14,3 \%)$ e $\alpha$-terpineol (21,5\%), os quais já são reconhecidos por possuírem ação antibacteriana, sendo o $\alpha$ terpineol também consagrado por sua importante atividade antifúngica (HENRIQUES et al., 2007).

Tabela 33 - Atividade antimicrobiana dos óleos testados.

\begin{tabular}{ccccc}
\hline Controle e & \multicolumn{4}{c}{ \% de inibição (concentração teste: $\mathbf{3 , 1 2 5} \boldsymbol{\mu L} / \mathbf{m L}$ ) } \\
\cline { 2 - 5 } amostras & C. albicans & E. coli & S. aureus & P. aeruginosa \\
\hline IJ-Folhas & 0,0 & 0,0 & 98,1 & 0,0 \\
IJ-Pericarpos & 74,9 & 13,6 & 84,8 & 0,0 \\
OP-Folhas & 78,6 & 0,0 & 45,8 & 0,0 \\
OP-Pericarpos & 86,7 & 94,2 & 76,5 & 0,0 \\
\hline C+ & 91,2 & 104,5 & 100,0 & 100,0 \\
$C-$ & 6,1 & 0,0 & 0,0 & 0,0 \\
\hline
\end{tabular}

Legenda: $(\mathrm{C}+)$ cloranfenicol/nistatina (1 mg/mL); (C-) DMSO:MeOH (1:1).

Em geral, os óleos voláteis obtidos dos pericarpos foram mais ativos do que os extraídos das folhas, o que de certa forma, reforça a função protetora exercida pelo pericarpo sobre a semente. 


\section{CONCLUSÕES}

Embora não se tenha realizado um estudo fitoquímico exaustivo com os frutos das três espécies selecionadas, é possível tirar algumas conclusões sobre os principais metabólitos secundários encontrados nessas espécies.

O fracionamento cromatográfico do resíduo clorofórmico do arilo de Virola pavonis (A. DC.) A. C. Sm. resultou no isolamento dos lignóides carinatina (1), carinatidina (2), dihidrocarinatina (3), di-hidrocarinatidina (4), desidro-dieugenol (5), galgravina (6), nectandrina A (7), galbelgina (9) e as formas eritro (11) e treo (12) da 1'-alil-7-hidroxi-3,4,3'-trimetoxi-8,4'oxineolignana, enquanto que do resíduo clorofórmico de seu pericarpo foram obtidas as substâncias carinatona (13), nectandrina $B(\mathbf{8})$ e verrucosina (10). O resíduo acetato de etila dos pericarpos forneceu a astilbina (22). Essa espécie se caracterizou pela significativa quantidade e variabilidade estrutural de lignóides.

Do resíduo clorofórmico do arilo de Iryanthera juruensis Warburg foram isolados os lignóides verrucosina (10) e guaiacina (14), juntamente com os tocotrienóides sargaol (15) e sargacromenol (16). Essa espécie se mostrou bem diferente das demais espécies pertencentes ao gênero Iryanthera, que de acordo com a literatura se caracterizam pela predominância de $\gamma$-lactonas e flavonóides.

A composição química de O. platyspermum (Spruce ex A. DC.) Warburg se mostrou bem peculiar, sendo caracterizada pelo acúmulo de metabólitos pertencentes à classe dos terpenóides, os quais não são comuns nos demais gêneros da família. Além disso, neste estudo não foram isolados lignóides, principais marcadores quimiotaxonômicos da família Myristicaceae. Do resíduo clorofórmico de seu pericarpo foram isolados o espatulenol (68), ent-4(15)-eudesmeno-1 $\beta, 6 \alpha$-diol (79), ácido ent-caurenóico (80), ácido 17-hidroxi-16 $\alpha$-ent-

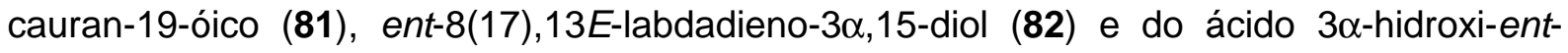
8(17),13E-labdadieno-15-óico (83). O estudo fitoquímico do resíduo acetato de etila de seus tegumentos resultou na obtenção de isoliquiritigenina (18), liquiritigenina (19), butina (20) e 3',4',7-tri-hidroxi-flavona (21). 
Em relação aos óleos essenciais, o óleo volátil extraído dos pericarpos de 0 . platyspermum apresentou o melhor rendimento, sendo caracterizado pela predominância de monoterpenos oxigenados que são reconhecidos por suas propriedades antimicrobianas.

Os lignóides isolados foram submetidos a testes de triagem antiplasmódica e leishmanicida, sendo as neolignanas di-hidrocarinatina (3) e di-hidrocarinatidina (4) as únicas ativas no ensaio antimalárico. Os lignóides verrucosina (10) e guaiacina (14) apresentaram resultados promissores frente à inibição das formas promastigotas de $L$. amazonensis. Embora tais observações sejam apenas de caráter preliminar, espera-se que as atividades biológicas aqui reportadas estimulem estudos sistemáticos posteriores que estabeleçam o real potencial dos lignóides avaliados perante o tratamento e/ou controle das doenças tropicais mencionadas. 


\section{REFERÊNCIAS BIBLIOGRÁFICAS}

ADAMS, R.P. Identification of essential oil components by gas chromatography/mass spectrometry. 4 ed. Illinois: Allured Publishing Corporation, 2007. 804p.

AGNANIET, H.; MAKANI, T.; MENUT, C.; BESSIERE, J. Chemical and biological investigation of essential oils from seeds and bark of Staudtia gabonensis Warb. Journal of Essential Oil Bearing Plants, v.7, n.2, p.107-112, 2004.

ANDRADE-NETO, V.F.; BRANDÃO, M.G.L.; STEHMANN, J.R.; OLIVEIRA, L.A.; KRETTLI, A.U. Antimalarial activity of Cinchona-like plants used to treat fever and malaria in Brasil. Journal of Ethnopharmacoly, v. 87, n. 2/3, p. 253-256, 2003.

APONTE, J.C.; VAISBERG, A.J.; ROJAS, R.; CAVIEDES, L.; LEWIS, W.H.; LAMAS, G.; SARASARA, C.; GILMAN, R.H.; HAMMOND, G.B. Isolation of cytotoxic metabolites from targeted peruvian Amazonian Medicinal plants. Journal of Natural Products, v.71, n., p.102105, 2008.

BARATA, L.E.S.; BAKER, P.M.; GOTTLIEB, O.R.; RÚVEDA, E.A. Neolignans from Virola surinamensis. Phytochemistry, v.17, p.783-786, 1978.

BARATA, L.E.S.; SANTOS, L.S.; FERRI, P.H.; PHILLIPSON, J.D.; PAINE, A.; CROFT, S. Anti-leishmanial activity of neolignans from Virola species and synthetic analogues. Phytochemistry, v.55, n.6, p.589-595, 2000.

BILIA, A.R. Non-nitrogenous Plant-derived Constituents with Antiplasmodial Activity. Natural Product Communications, v.1, n.12, p.1181-1204, 2006.

BRAGA, A.C.H.; ZACCHINO, S.; BADANO, H.; SIERRA, M.G.; RÚVEDA, E.A. ${ }^{13} \mathrm{C}$ NMR spectral and conformational analysis of 8-O-4' neolignans. Phytochemistry, v.23, n.9, p.20252028, 1984.

BRAZ FILHO, R.; GOTTLIEB, O.R.; MORAES, A.A.; PEDREIRA, G.; PINHO, S.L.V.; MAGALHÃES, M.T.; RIBEIRO, M.N. Isoflavonoids from Amazonian species. Lloydia, v.40, p.236-238, 1977.

BRAZ FILHO, R.; CARVALHO, M.G.; GOTTLIEB, O.R. The chemistry of Brazilian Myristicaceae. XVIII: Eperudiendiol, glycerides and neolignans from fruits of Osteophloeum platyspermum. Planta Medica, v.50, n.1, p.53-55, 1984.

CARVALHO, J.C.T.; FERREIRA, L.P.; SANTOS, L.S.; CORRÊA, M.J.C.; CAMPOS, L.M.O.; BASTOS, J.K.; SARTI, S.J. Anti-inflammatory activity of flavone and some of its derivates from Virola michelli Heckel. Journal of Ethnopharmacology, v.64, n.2, p.173-177, 1999. 
CHAMSUKSAI, P.; CHOI, J.S.; WOO, W.S. 3',4',7-Trihydroxyflavone in Albizzia julibrissin. Archives of Pharmacal Research, v.4, n.2, p.129-131, 1981.

DA SILVA FILHO, A.A.; COSTA, E.S.; CUNHA, W.R.; SILVA, M.L.A.; NANAYAKKARA, N.P.D.; BASTOS, J.K. In vitro antileishmanial and antimalarial activities of tetrahydrofuran lignans isolated from Nectandra megapotamica (Lauraceae). Phytotherapy Research, v.22, n.10, p.1307-1310, 2008.

DAVINO, S.C.; BARROS, S.; BARROS, S.B.M.; SILVA, D.H.S.; YOSHIDA, M. Antioxidant activity of Iryanthera sagotiana leaves. Fitoterapia, v.69, n.2, p.185-6, 1998.

DEVIENNE, K. F.; RADDI, M. S. G. Screening for antimicrobial activity of natural products using a microplate photometer. Brazilian Journal of Microbiology, v.33, n.2, p.166-168, 2002.

DU, Q.; LI, L.; JERZ, G. Purification of astilbin and isoastilbin in the extract of smilax glabra rhizome by high speed counter-current chromatography. Journal of Chromatography $A$, v.1077, n.1, p.98-101, 2005.

FERNANDES, J.B.; RIBEIRO, M.N.S.; GOTTLIEB, O.R.; GOTTLIEB, H.E. Eusiderins and 1,3-diarylpropanes from Virola species. Phytochemistry, v.19, n.7, p.1523-1525, 1980.

FERRI, P.H.; BARATA, L.E.S. (-)-Di-de-O-methylgrandisin, a lignan from Virola pavonis leaves. Phytochemistry, v.30, n.12, p.4204-4205, 1991.

FERRI, P.H.; BARATA, L.E.S. Neolignans and a phenylpropanoid from Virola pavonis leaves. Phytochemistry, v.31, n.4, p.1375-1377, 1992.

FONSECA, S.F.; BARATA, L.E.S.; RÚVEDA, E.; BAKER, P.M. ${ }^{13} \mathrm{C}$ nuclear magnetic resonance spectral and conformational analysis of naturally occurring tetrahydrofuran lignans. Canadian Journal of Chemistry, v.57, n.4, p.441-443, 1979.

FORT, D.M.; UBILLAS, R.P.; MENDEZ, C.D.; JOLAD, S.D.; INMAN, W.D.; CARNEY, J.R.; CHEN, J.L.; IANIRO, T.T.; HASBUN, C.; BRUENING, R.C.; LUO, J.; REED, M.J.; IWU, M.; CARLSON, T.J.; KING, S.R.; BIERER, D.; COOPER, R. Novel antihyperglycemic terpenoidquinones from Pycnanthus angolensis. The Journal of Organic Chemistry, v.65, n.20, p.6534-6539, 2000.

FRANCA, N.C.; DIAZ, P.P.D.; GOTTLIEB, O.R.; ROSA, B.P. Flavans from Iryanthera species. Phytochemistry, v.13, n.3, p.1631-1632, 1974.

GOTTLIEB, O.R. Neolignans. Progress in the Chemistry of Organic Natural Products, v.35, n.1, p.1-72, 1978.

GOTTLIEB, O.R. Chemical studies on medicinal Myristicaceae from Amazonia. Journal of Ethnopharmacology, v.1, n.4, p.309-323, 1979. 
GOTTLIEB, O.R.; YOSHIDA, M. Lignóides com atenção especial à química das neolignanas. Química Nova, v.7, n.4, p.250-273, 1984.

GOTTLIEB, O.R. Lignóides de plantas amazônicas: investigações biológicas e químicas. Acta Amazonica, v.18, n.1/2, p.333-344, Suplemento, 1988.

HATTORI, M.; HADA, S.; KAWATA, Y.; TEZUKA, Y.; KIKUCHI, T.; NAMBA, T. New 2,5-Bisaryl-3,4-dimethyltetrahydrofuran Lignans from the Aril of Myristica fragrans. Chemical \& Pharmaceutical Bulletin, v.35, n.8, p.3315-3322, 1987.

HENRIQUES, A.T.; SIMÕES-PIRES, C.A.; APEL, M.A. Óleos essenciais: importância e perspectivas terapêuticas. In: YUNES, R.A. \& FILHO, V.C. Química de Produtos Naturais, novos fármacos e a moderna farmacognosia. Itajaí: Univali Editora, 2007. Capítulo IX, p. 211-235.

IWABUCHI, H.; YOSHIKURA, M.; KAMISAKO, W. Studies on the sesquiterpenoids of Panax ginseng C.A. Meyer III. Chemical \& Pharmaceutical Bulletin, v.37, n.2, p.509-510, 1989.

KAWANISHI, K.; UHARA, Y.; HASHIMOTO, Y. The neolignans (-)-carinatone and carinatin from Virola carinata. Phytochemistry, v.21, n.4, p.929-931, 1982.

KONISHI, T.; AZUMA, M.; ITOGA, R.; KIYOSAWA, S.; FUJIWARA, Y.; SHIMADA, Y. Three new labdane-type diterpenes from wood, Excoecarea agallocha. Chemical Pharmaceutical Bulletin, v.44, n.1, p.229-231, 1996.

LAMBROS, C.; VANDERBERG, J.P. Synchronization of Plasmodim falciparum erythrocyte stages in culture. Journal of Parasitology, v. 65, n.3, p. 418-420, 1979.

LENCZEWSKI, M. E.; McGAVIN, S. T.; VANDYKE, K. Comparison of automated and traditional minimum inibitory concentration procedures for microbiological cosmetic preservatives. Journal of AOAC International Arlington, v.79, n.6, p.1294-1299, 1996.

LOPES, N.P. Metabólitos secundários de Virola surinamensis (Rol.) Warb. (Myristicaceae). 1997. 137 f. Dissertação (Doutorado em Química) - Instituto de Química, Universidade de São Paulo, São Paulo, 1997.

LOPES, N.P.; CHICARO, P.; KATO, M.J.; ALBUQUERQUE, S.; YOSHIDA, M. Flavonoids and lignans from Virola surinamensis twigs and their in vitro activity against Trypanosoma cruzi. Planta Medica, v.64, p.667-669, 1998.

LOPES, N.P.; KATO, M.J.; ANDRADE, E.H.A.; MAIA, J.G.S.; YOSHIDA, M.; PLANCHART, A.R.; KATZIN, A.M. Antimalarial use of volatile oil from leaves of Virola surinamensis by Waiãpi Amazon Indians. Journal of Ethnopharmacology, v.67, n. 3, p.313-319, 1999.

LOPES, N.P.; KATO, M.J.; YOSHIDA, M. Antifungal constituents from roots of Virola surinamensis. Phytochemistry, v.51, n.1, p.29-33, 1999. 
LOPES, N.P.; SANTOS, P.A.; KATO, M.O.; YOSHIDA, M. New butenolides in plantlets of Virola surinamensis (Myristicaceae). Chemical \& Pharmaceutical Bulletin, v.52, n.10, p.12551257, 2004.

LU, T.; VARGAS, D.; FRANZBLAU, S.G.; FISCHER, N.H. Diterpenes from Solidago rugosa. Phytochemistry, v.38, n.2, p.451-456, 1995.

MARQUES, M.O.M.; YOSHIDA, M.; GOTTLIEB, O.R. Neolignans from fruits of Virola pavonis. Phytochemistry, v.31, n.12, p.4380-4381, 1992.

MARTINEZ, J.C.V.; TORRES, R.C. Lignans from Virola aff. pavonis leaves. Phytochemistry, v.44, n.6, p.1179-1182, 1997.

MATILA, T. A modified Kelsey-Sykes method for testing disinfectants with 2,3,5triphenyltetrazolium clorid reduction as an indicator of bacterial growth. The Journal of Applied Bacteriology, v.62, n.6, p.551-554, 1987.

MC LAFFERTY, F.W.; STAUFFER, D. The Wiley/NBS Registry of Mass Spectral Data. New York: John Wiley Sons, 1989.

MCRAE, W.D.; TOWERS, G.H.N. Biological activities of lignans. Phytochemistry, v.23, n.6, p.1207-1220, 1984.

Ministério da Saúde, Secretaria de Vigilância em Saúde, Departamento de Vigilância Epidemiológica. Manual de vigilância da leishmaniose tegumentar americana. Brasília, Tiragem: 2ed, 2007. Disponível em: <http://portal.saude.gov.br> Acesso em: 02 out. 2008.

MOBOT - Missouri Botanical Garden <www.mobot.org> / MBG:W3TROPICOS: <mobot.mobot.org/W3T/Search/vast.html>. Acesso em: 03 out. 2008.

MOSS, G.P. Nomenclature of lignans and neolignans (IUPAC Recommendations 2000). Pure and Applied Chemistry, v.72, n.8, p.1493-1523, 2000.

MUNÕZ, V.; SAUVAIN, M.; BOURDY, G.; CALLAPA, J.; BERGERON, S.; ROJAS, I.; BRAVO, J.A.; BALDERRAMA, L.; ORTIZ, B.; GIMENEZ, A.; DEHARO, E. A search for natural bioactive compounds in Bolivia through a multidisciplinary approach. Part I. Evaluation of the antimalarial activity of plants used by the Chacobo Indians. Journal of Ethnopharmacology, v.69, p.127-137, 2000.

NAGASHIMA, F.; KISHI, K.; HAMADA, Y.; TAKAOKA, S.; ASAKAWA, Y. ent- Verticillanetype diterpenoids from the Japanese liverwort Jackiella javanica. Phytochemistry, v.66, n.14, p.1662-1670, 2005. 
NUMATA, A.; KANBARA, S.; TAKAHASHI, C.; FUJIKI, R.; YONEDA, M.; USAMI, Y.; FUJITA, E. Acytotoxic principle of the brown alga Sargassum tortile and structures of chromenes. Phytochemistry, v.31, n.4, p.1209-1213, 1992.

NUNOMURA, S.; YOSHIDA, M. Lignans and benzoic acid derivatives from pericarps of Virola multinervia (Myristicaceae). Biochemical Systematics and Ecology, v.30, n.10, p.985987, 2002.

PAULO, M.Q. Estudo fitoquímico das folhas de Virola surinamensis e Osteophloeum platyspermum. 1983. 153 f. Dissertação (Mestrado em Química) - Instituto de Química, Universidade Estadual de Campinas, São Paulo, 1983.

RODRIGUES, W.A. Revisão taxonômica das espécies de Virola Aublet (Myristicaceae) do Brasil. Acta Amazonica, v.10, n.1, p.5-127, 1980.

ROMOFF, P.; YOSHIDA, M. Chemical constituents from Myristicaceae. Ciência e Cultura Journal of the Brazilian Association for the Advancement of Science, v.49, n.5/6, p.345-353, 1997.

ROUMY, V.; PIZANGO-GARCIA, G.; CHOQUEVILCA-GUTIERREZ, A.L.; RUIZ, L.; JULLIAN, V.; WINTERTON, P.; FABRE, N.; MOULIS, C.; VALENTIN, A. Amazonian plants from Peru used by Quechua and Mestizo to treat malaria with evaluation of their activity. Journal of Ethnopharmacology, v.12, n.3, p.482-489, 2007.

SABULAL, B.; KURUP, R.; SUMITHA, B.; GEORGE, V. Chemical composition of the leaf oils of Myristica malabarica Lam. and Gymnacranthera canarica (King) Warb. Journal of Essential Oil Research, v. 19, n.4, p.323-325, 2007.

SALIE, F.; EAGLES, P.F.K.; LENG, H.M.J. Preliminary antimicrobial screening of four South African Asteraceae species. Journal of Ethnopharmacology, v.52, n.1, p.27-33, 1996.

SANTOS, B.C.B. Seasonal evaluation of essential oil chemical composition of Virola surinamensis leaves in the topical anti-inflammatory activity (apresentação oral). In: XX Simpósio de Plantas Medicinais do Brasil e X International Congress of Ethnopharmacology, 2008, São Paulo.

SARTORELLI, P.; YOUNG, C.M.M.; KATO, M.J. Antifungal lignans from the arils of Virola oleifera. Phytochemistry, v.47, n.6, p.1003-1006, 1998.

SCHULTES, R.E.; HOLMSTED, B. De plantis toxicaris et mundo novo tropicale commentationes. VIII. Miscellaneous Notes on Myristicaceous Plants of South America. Lloydia, v. 34, p. 61-78, 1971. 
SCHULTES, R.E. De plantis toxicariis e mundo novo tropicale commentationes XXXV: Miscellaneous Notes on Biodynamic Plants of the Northwest Amazon. Journal of Ethnopharmacology, v.14, n.1, p.125-158, 1985.

SEO, Y.; PARK, K.E.; NAM, T.J. Isolation of a new chromene from the brown alga Sargassum thunbergii. Bulletim Korean Chemical Society, v.28, n.10, p.1831-1833, 2007.

SHIMOMURA, H.; SASHIDA, Y.; OOHARA, M. Lignans from Machilus thunbergii. Phytochemistry, v.27, n.2, p.634-636, 1988.

SILVA, D.H.S.; PEREIRA, F.C.; ZANONI, M.V.B.; YOSHIDA, M. Lipophyllic antioxidants from Iryanthera juruensis fruits. Phytochemistry, v.57, n.3, p.437-442, 2001.

SILVA, D.H.S.; ZHANG, Y.; SANTOS, L.A.; BOLZANI, V.S.; NAIR, M.G. Lipoperoxidation and cyclooxygenases 1 e 2 inhibitory compounds from Iryanthera juruensis. Journal of Agricultural and Food Chemistry, v.55, n.7, p.2569-2574, 2007.

SIMIC, A.; KROEPFL, D.; SIMIC, N.; OGUNWANDE, I. Pycnanthus angolensis (Welw) Excell: volatile oil constituents and antimicrobial activity. Natural Product Communications, v.1, n.8, p.651-654, 2006.

SOUZA, V.C.; LORENZI, H. Botânica sistemática: Guia ilustrado para identificação das famílias de Angiospermas da flora brasileira, baseado em APG II. São Paulo: Instituto Plantarum, 2005. 639p.

SUAREZ, M.; BONILLA, J.; DIAZ, A.M.P.; ACHENBACH, H. Dehydrodieugenols from Nectandra polita. Phytochemistry, v.22, n.2, p.609-610, 1983.

THERIAULT, A.; CHAO, J.T.; WANG, Q.; GAPOR, A.; ADELI, K. Tocotrienol: A review of its therapeutic potential. Clinical Biochemistry, v.32, n.5, p.309-319, 1999.

TIAN, G.; ZHANG, U.; ZHANG, T.; YANG, F.; YOICHIRO, I. Separation of flavonoids from seeds of Vernonia anthelmintica willd by high-seep counter-current chromatography. Journal of Chromatography A, v.1094, n.1/2, p.219-222, 2004.

TORRES, Z.E.S. Óleo volátil e antioxidantes de folhas de Virola michelii Heckel (Myristicaceae). 2005. 88 f. Dissertação (Mestrado em Biotecnologia e Recursos Naturais) Universidade do Estado do Amazonas, Manaus, 2005.

TRAGER, W.; JENSEN, J.B. Human malaria parasites in continuous culture. Science, v. 193, n.4254, p. 673-675, 1976.

VALDERRAMA, J.C.M. Distribution of flavonoids in the Myristicaceae. Phytochemistry, v.55, n.6, p.505-511, 2000. 
VAN ROOSMALEN, M.G.M.; BARDALES, M.P.D.; GARCIA, O.M.C.G. Frutos da floresta amazônica. Parte I: Myristicaceae. Acta Amazonica, v.26, n.4, p.209-264, 1996.

VEITCH, N.C.; SUTTON, P.S.E.; KITE, G.C.; IRELAND, H.E. Six new isoflavones and a 5deoxyflavonol glycoside from the leaves of Ateleia herbert-smithii. Journal of Natural Products, v.66, n.2, p.210-216, 2003.

VELANDIA, J.R.; CARVALHO, M.G.; BRAZ-FILHO, R. Ácido ent-16 $\alpha, 17$-diidroxicauran-19óico isolado de Ouratea semiserrata e os desafios estereoquímicos dos carbonos quirais C4 e C-16. Química Nova, v.21, n.4, p.397-404, 1998.

VICENTINI, A.; RODRIGUES, W. Myristicaceae. In: RIBEIRO, J.E.L.S.; HOPKINS, M.J.G.; VICENTINI, A.; SOTHERS, M.A.C.; BRITO, J.M.; SOUZA, M.A.D.; MARTINS, L.H.P.; LOHMANN, L.G.; ASSUNÇÃO, P.A.C.L.; PEREIRA, E.C.; SILVA, C.F.; MESQUITA, M.R.; PROCÓPIO, L.C. Flora da Reserva Ducke - Guia de identificação das plantas vasculares de uma floresta de terra firme na Amazônia Central. Manaus: INPA - DFID, 1999, p. 136-145. Disponível em: <http://www.umsl.edu/ av0f3/pdf/myristicaceae.pdf>. Acesso em: 10 nov. 2006.

VIEIRA, P.C.; YOSHIDA, M.; GOTTLIEB, O.R.; PAULINO FILHO, H.F.; NAGEM, T.J.; BRAZ FILHO, R. $\gamma$-Lactones from Iryanthera species. Phytochemistry, v.22, n.3, p.711-713, 1983.

WILLINGER, B.; APFALFER, P.; HIRSCHL, A. M.; MAKRISTATHIS, A.; ROTTER, M.; SEIBOLD, M. Susceptibility testing of Candida species: comparison of NCCLS microdilution method with Fungitest ${ }^{\circledR}$. Diagnostic Microbiology Infectious and Disease, v.38, n.1, p.11-15, 2000.

WONG, W.S.; GUO, D.; WANG, X.L.; YIN, Z.Q.; XIA, B.; LI, N. Study of cis-cinnamic acid in Arabidopsis thaliana. Plant Physiology and Biochemistry, v.43, n.10/11, p.929-937, 2005.

WU, Y.C.; HUNG, Y.C.; CHANG, F.R.; COSENTINO, M.; WANG, H.K.; LEE, K.H. Identification of ent-16ß,17-dihydroxykauran-19-oic acid as an anti-HIV principle and isolation of the new diterpenoids annosquamosins A and B from Annona squamosa. Journal of Natural Products, v.59, n. 6, p.635-637, 1996.

YANG, Y.L.; CHANG, F.R.; WU, C.C.; WANG, W.Y.; WU, Y.C. New ent-kaurane diterpenoids with anti-platelet aggregation activity from Annona squamosa. Journal of Natural Products, v.65, n.10, p.1462-1467, 2002.

YOSHIDA, M. Biologically active neolignans from Amazonian trees. In: SEIDEL, P.R., GOTLLIEB, O.R., KAPLAN, M.A. Chemistry of Amazon. Washington: ACS, 1995. p.85. 
YOUSSEF, D.T.A.; RAMADAN, M.A.; KHALIFA, A.A. Acetophenones, a chalcone, a chromone and flavonoids from pancratium maritimum. Phytochemistry, v.49, n.8, p.25792583, 1998.

ZACCHINO, S.; RODRÍGUEZ, G.; PEZZENATI, G.; ORELLANA, G.; ENRIZ, R.; SIERRA, M.G. In vitro evaluation of antifungal properties of 8.O.4'-neolignans. Journal of Natural Products, v.60, n.7, p.659-662, 1997.

ZDERO, C.; BOHLMANN, F.; KING, R.M. Clerodane and labdane derivatives from Olearia teretifolia. Phytochemistry, v.31, n.5, p.1703-1711, 1992.

ZUANAZZI, J.A.S.; MONTANHA, J.A. Flavonóides. In: SIMÕES, C.M.O.; SCHENKEL, E.P.; GOSMANN, G.; MELLO, J.C.P.; MENTZ, L.A.; PETROVICK, P.R. Farmacognosia da planta ao medicamento. Porto Alegre/Florianópolis: Editora da UFRGS/Editora da UFSC, 2004. Capítulo 23, p. 577-614. 


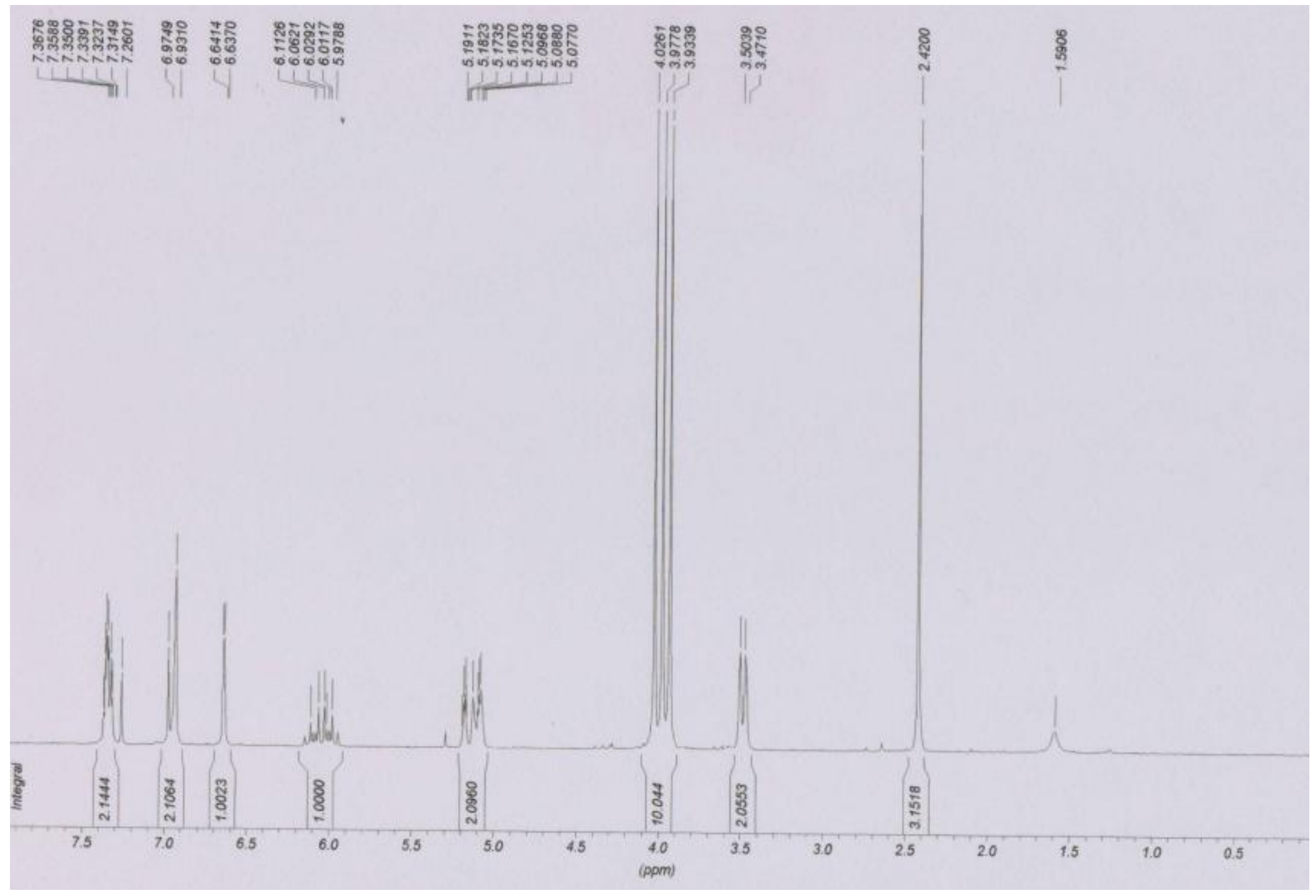

Espectro 1. RMN de ${ }^{1} \mathrm{H}$ da substância $1\left(\mathrm{CDCl}_{3}, 4,7 \mathrm{~T}\right)$. 


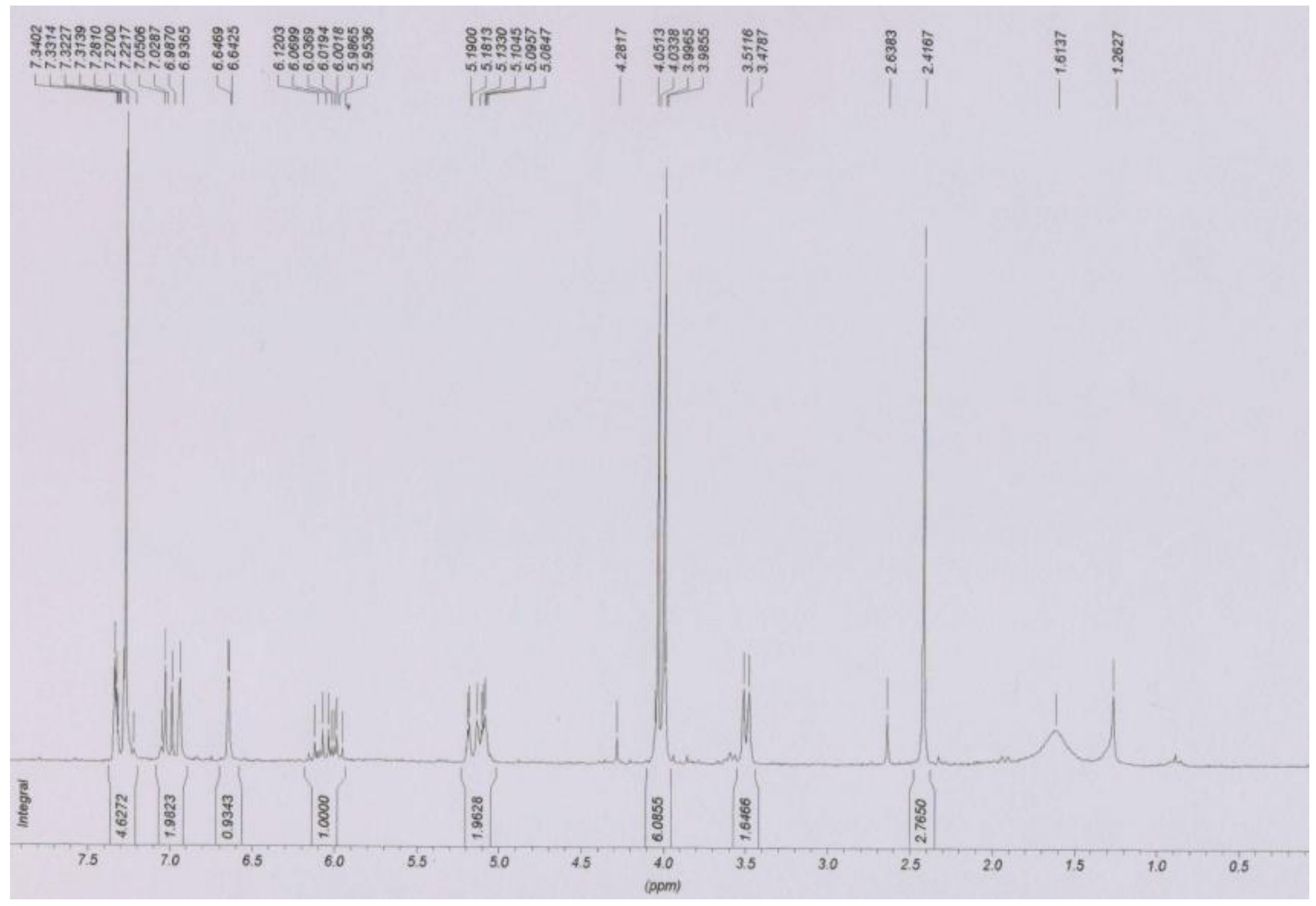

Espectro 2. RMN de ${ }^{1} \mathrm{H}$ da substância $2\left(\mathrm{CDCl}_{3}, 4,7 \mathrm{~T}\right)$. 


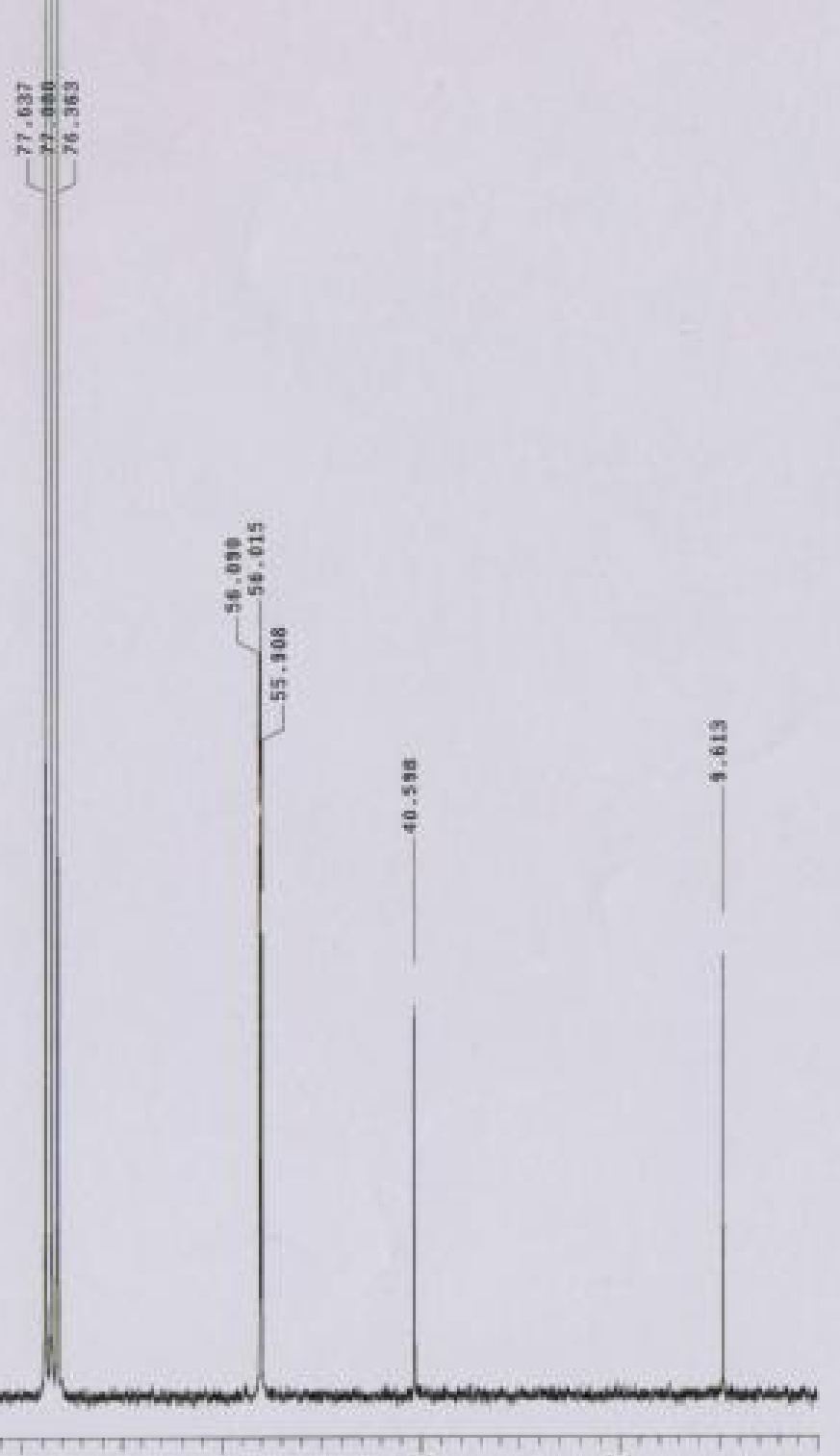

Espectro 3. RMN de ${ }^{13} \mathrm{C}$ da substância $1\left(\mathrm{CDCl}_{3}, 4,7 \mathrm{~T}\right)$. 


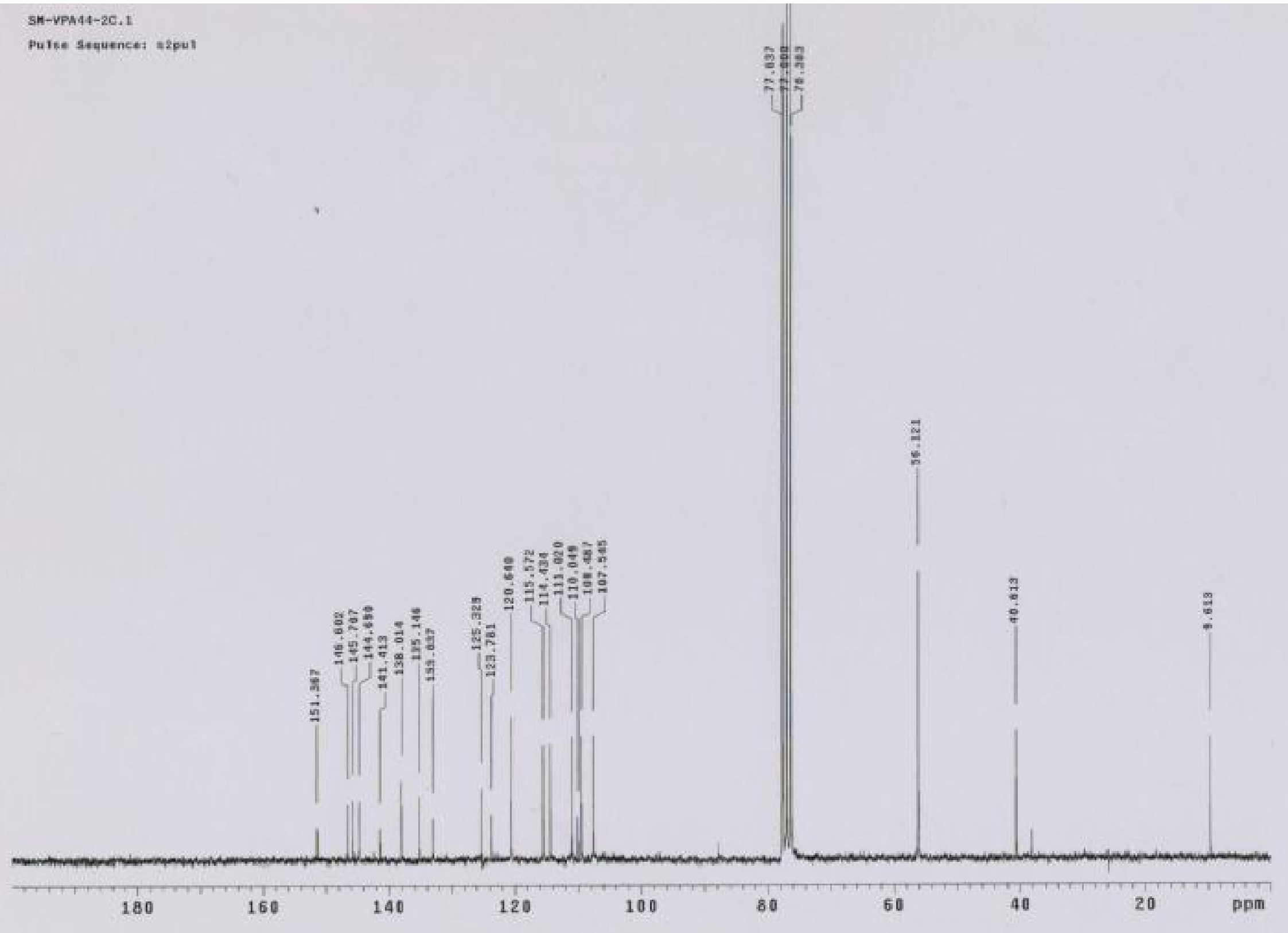

Espectro 4. RMN de ${ }^{13} \mathrm{C}$ da substância $2\left(\mathrm{CDCl}_{3}, 4,7 \mathrm{~T}\right)$. 


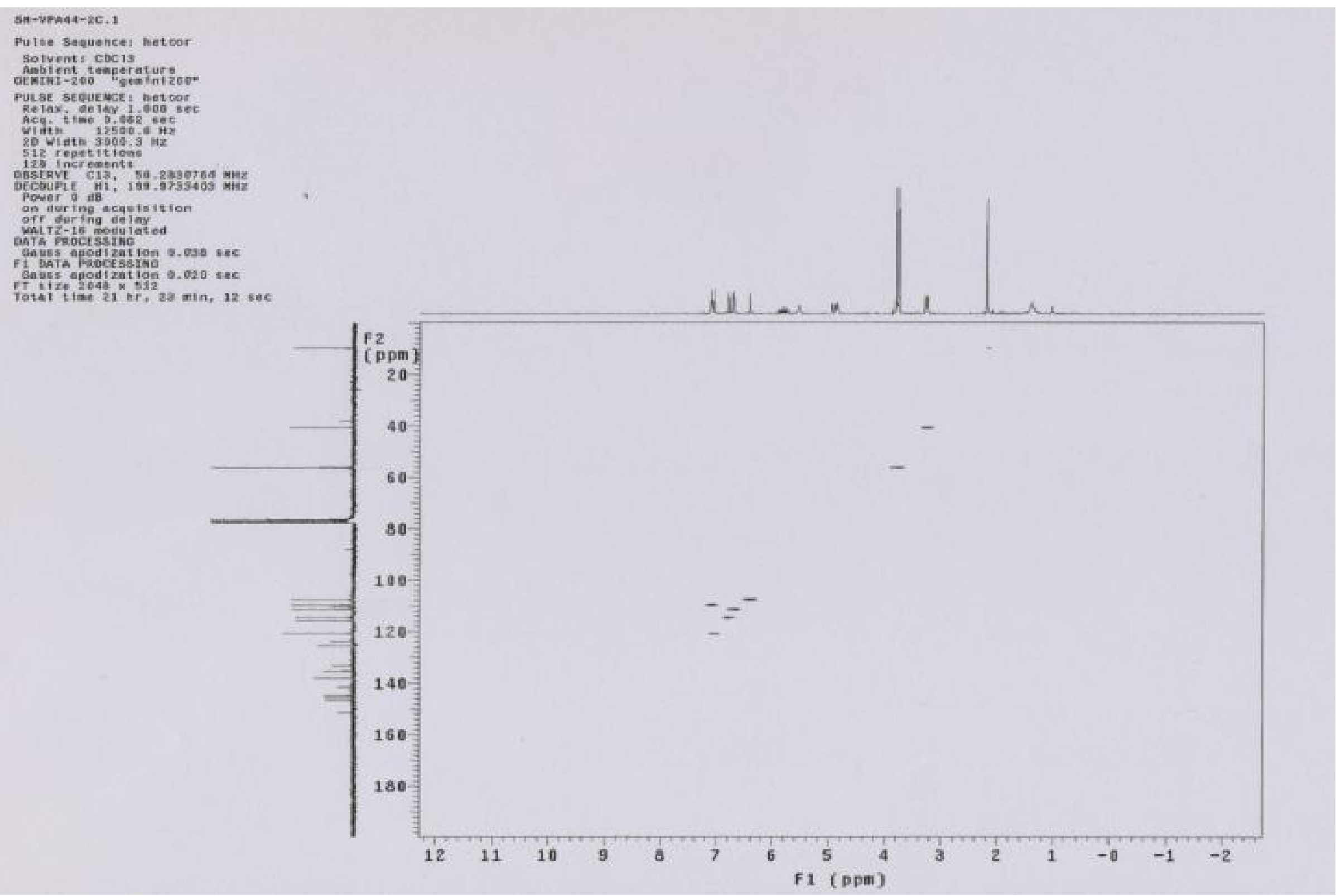

Espectro 5. HETERO-COSY da substância $2\left(\mathrm{CDCl}_{3}, 4,7 \mathrm{~T}\right)$. 


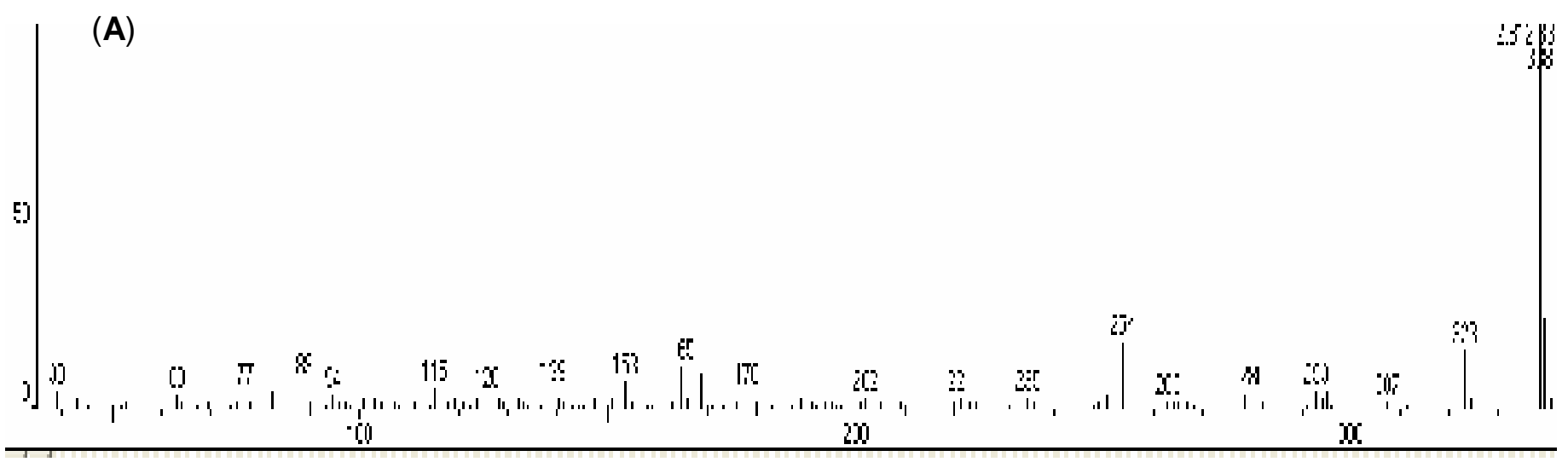

(B)

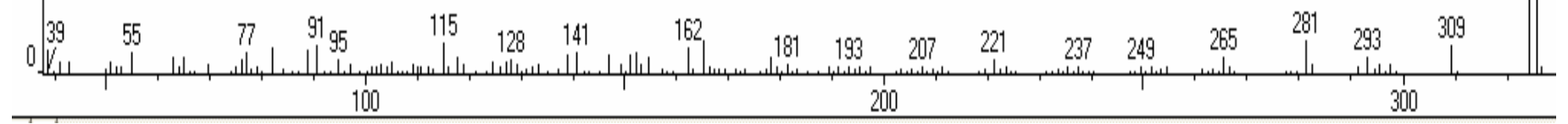

Espectro 6. (A) EM da substância 1 e (B) EM da substância 2 (IE, 70 ev). 


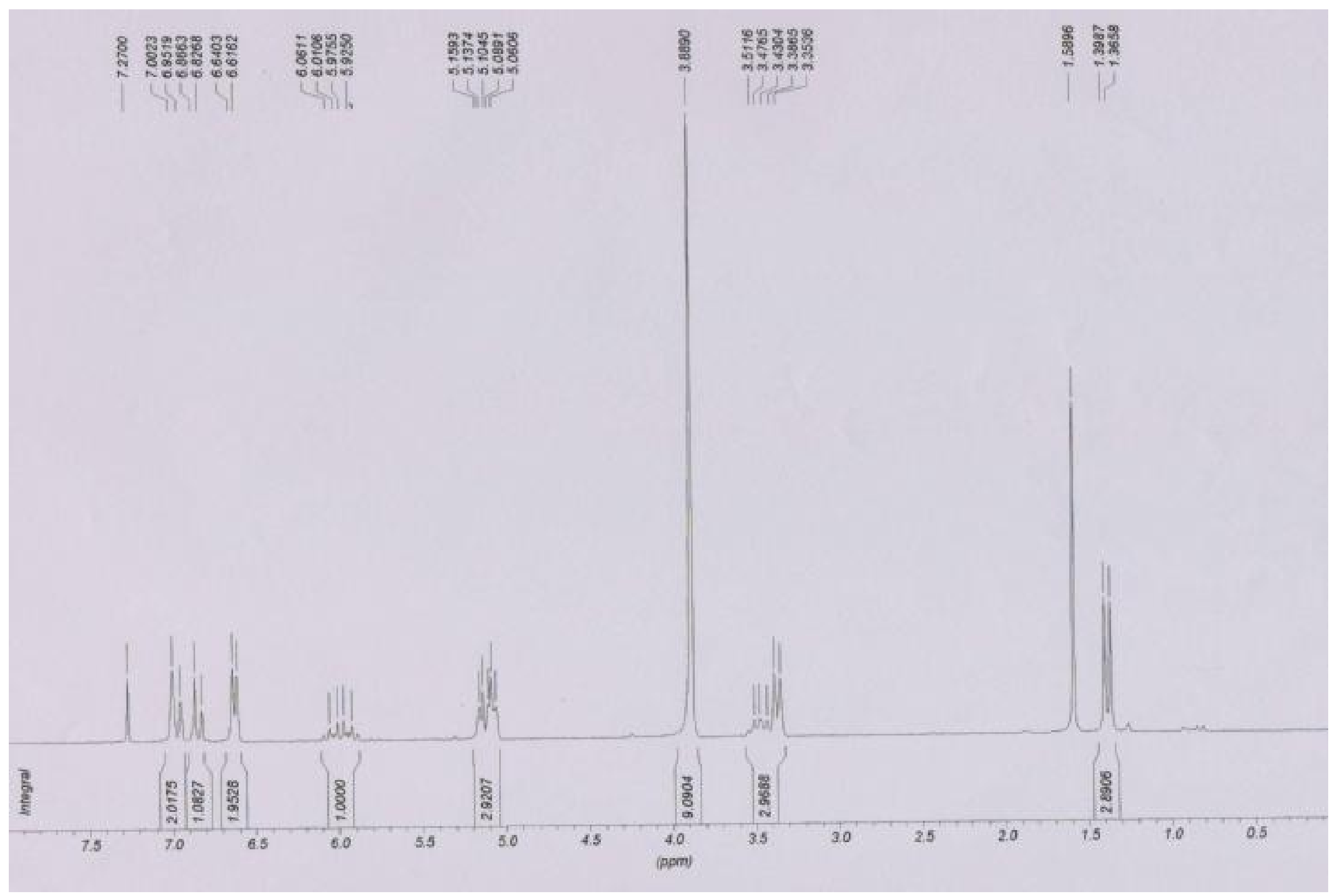

Espectro 7. RMN de ${ }^{1} \mathrm{H}$ da substância $3\left(\mathrm{CDCl}_{3}, 4,7 \mathrm{~T}\right)$. 


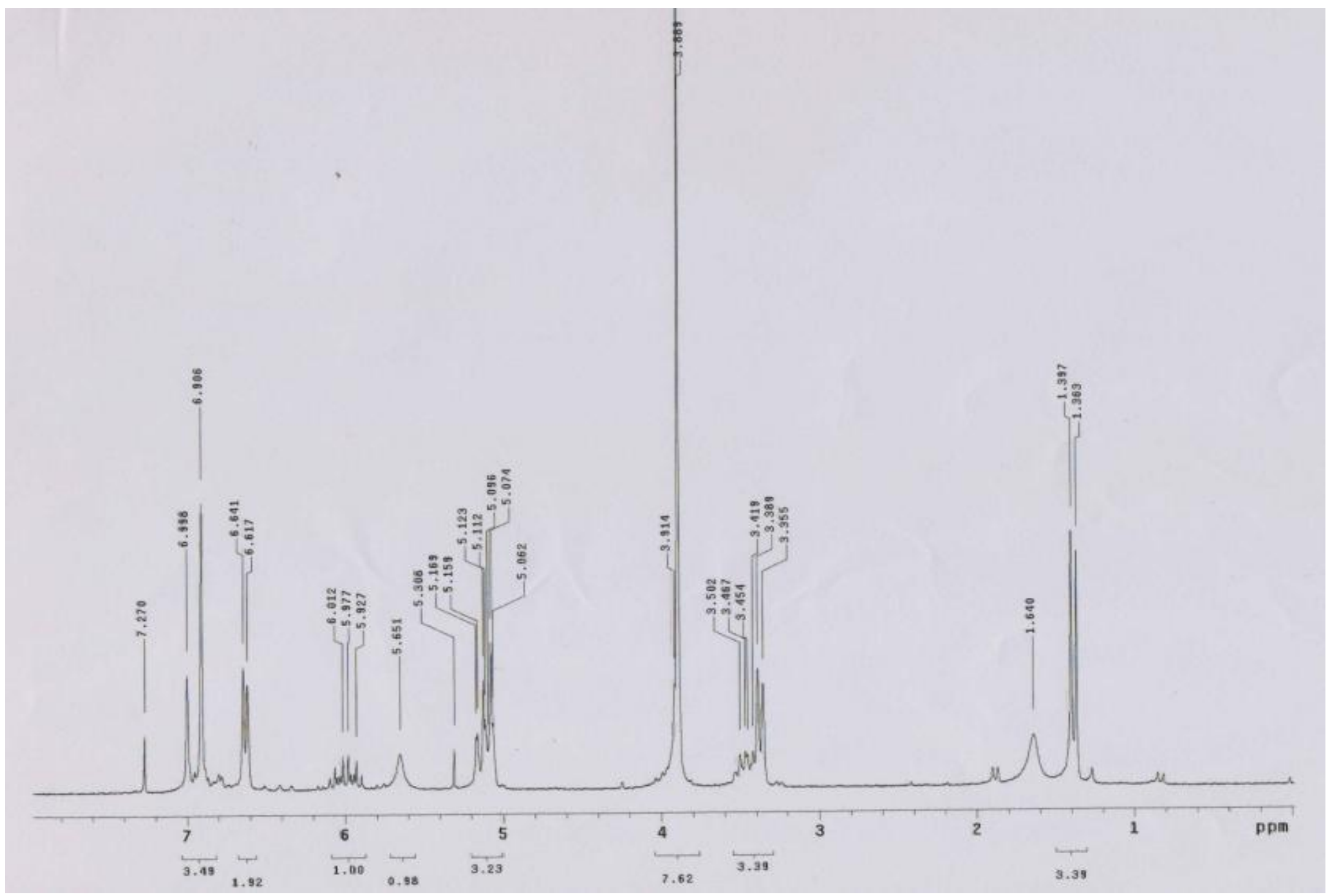

Espectro 8. RMN de ${ }^{1} \mathrm{H}$ da substância $4\left(\mathrm{CDCl}_{3}, 4,7 \mathrm{~T}\right)$. 


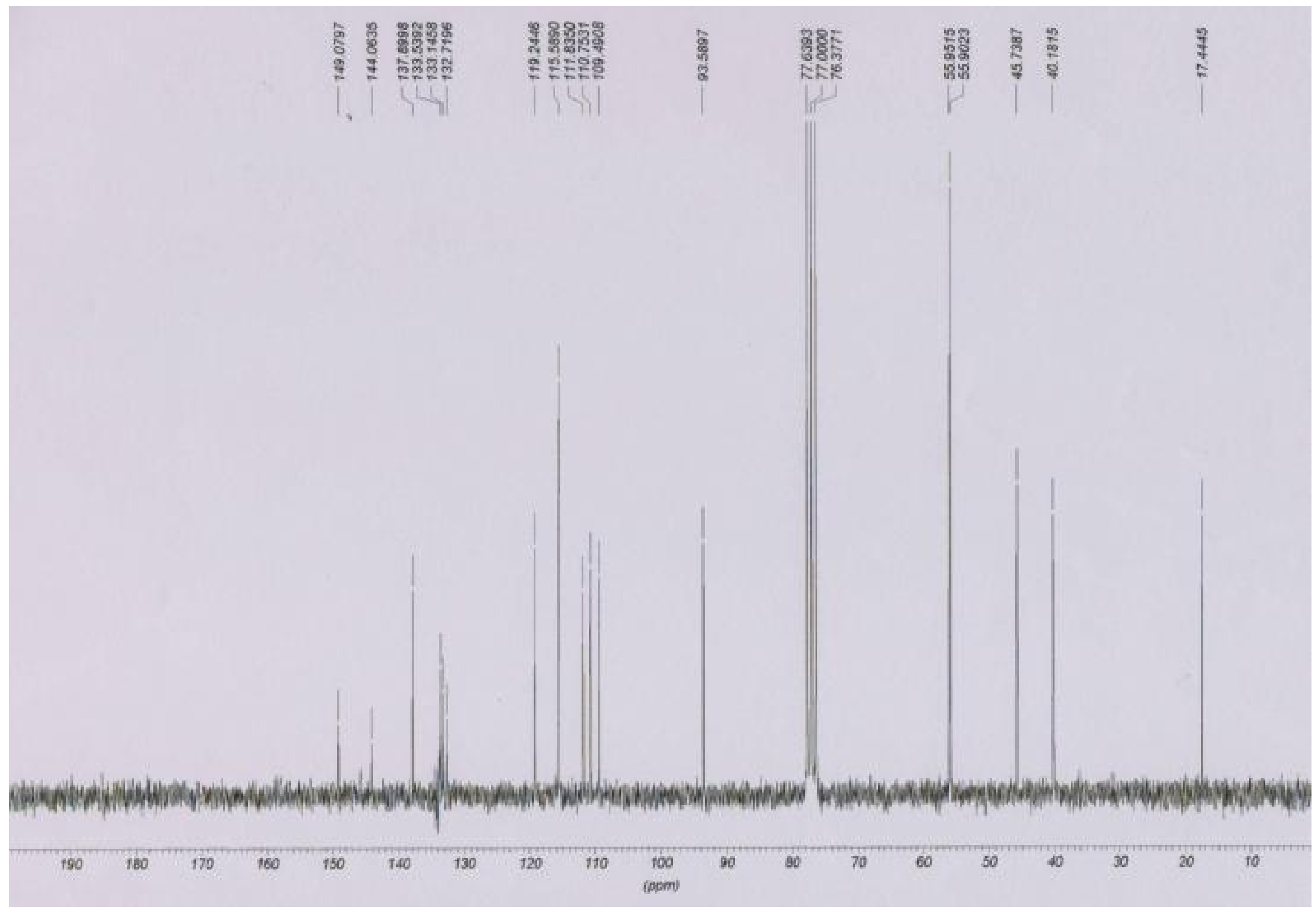

Espectro 9. RMN de ${ }^{13} \mathrm{C}$ da substância $3\left(\mathrm{CDCl}_{3}, 4,7 \mathrm{~T}\right)$. 


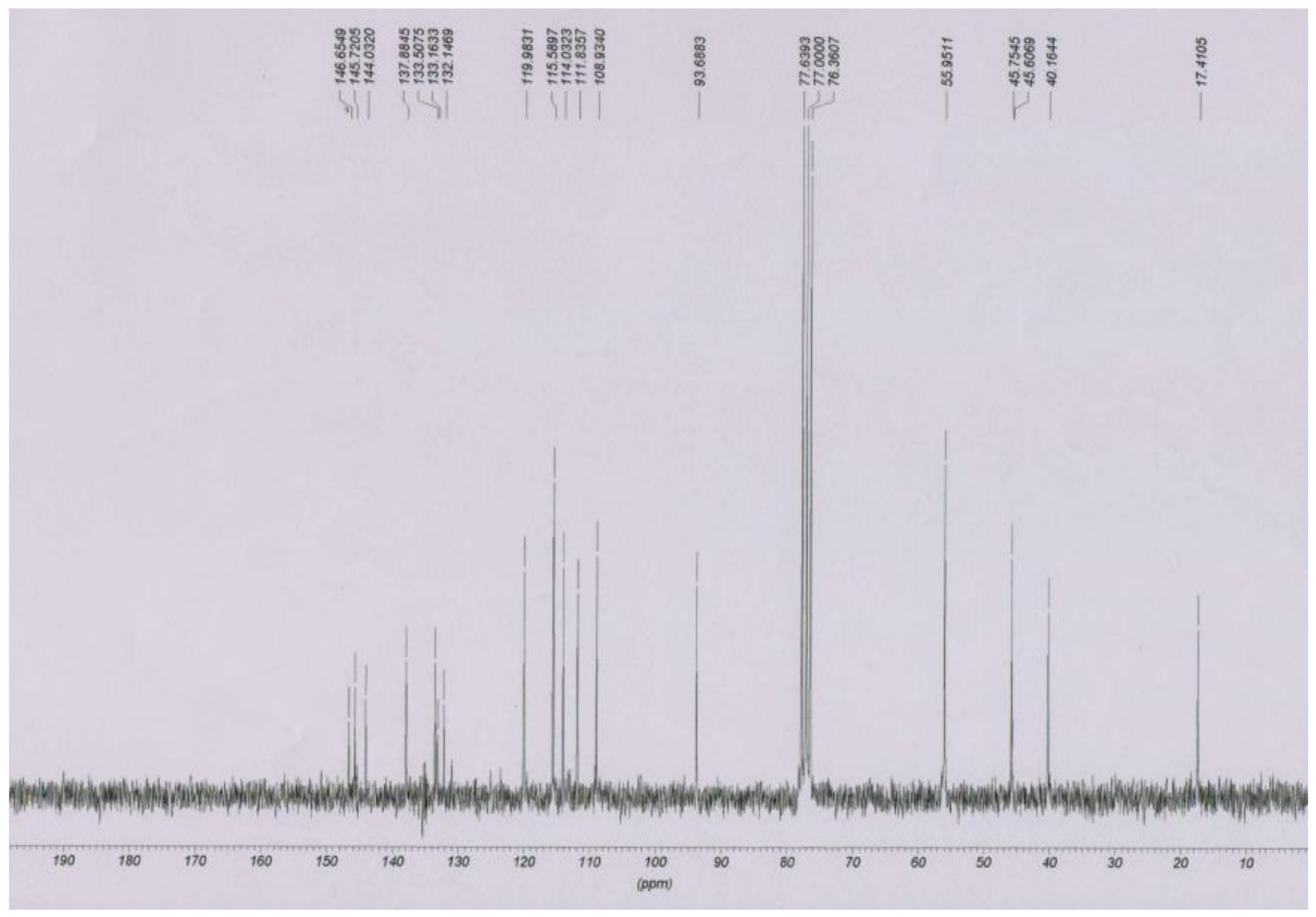

Espectro 10. RMN de ${ }^{13} \mathrm{C}$ da substância $4\left(\mathrm{CDCl}_{3}, 4,7 \mathrm{~T}\right)$. 
(A)

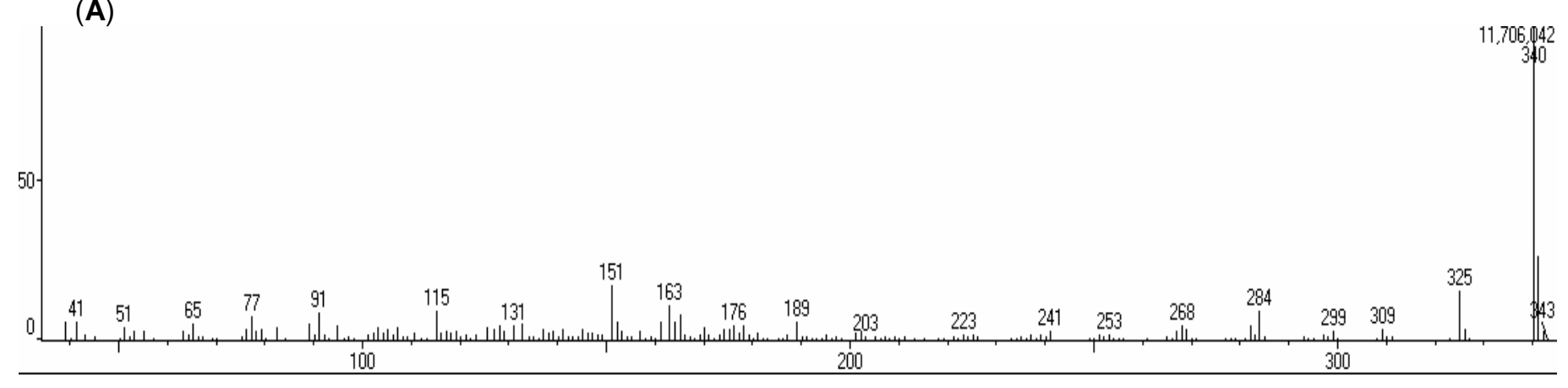

(B)

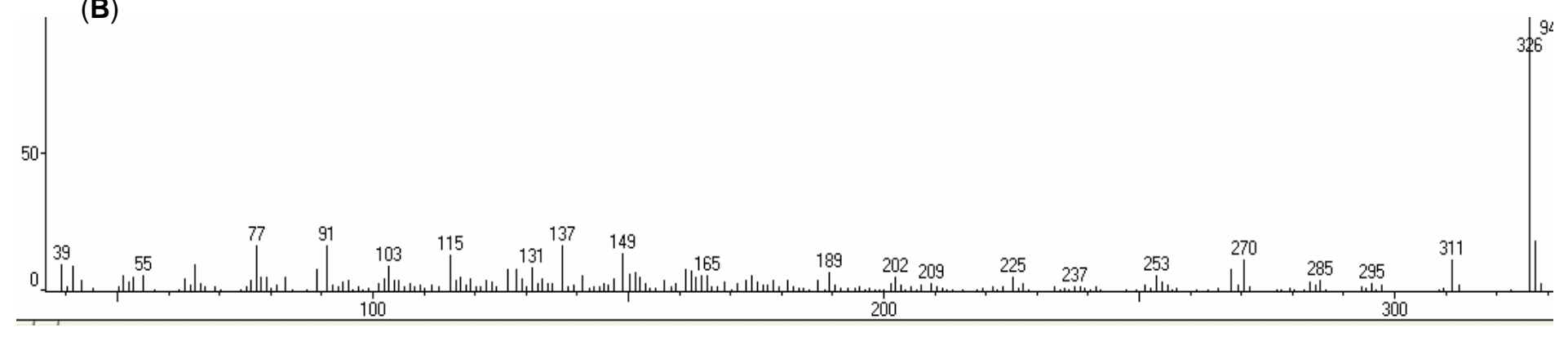

Espectro 11. (A) EM da substância 3 e (B) EM da substância 4 (IE, 70 eV). 


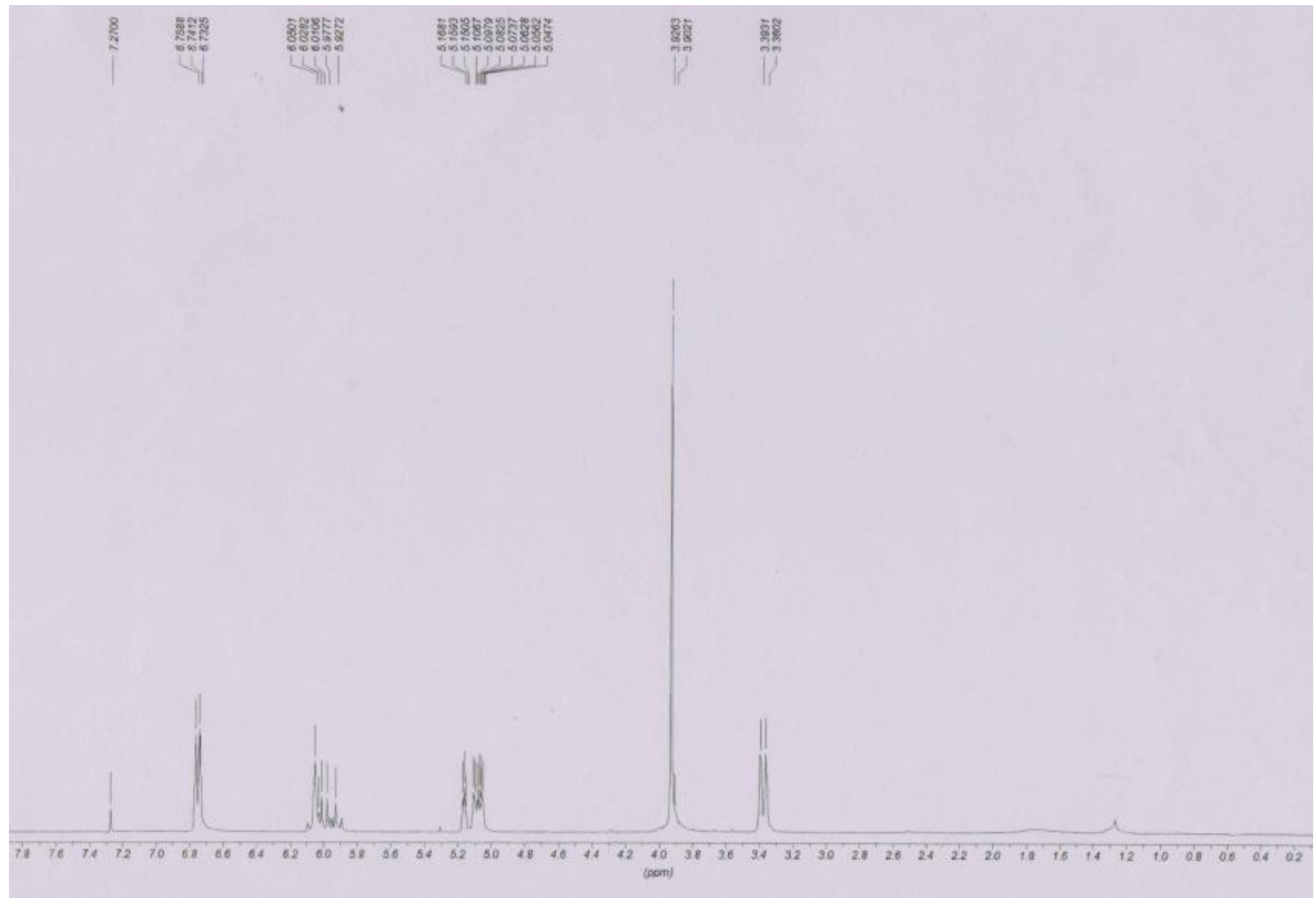

Espectro 12. RMN de ${ }^{1} \mathrm{H}$ da substância $5\left(\mathrm{CDCl}_{3}, 4,7 \mathrm{~T}\right)$. 


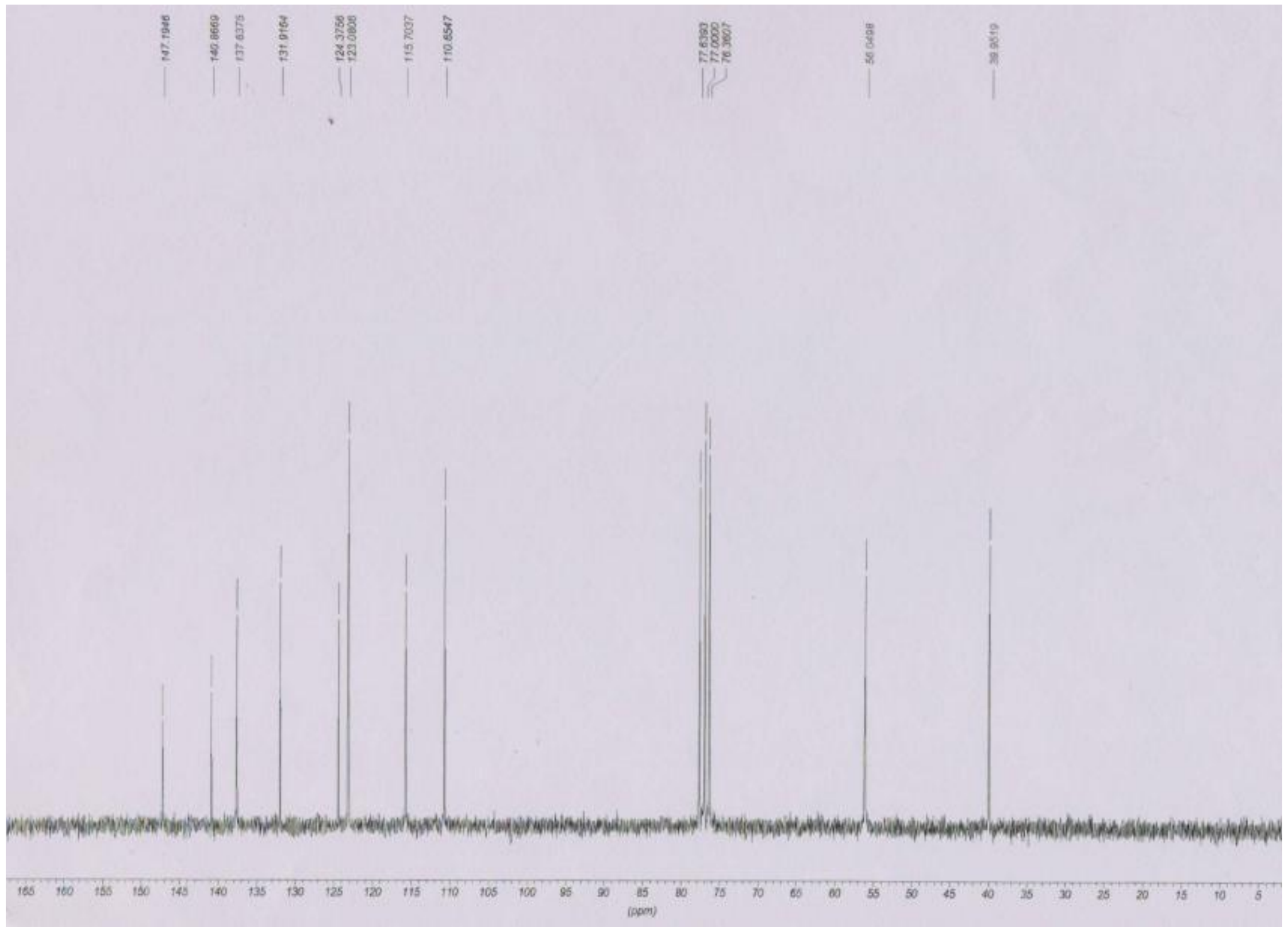

Espectro 13. RMN de ${ }^{13} \mathrm{C}$ da substância $5\left(\mathrm{CDCl}_{3}, 4,7 \mathrm{~T}\right)$. 


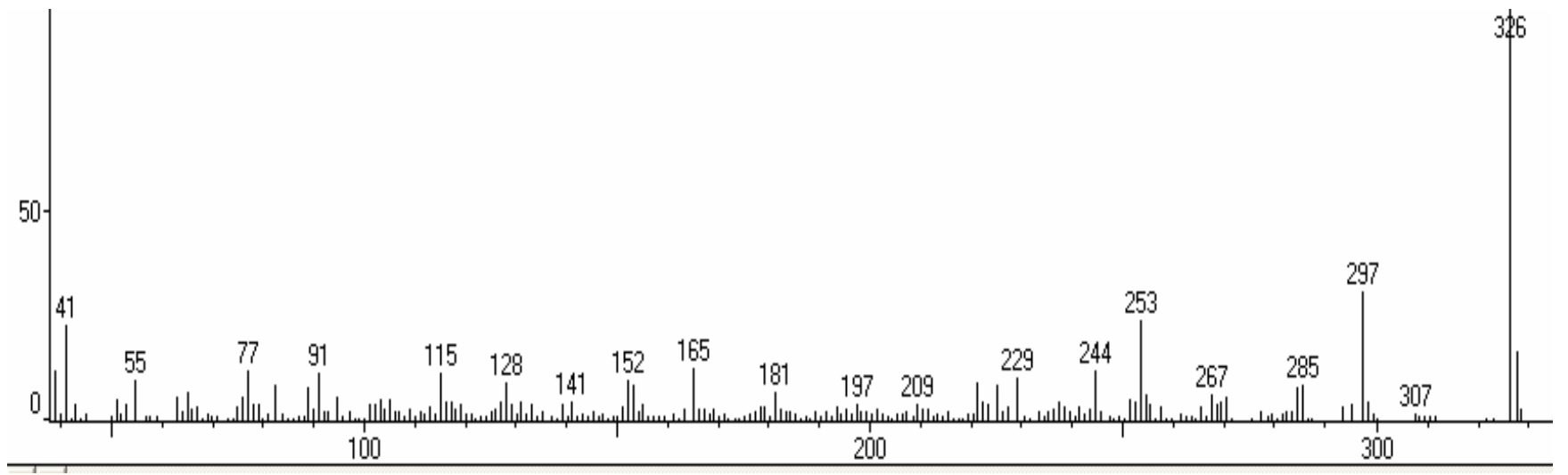

Espectro 14. EM da substância 5 (IE, 70 eV). 
Espectro 15. RMN de ${ }^{1} \mathrm{H}$ da substância $6\left(\mathrm{CDCl}_{3}, 7,05 \mathrm{~T}\right)$. 


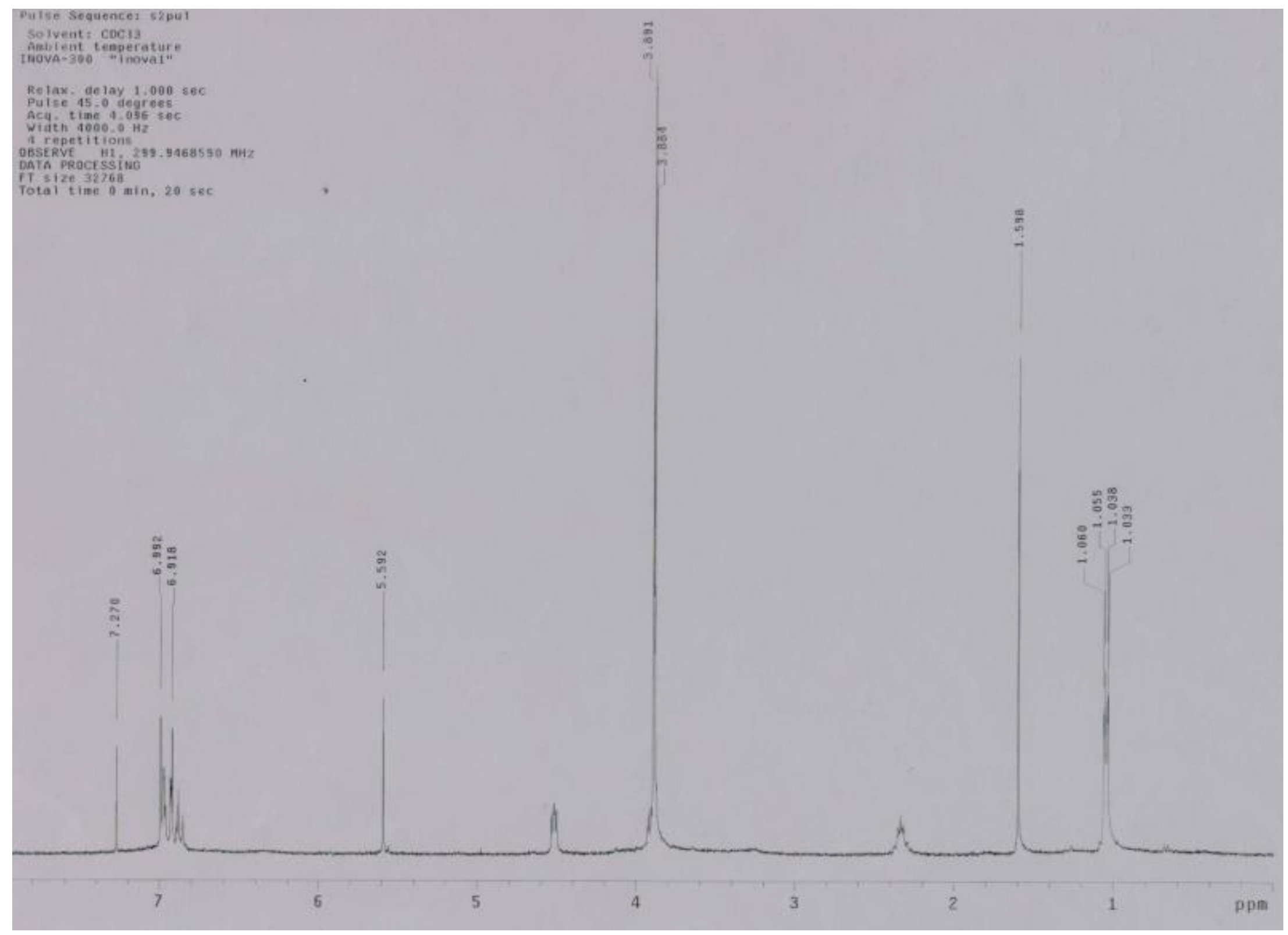

Espectro 16. RMN de ${ }^{1} \mathrm{H}$ da substância $7\left(\mathrm{CDCl}_{3}, 7,05 \mathrm{~T}\right)$. 


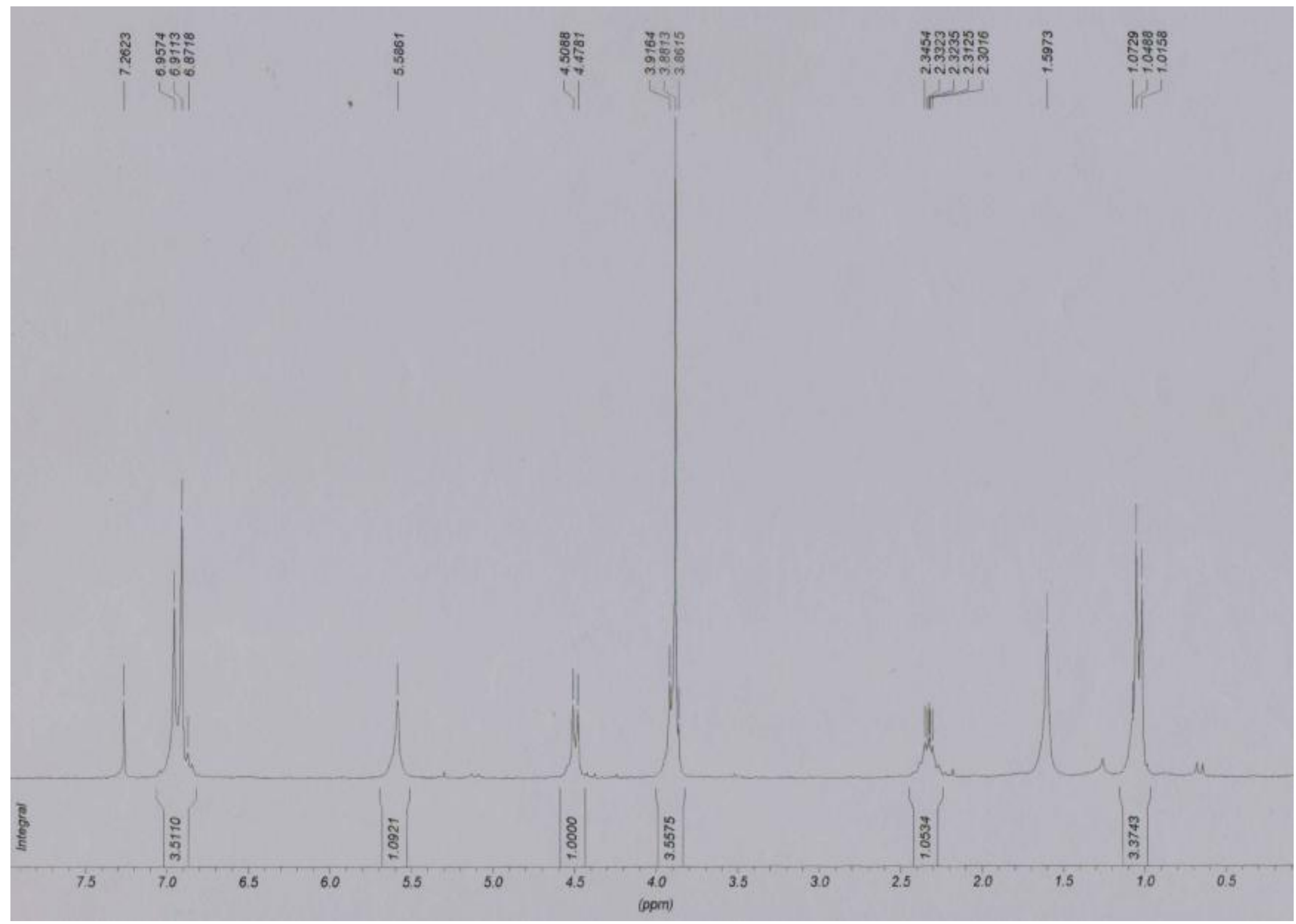

Espectro 17. RMN de ${ }^{1} \mathrm{H}$ da substância $8\left(\mathrm{CDCl}_{3}, 4,7 \mathrm{~T}\right)$. 


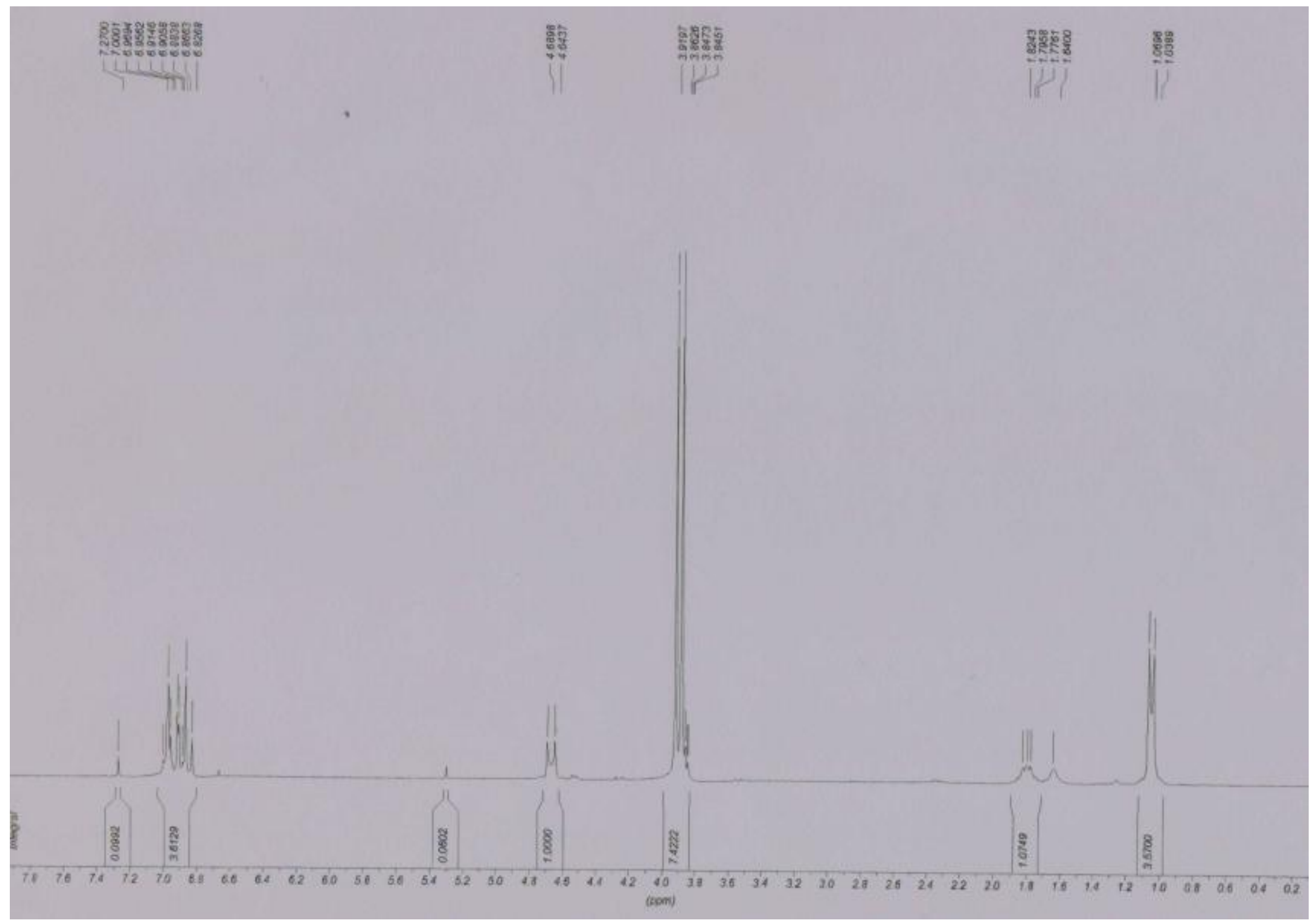

Espectro 18. RMN de ${ }^{1} \mathrm{H}$ da substância $9\left(\mathrm{CDCl}_{3}, 4,7 \mathrm{~T}\right)$. 


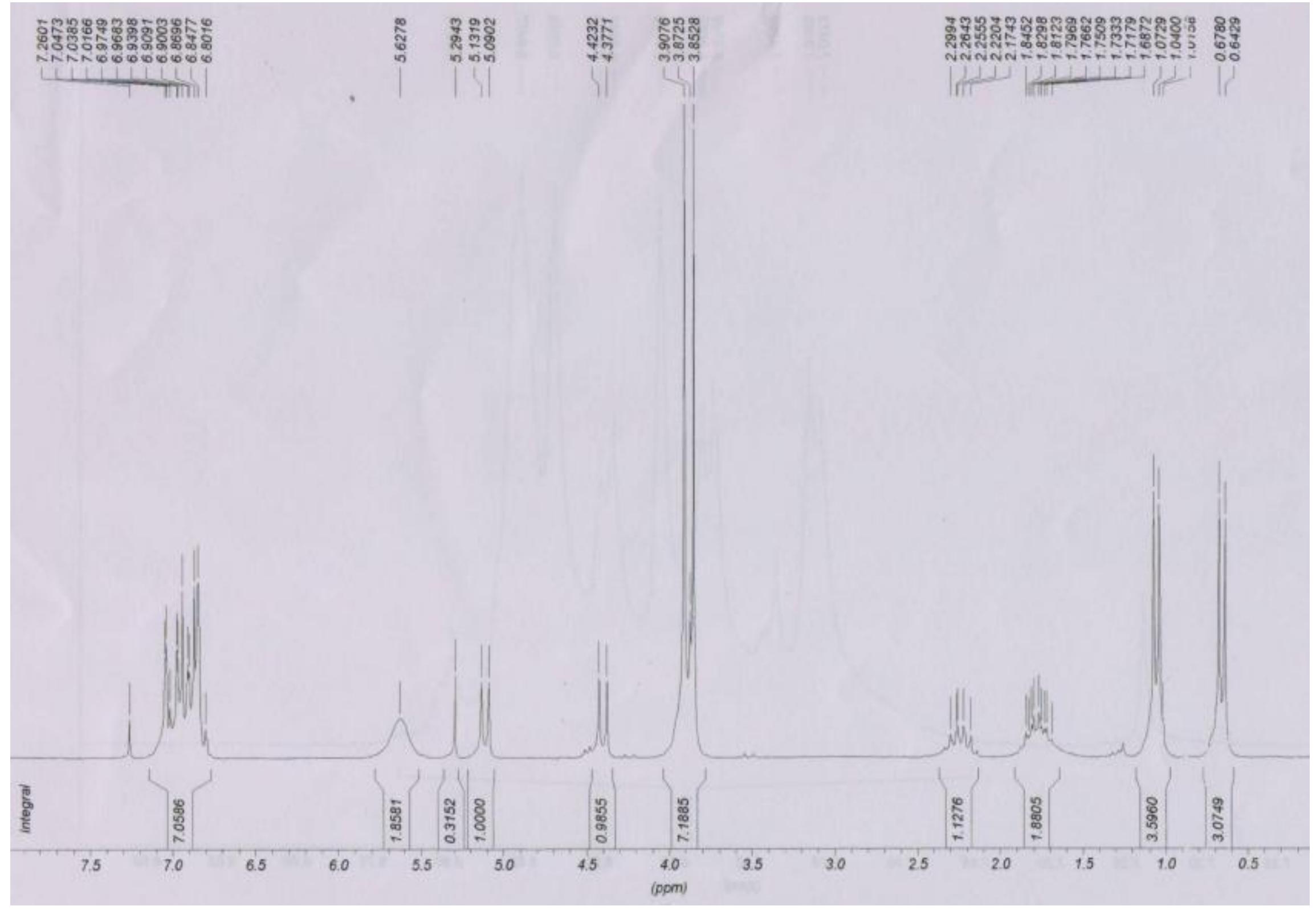

Espectro 19. RMN de ${ }^{1} \mathrm{H}$ da substância $10\left(\mathrm{CDCl}_{3}, 4,7 \mathrm{~T}\right)$. 


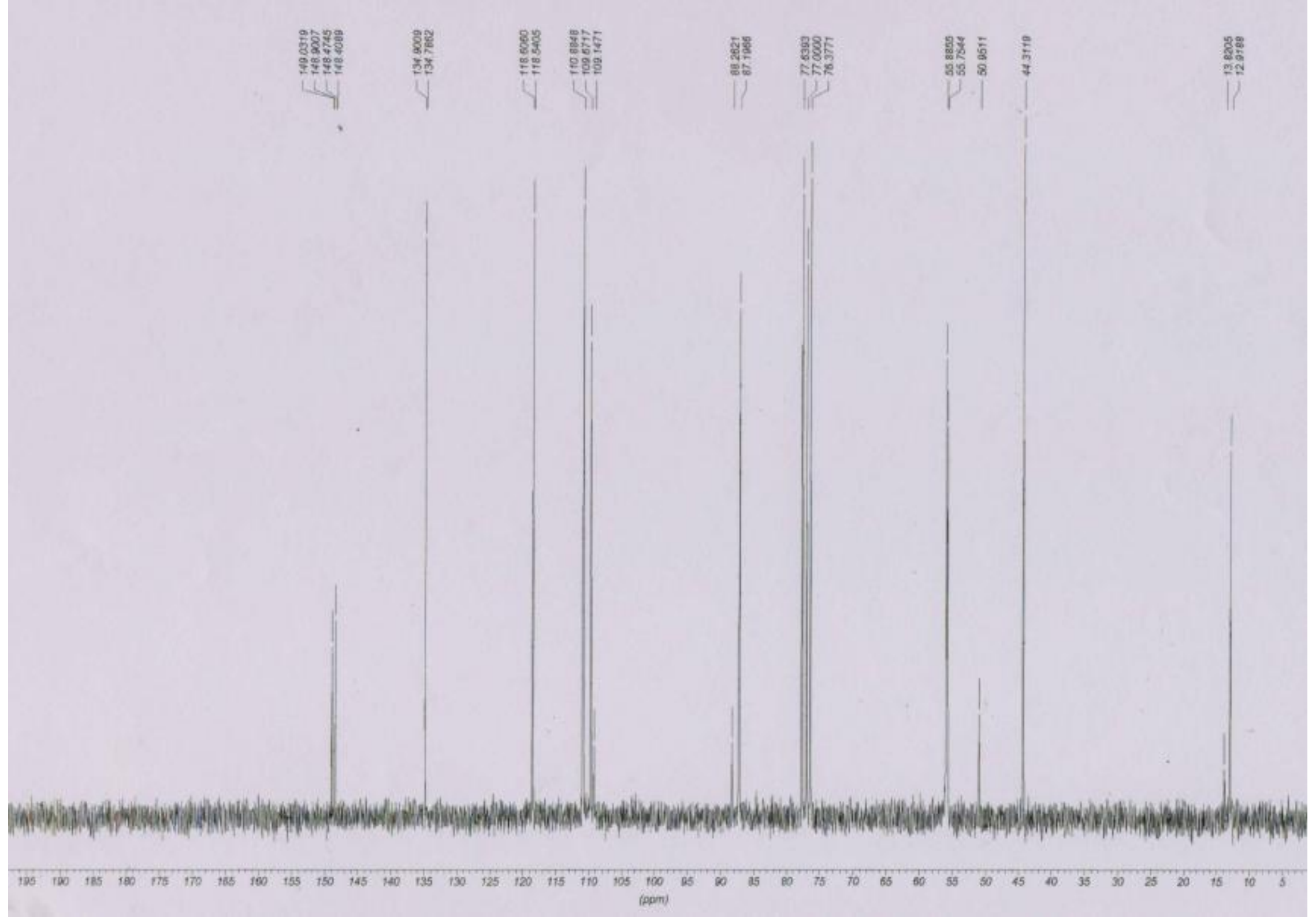

Espectro 20. RMN de ${ }^{13} \mathrm{C}$ da substância $6\left(\mathrm{CDCl}_{3}, 4,7 \mathrm{~T}\right)$. 


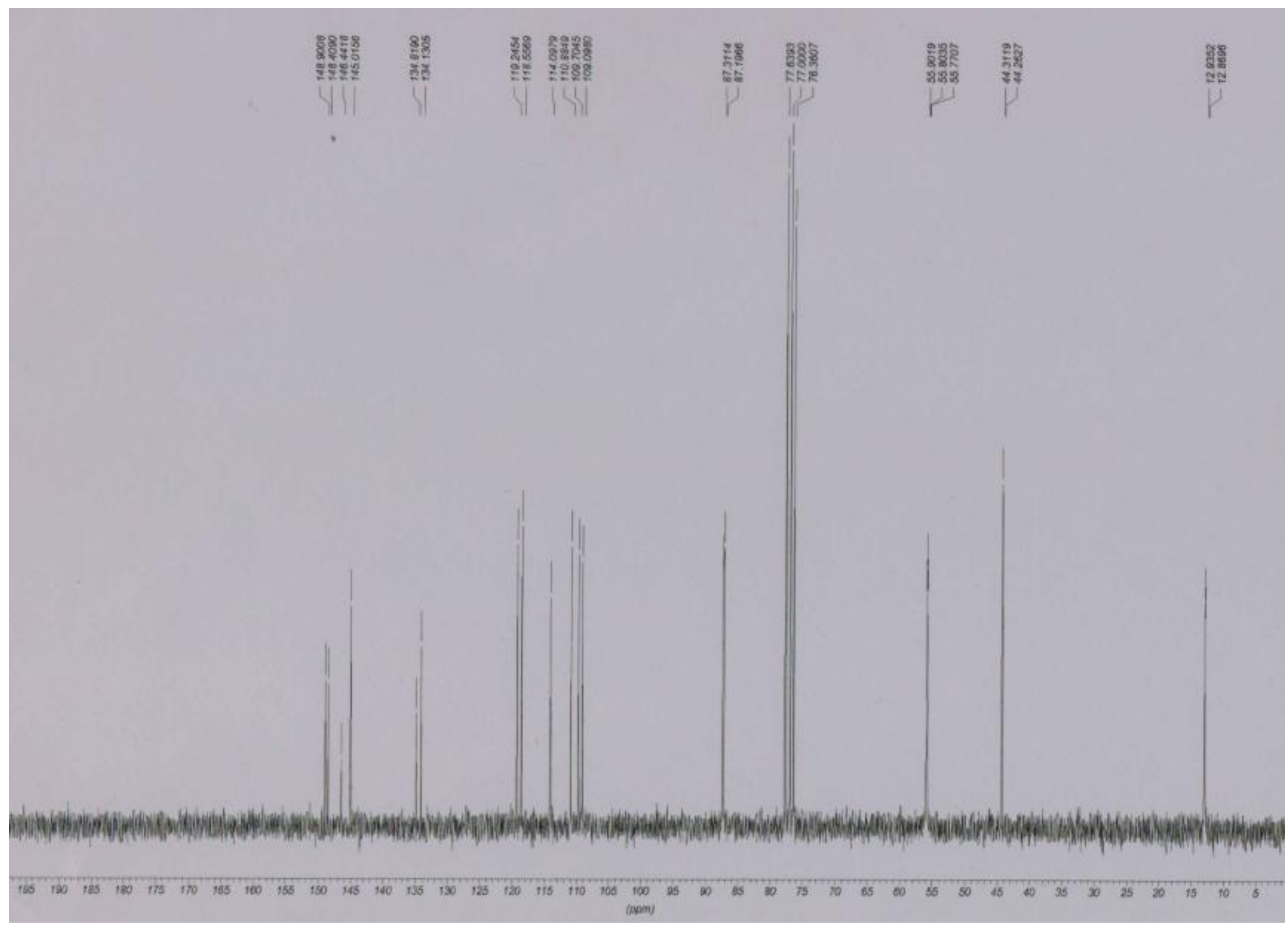

Espectro 21. RMN de ${ }^{13} \mathrm{C}$ da substância $7\left(\mathrm{CDCl}_{3}, 4,7 \mathrm{~T}\right)$. 


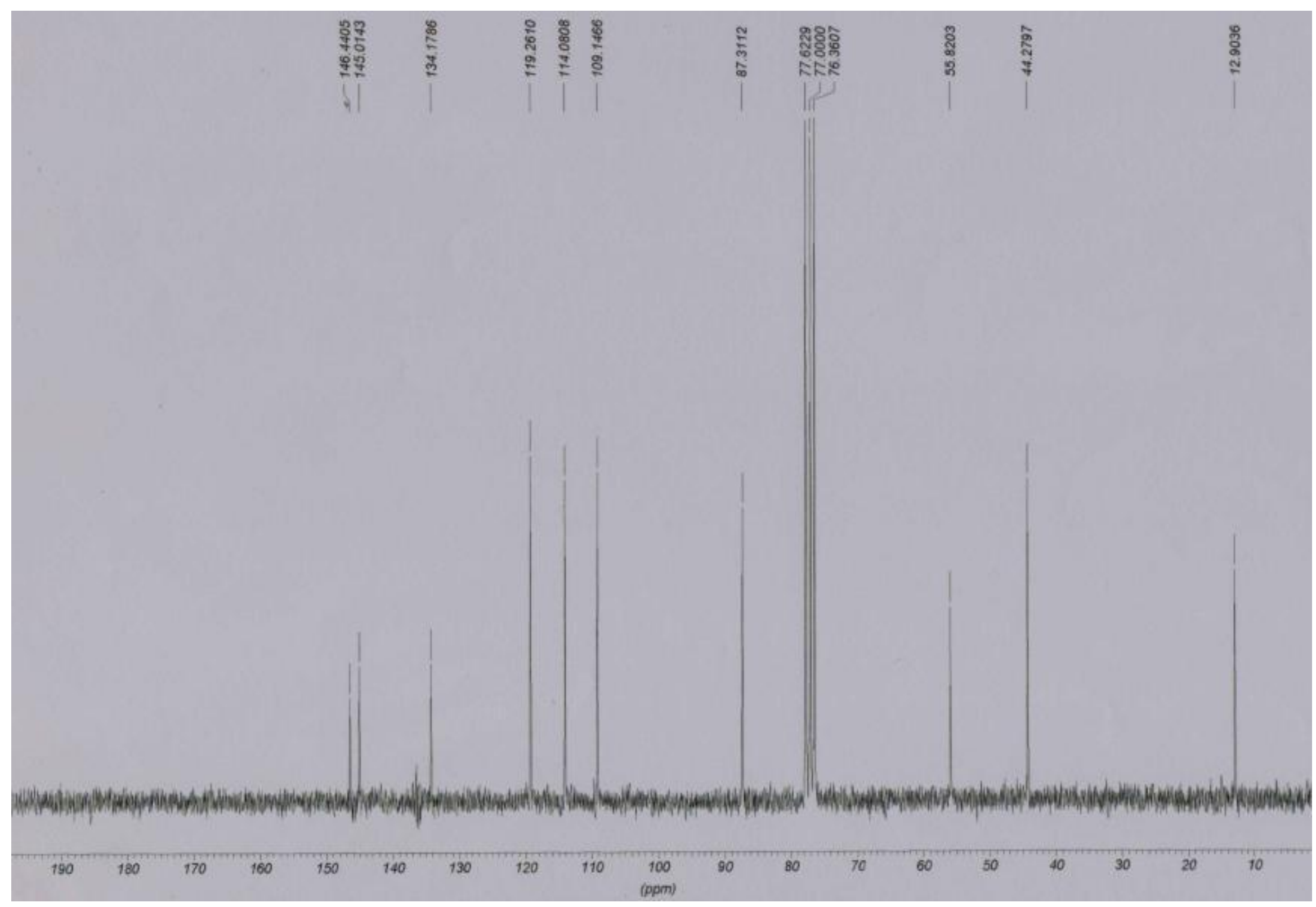

Espectro 22. RMN de ${ }^{13} \mathrm{C}$ da substância $8\left(\mathrm{CDCl}_{3}, 4,7 \mathrm{~T}\right)$. 


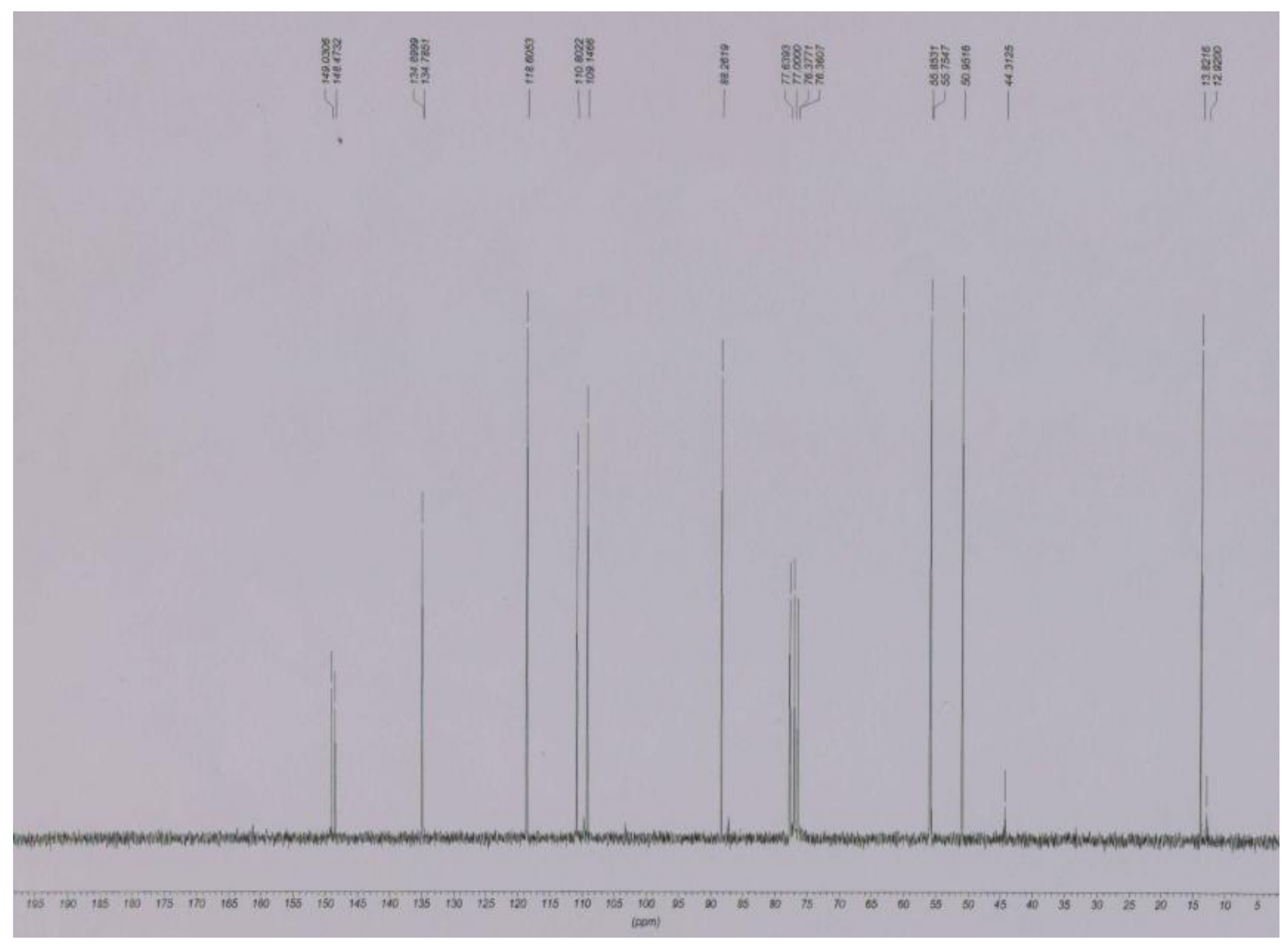

Espectro 23. RMN de ${ }^{13} \mathrm{C}$ da substância $9\left(\mathrm{CDCl}_{3}, 4,7 \mathrm{~T}\right)$. 


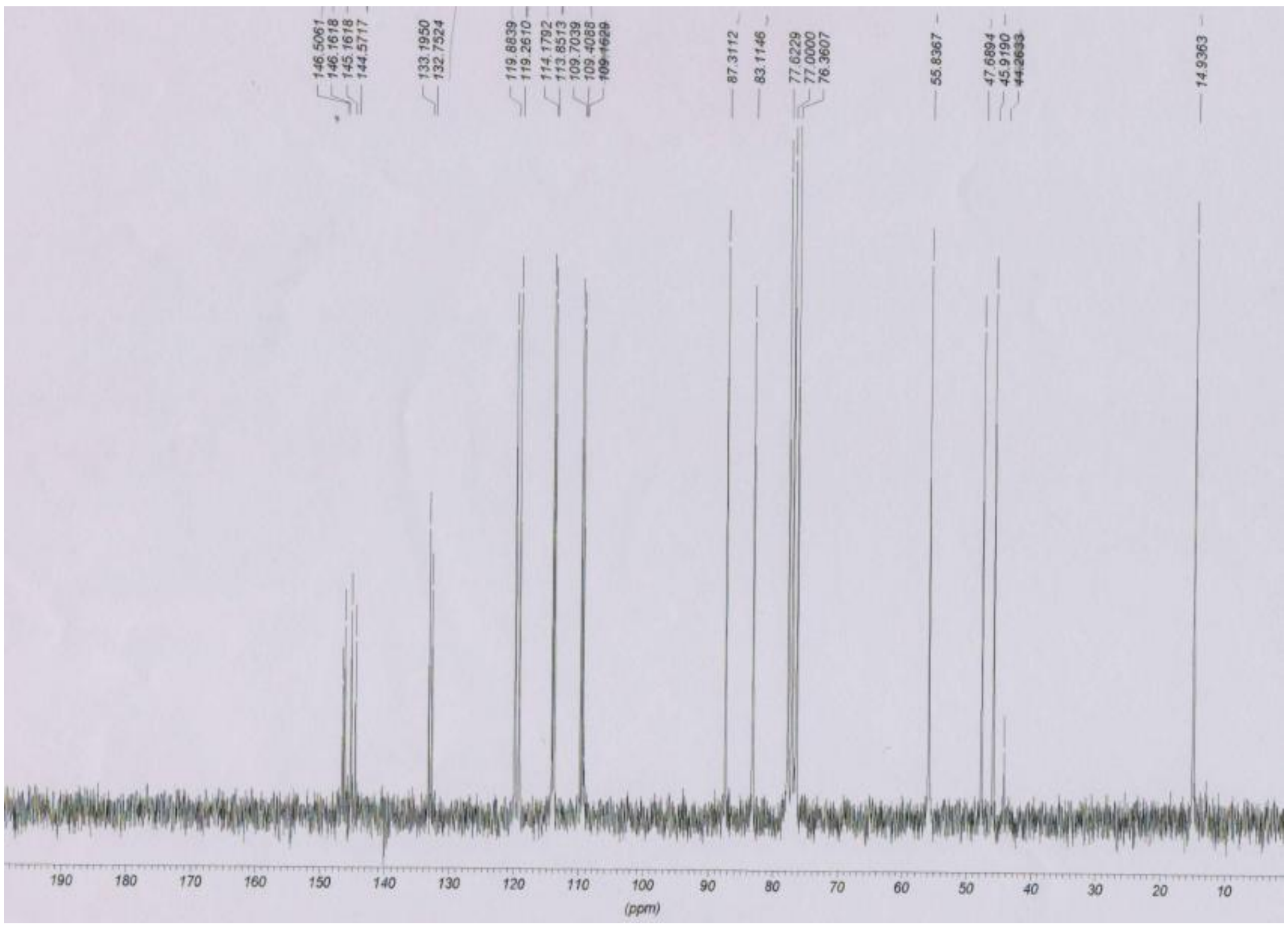

Espectro 24. RMN de ${ }^{13} \mathrm{C}$ da substância $10\left(\mathrm{CDCl}_{3}, 4,7 \mathrm{~T}\right)$. 
(A)
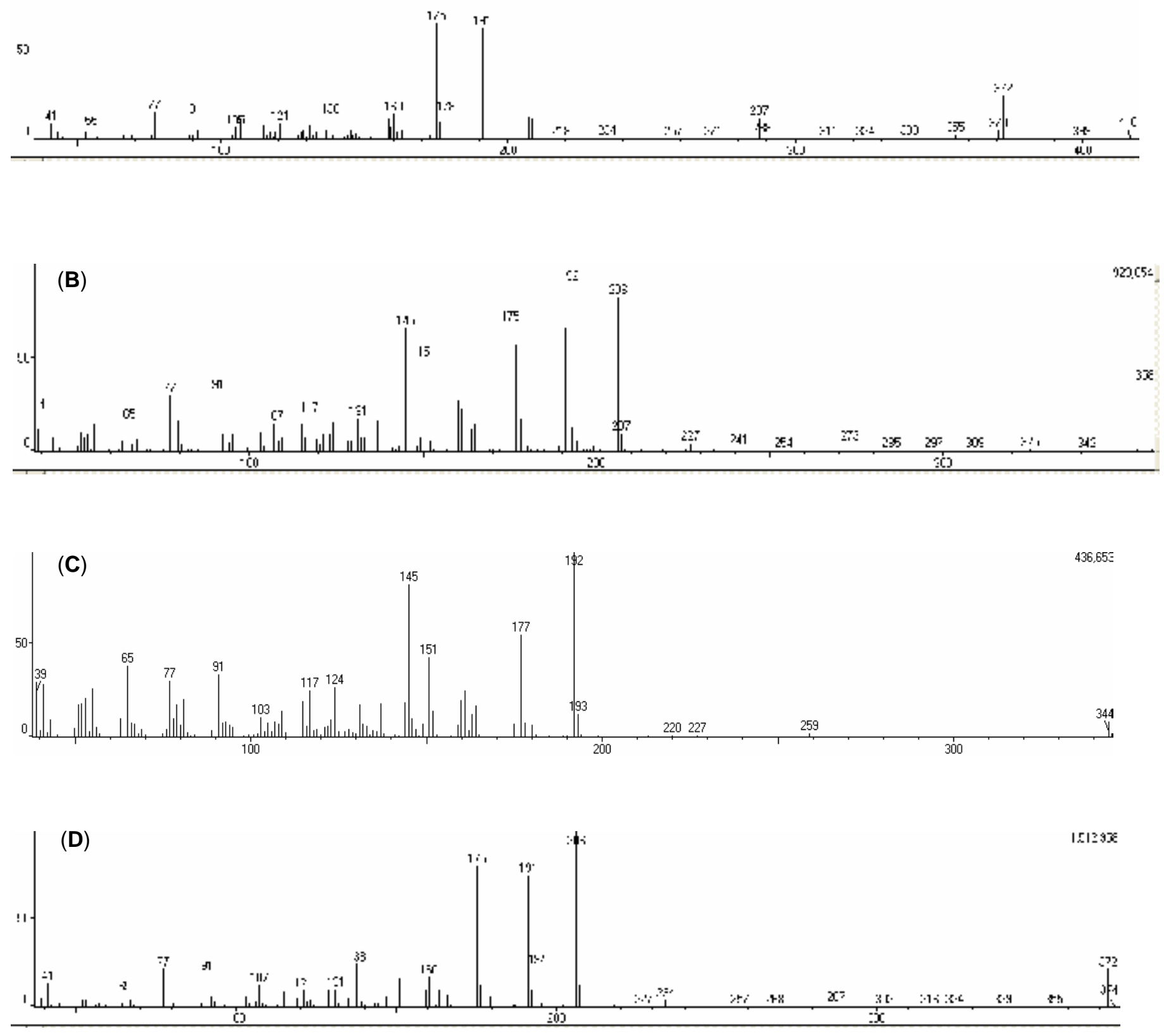

(E)

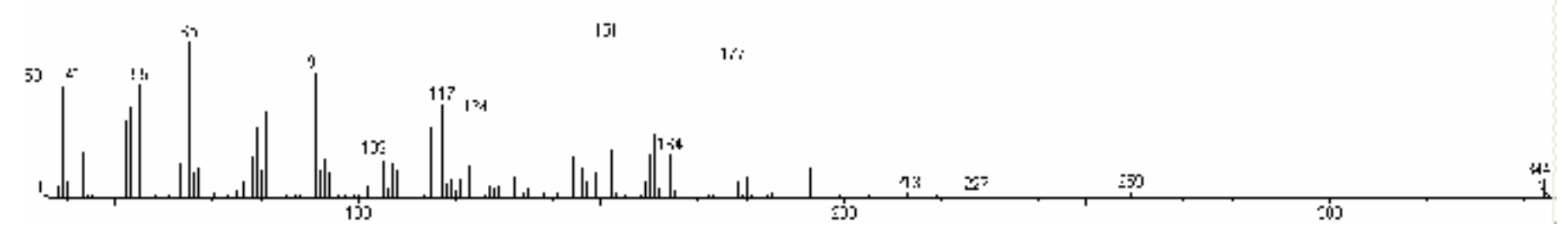

Espectro 25. (A) EM da substância 6, (B) EM da substância 7, (C) EM da substância 8, (D) EM da substância 9 e (E) EM da substância 10 (IE, 70 eV). 


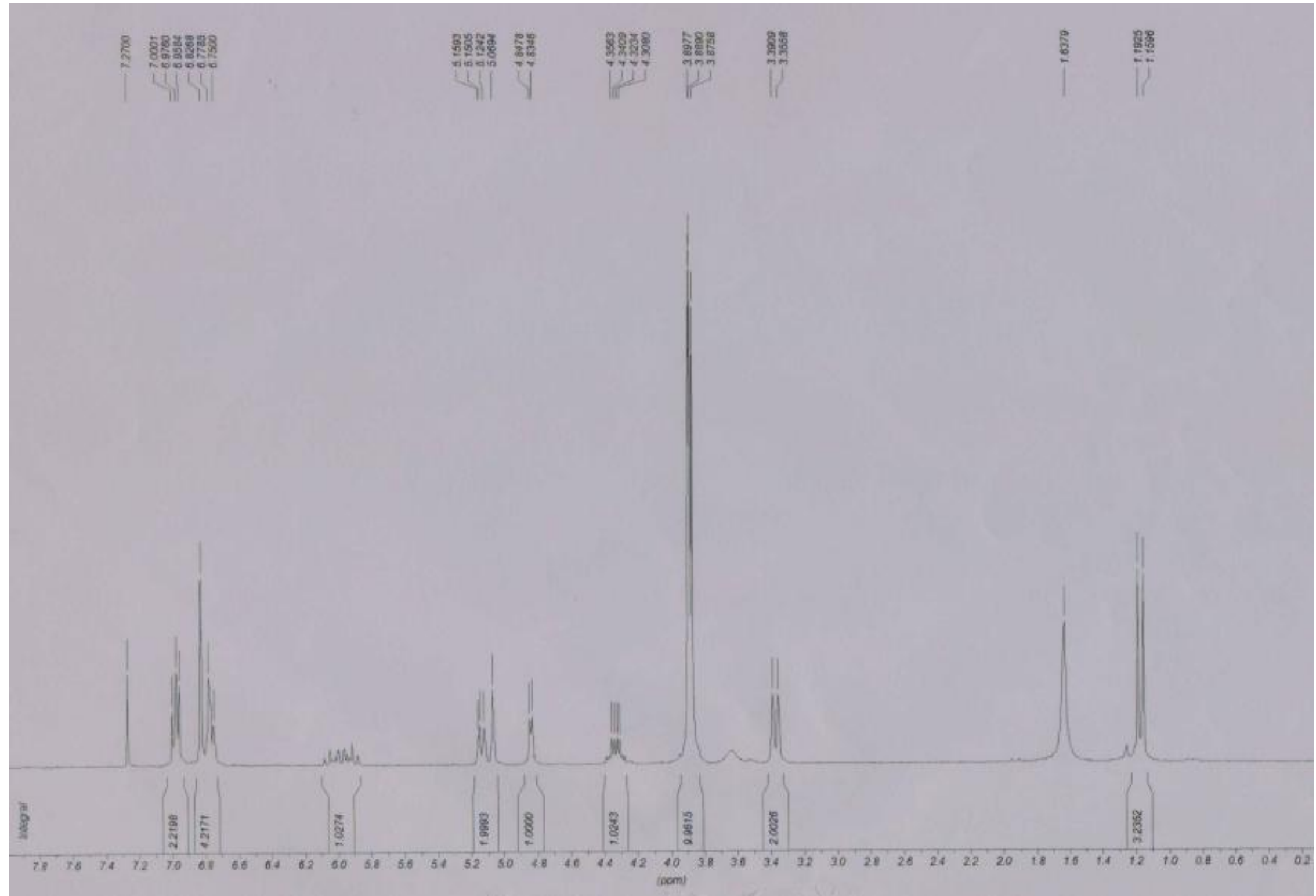

Espectro 26. RMN de ${ }^{1} \mathrm{H}$ da sustância $11\left(\mathrm{CDCl}_{3}, 4,7 \mathrm{~T}\right)$. 


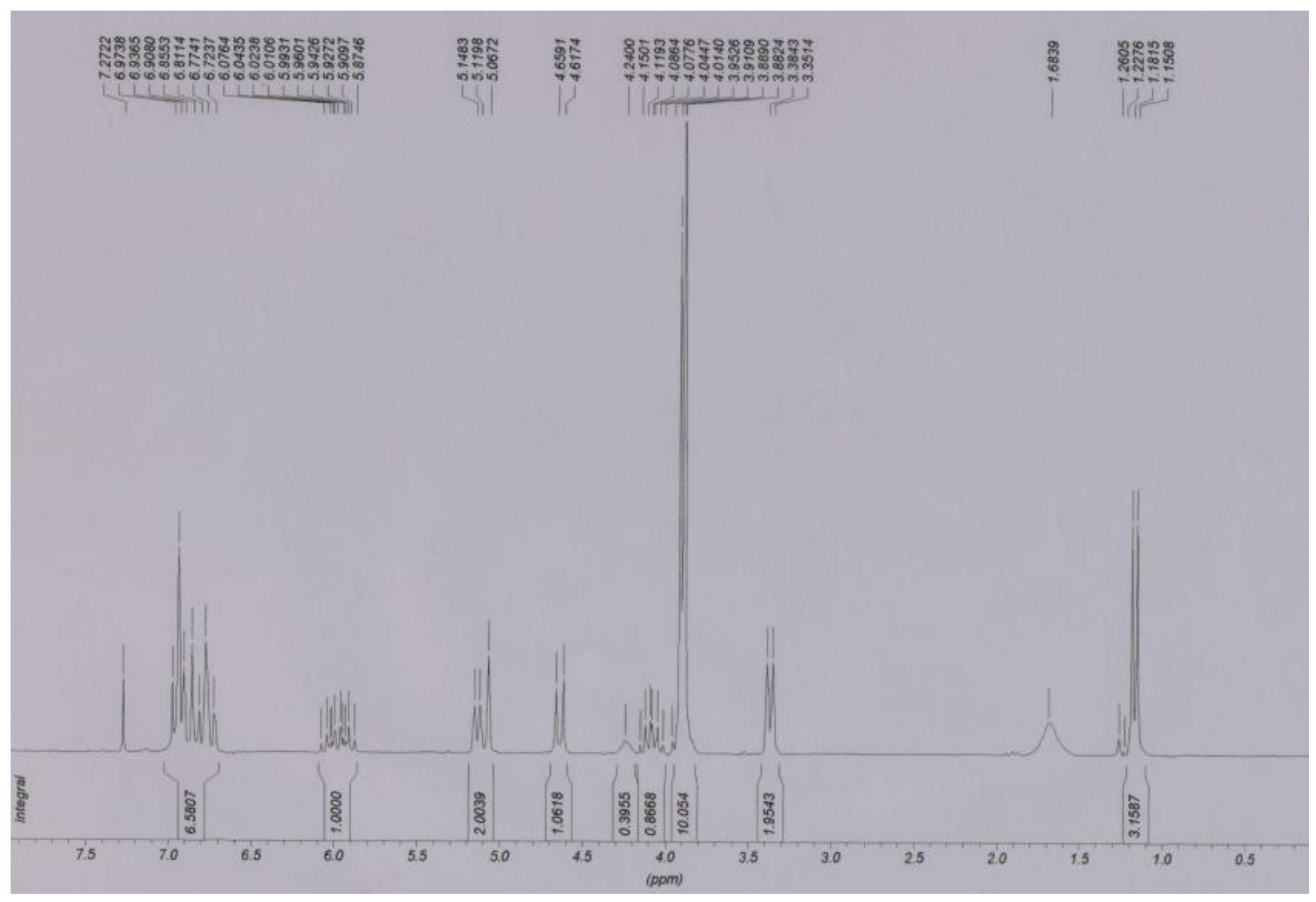

Espectro 27. RMN de ${ }^{1} \mathrm{H}$ da substância $12\left(\mathrm{CDCl}_{3}, 4,7 \mathrm{~T}\right)$. 


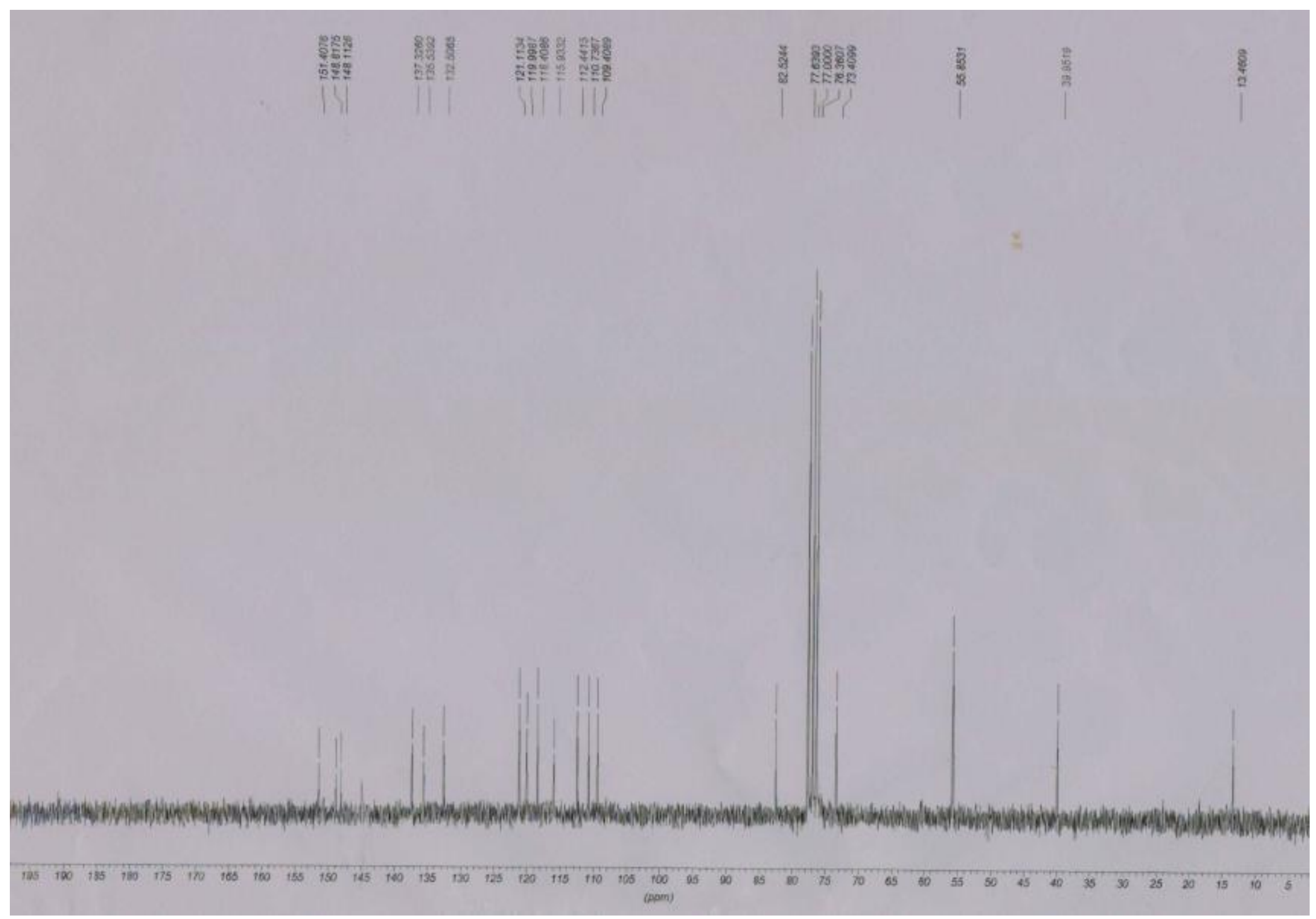

Espectro 28. RMN de ${ }^{13} \mathrm{C}$ da substância $11\left(\mathrm{CDCl}_{3}, 4,7 \mathrm{~T}\right)$. 


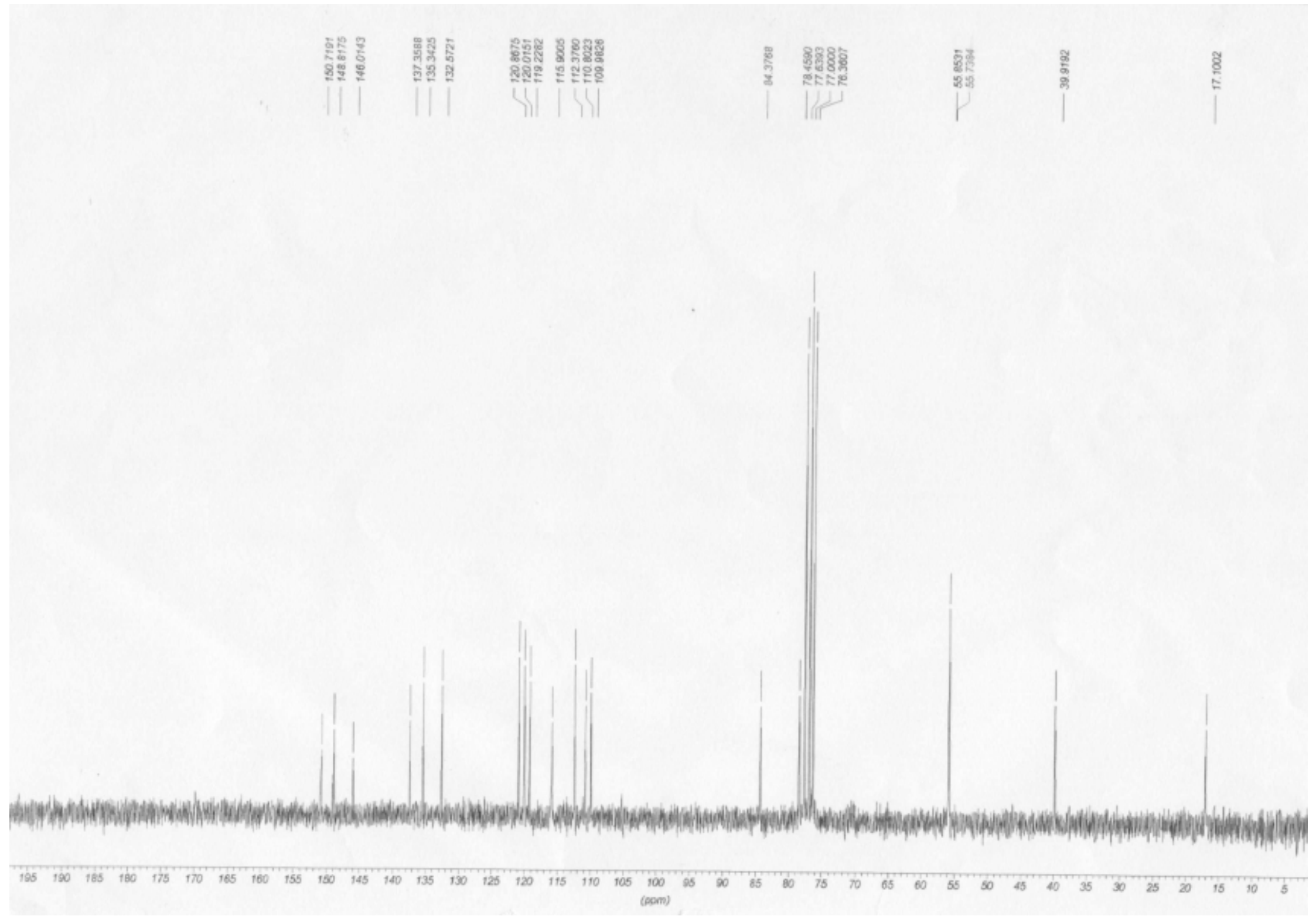

Espectro 29. RMN de ${ }^{13} \mathrm{C}$ da substância $12\left(\mathrm{CDCl}_{3}, 4,7 \mathrm{~T}\right)$. 


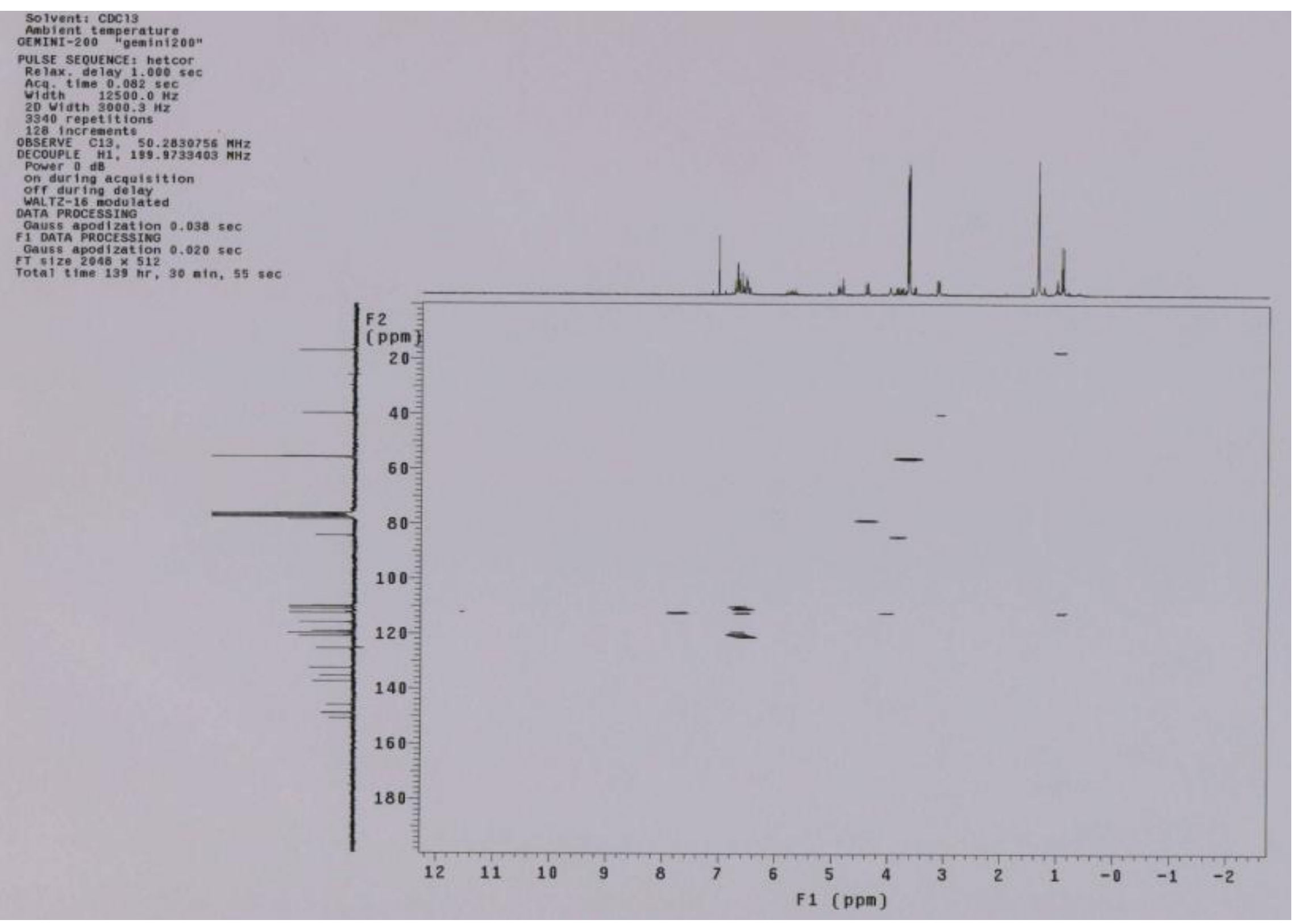

Espectro 30. HETERO-COSY da substância $12\left(\mathrm{CDCl}_{3}, 4,7 \mathrm{~T}\right)$. 
(A)
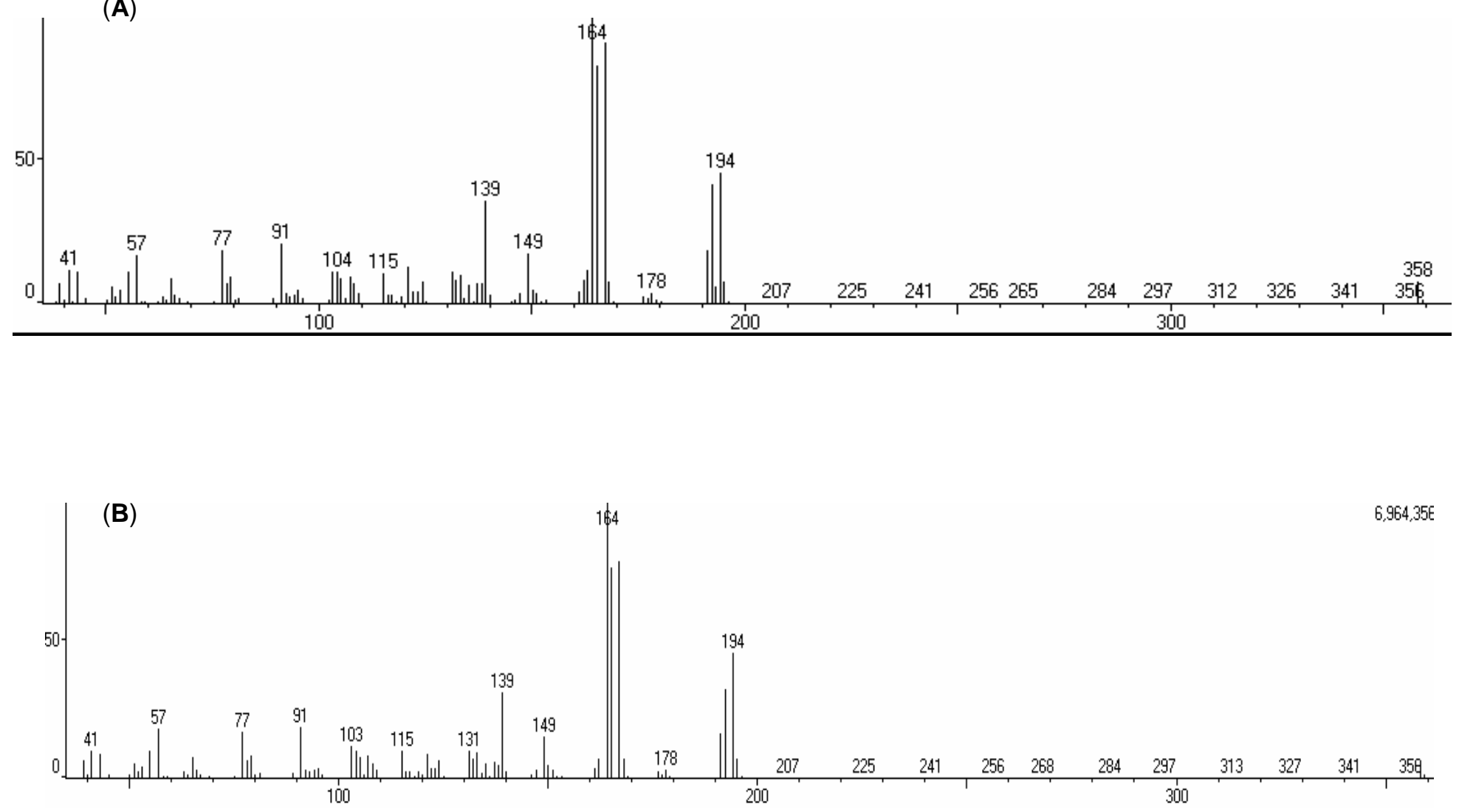

Espectro 31. (A) EM da substância 11 e (B) EM da substância 12 (IE, 70 eV). 


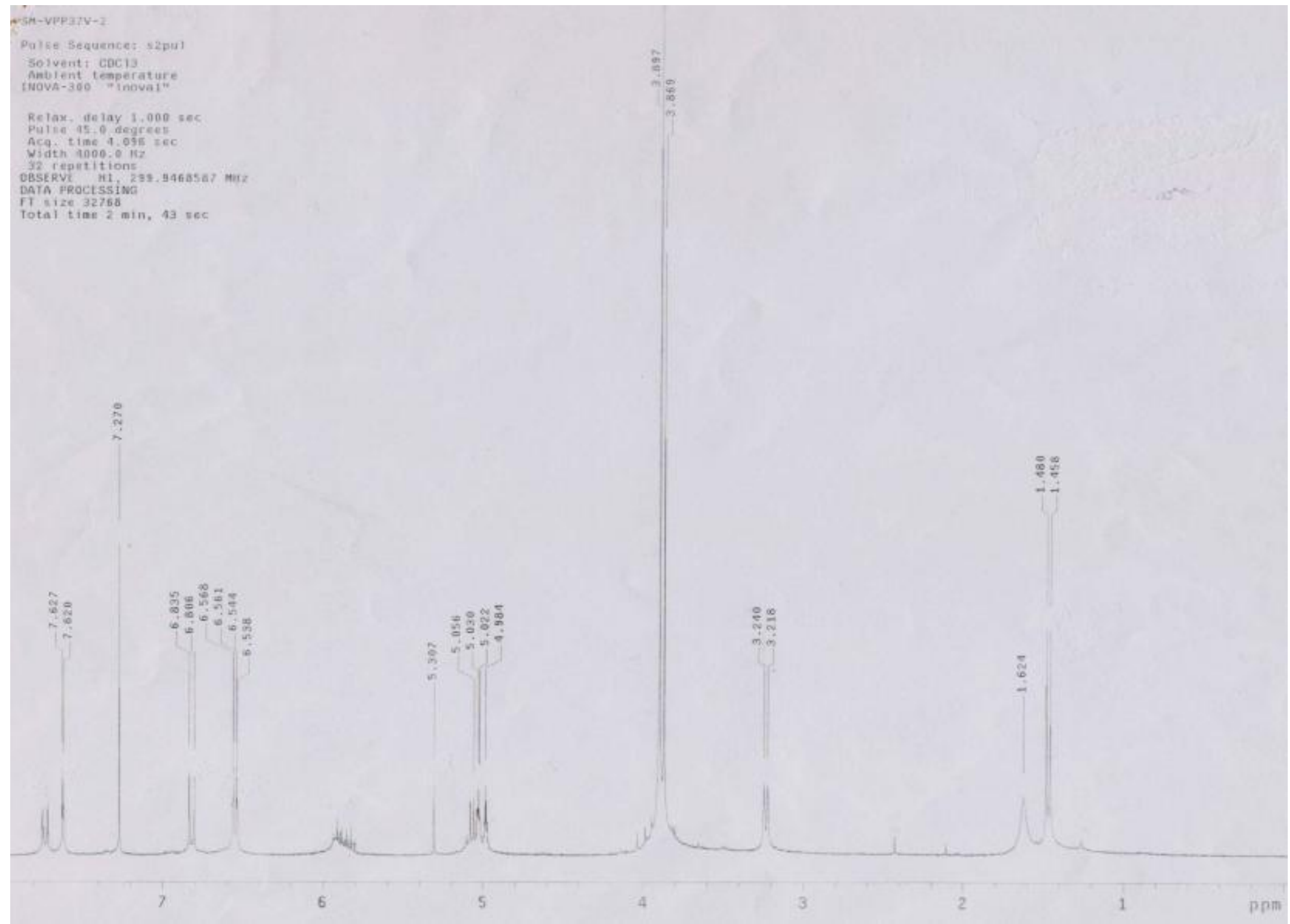

Espectro 32. RMN de ${ }^{1} \mathrm{H}$ da substância $13\left(\mathrm{CDCl}_{3}, 7,05 \mathrm{~T}\right)$. 


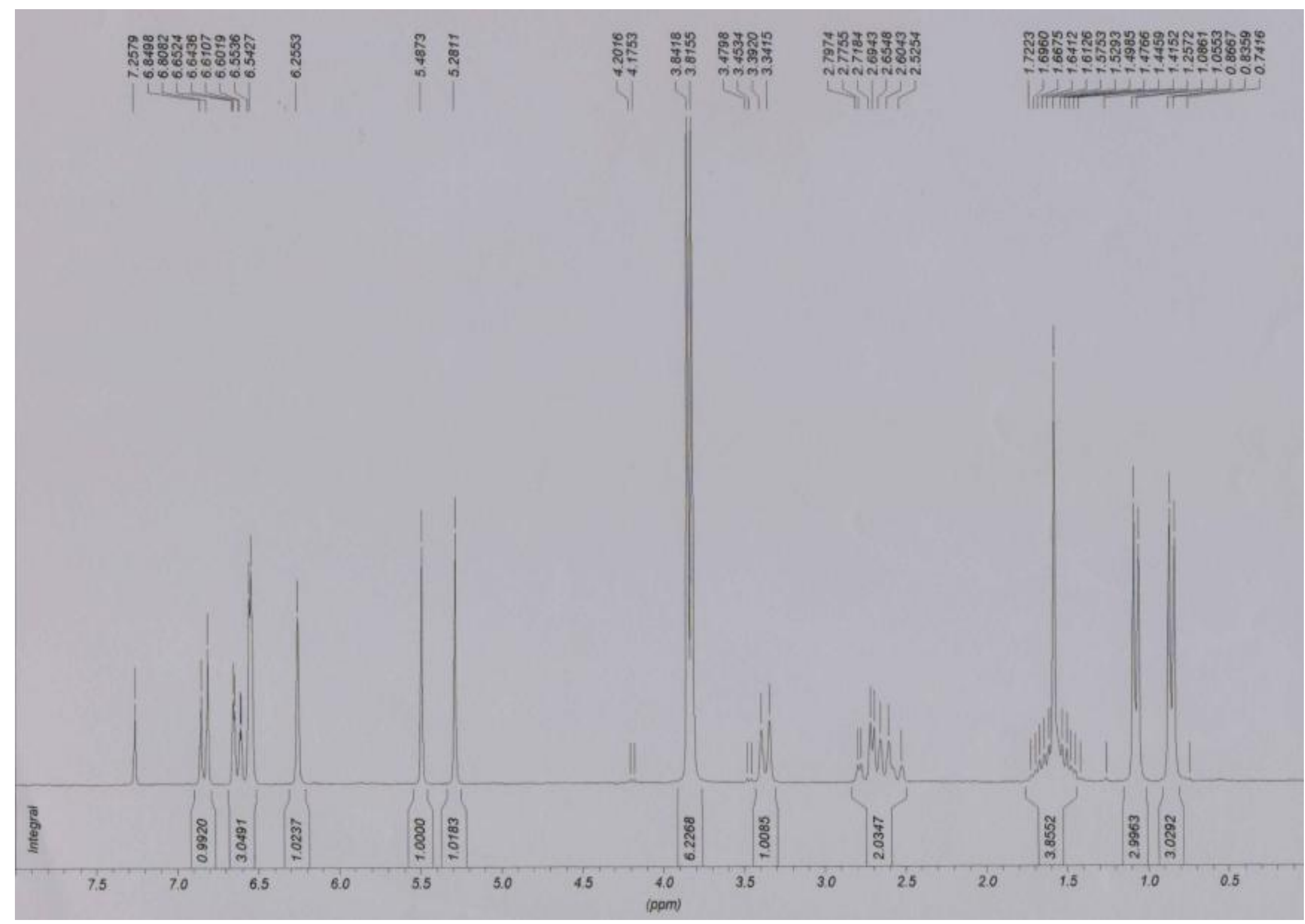

Espectro 33. RMN de ${ }^{1} \mathrm{H}$ da substância $14\left(\mathrm{CDCl}_{3}, 4,7 \mathrm{~T}\right)$. 


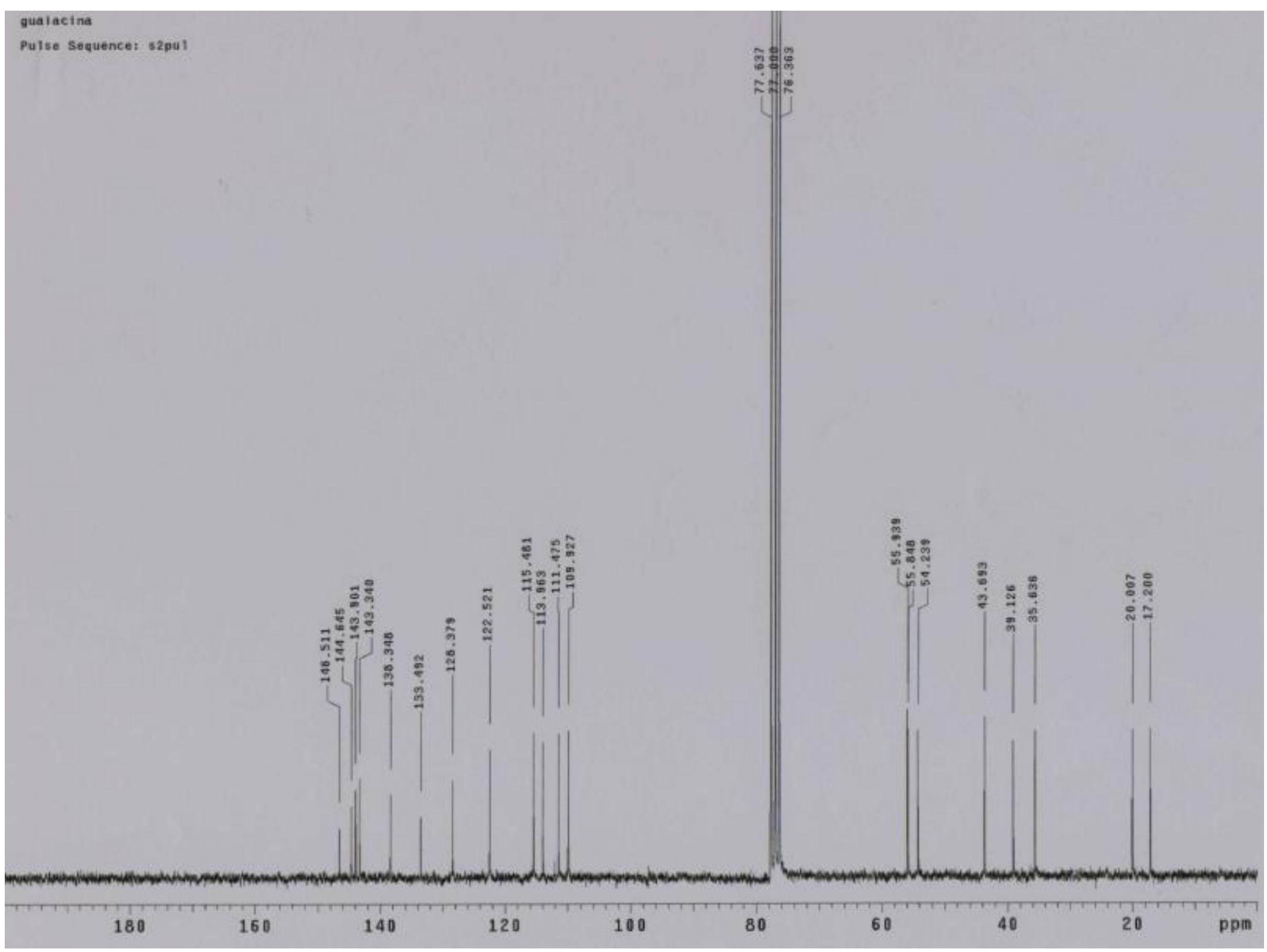

Espectro 34. RMN de ${ }^{13} \mathrm{C}$ da substância $14\left(\mathrm{CDCl}_{3}, 4,7 \mathrm{~T}\right)$. 
Espectro 35. HETERO-COSY da substância $14\left(\mathrm{CDCl}_{3}, 4,7 \mathrm{~T}\right)$. 


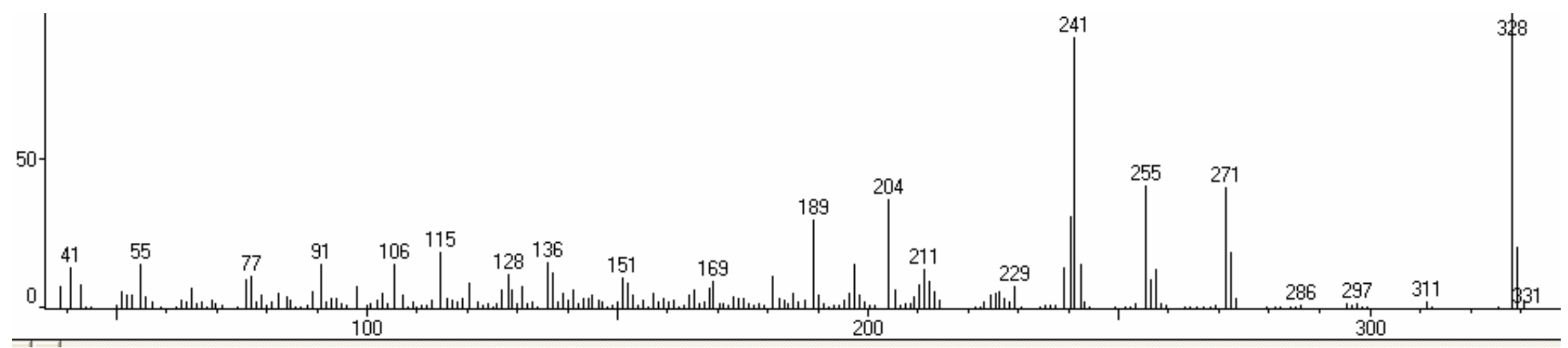

Espectro 36. EM da substância 14 (IE, 70 eV). 


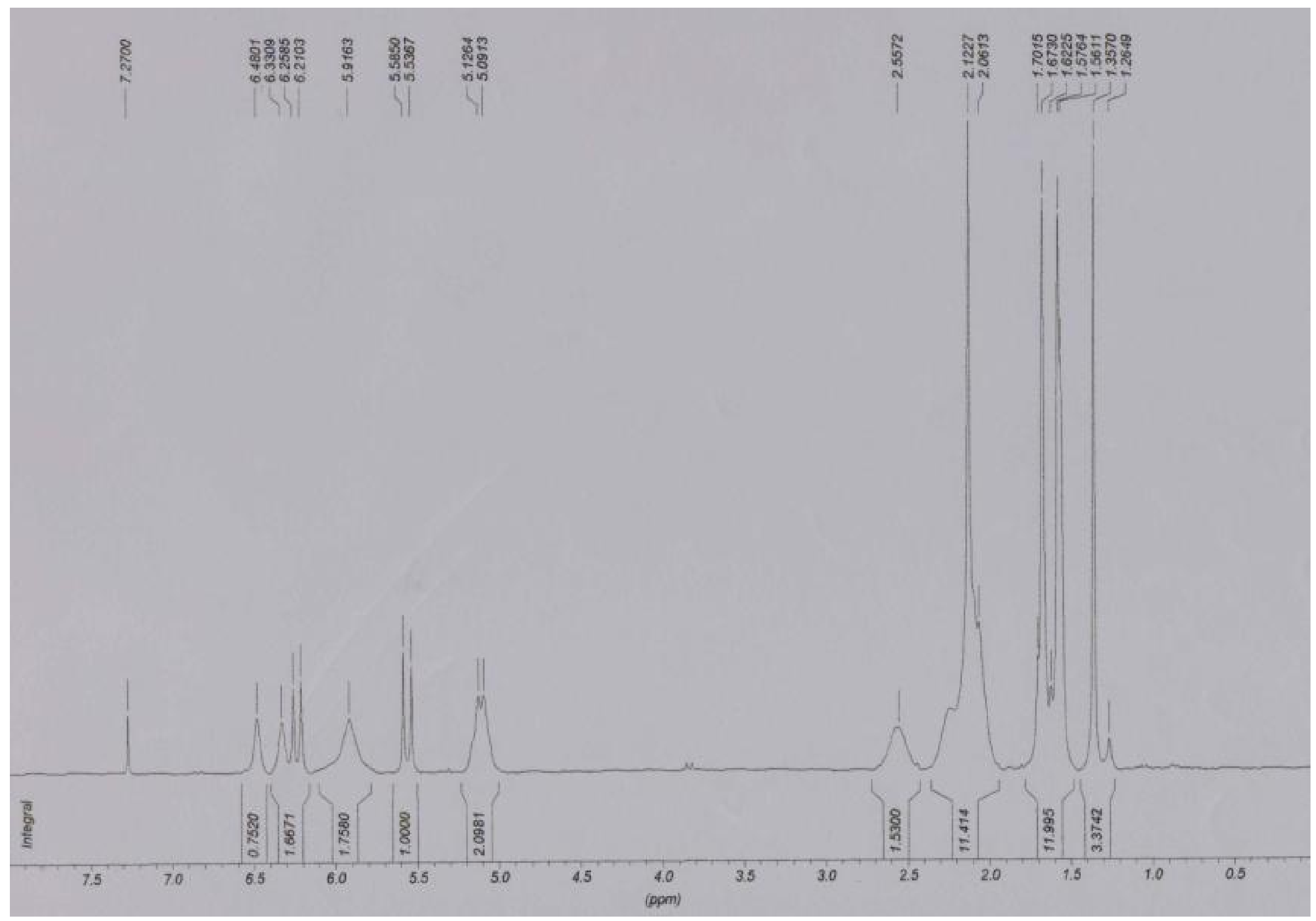

Espectro 37. RMN de ${ }^{1} \mathrm{H}$ da substância $15\left(\mathrm{CDCl}_{3}, 4,7 \mathrm{~T}\right)$. 


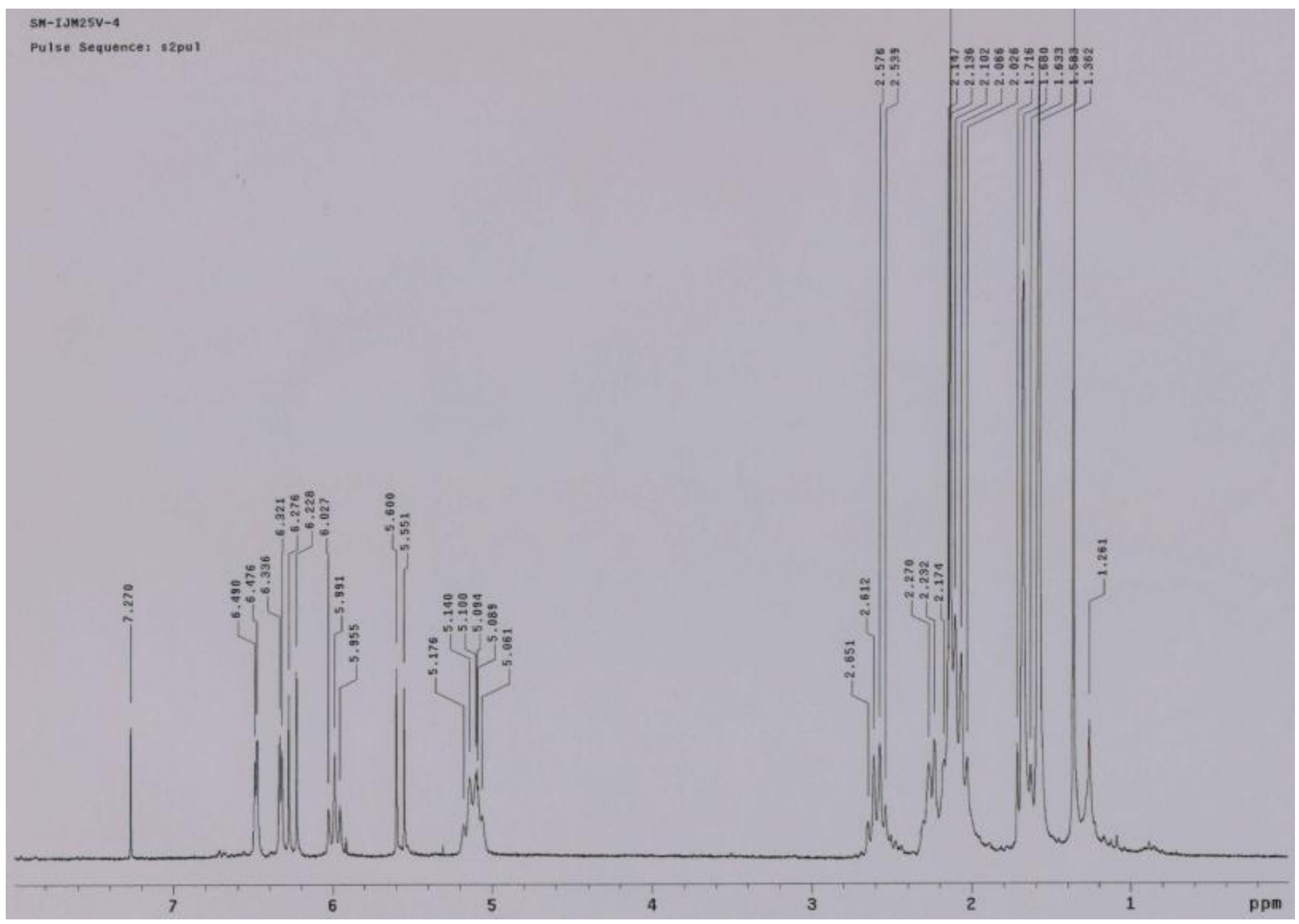

Espectro 38. RMN de ${ }^{1} \mathrm{H}$ da substância $16\left(\mathrm{CDCl}_{3}, 4,7 \mathrm{~T}\right)$. 


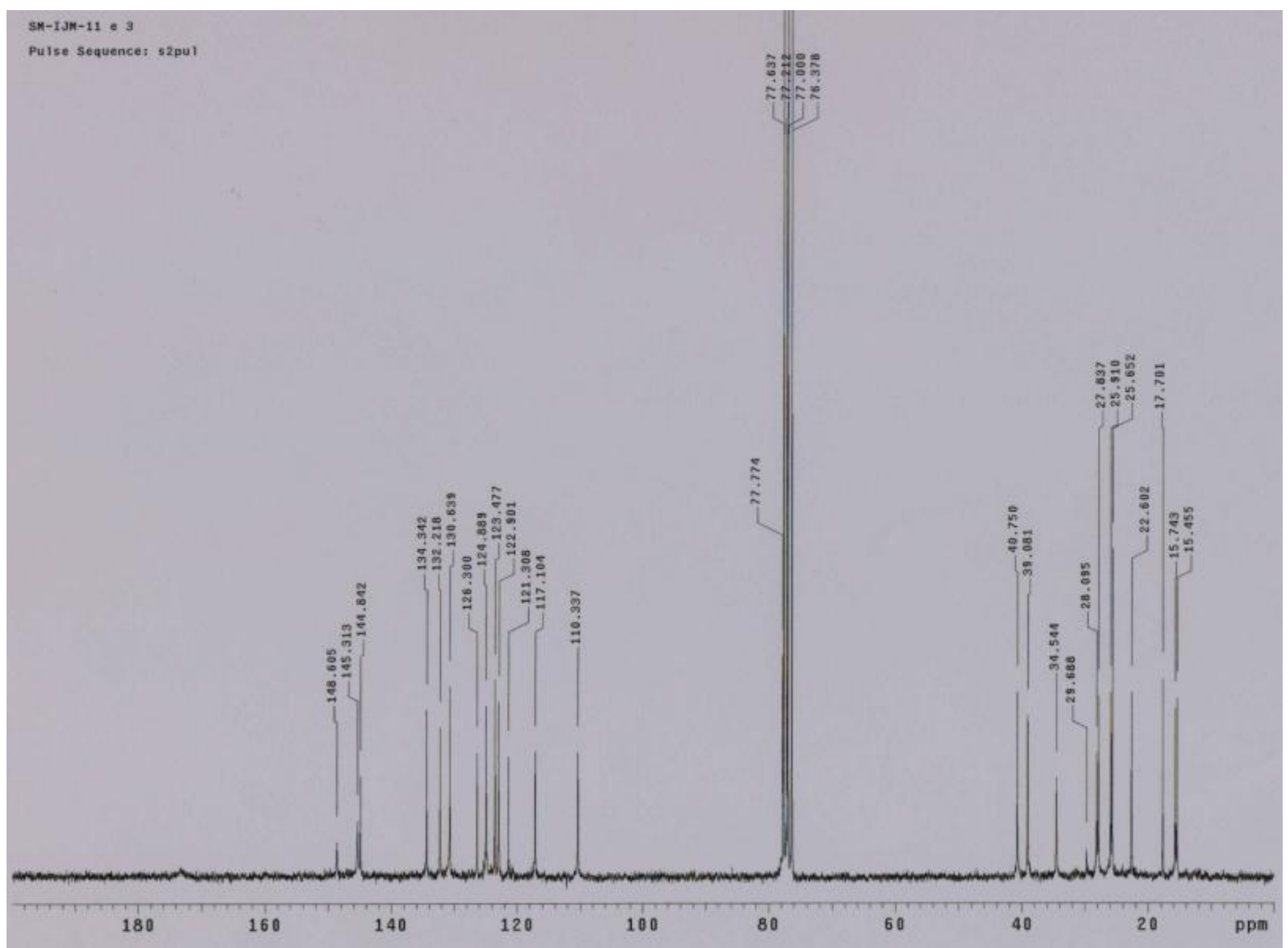

Espectro 39. RMN de ${ }^{13} \mathrm{C}$ da substância $15\left(\mathrm{CDCl}_{3}, 4,7 \mathrm{~T}\right)$. 


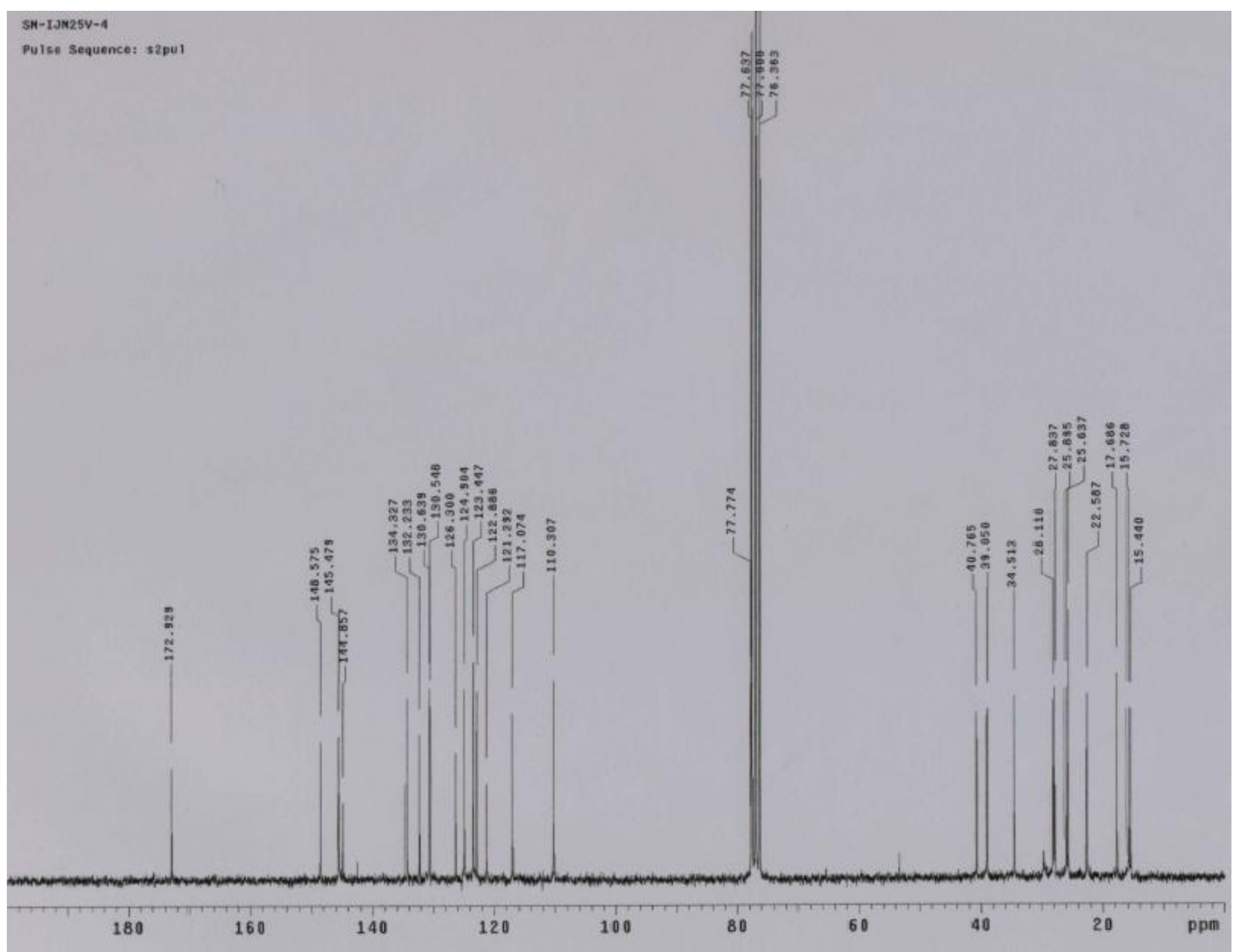

Espectro 40. RMN de ${ }^{13} \mathrm{C}$ da substância $16\left(\mathrm{CDCl}_{3}, 4,7 \mathrm{~T}\right)$. 
(A)

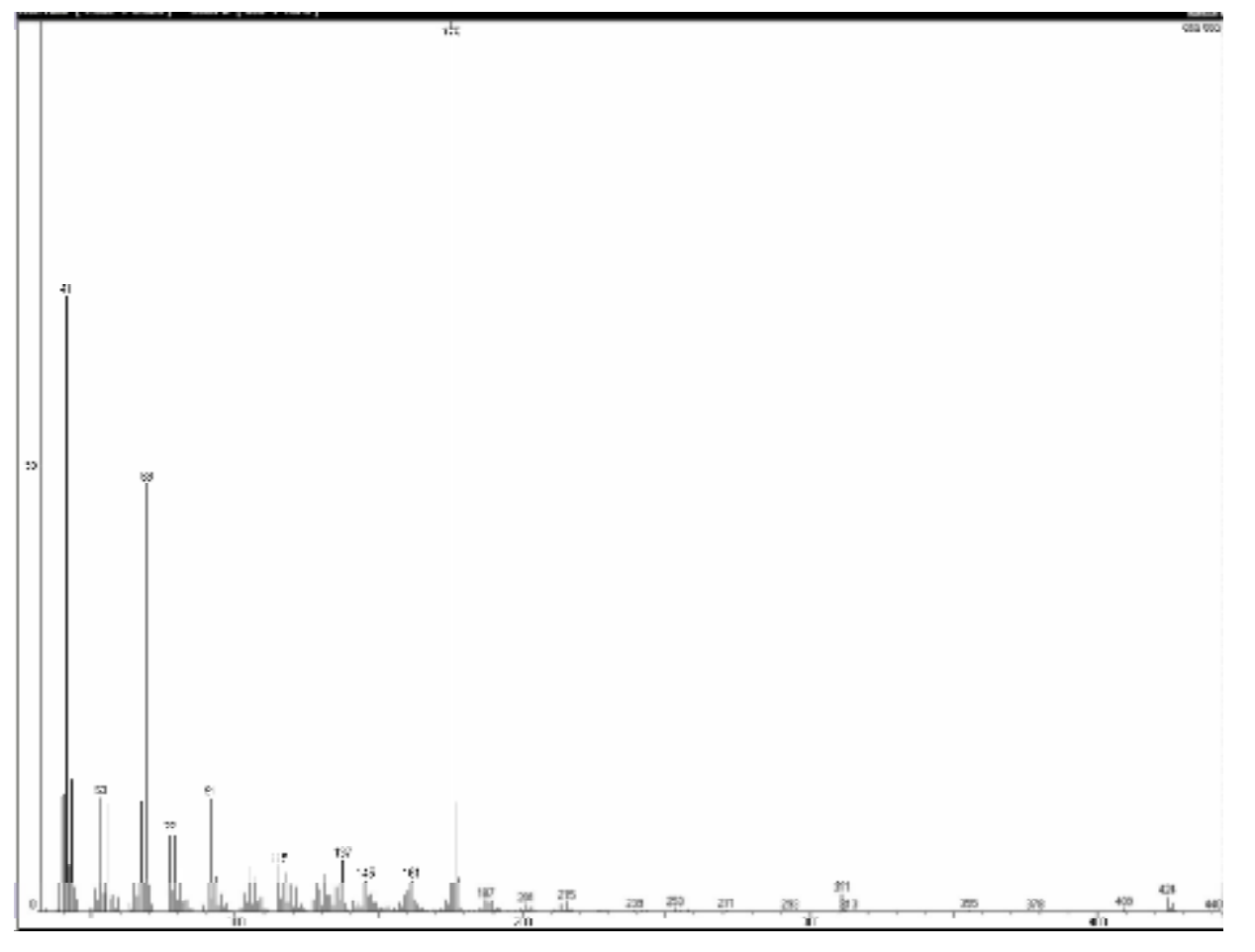

(B)

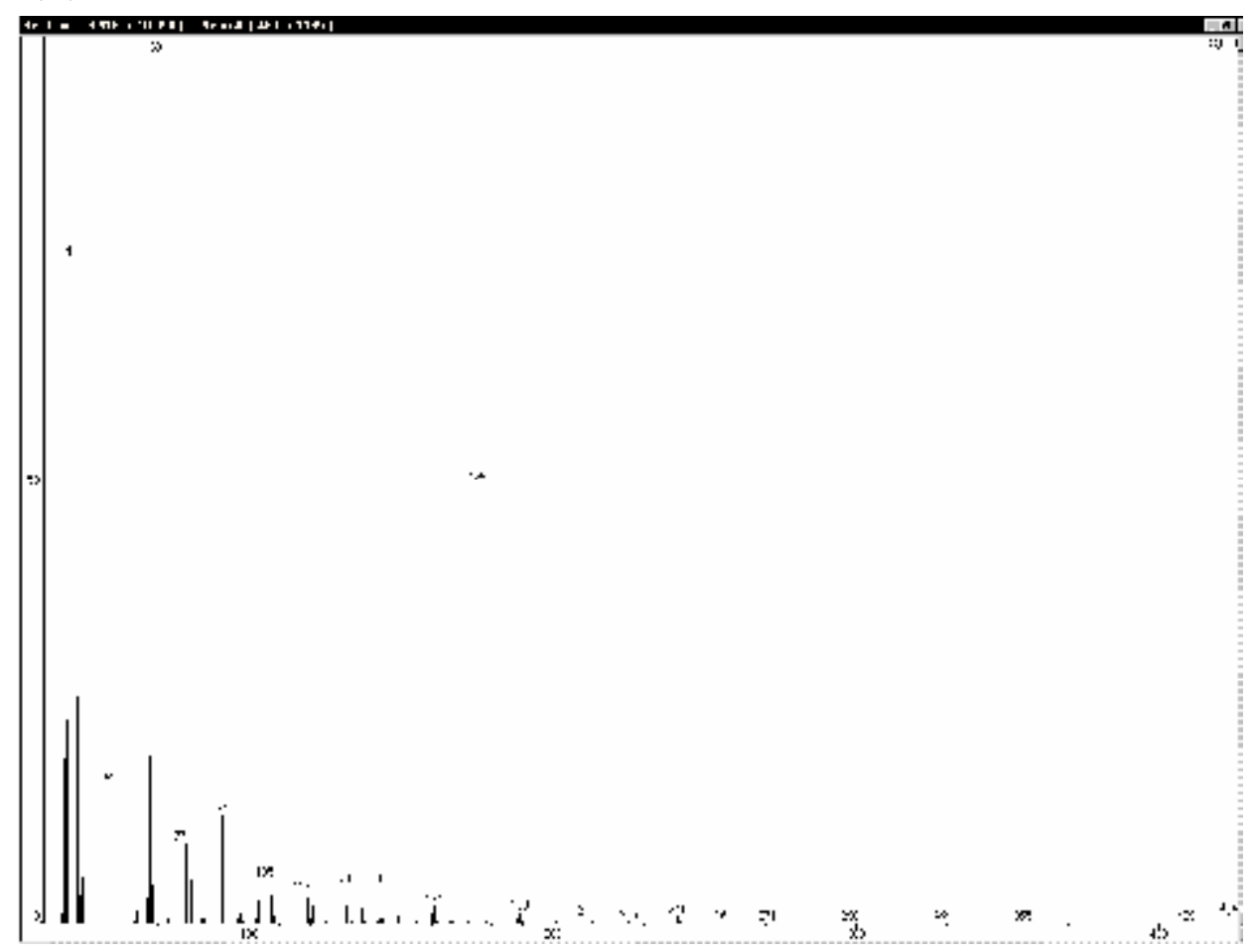

Espectro 41. (A) EM da substância 15 e (B) EM da substância 16 (IE, 70 eV). 


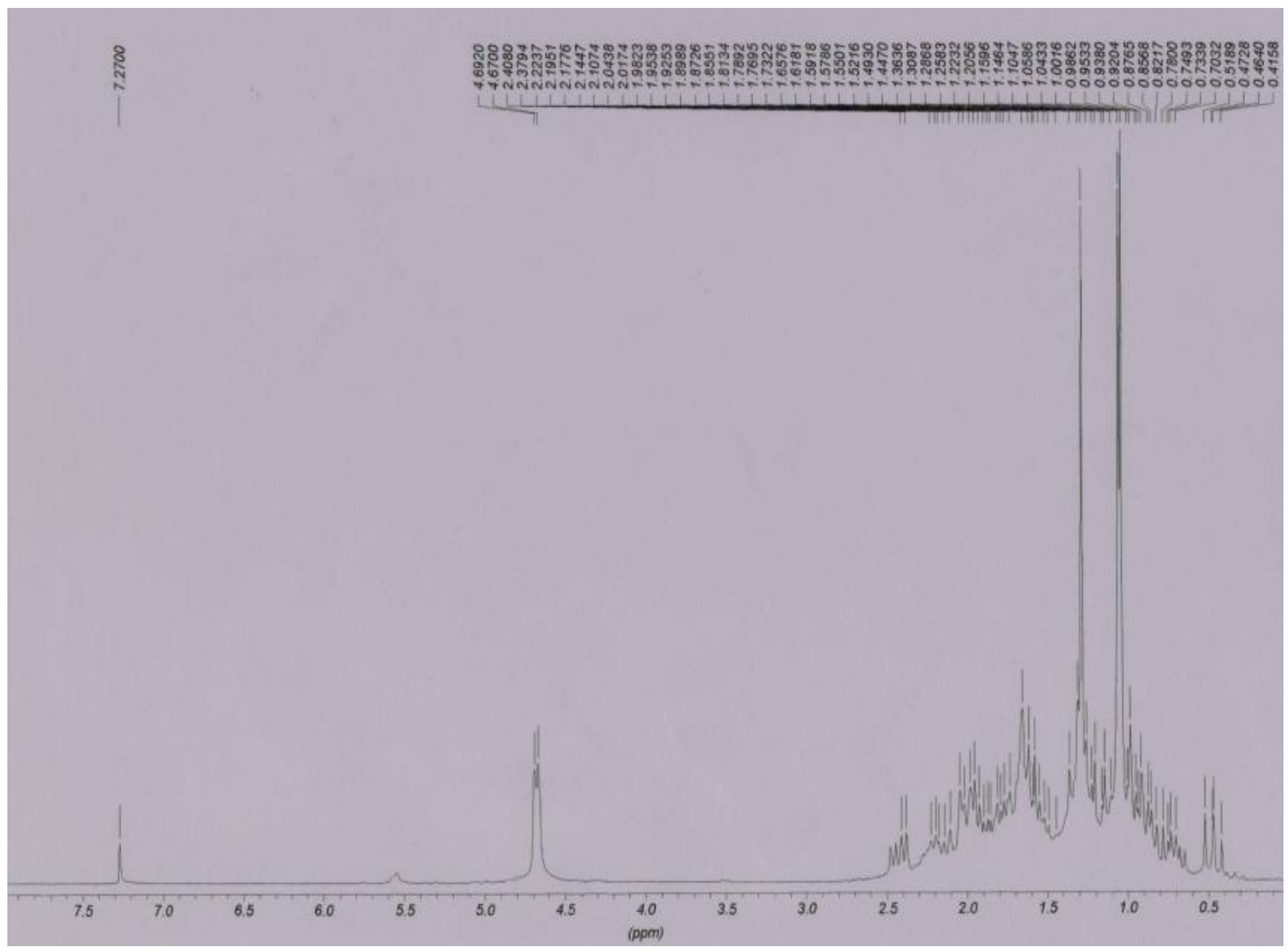

Espectro 42. RMN de ${ }^{1} \mathrm{H}$ da substância $64\left(\mathrm{CDCl}_{3}, 4,7 \mathrm{~T}\right)$. 


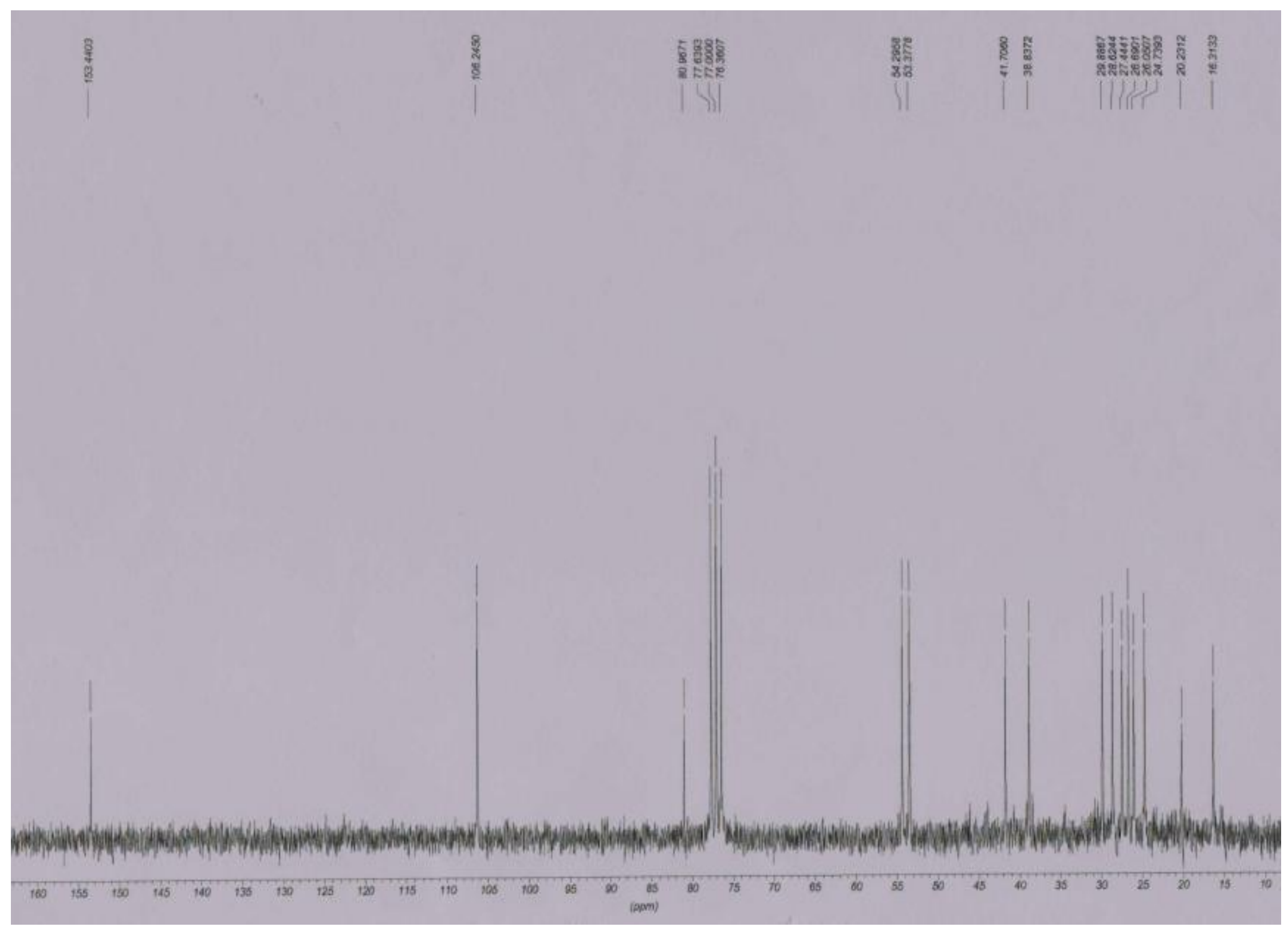

Espectro 43. RMN de ${ }^{13} \mathrm{C}$ da substância $64\left(\mathrm{CDCl}_{3}, 4,7 \mathrm{~T}\right)$. 


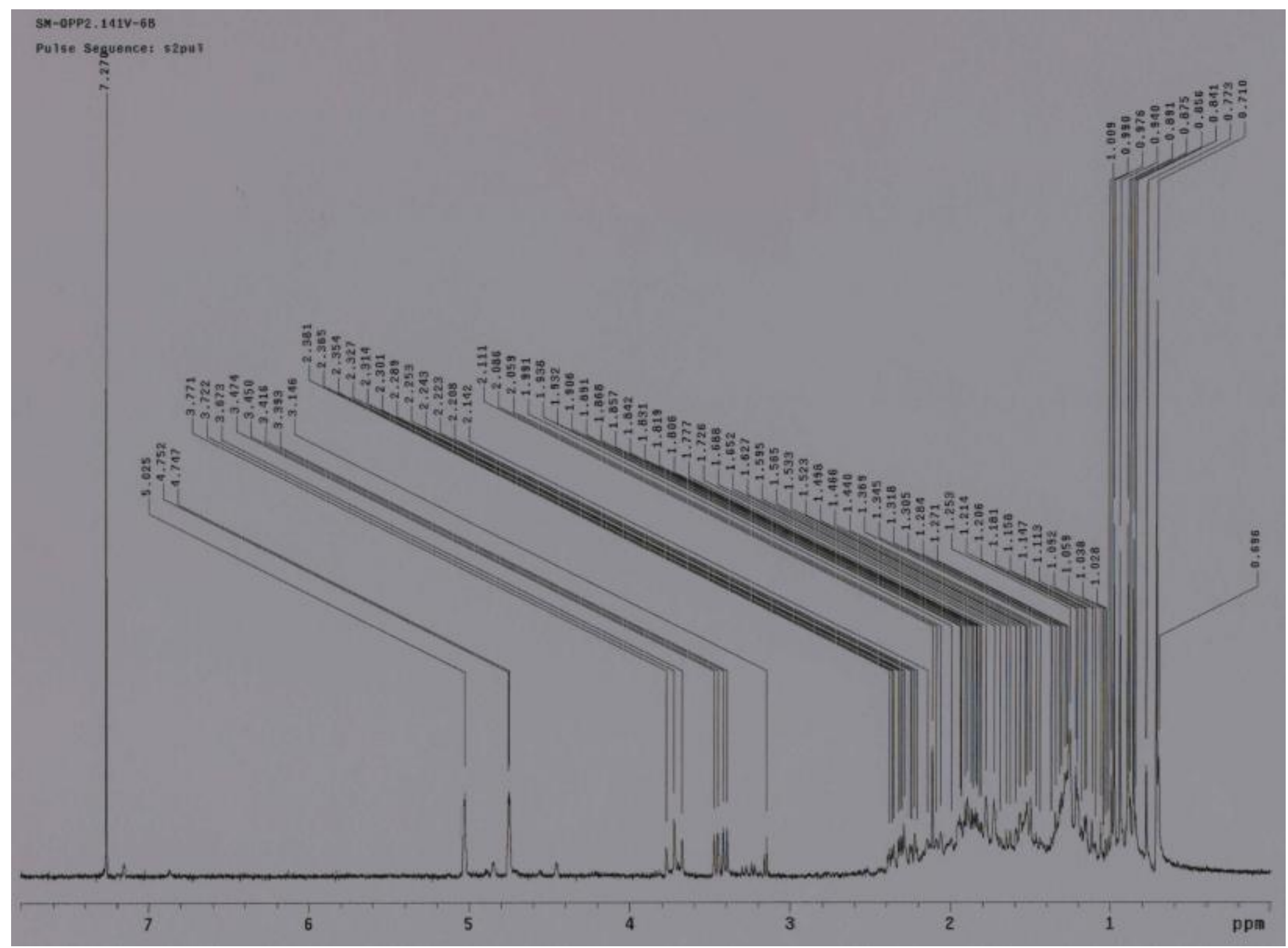

Espectro 44. RMN de ${ }^{1} \mathrm{H}$ da substância $79\left(\mathrm{CDCl}_{3}, 4,7 \mathrm{~T}\right)$. 


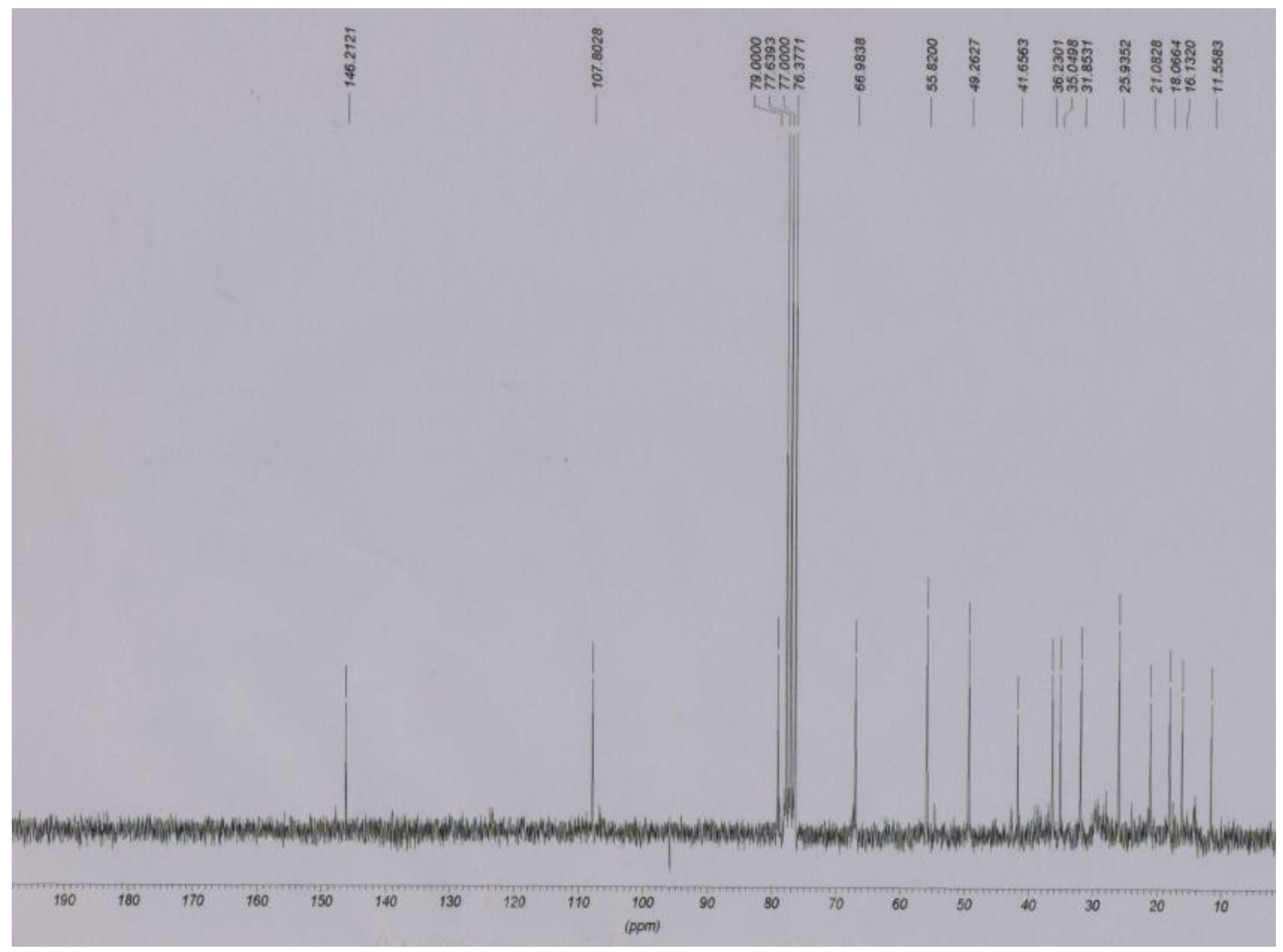

Espectro 45. RMN de ${ }^{13} \mathrm{C}$ da substância $79\left(\mathrm{CDCl}_{3}, 4,7 \mathrm{~T}\right)$. 


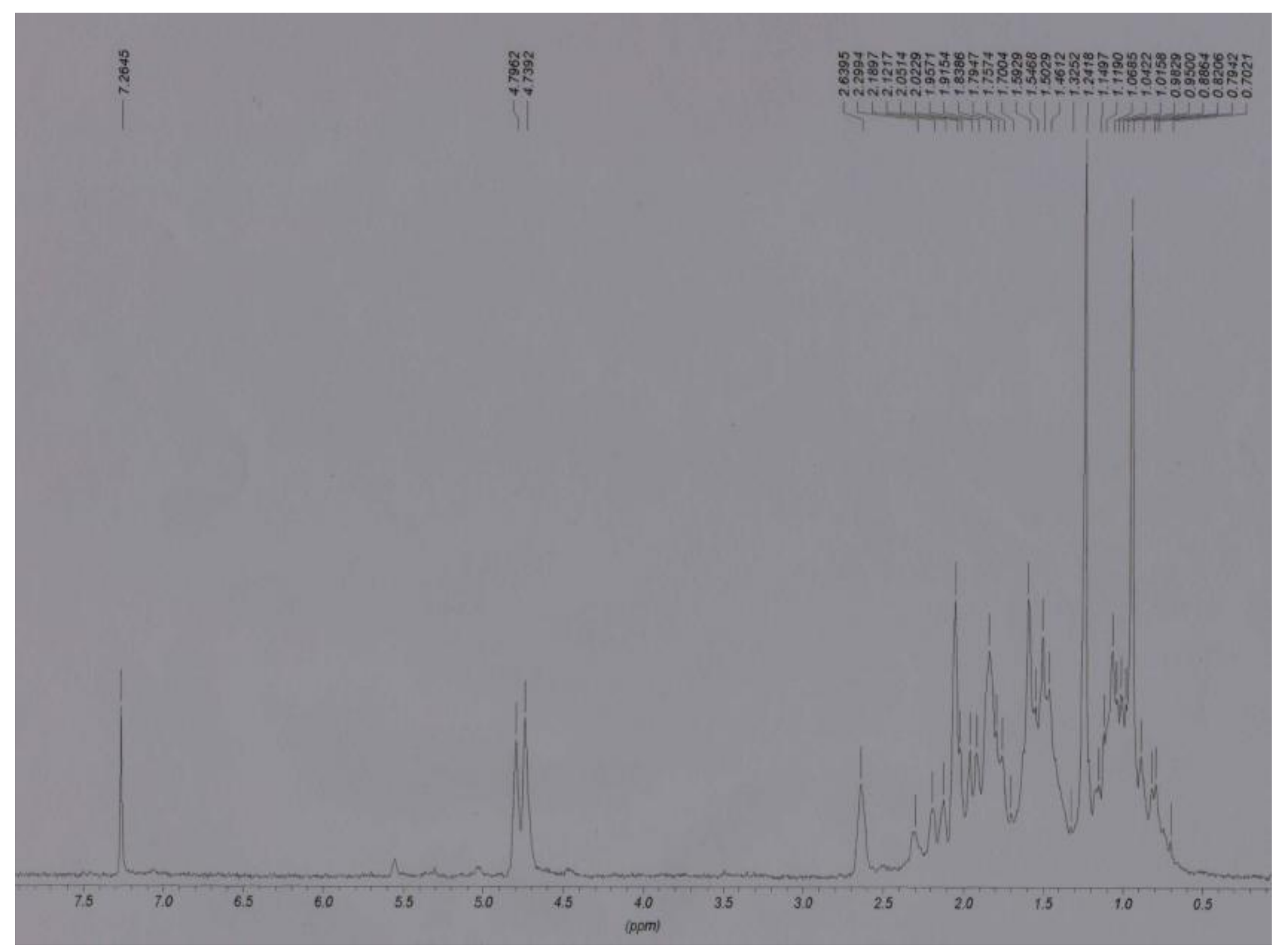

Espectro 46. RMN de ${ }^{1} \mathrm{H}$ da substância $80\left(\mathrm{CDCl}_{3}, 4,7 \mathrm{~T}\right)$. 


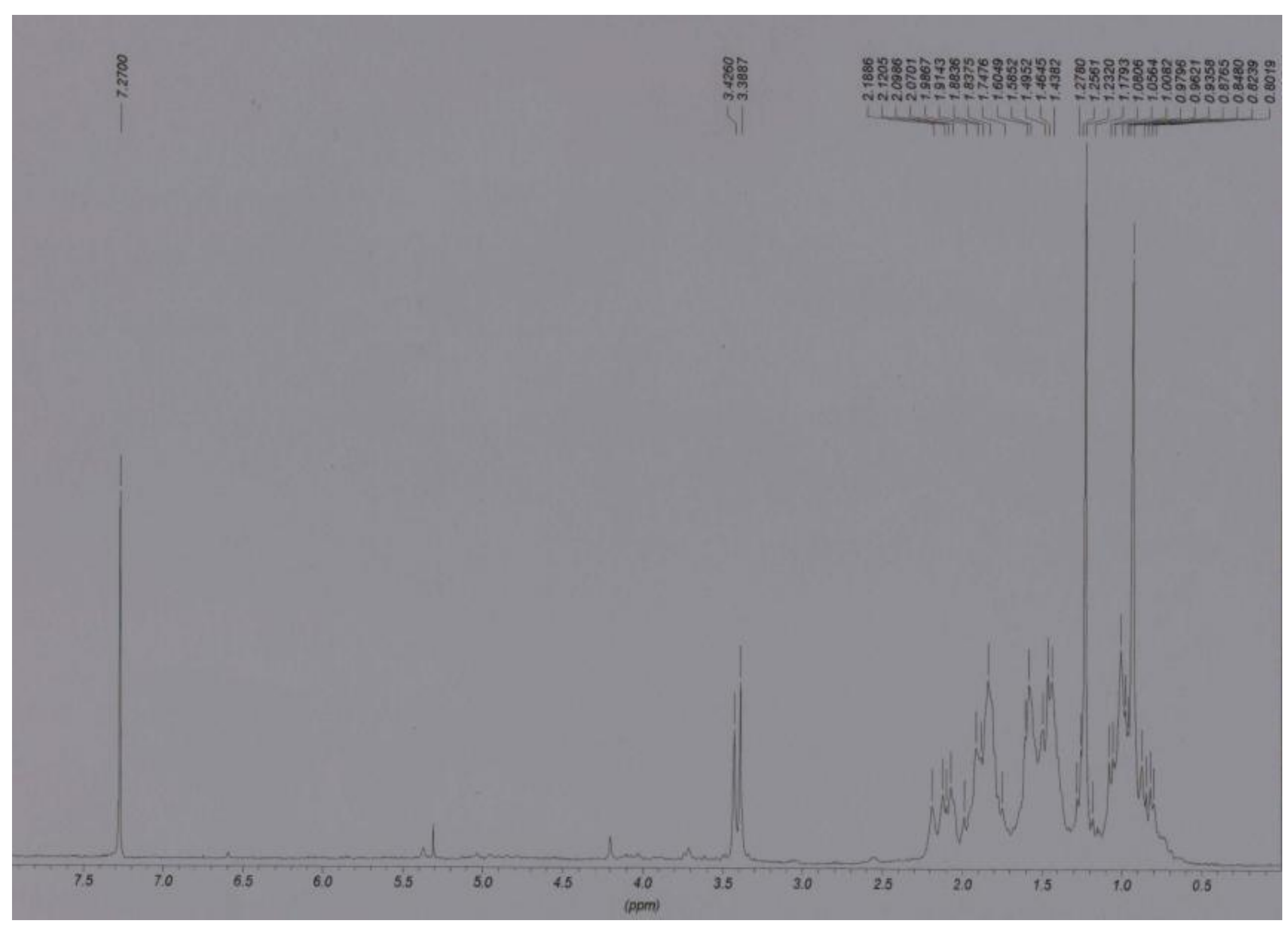

Espectro 47. RMN de ${ }^{1} \mathrm{H}$ da substância $81\left(\mathrm{CDCl}_{3}, 4,7 \mathrm{~T}\right)$. 


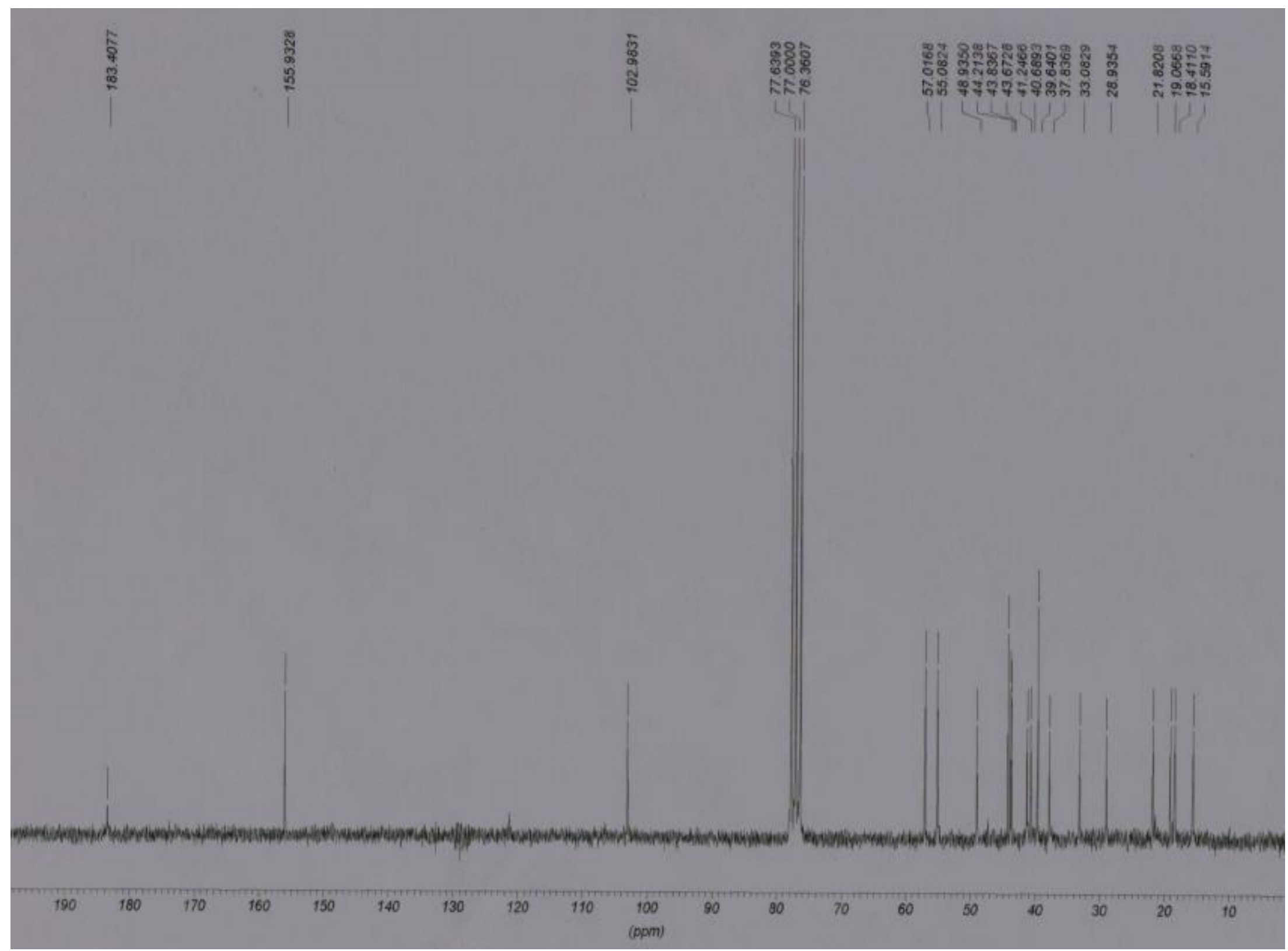

Espectro 48. RMN de ${ }^{13} \mathrm{C}$ da substância $80\left(\mathrm{CDCl}_{3}, 4,7 \mathrm{~T}\right)$. 


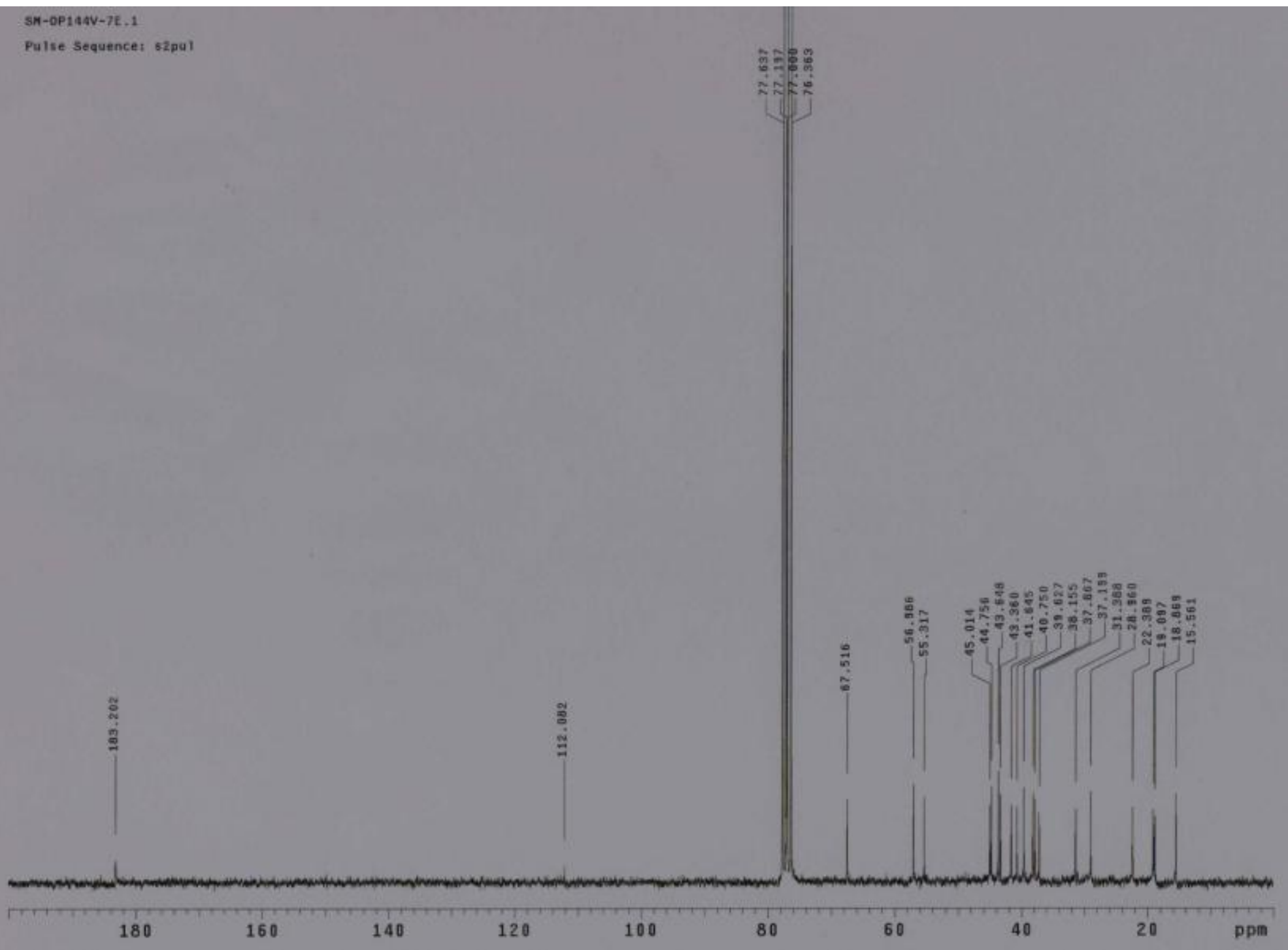

Espectro 49. RMN de ${ }^{13} \mathrm{C}$ da substância $81\left(\mathrm{CDCl}_{3}, 4,7 \mathrm{~T}\right)$. 


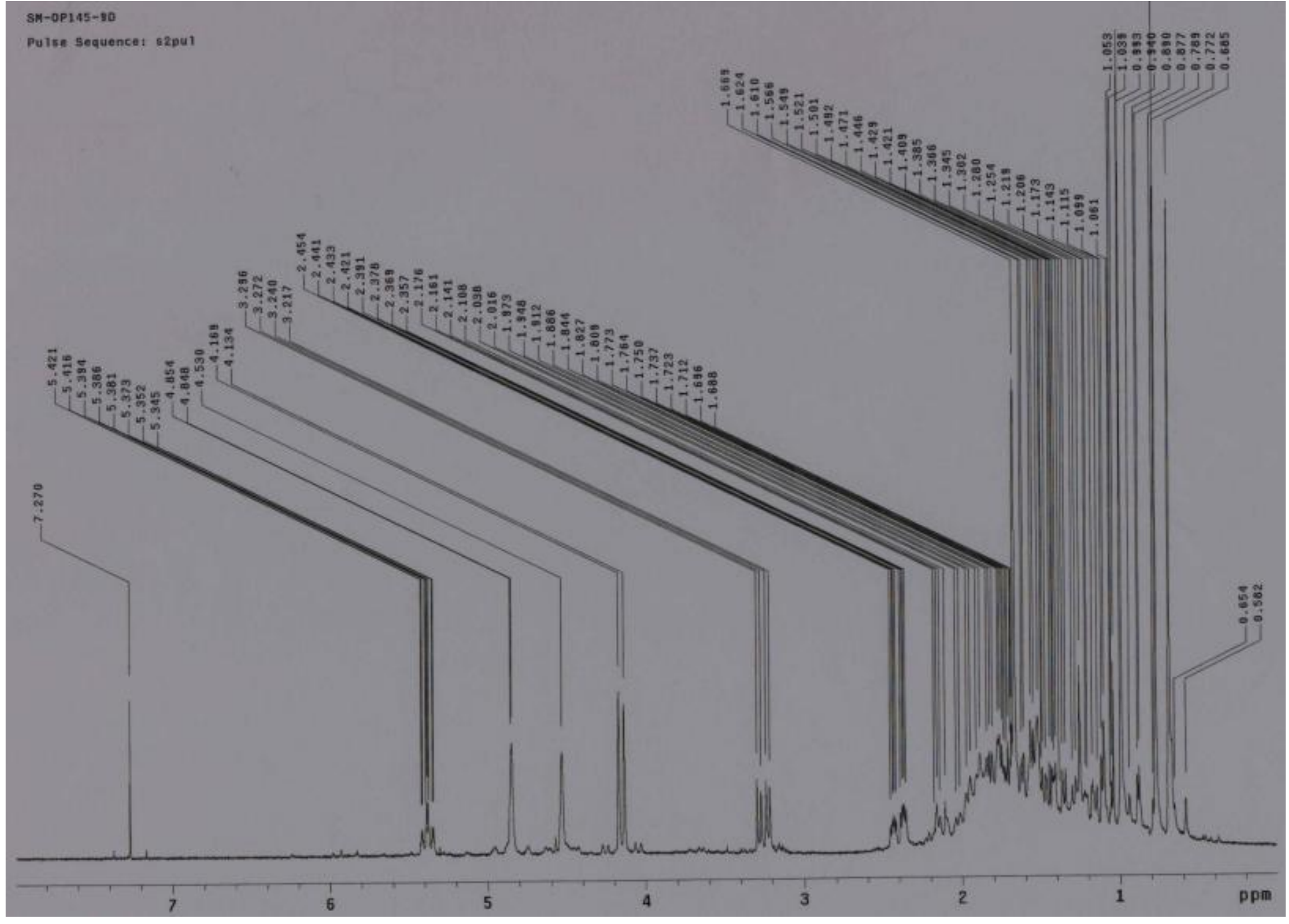

Espectro 50. RMN de ${ }^{1} \mathrm{H}$ da substância $82\left(\mathrm{CDCl}_{3}, 4,7 \mathrm{~T}\right)$. 


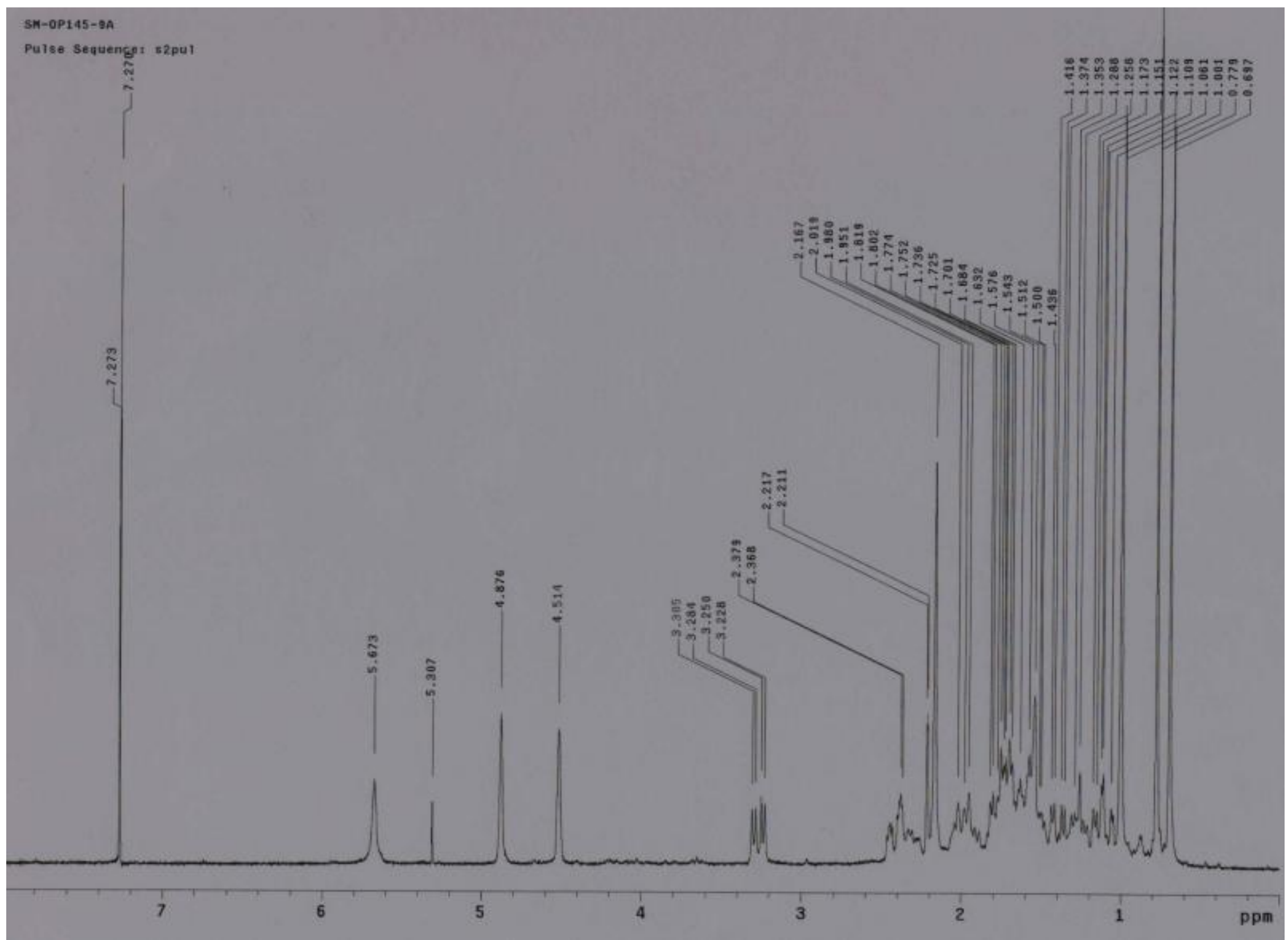

Espectro 51. RMN de ${ }^{1} \mathrm{H}$ da substância $83\left(\mathrm{CDCl}_{3}, 4,7 \mathrm{~T}\right)$. 


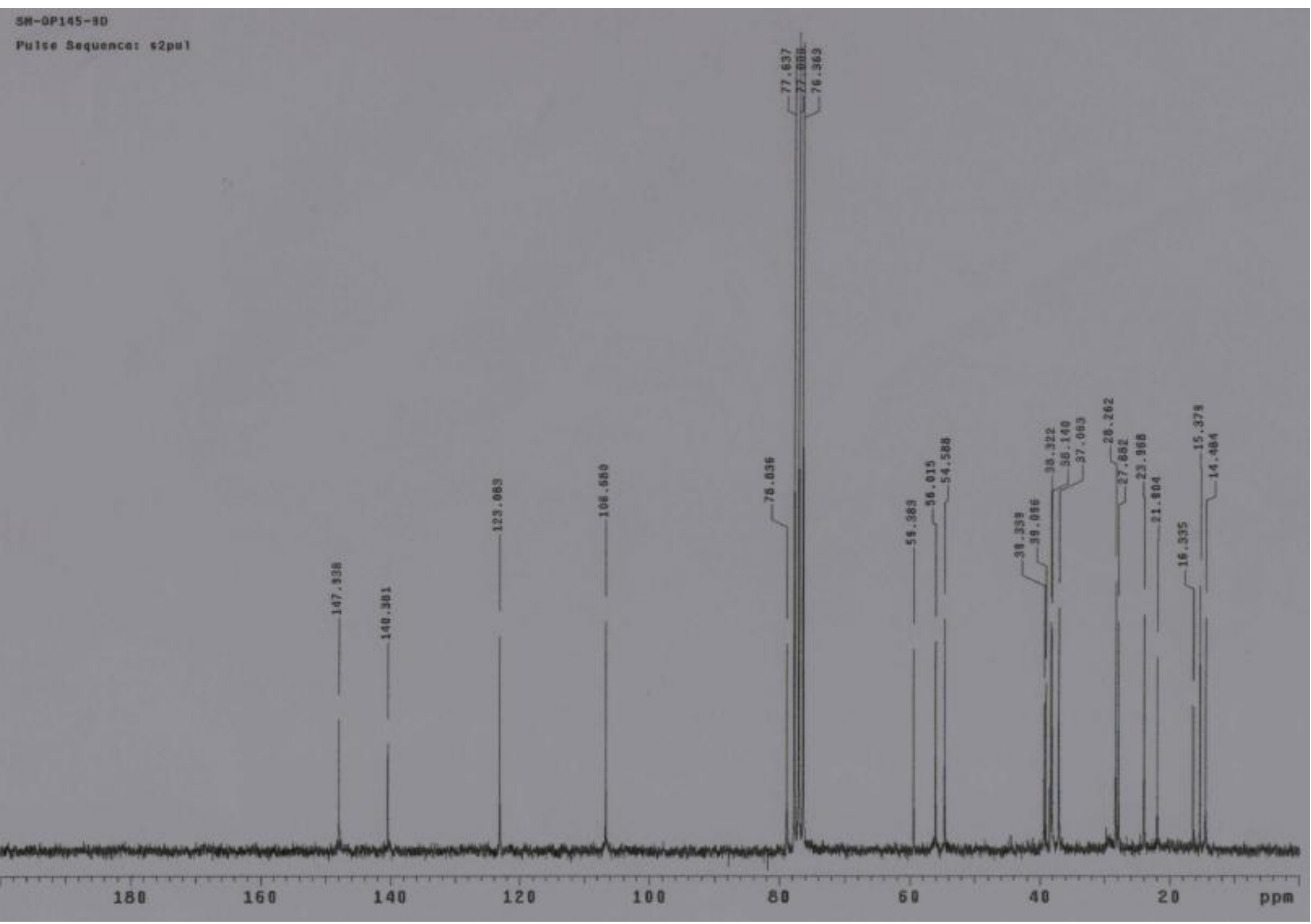

Espectro 52. RMN de ${ }^{13} \mathrm{C}$ da substância $82\left(\mathrm{CDCl}_{3}, 4,7 \mathrm{~T}\right)$. 


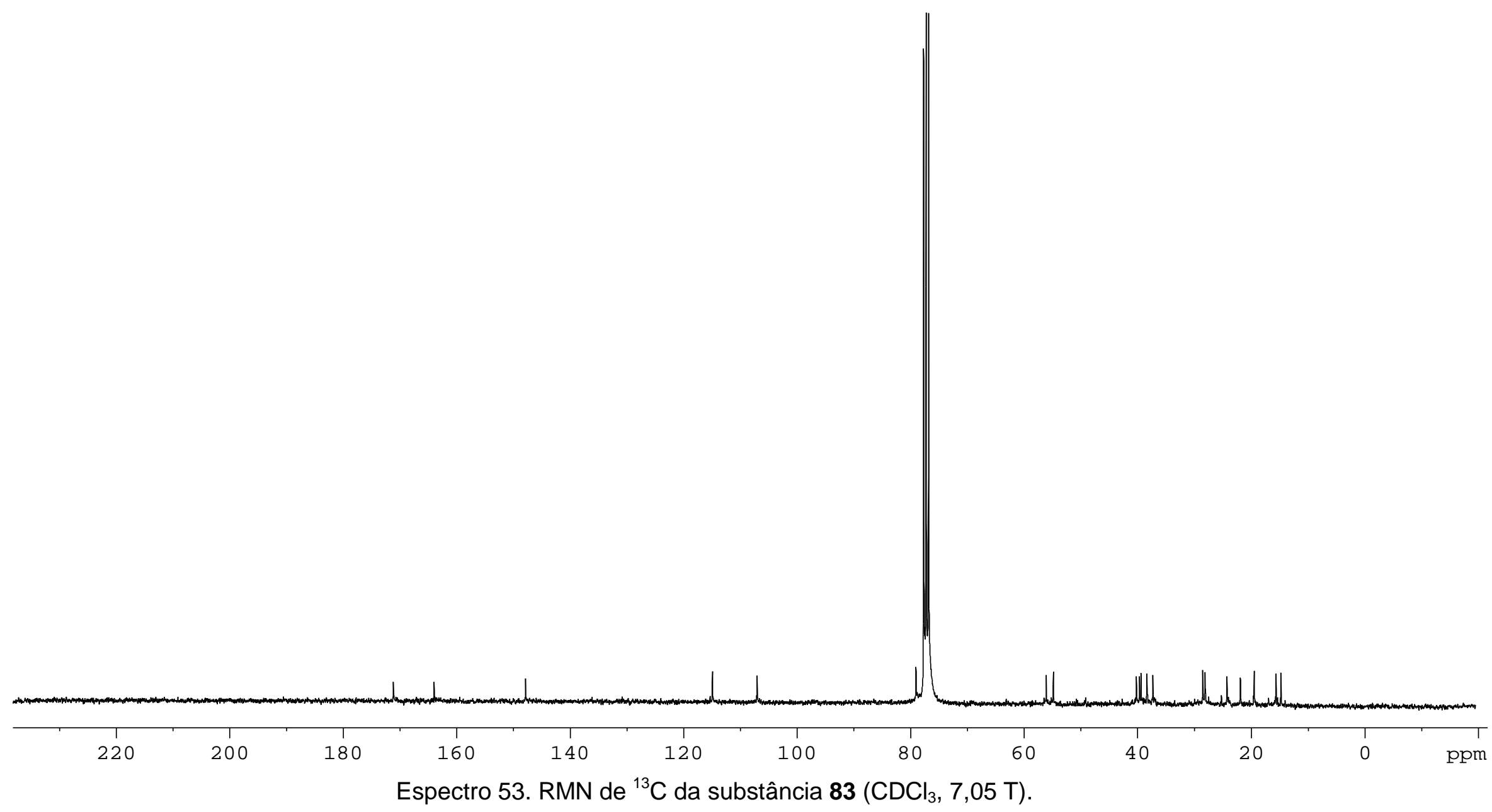




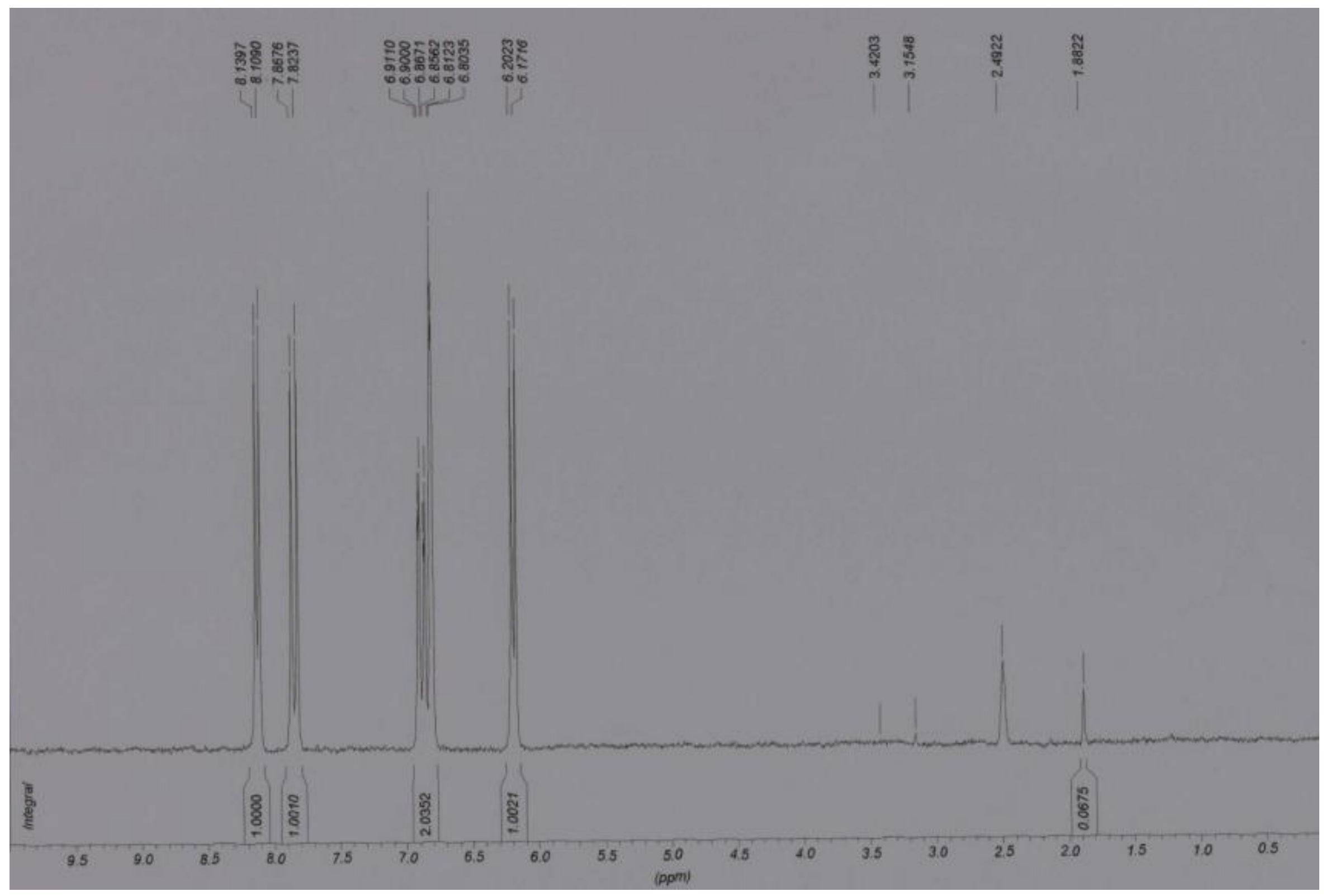

Espectro 54. RMN de ${ }^{1} \mathrm{H}$ da substância 17 (DMSO-d 6 , 4,7 T). 


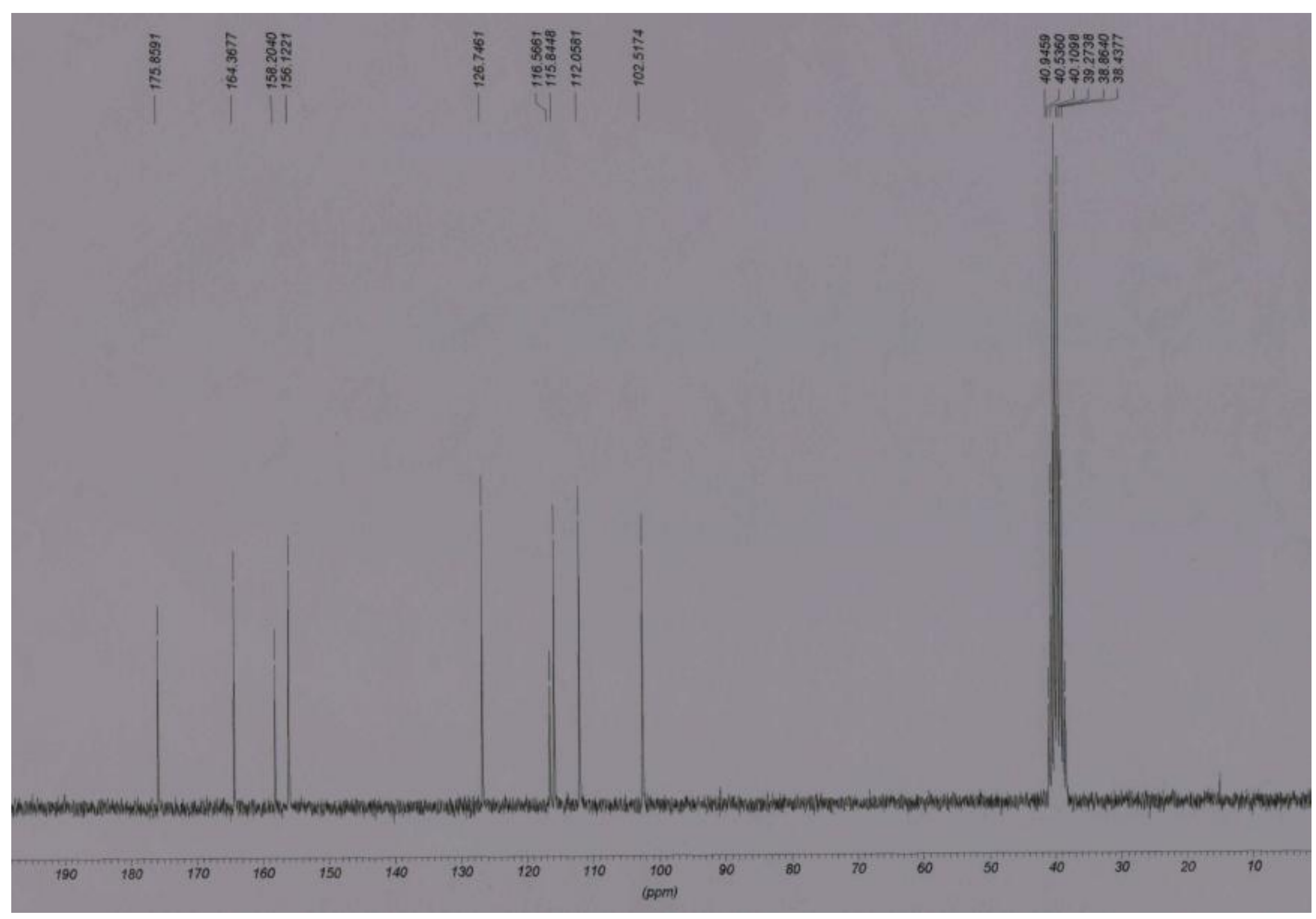

Espectro 55. RMN de ${ }^{13} \mathrm{C}$ da substância 17 (DMSO-d 6 , 4,7 T). 


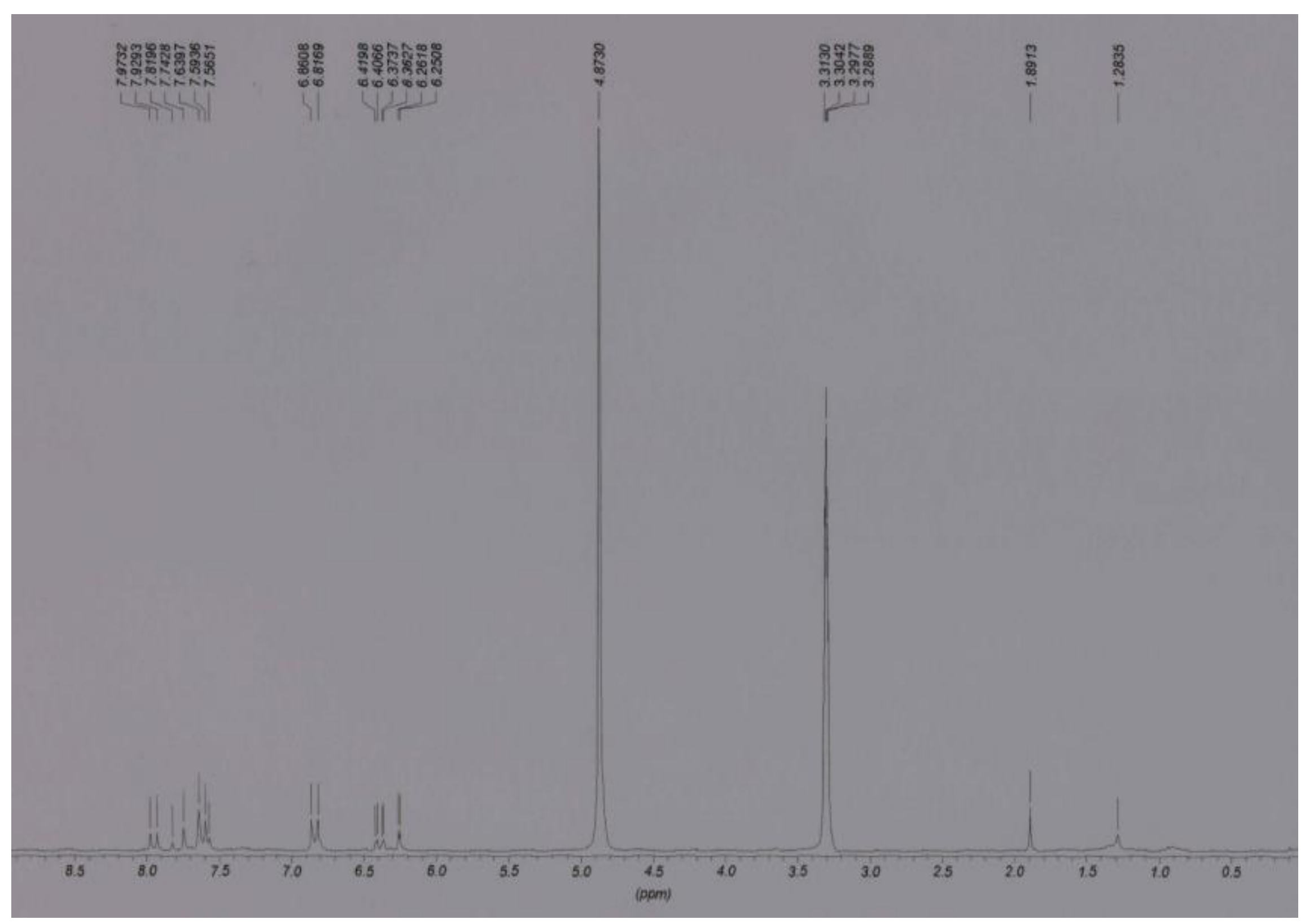

Espectro 56. RMN de ${ }^{1} \mathrm{H}$ da substância $18\left(\mathrm{CD}_{3} \mathrm{OD}, 4,7 \mathrm{~T}\right)$. 

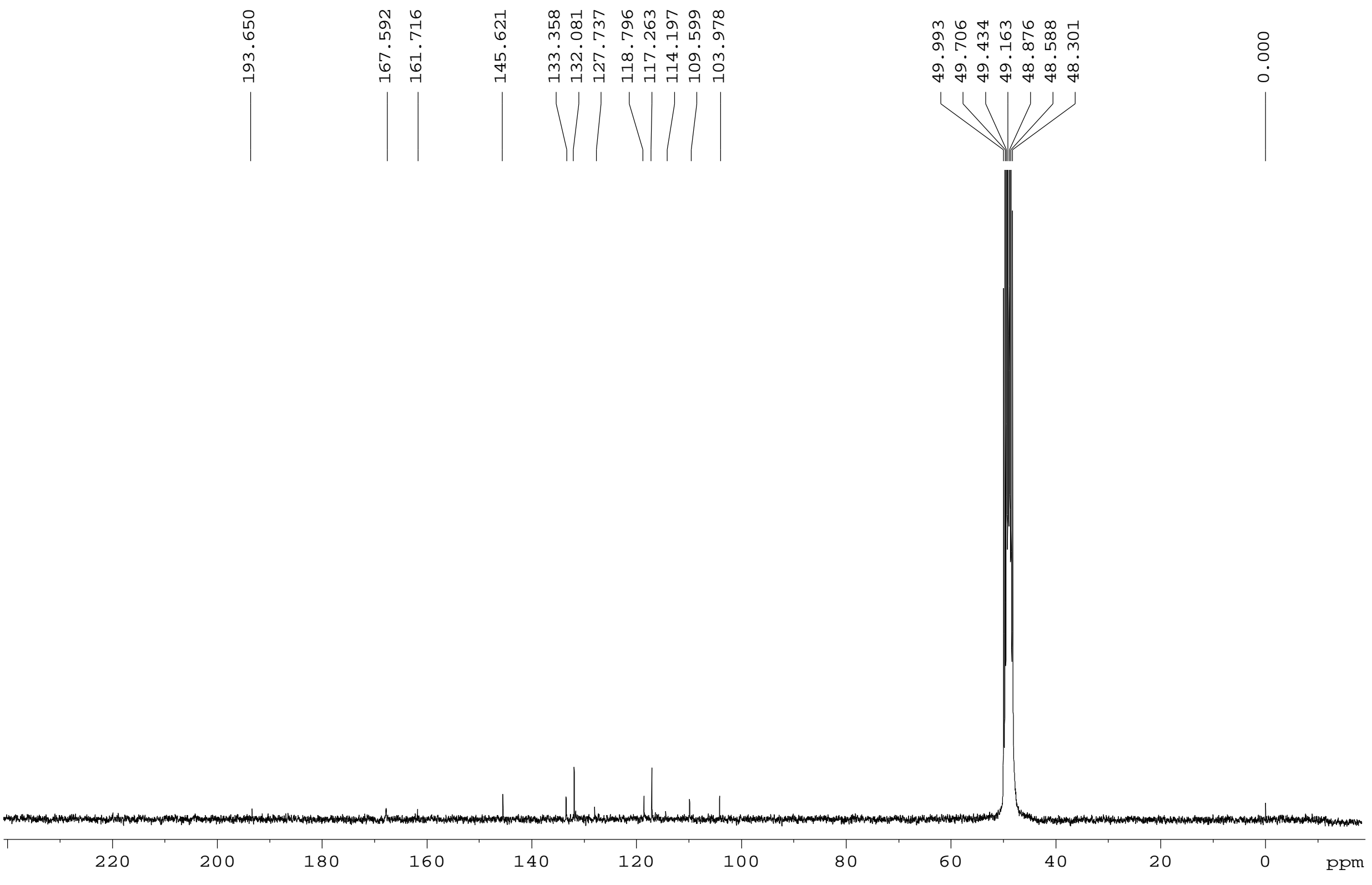

Espectro 57. RMN de ${ }^{13} \mathrm{C}$ da substância $18\left(\mathrm{CD}_{3} \mathrm{OD}, 7,05 \mathrm{~T}\right)$. 


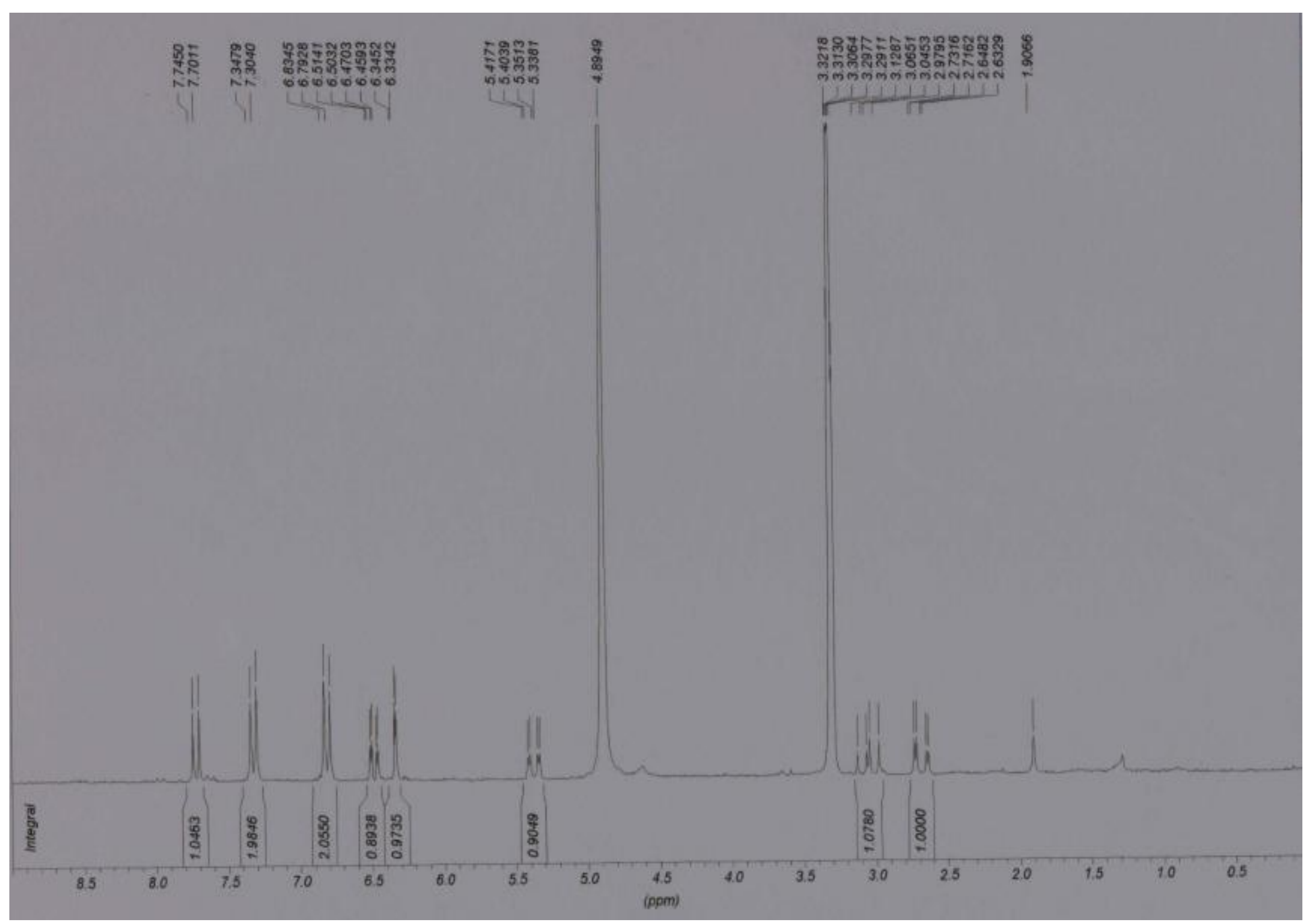

Espectro 58. RMN de ${ }^{1} \mathrm{H}$ da substância $19\left(\mathrm{CD}_{3} \mathrm{OD}, 4,7 \mathrm{~T}\right)$. 


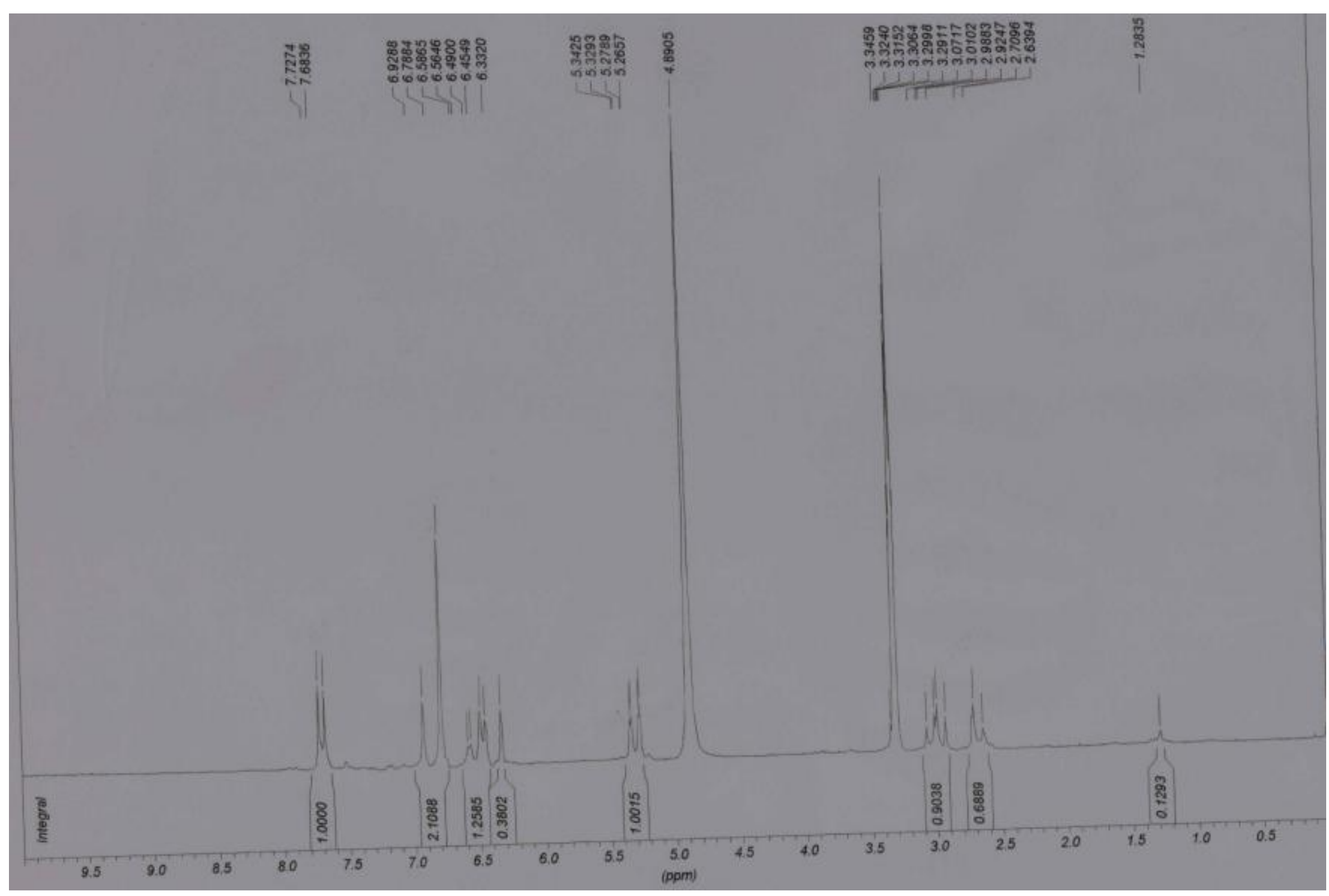

Espectro 59. RMN de ${ }^{1} \mathrm{H}$ da substância $20\left(\mathrm{CD}_{3} \mathrm{OD}, 4,7 \mathrm{~T}\right)$. 


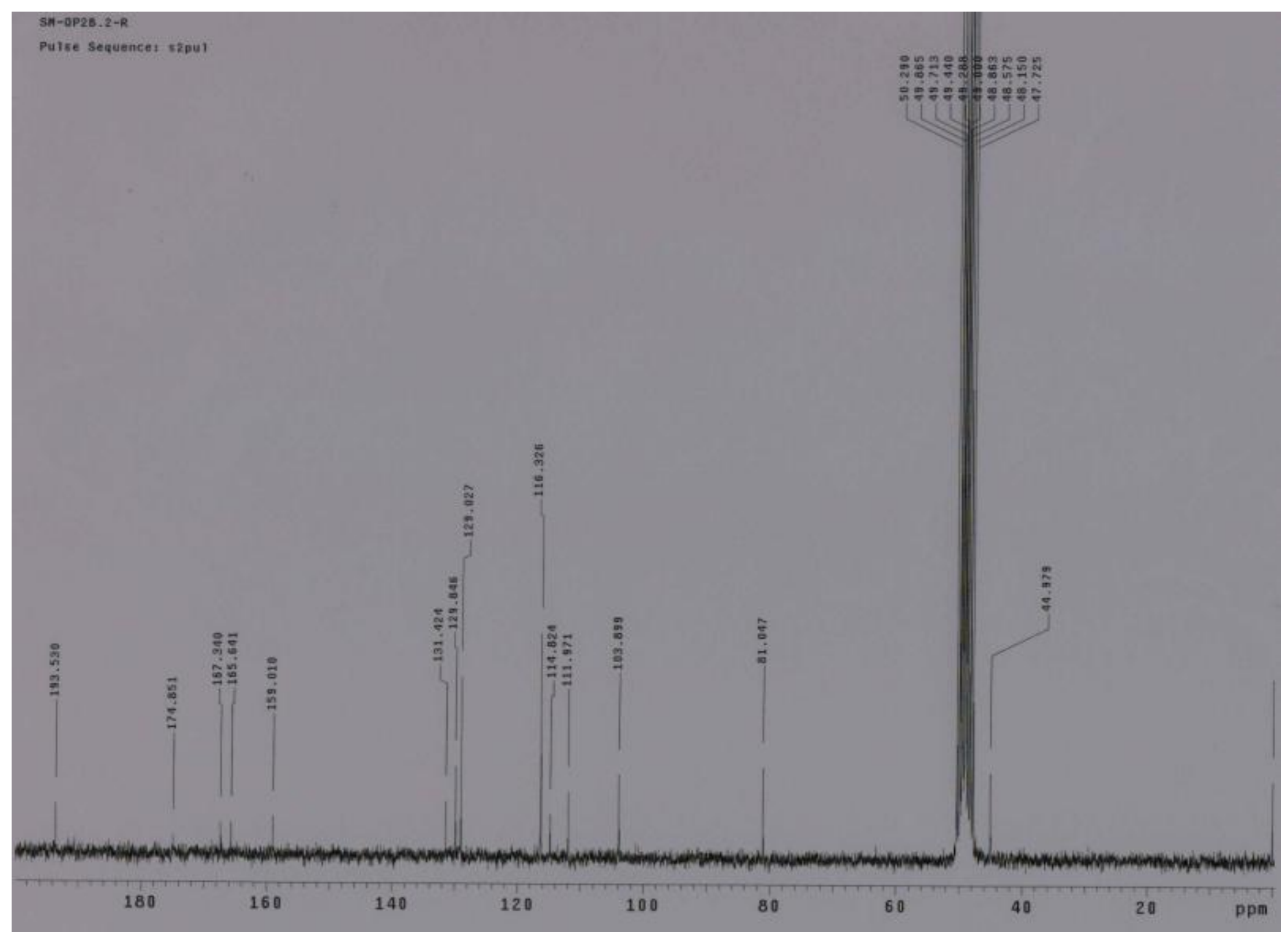

Espectro 60. RMN de ${ }^{13} \mathrm{C}$ da substância $19\left(\mathrm{CD}_{3} \mathrm{OD}, 4,7 \mathrm{~T}\right)$. 


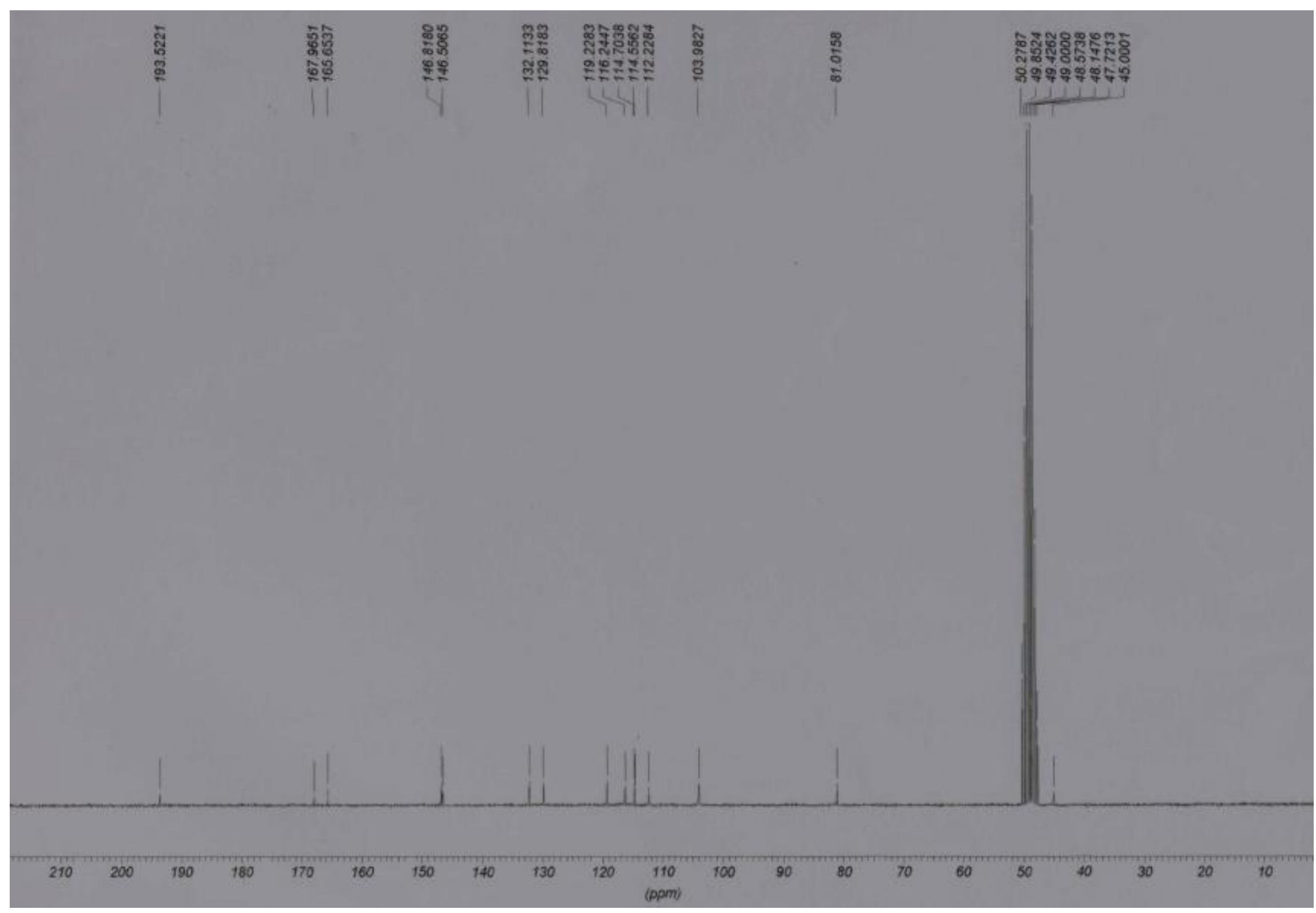

Espectro 61. RMN de ${ }^{13} \mathrm{C}$ da substância $20\left(\mathrm{CD}_{3} \mathrm{OD}, 4,7 \mathrm{~T}\right)$. 

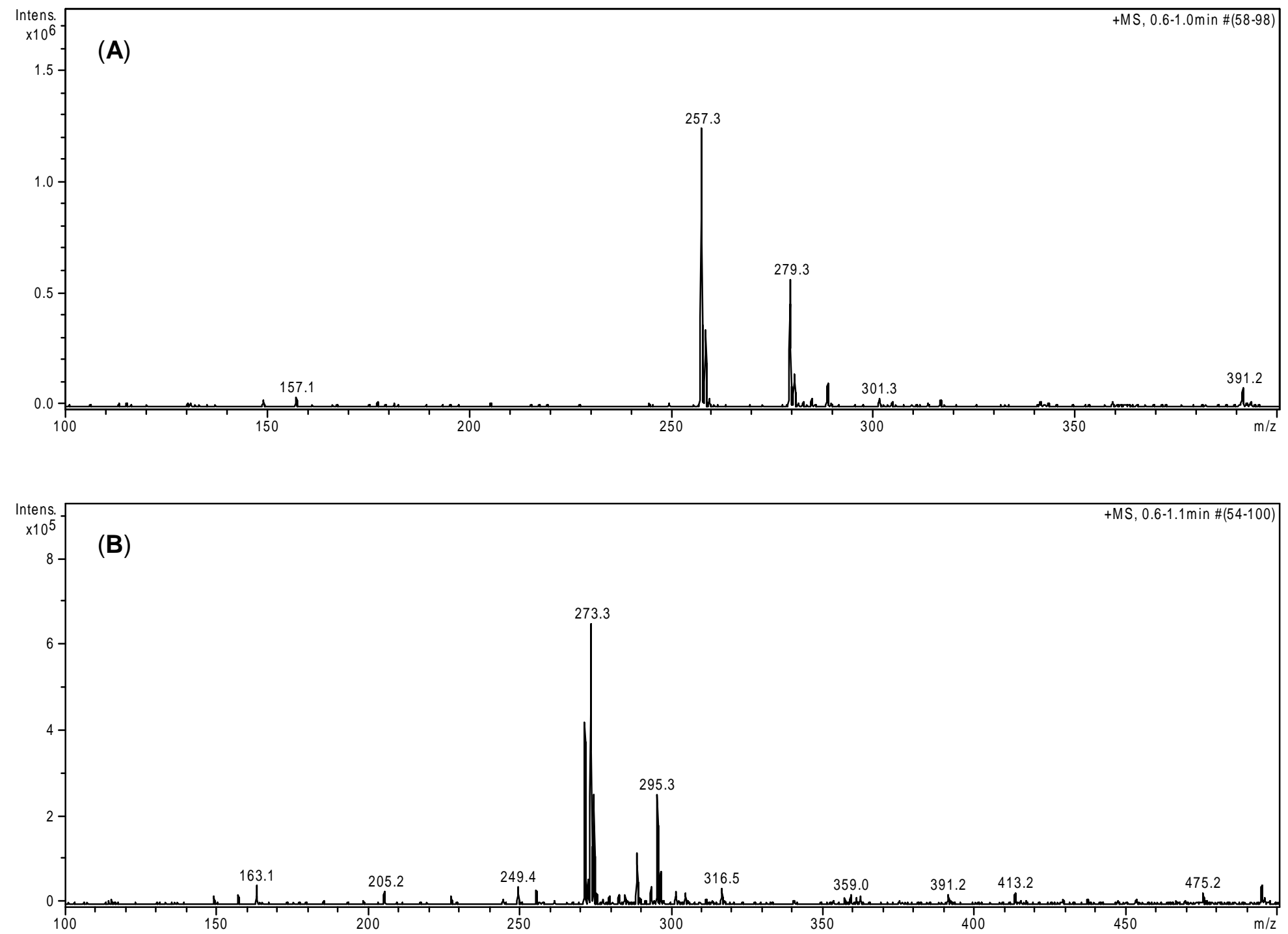

Espectro 62. (A) ESI/EM da substância 19 e (B) ESI/EM da substância 20 (iozinação positiva: MeOH + ácido fórmico 0,2\%). 


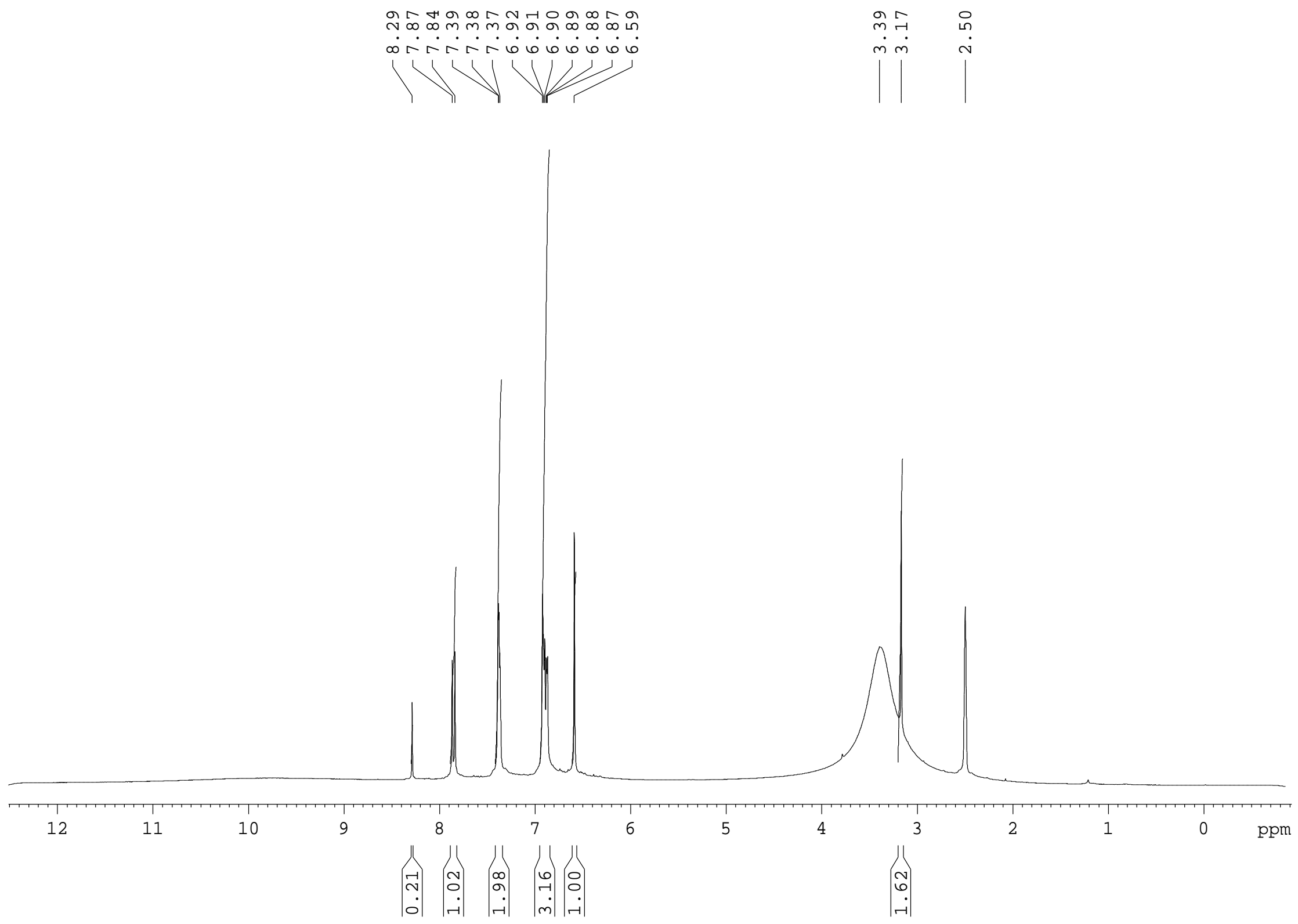

Espectro 63. RMN de ${ }^{1} \mathrm{H}$ da substância 21 (DMSO- $d_{6}, 4,7 \mathrm{~T}$ ). 


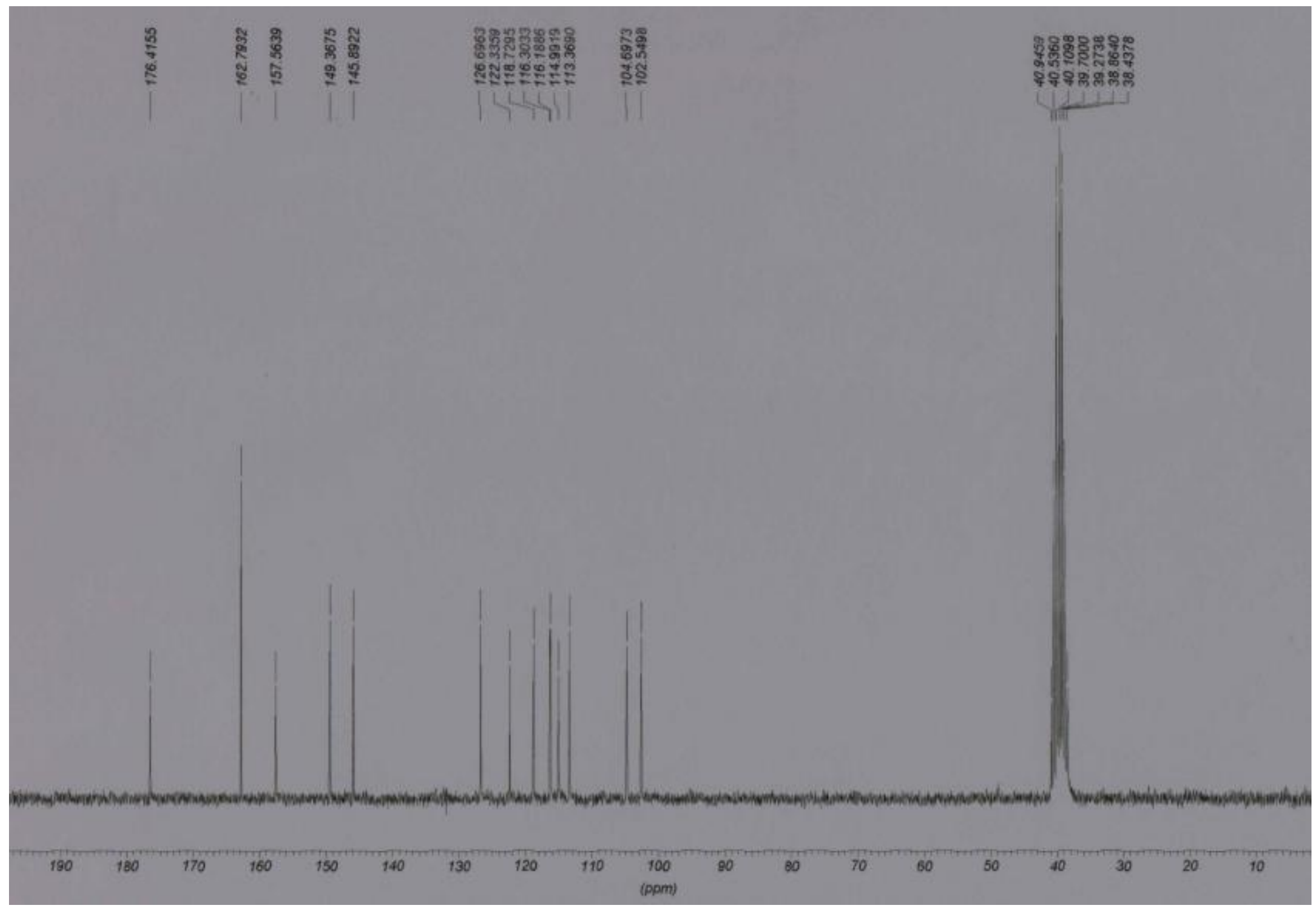

Espectro 64. RMN de ${ }^{13} \mathrm{C}$ da substância 21 (DMSO-d 6 , 4,7 T). 


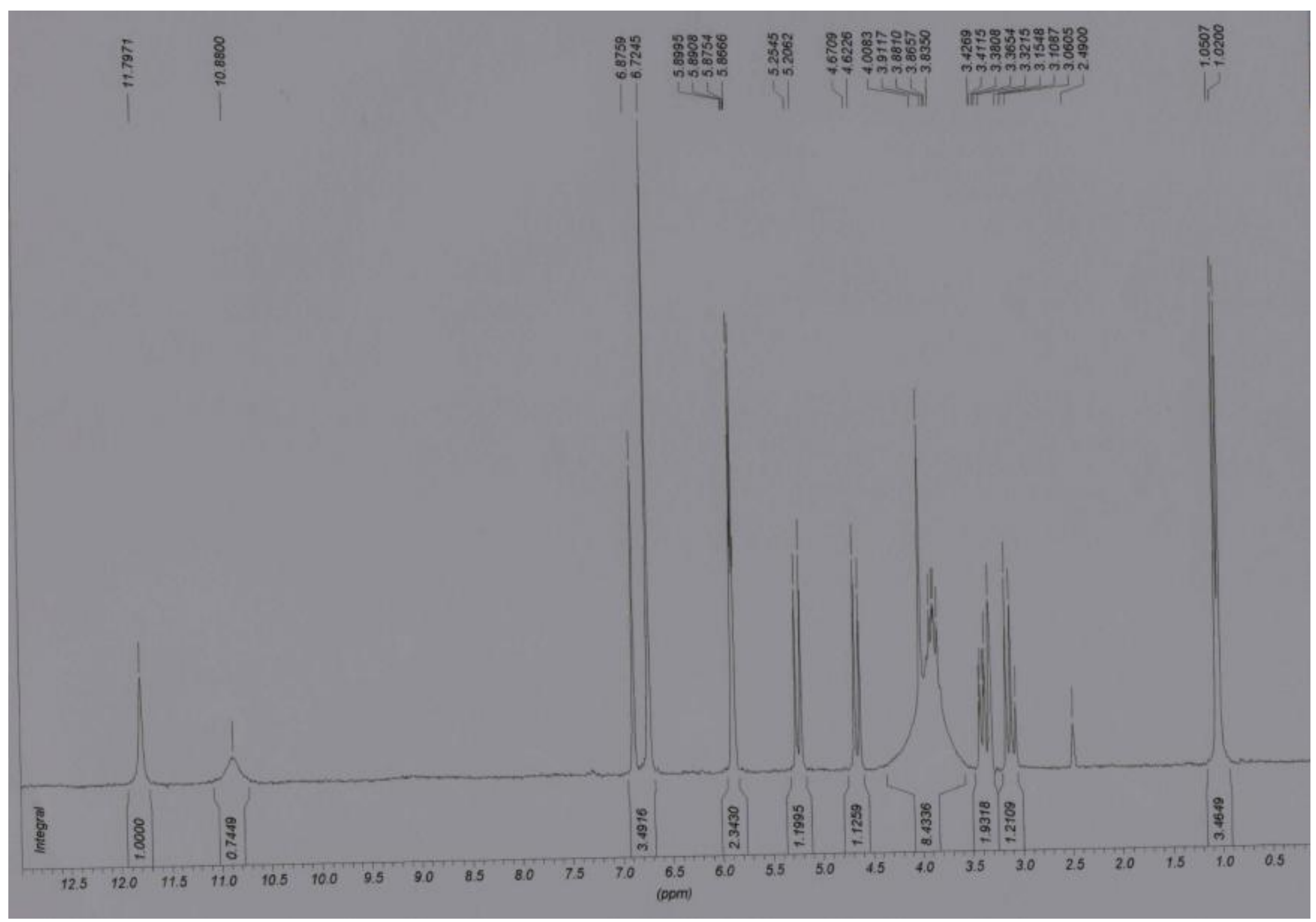

Espectro 65. RMN de ${ }^{1} \mathrm{H}$ da substância 22 (DMSO-d 6 , 4,7 T). 


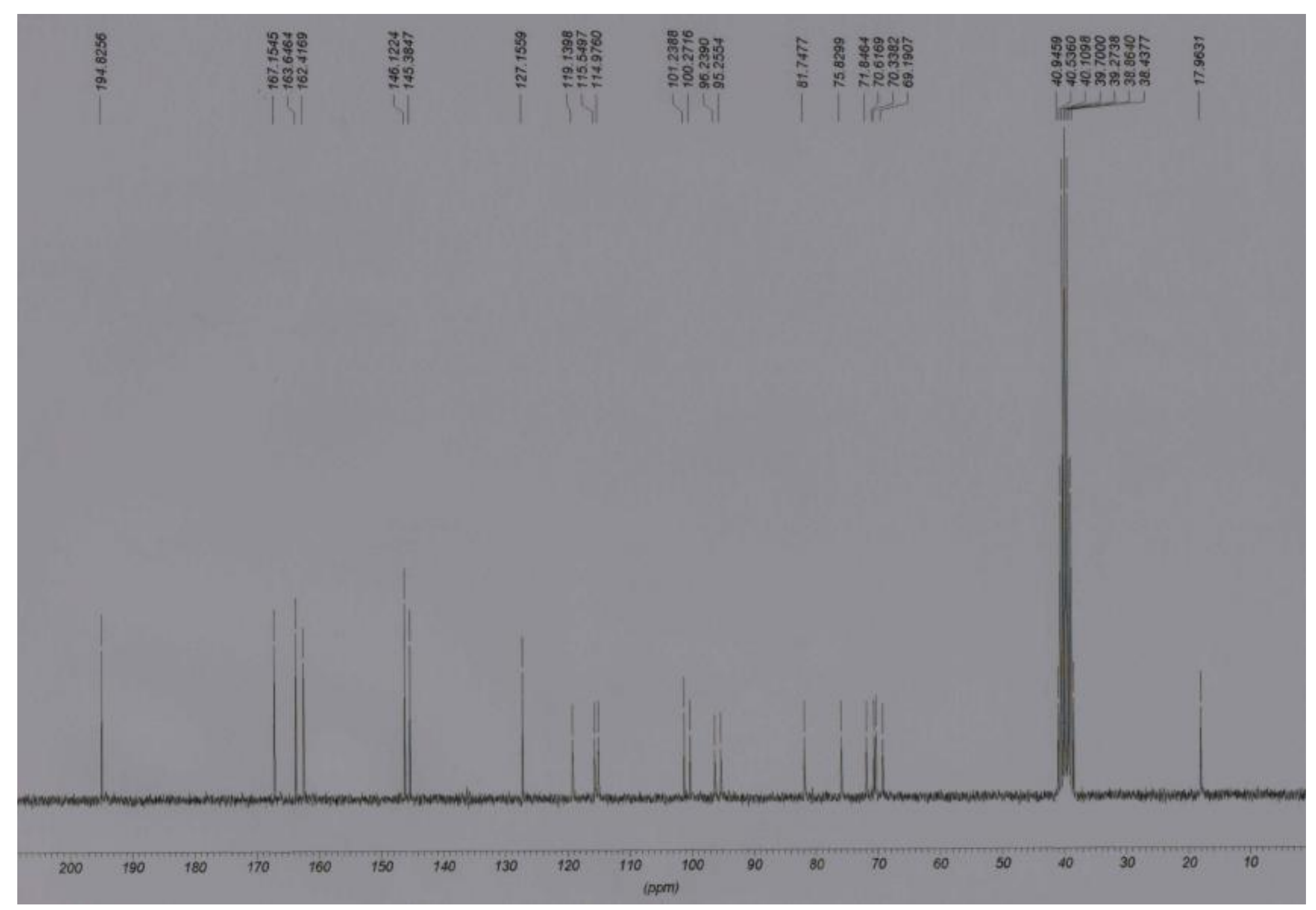

Espectro 66. RMN de ${ }^{13} \mathrm{C}$ da substância 22 (DMSO-d 6 , 4,7 T). 


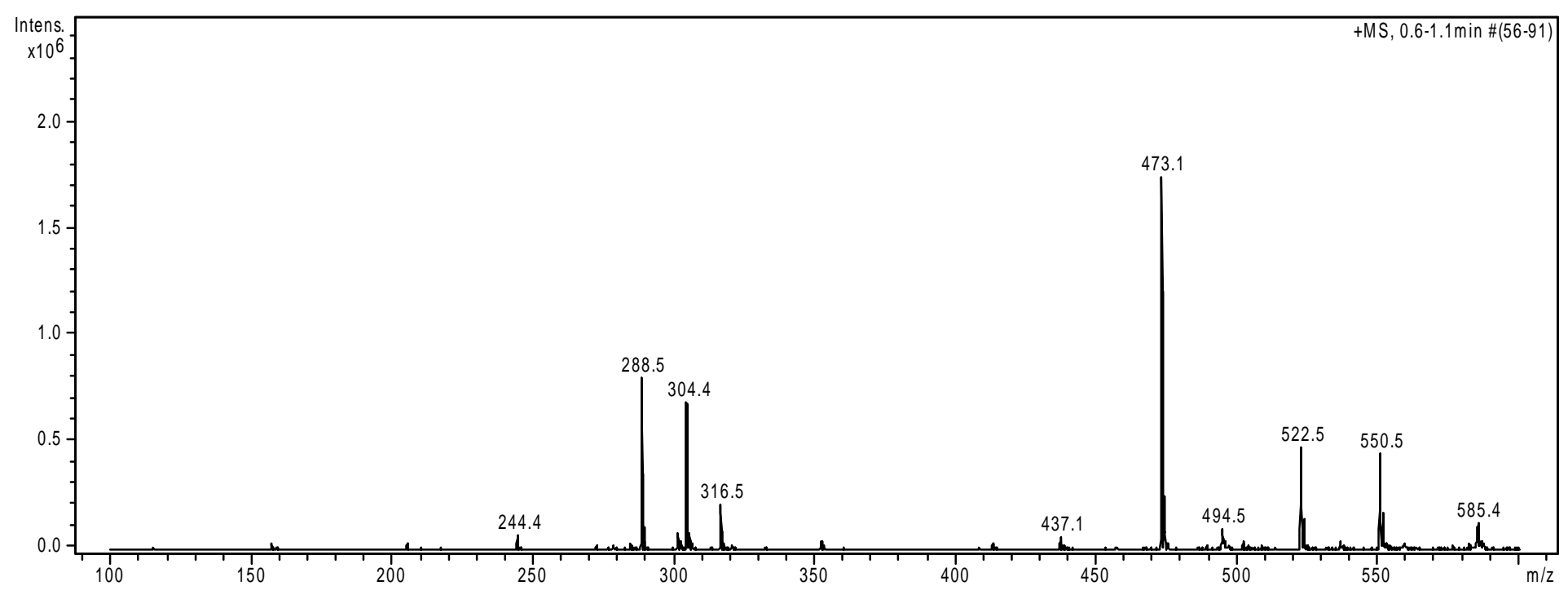

Espectro 67. ESI/EM da substância 22 (iozinação positiva: $\mathrm{MeOH}$ + ácido fórmico 0,2\%). 